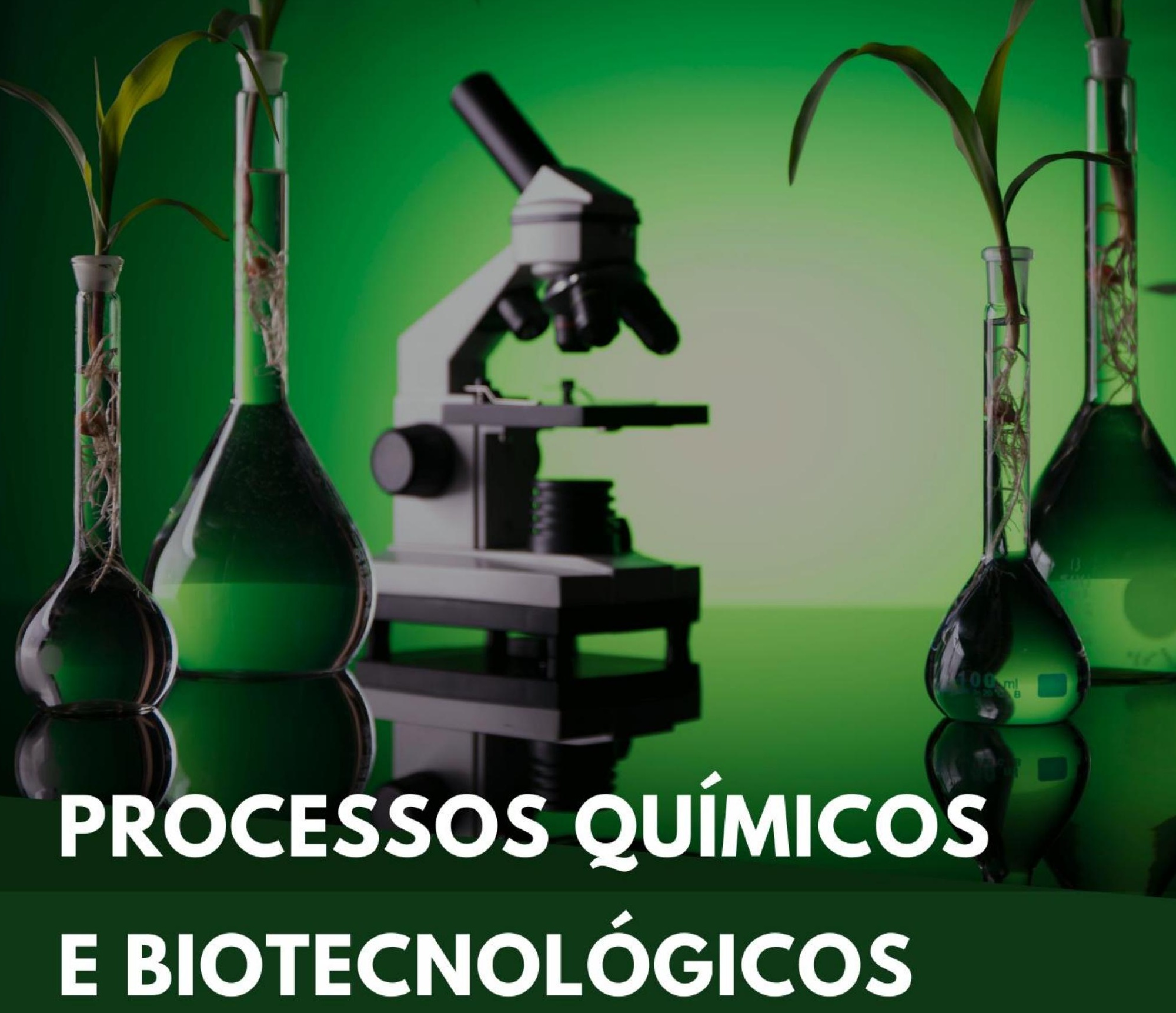


Editora Poisson

\section{Processos Químicos e Biotecnológicos Volume 6}

1a Edição

Belo Horizonte

Poisson

2020 


\section{Editor Chefe: Dr. Darly Fernando Andrade}

\section{Conselho Editorial}

Dr. Antônio Artur de Souza - Universidade Federal de Minas Gerais

Msc. Davilson Eduardo Andrade

Dra. Elizângela de Jesus Oliveira - Universidade Federal do Amazonas

Msc. Fabiane dos Santos

Dr. José Eduardo Ferreira Lopes - Universidade Federal de Uberlândia

Dr. Otaviano Francisco Neves - Pontifícia Universidade Católica de Minas Gerais

Dr. Luiz Cláudio de Lima - Universidade FUMEC

Dr. Nelson Ferreira Filho - Faculdades Kennedy

Ms. Valdiney Alves de Oliveira - Universidade Federal de Uberlândia

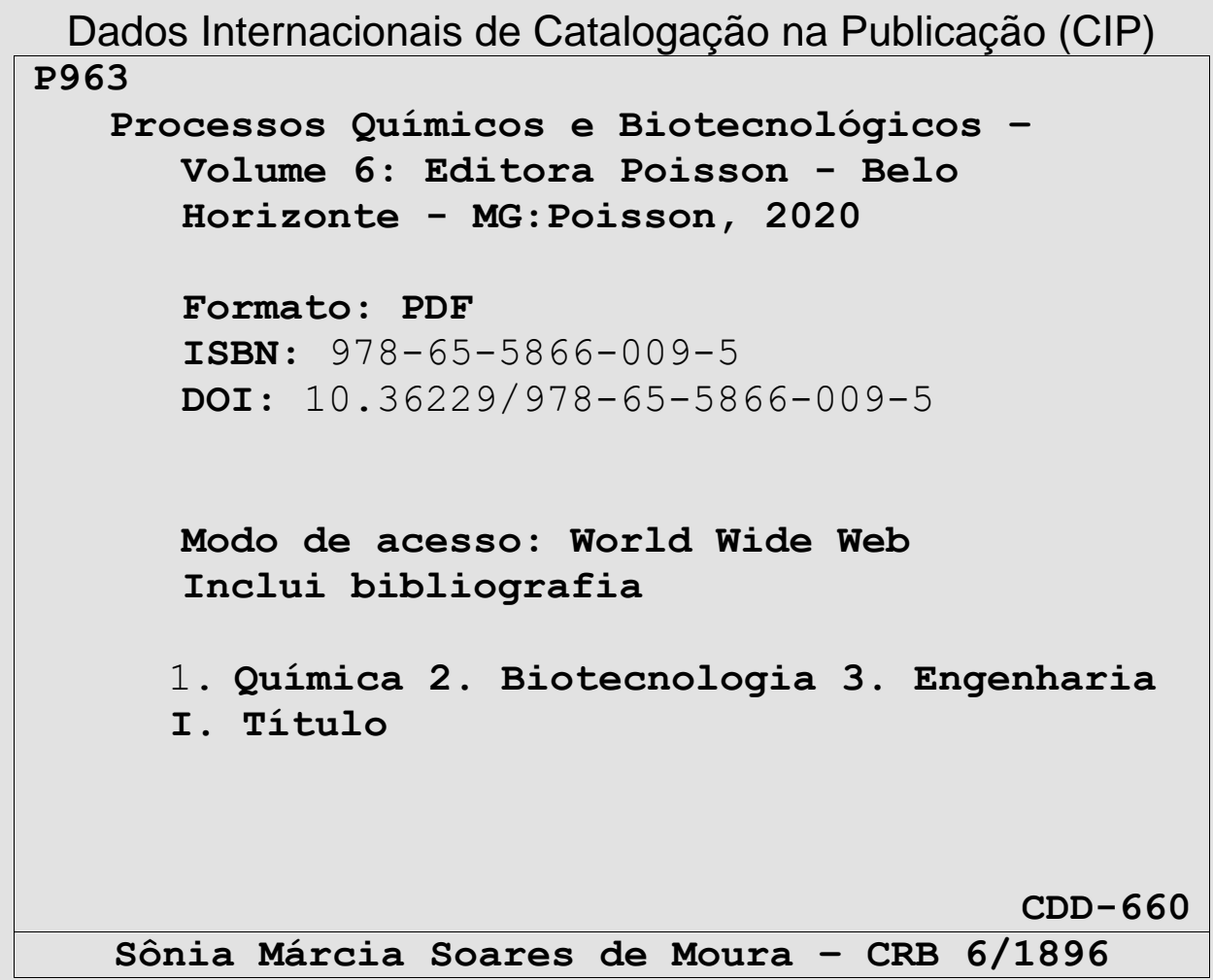

O conteúdo dos artigos e seus dados em sua forma, correção e confiabilidade são de responsabilidade exclusiva dos seus respectivos autores

$\underline{\text { www.poisson.com.br }}$

contato@poisson.com.br 


\section{SUMÁRIO}

Capítulo 1: Seleção de fungos produtores de $\beta$-D-frutosiltransferase por fermentação em estado sólido. 07

Juanize Matias da Silva Batista, Thiago Pajeú Nascimento, Márcia Nieves Carneiro da Cunha, Camila Souza Porto, José António Couto Teixeira, Ana Lúcia Figueiredo Porto

DOI: $10.36229 / 978-65-5866-009-5 . C A P .01$

Capítulo 2: Estudo físico-químico e quimiométrico de chá de gengibre (Zingiber officinale)

Kamila Leal Correa, Gabriely dos Santos, Débora Mendes de Andrade, Kelson do Carmo Freitas Faial, Neuton Trindade Vasconcelos Junior, Mônia Maria Carvalho da Silva, Allyson Allennon Pinheiro do Rosário, Charles Alberto Brito Negrão, Ewerton Carvalho de Souza, Antonio dos Santos Silva

DOI: $10.36229 / 978-65-5866-009-5 . C A P .02$

Capítulo 3: Extração e caracterização de amido de diferentes fontes vegetais: Uma alternativa para materiais biodegradáveis a base de amido

Dayane Gonzaga Domingos, Beatriz Lima Santos Klienchen Dalari, Ana Silvia de Lima Vielmo, Juliana Barden Schallemberger, Daiana Cardoso de Oliveira

DOI: 10.36229/978-65-5866-009-5.CAP.03

Capítulo 4: Peptídeos bioativos obtidos de produtos lácteos: Uma revisão narrativa 32

Meire dos Santos Falcão de Lima, Amanda Lopes Gueiros, Geziane Celina Sátiro, Gleidce Nayra André da Silva, Karoline Mirella Soares de Souza, Ana Lúcia Figueiredo Porto, Maria Taciana Holanda Cavalcanti

DOI: 10.36229/978-65-5866-009-5.CAP.04

Capítulo 5: Fenomenologia na proteção de vasos sanguíneos por controle da viscosidade do sangue 40

Matheus Guisoni Pereira, Klívia Faria Finzer, José Roberto Delalibera Finzer, Ricardo Amâncio Malagoni DOI: 10.36229/978-65-5866-009-5.CAP.05

Capítulo 6: Avaliação dos compósitos $\mathrm{CuFe}_{2} \mathrm{O}_{4} /$ Biochar e $\mathrm{ZnFe}_{2} \mathrm{O}_{4} /$ Biochar na degradação de rodamina $B$ via processo foto-Fenton 50

Jandira Leichtweis, Nicoly Welter, Siara Silvestri, Yasmin Vieira, Bruna Machado Sanini, Elvis Carissimi DOI: $10.36229 / 978-65-5866-009-5 . C A P .06$

Capítulo 7: Síntese de chalconas 57

Heriberto Rodrigues Bitencourt, Andrey Moacir do Rosario Marinho, Antonio Pedro da Silva Souza Filho, José Ciríaco Pinheiro, Maria das Graças Cardoso Tavares, Ossalin de Almeida, Rômulo Augusto Feio Farias 


\section{SUMÁRIO}

Capítulo 8: Desenvolvimento e avaliação da qualidade físico-química de sabonete em barra a base de óleo de coco (Cocos nucifera). 67

Keliane Gonçalves Costa, Josefa Renalva de Macêdo Costa, Flavia Scigliano Dabbur

DOI: 10.36229/978-65-5866-009-5.CAP.08

Capítulo 9: Caracterização e aplicação da casca de Citrus Reticulada como um eficiente adsorvente para remoção de contaminante emergente em solução líquida 81

Matias Schadeck Netto, Isadora Argenta Preigschadt, Raíssa da Cunha Bevilacqua, Evandro Stoffels Mallmann, Guilherme Luiz Dotto, Edson Luiz Foletto

DOI: $10.36229 / 978-65-5866-009-5 . C A P .09$

Capítulo 10: Preparação e caracterização de membrana inorgânica com propriedades para remoção de corante amarelo reativo $\mathrm{BF}-3 \mathrm{R}$ 93

Fabiana Medeiros do Nascimento Silva, Rondinele Nunes de Araújo, Antonielly dos Santos Barbosa, Rochelia Silva Souza Cunha, Meiry Glaucia Freire Rodrigues

DOI: $10.36229 / 978-65-5866-009-5 . C A P .10$

Capítulo 11: Planejamento experimental da remoção de corante amarelo reativo através de argila esmectita.

Luana Araujo de Oliveira, Iwalisson Nicolau de Araújo, Rochelia Silva Souza Cunha, Joseane Damasceno Mota, Meiry Glaucia Freire Rodrigues

DOI: $10.36229 / 978-65-5866-009-5 . C A P .11$

Capítulo 12: Sorção de metal pesado em efluentes sintéticos utilizando minerais argilosos: Bofe e Brasgel

Rochelia Silva Souza Cunha, Joseane Damasceno Mota, Wellington Siqueira Lima, Meiry Gláucia Freire Rodrigues

DOI: 10.36229/978-65-5866-009-5.CAP.12

Capítulo 13: Estudo de parâmetros aplicado a remoção de metais de resíduos eletroeletrônicos

Maria do Socorro Bezerra da Silva, Raffael Andrade Costa de Melo, André Luis Lopes Moriyama, Carlson Pereira de Souza

DOI: 10.36229/978-65-5866-009-5.CAP.13

Capítulo 14: Formulação de tintas com dióxido de titânio. 137

Gabriela Silva Spirlandelli, José Roberto Delalibera Finzer, David Maikel Fernandes

DOI: 10.36229/978-65-5866-009-5.CAP.14 


\section{SUMÁRIO}

Capítulo 15: Análise de desempenho do pré-tratamento do bagaço do abacaxi com peróxido de hidrogênio na obtenção de açúcares redutores totais para produção de bioetanol de segunda geração

Araceli Aparecida Seolatto, Lorena Costa Vasconcelos Macedo, Fernanda Ferreira Freitas, Mariana Bisinotto Pereira, Rodrigo Silva Fontoura, Danielle Pires Nogueira

DOI: $10.36229 / 978-65-5866-009-5 . C A P .15$

Capítulo 16: Estudo do potencial teórico de geração de biogás para o Aterro Sanitário em Campina Grande - PB

Maria Josicleide Felipe Guedes, Francisco Gleson dos Santos Moreira, Kellianny Oliveira Aires, Rosires Catão Curi, Veruschka Escarião Dessoles Monteiro

DOI: 10.36229/978-65-5866-009-5.CAP.016

Capítulo 17: Modelagem termoquímica da reforma do $\mathrm{CO}_{2}$ para a produção de hidrogênio em um reformador termoquímico solar: Um estudo computacional

Vitória da Fonseca Dias, Jornandes Dias da Silva

DOI: 10.36229/978-65-5866-009-5.CAP.17

Autores: 


\section{Capítulo 1}

Seleção de fungos produtores de $\beta$ - $D$ frutosiltransferase por fermentação em estado sólido

Juanize Matias da Silva Batista

Thiago Pajeú Nascimento

Márcia Nieves Carneiro da Cunha

Camila Souza Porto

José António Couto Teixeira

Ana Lúcia Figueiredo Porto

Resumo: A enzima $\beta$-D-frutosiltransferase é responsável pela síntese de FOS (frutooligossacarídeos) a partir de sacarose por reação de transfrutosilação é produzida por diferentes micro-organismos, principalmente por fungos filamentosos. 0 objetivo deste trabalho foi selecionar a melhor linhagem fúngica produtora da $\beta$-Dfrutosiltransferase por fermentação em estado sólido, bem como o método de extração. A fermentação em estado sólido utilizando o substrato farelo de trigo umedecido com solução de sacarose atingindo $70 \%$ de umidade na concentração de esporos de 107 no tempo de 96 horas de crescimento. Todas as linhagens manipuladas apresentaram atividade hidrolítica, no entanto apenas uma linhagem não demonstrou atividade transfrutosilação. 0 isolado SIS 14 que pertence ao gênero Aspergillus sp. destacou-se pelos maiores valores em atividade no método de extração utilizando água destilada, apresentando 300,90 U/mL na atividade de transfrutosilação e na atividade hidrolítica de $155,74 \mathrm{U} / \mathrm{mL}$. Contudo, pode-se perceber que dos solventes estudados a água destilada foi melhor obtendo o valor em atividade de transfrutosilação, como também a linhagem SIS 14 é promissora para a produção da $\beta$-D-frutosiltransferase.

Palavras-chave: $\beta$-D-frutosiltransferase, frutooligossacarídeos, fermentação em estado sólido 


\section{INTRODUÇÃO}

Nos últimos tempos, muitos pesquisadores estão expressando imenso interesse em nutracêuticos e alimentos funcionais para o combate a várias doenças ou condições anormais, pois são fontes de vitaminais e minerais que apoiam a resposta imune. Logo, os alimentos funcionais são definidos como alimentos que são fortificados ou modificados para aumentar seu valor nutritivo e biológico para melhorar estado de saúde e reduzir o risco de doenças. 0 mercado dos alimentos funcionais nos países Estados Unidos, Japão, Ásia-Pacífico e União Europeia apresenta uma estimativa para 2020 uma movimentação de \$ 304,5 bilhões com uma taxa média de crescimento anual de 8,5\% (Venkatakrishnan et al.2020; Granato et al. 2020).

Os ingredientes bioativos que compoem os alimentos funcionais são os probióticos, prebióticos e simbióticos. Probióticos são microrganismos intestinais vivos que ajudam na função de saúde do hospedeiro, enquanto prebióticos são materiais alimentares não digeridos que estimulam o crescimento dos microrganismos presentes no intestino (probióticos) e, portanto, ajudam a melhorar o estado de saúde do hospedeiro (Venkatakrishnan et al. 2020; O'Connell, 2020).

Os prebióticos são oligossacarídeos como os frutooligossacarídeos (FOS) são oligossacarídeos denominados de açúcares não convencionais e têm recebido um interesse especial devido as suas propriedades biológicas e funcionais, principalmente para utilização como prebióticos. FOS podem ser encontrados em pequenas quantidades em frutas e vegetais, tais como, cebola, alho, aspargos, centeio e tomate (Ghazi et al., 2007; Bharti et al., 2015; Wang et al., 2020).

No entanto, a produção de FOS industrialmente é através da síntese enzimática a partir da sacarose por enzimas microbianas com atividade de transfrutosilação, podendo ser denominadas de $\beta$-Dfrutosiltransferase (EC 2.4.1.9) e $\beta$-frutofuranosidase (EC 3.2.1.26), são produzidas intracelular e extracelular por diferentes gêneros de fungos, como Auerobasidium sp., Penicillium sp., Fusarium sp. e Aspergillus sp., no entanto as espécies Aspergillus oryzae e Aspergillus niger apresentam o status de Generally Recognized as safe (GRAS) (Lateef, Oloke, e Prapulla, 2007; Mussatto et al., 2009; Ganaie et al., 2014;).

Devido à importância biotecnológica de buscar novas fontes de enzimas para síntese de FOS com relação a altos valores em atividade e custo de produção reduzido este trabalho como objetivo selecionar a linhagem de fungo filamentoso com melhor produção da $\beta$-D-frutosiltransferase por cultivo em estadosólido bem como o método de extração da enzima.

\section{MATERIAL E MÉTODO}

\subsection{MICRORGANISMOS}

Os microrganismos utilizados para seleção foram pertencentes aos gêneros Aspergillus sp. e Mucor sp. isolados do solo da Caatinga mantidos em meio sólido CZ (Czapek Ágar) e incubados em estufa microbiológica a $30^{\circ} \mathrm{C}$ por 72 horas para esporulação. Após este tempo foram armazenados a $4^{\circ} \mathrm{C}$. Todos os microrganismos apresentam cadastro no Sistema Nacional de Gestão do Patrimônio genético e do conhecimento tradicional associado (Cadastro $\mathrm{N}^{\circ} \mathrm{AA30B0B}$ ).

\subsection{SELEÇÃO DA LINHAGEM MELHOR PRODUTORA POR FERMENTAÇÃO EM ESTADO-SÓLIDO}

Como substrato foi utilizado farelo de trigo obtido do comércio local da região metropolitana do Recife/PE. Os ensaios foram realizados em frascos cônicos de $125 \mathrm{~mL}$ contendo $3 \mathrm{~g}$ do substrato, foram esterilizados $121^{\circ} \mathrm{C} / 1 \mathrm{~atm}$ de pressão, durante 30 minutos. Após a esterilização o substrato sendo umedecido com uma solução de sacarose $(200 \mathrm{~g} / \mathrm{L})$ para obter $70 \%$ de teor de umidade e inoculado com a concentração de 107 esporos/mL. Os ensaios foram mantidos em escuro e incubados a $30^{\circ} \mathrm{C}$ por 96 horas.

\subsection{EXTRAÇÃO DO CALDO FERMENTADO}

A extração foi realizada utilizando a proporção de $7,5 \mathrm{~mL}$ para cada $1 \mathrm{~g}$ de substrato, sendo água destilada e tampão citrato de sódio 0,1M pH 5,15 como solventes, o qual foi encaminhado para um agitador orbital a $100 \mathrm{rpm}$ por 2 horas. Em seguida, foi filtrado utilizando papel de filtro (Watman no1), por fim realizou uma centrifugação por 20 minutos a $12.000 \mathrm{rpm}$. 0 sobrenadante encaminhado para determinação da atividade de transfrutosilação e hidrolítica. 


\subsection{DETERMINAÇÃO DAS ATIVIDADES DE TRANSFRUTOSILAÇÃO E HIDROLÍTICA}

A atividade de transfrutosilação foi determinada de acordo com Sangeetha et al. (2004), realizada por incubação de $0,25 \mathrm{~mL}$ do caldo fermentado livre de células com $0,75 \mathrm{~mL}$ do substrato $(60 \%$ solução de sacarose em tampão citrato de sódio $0,1 \mathrm{M}$ no $\mathrm{pH} 5,15)$ a $55^{\circ} \mathrm{C}$ por 60 minutos. A atividade de transfrutosilação e atividade hidrolítica foram definidas conforme Chen et al. (1996) medindo a liberação da glicose pelo Kit de glicose-oxidase (BioSystem S.A) e os açúcares redutores por Miller (1959).

As equações abaixo foram utilizadas para calcular as concentrações de frutose livre (F) e frutose transferida

(F') na reação:

$$
F=R-G \text { e } F^{\prime}=G-F=2 G-R
$$

Uma unidade de atividade transfrutosilação (UTF) é definida como a quantidade de enzima necessária para transferir $1 \mu \mathrm{mol}$ de frutose por minuto e uma unidade de atividade hidrolítica (UH) é definida por 1 $\mu$ mol de glicose liberada por minuto.

\section{RESULTADOS E DISCUSSÃO}

De acordo com a Tabela 1 pode ser visualizado os resultados das atividades de transfrutosilação e hidrolítica dos fungos filamentosos no cultivo em estado sólido em 96 horas, utilizando o farelo de trigo como substrato. Das seis linhagens estudadas três apresentaram alta atividade hidrolítica em comparação a atividade de transfrutosilação, independentemente do método de extração utilizado, todos os fungos filamentosos pesquisados apresentaram atividade hidrolítica e apenas o isolado SIS 42 (Mucor subtillissimus) não apresentou atividade de transfrutosilação em nenhum dos métodos de extração estudados.

O valor máximo de atividade transfrutosilação foi apresentada pela linhagem SIS 14 (Aspergillus sp.) com $300,90 \mathrm{U} / \mathrm{mL}$ utilizando água destilada como solvente e sua atividade hidrolítica foi de 155,74 U/mL. Quando comparado os resultados desta mesma linhagem utilizando tampão citrato de sódio como solvente da extração conclui-se que o contato da solubilização da enzima de interesse com o tampão influenciou consideravelmente na atividade da $\beta$-D-frutosiltransferase no qual utilizando o tampão citrato de sódio obteve o valor de 188,01 U/mL em atividade de transfrutosilação. Percebe-se que ao colocar este tampão como solvente para este fungo na extração obteve uma queda relevante da atividade enzimática pesquisada.

Em comparação com o trabalho de Mussatto et al. (2013) que pesquisou a produção de FOS pela $\beta$ frutofuranosidase de Aspergillus japonicus por fermentação em estado sólido utilizando a parte intertegumentar da semente de café e utilizando a água destilada como solvente, obtiveram o valor de $64,12 \mathrm{U} / \mathrm{mL}$ em atividade, sendo inferior a este trabalho, pelo qual obteve-se 300,90 U/mL.

Tabela 1. Produção de $\beta$-D-frutosiltransferase por fungos filamentosos isolados da Caatinga.

\begin{tabular}{|c|c|c|c|c|}
\hline \multirow[b]{2}{*}{ Microrganismos } & \multicolumn{2}{|c|}{ Água destilada } & \multicolumn{2}{|c|}{ Tampão citrato de sódio } \\
\hline & $\mathrm{U}_{\mathrm{TF}^{*}}$ & $\mathrm{U}_{\mathrm{H}^{* *}}$ & $\mathrm{U}_{\mathrm{TF}}$ & $\mathrm{UH}_{\mathrm{H}}$ \\
\hline SIS 11 (Aspergillus sp.) & 142,19 & 108,05 & 137,17 & 109,36 \\
\hline SIS 14 (Aspergillus sp.) & 300,90 & 155,74 & 188,01 & 164,95 \\
\hline SIS 15 (Aspergillus sp.) & 90,71 & 94,23 & 126,96 & 129,76 \\
\hline SIS 16 (Aspergillus sp.) & 150,99 & 127,95 & 201,16 & 156,56 \\
\hline SIS 25 (Aspergillus sp.) & 62,40 & 94,23 & 50,76 & 91,60 \\
\hline SIS 42 (Mucor subtillissimus) & 0 & 72,36 & 0 & 93,57 \\
\hline
\end{tabular}

\section{CONCLUSÕES}

Foi selecionado a linhagem SIS 14 (Aspergillus sp.) apresentando maior o valor em atividade FTase de $300,90 \mathrm{U} / \mathrm{mL}$ utilizando água destilada como solvente na extração. Neste trabalho foi observado que o solvente de extração influencia consideravelmente na atividade de transfrutosilação e hidrolítica. Portanto, é um aspecto importante a ser discutido ao se tratar de produção e purificação desta enzima na qual tem aplicação industrial na produção de frutooligossacarídeos. 


\section{REFERÊNCIAS}

[1] Cheng, W., Liu, Chi-hsien., 1996. Production of $\beta$-fructofuranosidase by Aspergillus japonicus. Enzyme and Microbial Technology. 18, 153 - 160.

[2] Bharti, S. K., Krishnan, S., Kumar, A., Gupta, A. K., Ghosh, A. K., Kumar, A., 2015. Mechanism-based antidiabetic activity of Fructo- and isomalto-oligosaccharides: Validation by in vivo, in silico and in vitro interaction potential. Process Biochemistry. 50, 317-327.

[3] Ghazi, I.; Fernandez-Arrojo, L., Garcia-Arellano, H., Ferrer, M., Ballesteros, A., Plou, F.J, 2007. Purification and kinetic characterization of a fructosyltransferase from Aspergillus aculeatus. Journal of biotechnology. 128, 204-11, 2007.

[4] Granato, D., Barba, F. J., Kovačević, D. B., Lorenzo, J. M., Cruz, A. G., \& Putnik, P., 2020. Functional Foods: Product Development, Technological Trends, Efficacy Testing, and Safety. Annual Review of Food Science and Technology, 11(1). doi:10.1146/annurev-food-032519-051708

[5] Lateef, A., Oloke, J. K., Prapulla, S. G., 2007. The effect of ultrasonication on the release of fructosyltransferase from Aureobasidium pullulans CFR 77. Enzyme and Microbial Technology. 40, 1067-1070.

[6] L'Hocine, L., Wang, Z., Jiang, B., Xu, S., 2000. Purification and partial characterization of fructosyltransferase and invertase from Aspergillus niger AS0023. Journal of biotechnology. 81, 73-84.

[7] Miller, G.L., 1959. Use of dinitrosalicyclic acid reagent for determination of reducing sugar. Anal. Chem. 31, $426-428$

[8] Mohd, A. G., Uma S. G., 2014. Recycling of cell culture and efficient release of intracellular fructosyltransferase by ultrasonication for the production of fructooligosaccharides. Carbohydrate polymers. 110, 253-258.

[9] Mussatto, S. I., Ballesteros, L. F A., Cristóbal N., Teixeira, J. A., 2013.Maximization of Fructooligosaccharides and $\beta$-Fructofuranosidase Production by Aspergillus japonicus under Solid-State Fermentation Conditions. Food Bioprocess Technol. 6, 2128-2134.

[10] Mussatto, S.I., Teixeira, J.A., 2009. Increase in the fructooligosaccharides yield and productivity by solid-state fermentation with Aspergillus japonicus using agro-industrial residues as support and nutrient source. Biochemical Engineering Journal. 58, 154-157.

[11] O'Connell, T. M., 2020. The Application of Metabolomics to Probiotic and Prebiotic Interventions in Human Clinical Studies; Metabolites, 10, 120; doi:10.3390/metabo10030120.

[12] Sangeetha, P.T., Ramesh, M.N., Prapulla, S.G, 2004. Production of fructosyltransferase by Aspergillus oryzae CFR 202 in solid-state fermentation using agricultural by-products. Applied Microbiology Biotechnology. 65, 530-537.

[13] Venkatakrishnan, K., Chiu, H., \& Wang, C. K., 2020. Impact of functional foods and nutraceuticals on high blood pressure with special focus on Meta-analysis: Review from a public health perspective. Food \& Function. doi:10.1039/d0fo00357c

[14] Wang, Z., Tauzin, A. S., Laville, E., Tedesco, P., Létisse, F., Terrapon, N., Potocki-Veronese, G., 2020. Harvesting of Prebiotic Fructooligosaccharides by Nonbeneficial Human Gut Bacteria. mSphere, 5(1). doi:10.1128/msphere.00771-19 


\section{Capítulo 2}

Estudo físico-químico e quimiométrico de chá de gengibre (Zingiber officinale)

\section{Kamila Leal Correa}

Gabriely dos Santos

Débora Mendes de Andrade

Kelson do Carmo Freitas Faial

Neuton Trindade Vasconcelos Junior

Mônia Maria Carvalho da Silva

Allyson Allennon Pinheiro do Rosário

Charles Alberto Brito Negrão

Ewerton Carvalho de Souza

Antonio dos Santos Silva

Resumo: 0 gengibre é uma raiz ou rizoma muito utilizado pela população para o preparo de chás com diversos fins medicinais, sendo também conhecido como açafrão. 0 presente trabalho se ocupou em analisar quatro variáveis físico-químicas $(\mathrm{pH}$, densidade, teor de extrativos e acidez) em chás de gengibre e duas variáveis físicoquímicas (umidade e cinzas) nos rizomas in natura, provenientes de duas localidades do Pará (Ananindeua e Belém). Os resultados encontrados para essas seis variáveis físicoquímicas se mostraram coerentes e condizentes com valores encontrados na literatura, tanto para o gengibre como para outros rizomas. As técnicas estatísticas empregadas conseguiram discriminar as amostras conforme sua origem.

Palavras-chave: Plantas Medicinais, Estatística Multivariada, Controle de Qualidade. 


\section{INTRODUÇ̃̃O}

Pedro et al. (2016) definem chá medicinal como sendo uma bebida obtida da infusão ou decocção de folhas, cascas ou raízes na forma seca ou in natura de um vegetal que contém substâncias ou classes de substâncias responsáveis por ação terapêutica.

A Agência Nacional de Vigilância Sanitária (ANVISA), através de sua RDC № 10, de 9 de março de 2010, define legalmente decoç̧ão como sendo "preparação que consiste na ebulição da droga vegetal em água potável por tempo determinado. Método indicado para partes de drogas vegetais com consistência rígida, tais como cascas, raízes, rizomas, caules, sementes e folhas coriáceas" (BRASIL, 2010).

Assis et al. (2015) lembram que a população faz uso frequente de plantas medicinais na forma de chá com o objeto de aproveitar de suas propriedades terapêuticas, e, dentre as formas de se preparar as plantas medicinais, deve destacar a infusão e a decocção.

Dentre as plantas medicinais mais populares da antiguidade, destaca-se o gengibre (Zingiber officinale Roscoe), uma espécie herbácea, pertencente à família das Zingiberaceae, e que é composta por parte aérea e rizoma. A parte aérea dessa planta é formada por caules articulados eretos, que atinge de 30 a $150 \mathrm{~cm}$ de altura, com folhas grandes lanceoladas e invaginantes (Figura 1A), suas flores são hermafroditas, de coloração verde ou branca amareladas, dispostas em inflorescências com espigas ovoides (LUCIO et al., 2010; PEREIRA et al., 2012). O rizoma é conhecido como a parte comercial da planta (Figura 1B), o qual é formado por ramificações horizontais, palmadas, carnosas, e pouco fibrosas (LUCIO et al., 2010).

Figura 1. O cultivo da planta Zingiber officinale (A) e o rizoma do gengibre (B).
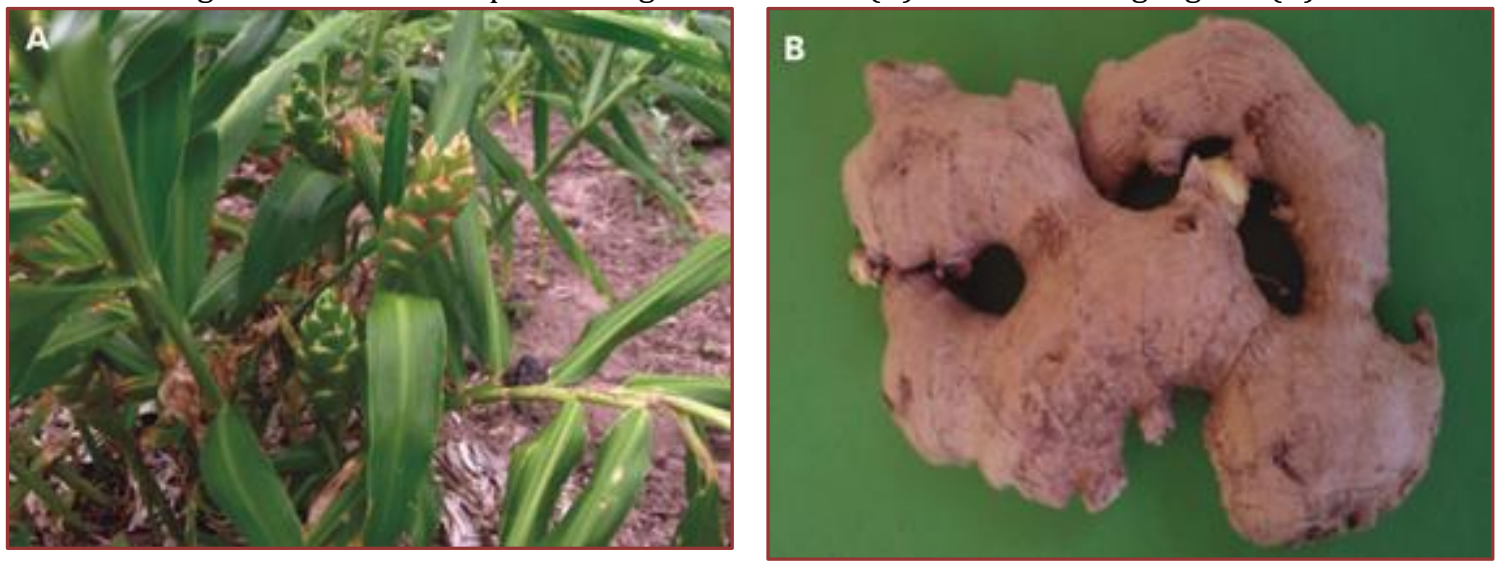

Fonte: PEREIRA et al. (2012).

O gengibre (Z. officinale) é um caule subterrâneo nativo do sudeste asiático comumente encontrado em florestas tropicais, sendo utilizado como especiaria na culinária e na preparação de medicamentos (SOUSA et al., 2014). 0 rizoma in natura é ofertado ao mercado consumidor, como gengibre fresco, em conserva, cristalizado e seco (LUCIO et al., 2010).

0 gengibre (Z. officinale) é popularmente utilizado para tratamento de asma, bronquite, gripe, pneumonia, infecções gerais e para dores no ombro e na garganta (RIBEIRO et al., 2017). Além disso, é conhecido também pelo seu uso medicinal como carminativo, hepatoprotetor, estomacal, antiemético, antiinflamatório, antipirético, antibacteriano, antioxidante, hipoglicemiante e diurético (PEREIRA et al., 2015; BHATT et al., 2013). As propriedades terapêuticas dessa planta são resultado da ação de várias substâncias, como, por exemplo, do seu óleo essencial que contém canfeno, felandreno, zingibereno e zingerona, bem como é composto por um óleo resina, rico em gingerois, os quais são responsáveis pelo odor forte e picante do gengibre (Z. officinale) (LORENZI; MATOS, 2002; SOUSA et al., 2014).

Durante séculos, o gengibre tem sido utilizado nos sistemas populares da medicina na China e na Índia, para o tratamento de diversas doenças, tais como: dores de cabeça, resfriados, osteoartrite, doenças nervosas, gengivite, dor de dente e asma (LI et al., 2019). Além disso, seus vários efeitos farmacológicos foram relatados e incluem inibição do estresse oxidativo e da inflamação, tratamento de Alzheimer, doenças cardiovasculares e depressão (EBRAHIMZADEH ATTARI et al., 2017; BANIHANI, 2018). 
O chá de gengibre (Z. officinale) feito com pedaços do rizoma fresco é indicado para tratamento de tosse, resfriado e congestão nasal, porém é contraindicado para pacientes com insuficiência cardíaca, pois ele potencializa os efeitos anticoagulantes, o que pode aumentar o risco de hemorragias, assim como o seu uso por pacientes hipertensos deve ser controlado, pois o gengibre ocasiona um aumento do metabolismo devido ao seu efeito termogênico, o que pode causar a elevação da pressão arterial (NICÁCIO et al., 2018; SACCHETTI, 2004).

Cada um dos produtos e formas farmacêuticas obtidas dessa planta apresentam determinadas características físico-químicas que variam dependendo da sua origem e do seu método de preparo, sendo por isso importante realizar ensaios físicos e químicos que garantam a qualidade desse material (GOMES et al., 2016; PINHEIRO et al., 2020).

\section{OBJETIVOS}

Este trabalho teve como objetivo a determinação de quatro variáveis físico-químicas ( $\mathrm{pH}$, teor de extrativos, densidade e acidez) de chá de gengibre (Zingiber officinale) e de duas variáveis físico-químicas (umidade e cinzas) do rizoma dessa planta, em amostras provenientes de dois municípios do Estado do Pará (Ananindeua e Belém), além de discriminar tais amostras conforme sua origem geográfica empregando duas técnicas estatísticas multivariadas (análise de componentes principais, ACP, e análise hierárquica de agrupamentos, AHA).

\section{MATERIAIS E MÉTODOS}

\subsection{AMOSTRAS}

Foram adquiridas vinte amostras de aproximadamente $100 \mathrm{~g}$ de rizoma de gengibre (Zingiber officinale), sendo dez adquiridas no município de Belém do Pará e dez adquiridas no município de Ananindeua. As amostras de Belém foram rotuladas com a letra B e as de Ananindeua com a letra A. Após adquiridas, elas foram levadas para o Laboratório de Física Aplicada à Farmácia (LAFFA) da Universidade Federal do Pará (UFPA) para realizar as análises físico-químicas dos chás preparados com os rizomas e dos próprios rizomas, seguindo-se metodologias preconizadas pela Farmacopeia Brasileira (2010), tendo sido cada um dos seis parâmetros realizado em triplicata.

\subsection{PREPARO DO CHÁ DE GENGIBRE (ZINGIBER OFFICINALE)}

0 chá de gengibre (Zingiber officinale) foi preparado por meio do método de decocção, por se tratar de um rizoma, que é uma parte "dura" do vegetal (BRASIL, 2010). Utilizou-se aproximadamente $5 \mathrm{~g}$ de amostra previamente triturada em gral com pistilo sendo posto esse material em contato com $100 \mathrm{~mL}$ de água destilada fervendo, por 15 minutos. Após 30 minutos em repouso, e resfriada a solução obtida, esta solução foi filtrada com papel de filtro qualitativo e seu volume completado para $100 \mathrm{~mL}$ com água destilada.

\subsection{PARÂMETROS FíSICO-QUíMICOS DOS CHÁS DE GENGIBRE (ZINGIBER OFFICINALE)}

Foram analisados os seguintes parâmetros físico-químicos nos chás de Gengibre (Zingiber officinale) preparados:

\subsubsection{DETERMINAÇÃO DE PH DO CHÁ DE GENGIBRE (ZINGIBER OFFICINALE)}

Para a determinação do $\mathrm{pH}$ do chá, inseriu-se o eletrodo de um pHmetro, previamente calibrado com soluções tampão de $\mathrm{pH} 4,0$ e de 7,0, diretamente no chá preparado como descrito acima, sendo obtida a leitura do $\mathrm{pH}$ diretamente no visor do aparelho. 


\subsubsection{DETERMINAÇÃO DA DENSIDADE DO CHÁ DE GENGIBRE (ZINGIBER OFFICINALE)}

Uma proveta de $50 \mathrm{~mL}$, de massa previamente aferida, foi preenchida com o chá e então se calculou a densidade pela divisão da massa do pó pelo volume da proveta, sendo a densidade determinada pela equação (1), em que m é a massa de chá e $V$ é o volume da proveta.

$$
\mathrm{d}(\mathrm{g} / \mathrm{mL})=\frac{\mathrm{m}}{\mathrm{V}}
$$

\subsubsection{DETERMINAÇÃO DA ACIDEZ DO CHÁ DE GENGIBRE (ZINGIBER OFFICINALE)}

Para determinar a acidez foi retirada uma alíquota de $10 \mathrm{~mL}$ de chá preparado conforme descrito anteriormente, que foi diluída em Erlenmeyer de $250 \mathrm{~mL}$ com água destilada para completar $100 \mathrm{~mL}$. Em uma bureta de vidro de $100 \mathrm{~mL}$ foi adicionado solução de hidróxido de sódio (NaOH) a 0,1 mol/L com fator de correção previamente determinado, e foram adicionadas 3 gotas de fenolftaleína $1 \%$, como indicador. 0 processo titulométrico foi interrompido ao se observar a coloração rosada persistente. 0 cálculo da acidez foi realizado através da equação (2), onde V é o volume utilizado de $\mathrm{NaOH}, \mathrm{M}$ concentração do hidróxido de sódio, F o fator de diluição, P massa usada no preparo do chá.

$$
\text { acidez }=\left(\frac{\mathrm{Vx}(\mathrm{M} \times \mathrm{F})}{\mathrm{P}}\right) \div 100
$$

\subsubsection{TEOR DE EXTRATIVOS DOS CHÁS DE GENGIBRE (ZINGIBER OFFICINALE)}

Do chá preparado conforme descrito anteriormente, foi pipetada uma alíquota de $20 \mathrm{~mL}$, em pesa-filtro previamente tarado e evaporado até a secura em chapa aquecedora (Figura 2). 0 resíduo foi posto em estufa à 105으 C até completa secura, em seguida, foi resfriado em dessecador e depois pesado.

Figura 2. Aquecimento em chapa de pesa-filtros para teor de extrativos

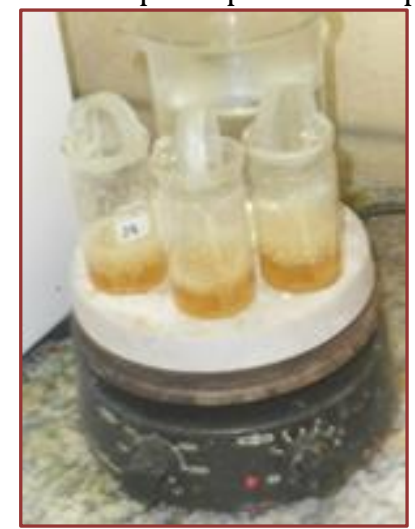

0 teor de extrativos foi determinado através da equação (3), onde TE é o teor de extrativos, expresso em porcentagem, $\mathrm{m}$ é a massa de resíduo seco, M é a massa da amostra pesada inicialmente, $\mathrm{F}$ é o fator que expressa a porcentagem volumétrica da alíquota retirada em relação ao volume de chá total preparado, por exemplo, para uma alíquota de $20 \mathrm{~mL}$, em um preparo de $100 \mathrm{~mL}$ de chá, o fator é 5 .

$$
\mathrm{TE}(\%)=\frac{\mathrm{m} \cdot \mathrm{F} \cdot 100}{\mathrm{M}}
$$




\subsection{PARÂMETROS FÍSICO-QUÍMICOS DOS RIZOMAS DE GENGIBRE (ZINGIBER OFFICINALE)}

Foram analisados os seguintes parâmetros físico-químicos nos rizomas de Gengibre (Zingiber officinale) preparados:

\subsubsection{TEOR DE UMIDADE}

Pesou-se aproximadamente 2 g de amostra de rizoma de gengibre (Zingiber officinale) em cápsula de porcelana previamente tarada, após isso, foi colocada em estufa a $105^{\circ} \mathrm{C}$ por até peso constante. Ao sair da estufa, foi colocada em dessecador em temperatura ambiente e logo após completo resfriamento foi pesado conjunto amostra seca mais cápsula de porcelana, em balança analítica. Os resultados foram expressos em porcentagem (\%) e obtidos pela equação (4), onde mf representa o conjunto a Massa da cápsula + amostra após a secagem, $\mathrm{m}_{\mathrm{c}}$ representa a massa da cápsula vazia e $\mathrm{m}_{0}$ a massa inicial da amostra.

$$
\text { Umidade }(\%)=100-\left(\frac{\left(\mathrm{m}_{\mathrm{f}}-\mathrm{m}_{\mathrm{c}}\right)}{\mathrm{m}_{0}} \cdot 100\right)
$$

\subsubsection{TEOR DE CINZAS DO RIZOMA DE GENGIBRE (ZINGIBER OFFICINALE)}

Foram pesados $5 \mathrm{~g}$ do rizoma de gengibre em cadinho de porcelana previamente tarado e calcinado. Depois se processou a incineração da amostra em forno mufla a $450^{\circ} \mathrm{C}$ até que só restasse cinza branca no cadinho. Então o cadinho foi levado para dessecador, onde resfriou para depois ser pesado o conjunto cadinho + cinzas. 0 teor de cinzas, expresso em percentagem (\%), foi determinado se utilizando a equação (5), onde $m_{c a}$ é o conjunto massa do cadinho mais amostra, $m_{c}$ é a massa do cadinho vazio e ma é a massa inicial da amostra.

$$
\text { Cinzas }(\%)=\left(\frac{\left(\mathrm{m}_{\mathrm{ca}}-\mathrm{m}_{\mathrm{c}}\right)}{\mathrm{m}_{\mathrm{a}}} * 100\right)
$$

\subsection{ANÁLISES ESTATÍSTICAS}

Foi aplicado o teste $\mathrm{t}$ de Student aos dados obtidos para se avaliar se os resultados obtidos para cada um dos seis parâmetros podem ser considerados iguais ou não entre si, adotando-se um nível de confiança de 95\%, conforme a localidade de coleta (Belém ou Ananindeua). Também foram aplicadas as técnicas estatísticas multivariadas de análise de componentes principais (ACP) e análise hierárquica de agrupamentos (AHA) aos dados obtidos e padronizados, se empregando a distância euclidiana como métrica e ligação completa, com a finalidade de se verificar a possível discriminação das amostras conforme sua origem (Belém ou Ananindeua).

\section{RESULTADO E DISCUSSÃO}

Os resultados das análises físico-químicas estão dados na Tabela 1, onde são apresentados valores médios de duas determinações por amostra, seguido do desvio padrão. 
Tabela 1. Resultados encontrados para as seis variáveis investigadas

\begin{tabular}{|c|c|c|c|c|c|c|}
\hline Amostra & $\mathrm{pH}$ & Densidade $(\mathrm{g} / \mathrm{mL})$ & Acidez (\%) & TE (\%) & Umidade (\%) & Cinzas (\%) \\
\hline A1 & $6,15 \pm 0,07$ & $1,001 \pm 0,000$ & $13,92 \pm 0,94$ & $14,13 \pm 0,34$ & $75,72 \pm 3,38$ & $5,94 \pm 0,82$ \\
\hline $\mathrm{A} 2$ & $6,15 \pm 0,07$ & $001 \pm 0,000$ & $11,70 \pm 0,80$ & $13,13 \pm 0,30$ & $81,73 \pm 6,53$ & $8,19 \pm 0,58$ \\
\hline A3 & $6,05 \pm 0,07$ & $1,001 \pm 0,000$ & $13,91 \pm 0,95$ & $17,57 \pm 0,52$ & $74,49 \pm 1,23$ & $6,71 \pm 0,43$ \\
\hline A4 & $6,10 \pm 0,00$ & $1,001 \pm 0,000$ & $11,13 \pm 0,01$ & $16,94 \pm 0,44$ & $74,94 \pm 2,02$ & 0,98 \\
\hline A5 & $6,05 \pm 0,07$ & $\pm 0,000$ & $8,24 \pm 0,89$ & $13,60 \pm 0,59$ & $72,95 \pm 1,41$ & 0,36 \\
\hline A6 & $6,15 \pm 0,07$ & $\pm 0,000$ & $8,31 \pm 0,98$ & $13,61 \pm 0,00$ & $81,91 \pm 0,18$ & 0,45 \\
\hline A7 & $6,15 \pm 0,07$ & 00 & $8,34 \pm 0,93$ & $13,35 \pm 0,06$ & $79,90 \pm 1,42$ & $4,19 \pm 0,11$ \\
\hline A8 & $6,20 \pm 0,07$ & 00 & $13,19 \pm 0,66$ & $16,03 \pm 0,89$ & $82,45 \pm 1,74$ & 0,40 \\
\hline A9 & $6,10 \pm 0,00$ & $\pm 0,000$ & $8,24 \pm 0,89$ & $13,67 \pm 0,57$ & $82,57 \pm 0,08$ & 0,98 \\
\hline A10 & $6,15 \pm 0,00$ & $\pm 0,000$ & $8,31 \pm 0,99$ & $12,61 \pm 0,76$ & $72,95 \pm 1,41$ & $\pm 0,15$ \\
\hline Geral & $6,13^{*} \pm 0,06$ & $* \pm 0,000$ & $10,53 * \pm 3,59$ & $14,46^{*} \pm 1,99$ & $77,96^{*} \pm 4,42$ & $6,43^{*} \pm 2,11$ \\
\hline B1 & $7,85 \pm 0,07$ & $4 \pm 0,000$ & $5,53 \pm 0,00$ & $6,31 \pm 0,35$ & $87,22 \pm 1,16$ & $6,57 \pm 0,19$ \\
\hline B2 & $7,80 \pm 0,00$ & $\pm 0,000$ & $5,53 \pm 0,00$ & $6,15 \pm 0,12$ & $88,85 \pm 1,16$ & 0,32 \\
\hline B3 & $80 \pm 0,00$ & $\pm 0,000$ & $5,53 \pm 0,00$ & $5,20 \pm 0,97$ & $88,34 \pm 2,85$ & 0,16 \\
\hline B4 & $7,80 \pm 0,00$ & $\pm 0,000$ & $5,53 \pm 0,00$ & $5,29 \pm 0,67$ & $88,40 \pm 0,05$ & $\pm 0,62$ \\
\hline B5 & $7,80 \pm 0,00$ & $\pm 0,000$ & $5,53 \pm 0,00$ & $5,40 \pm 0,13$ & $90,53 \pm 0,04$ & $\pm 0,67$ \\
\hline B6 & $7,80 \pm 0,00$ & $\pm 0,000$ & $5,53 \pm 0,00$ & $6,05 \pm 0,40$ & $90,21 \pm 0,22$ & 0,44 \\
\hline B7 & $7,85 \pm 0,07$ & $04 \pm 0,000$ & $5,53 \pm 0,00$ & $6,61 \pm 0,39$ & $88,62 \pm 0,76$ & $2 \pm 0,22$ \\
\hline B8 & $7,80 \pm 0,00$ & $4 \pm 0,000$ & $5,53 \pm 0,00$ & $5,94 \pm 0,40$ & $90,41 \pm 1,42$ & $\pm 0,22$ \\
\hline B9 & $7,80 \pm 0,00$ & $1,004 \pm 0,000$ & $5,53 \pm 0,00$ & $5,05 \pm 0,15$ & $89,27 \pm 1,01$ & $2,81 \pm 0,26$ \\
\hline $\mathrm{B} 10$ & $7,80 \pm 0,00$ & $1,004 \pm 0,000$ & $5,53 \pm 0,00$ & $7,41 \pm 0,74$ & $87,85 \pm 3,39$ & $5,41 \pm 0,00$ \\
\hline Geral & $7,81 * \pm 0,03$ & $1,004 * \pm 0,000$ & $5,53^{*} \pm 0,00$ & $5,94 * \pm 0,86$ & $88,97 * \pm 1,60$ & $3,94^{*} \pm 1,69$ \\
\hline
\end{tabular}

Legenda: TE $=$ teor de extrativos. ${ }^{*}$ sobre as médias gerais significam não haver diferença significativa, com $95 \%$ de significância, conforme aplicação do teste t de Student.

Percebe-se que todas as seis variáveis físico-químicas se mostraram diferentes conforme a localidade de procedência do rizoma de gengibre (Zingiber officinale).

Os valores de pH tiveram médias iguais a 6,13 (Ananindeua) e 7,81 (Belém), valores estes superiores aos valores médios encontrados de 5,14 para chás de casca de copaíba (JUNIOR et al., 2014) e 4,95 a 5,15 (PINHO et al., 2014) para chás elaborados a partir da decocção da casca de aroeira. Assim os chás elaborados a partir de rizomas de gengibre (Zingiber officinale) são menos ácidos do que os preparados a partir cascas de copaíba e casca de aroeira. Wehmuth Filho (2016) alerta que quanto mais baixo o pH e mais elevada a acidez titulável de uma bebida ou comida, maior é o potencial erosivo do produto para a dentição humana, sendo que o pH crítico para que o processo de erosão dental ocorra é de 4,5, valor esse bem inferior ao dos chás aqui analisados, logo esses chás não apresentam potencial alto de erosão dentária. Esse autor, Wehmuth Filho, estudando diversas bebidas e chás, encontrou valores de $\mathrm{pH}$ entre 2,98 (Ice Team Lemon) a 5,98 (Mate Herbal), valores também correspondentes a uma bebida mais ácida que os chás aqui estudados. Santos et al. (2014) obtiveram um pH médio para chás de capim-limão igual a 5,08 e 2,34 para chás de Hibiscus sabdariffa L., sendo também essas bebidas de menor pH que os chás de gengibre. Deve-se levar em conta o que diz Segundo Jay (2000), ou seja, que valores de pH mais baixos propiciam o desenvolvimento de fungos, enquanto que as leveduras desenvolvem-se em valores de $\mathrm{pH}$ entre 2,0 a 8,0 e valores acima de 6,0 favorecem a proliferação de bactérias. Dessa forma, ressalta a importância armazenamento dos chás de gengibre de forma adequada, pois apresentam uma faixa de $\mathrm{pH}$ favorável ao desenvolvimento de microrganismos.

A acidez média encontrada para os chás de Ananindeua foi de 10,53 \% e para os chás de Belém foi de 5,53 $\%$. Os valores médios encontrados por Wehmuth Filho (2016) para as bebidas por ele investigadas variou entre 0,20 \% (Mate Herbal) a 7,12 \% (Ice Team Lemon), desta forma, os chás oriundos de Ananindeua apresenta acidez dentro desta faixa, todavia os de Belém apresentaram uma acidez mais elevada. Por outro lado, Santos et al. (2014) obtiveram uma acidez média de 12,00 \% para chás de Hibiscus sabdariffa L., sendo esse valor superior ao encontrado para os chás de gengibre aqui investigados. 
A densidade dos chás de gengibre (Zingiber officinale) teve médias iguais a 1,001 g/mL e 1,004 g/mL são valores superiores ao encontrado por Junior et al. (2014) para chás de cascas de copaíba $(0,97 \mathrm{~g} / \mathrm{mL})$. Esses valores são ligeiramente superiores ao da água pura $(1,000 \mathrm{~g} / \mathrm{mL})$, o que mostra ser essa bebida de baixa densidade.

0 Departamento de Agricultura dos Estados Unidos (USDA, 2008) aponta um teor de umidade para o rizoma fresco de gengibre de 78,89 \%, o que é próximo à média de 77,96 \% encontrado para as amostras de Ananindeua e inferior a média de 88,97 \% determinada para as amostras de Belém. Prato (2010) associa a grande variedade do teor de umidade dos rizomas de gengibre a diversos fatores: características do solo, incidência de chuvas, clima, tempo de colheita, dentre outros. Os valores de umidade encontrada por esse autor variou de $85 \%$ a $88 \%$, que está próximo ao valor de umidade encontrado no presente trabalho para as amostras de Belém.

As cinzas encontradas tiveram uma média de 6,43\% para os rizomas provenientes de Ananindeua e de 3,94 \% para os de origem de Belém. Ascheri et al. (2010) encontrou um teor médio de cinzas igual a 6,94 \% para os rizomas de lírio-do-brejo (Hedychium coronarium), que é uma valor próximo ao encontrado para os rizmoas de Ananindeua.

0 teor de extrativos (TE) médio foi de 14,46\% (Ananindeua) e 5,94\% (Belém). 0 TE pode ser definido como o resíduo proveniente da evaporação, o qual representa a quantidade de substâncias extraídas na presença de um determinado solvente em condições de extração pré-estabelecidas (FERREIRA et al., 2020; SOARES; FARIAS, 2017). Para esse parâmetro faz-se necessário considerar a substância que se deseja extrair, bem como o solvente utilizado, o qual deverá apresentar polaridade semelhante aos constituintes da matéria-prima vegetal (HUBINGER et al., 2009). A quantidade de substâncias extraíveis foi calculada em massa percentual pela média das determinações, sendo essa análise necessária para caracterizar a matéria prima vegetal utilizada no chá, a qual permite estabelecer mais um parâmetro de comparação entre materiais vegetais de diversas procedências (MELLO; PETROVICK, 2000). Os teores de extrativos obtidas nesse estudo estão abaixo do encontrado por Hubinger e colaboradores (2009), os quais obtiveram um teor de 27,52 \% referente a espécie Carqueja (Baccharis trimera). Porém, as médias encontradas são superiores aos achados de Silva et al. (2013), os quais estudaram o chá verde (Camellia sinensis), obtiveram teores de extrativos que variaram entre 0,10 \% a 1,58 \%, o que, consequentemente, pode significar que o chá de gengibre apresenta uma maior quantidade de substâncias extraíveis em água sob o processo de decocção. Como constituintes do gengibre que podem ter sido extraídos nesse processo destacam-se o zingibereno e o geranial, os quais segundo o estudo de Dabague et al. (2011) apresentaram cerca de $20,6 \%$ a $24,3 \%$ e $17,7 \%$ a $21,6 \%$ desses constituintes, respectivamente, seguindo outro método de extração, nesse caso a hidrodestilação para óleos essenciais.

As técnicas estatísticas multivariadas possibilitam se obter explicações claras e concisas sobre correlações e variância, quando aplicadas agrupamento em amostras de características similares entre si.

A aplicação da análise estatística multivariada conhecida como análise de componentes principais, ou ACP, utilizando distâncias euclidianas e ligações completas, aos dados referentes as seis variáveis estudadas, gerou o gráfico presente na Figura 3, que apresenta as duas primeiras componentes principais, sendo que as duas componentes juntas explicam $92,70 \%$ da variabilidade das amostras. 
Figura 3. Gráfico das duas primeiras componentes principais

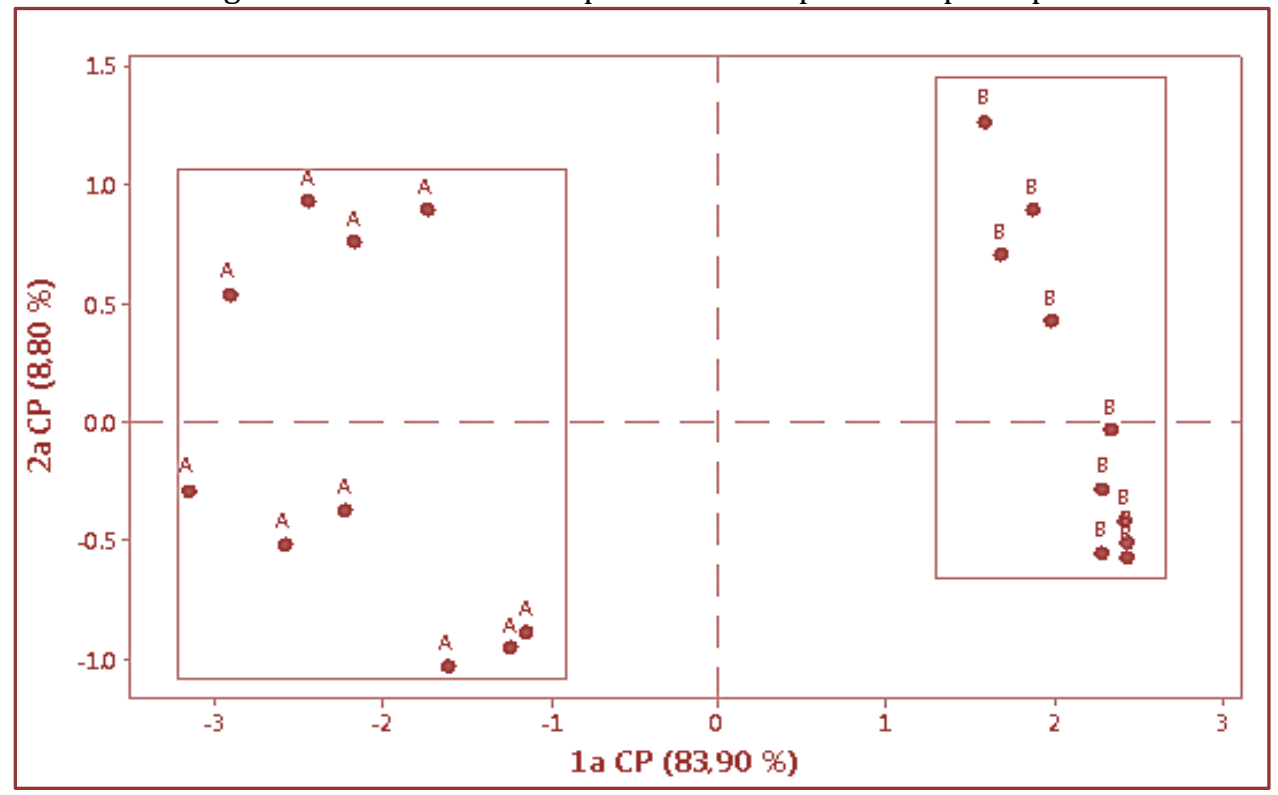

Formaram-se dois grupos distintos, sendo um formado exclusivamente por amostras da localidade A (Ananindeua), e outro somente por amostras da localidade B (Belém).

A aplicação da técnica multivariada denominada de análise hierárquica de agrupamentos, ou AHA, utilizando a distância euclidiana com ligação completa e níveis de similaridade, gerou o dendrograma presente na Figura 4. Esta análise representa a aglomeração feita em uma escala de 0 a $100 \%$ e mostrar as similaridades entre as amostras agrupadas, sendo que estas por sua vez estão situadas na base do dendrograma, que é uma representação bidimensional de uma relação n-dimensional.

Figura 4. Dendrograma obtido paras as amostras de chá de gengibre

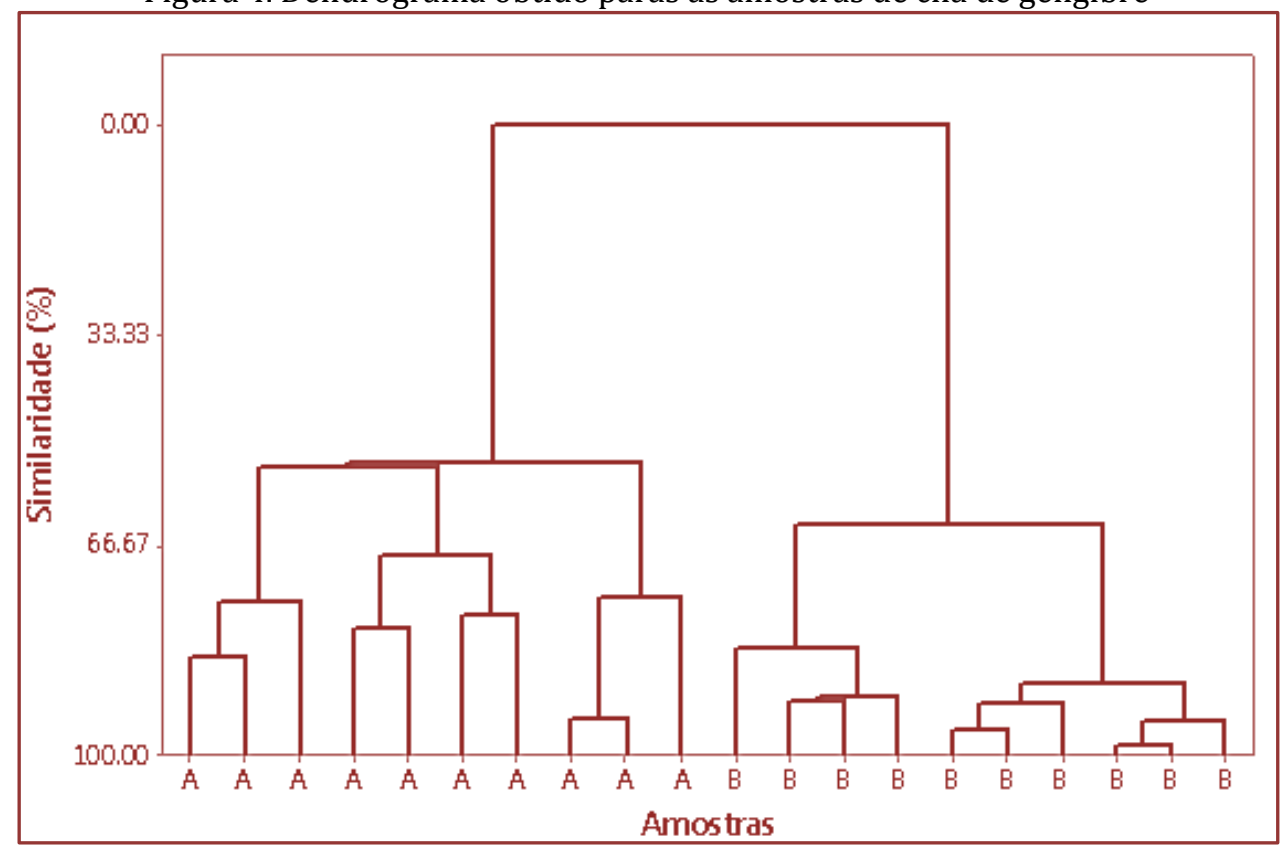


Pelo dendrograma pode-se verificar que as amostras de chá de gengibre das localidades A (Ananindeua) e B (Belém) são completamente diferentes entre si, pois apresenta 0,00\% de similaridade entre elas, o que concorda plenamente com os resultados obtidos pela técnica de ACP, pois na Figura 3, essas amostras se encontram em um grupo completamente disjunto.

\section{CONCLUSÃO}

Os resultados encontrados para os rizomas de gengibre (Zingiber officinale) e seus chás se mostraram condizentes com valores encontrados na literatura, indicando serem de boa qualidade e adequados ao consumo humano. As técnicas estatísticas empregadas se mostraram eficientes para a descriminação das amostras de acordo com sua localidade de origem, e, também, sugerem haver diferenças deste material que reflete as condições de seu plantio.

\section{REFERENCIAS}

[1] ASCHERI, D. P. R.; MOURA, W. S.; ASCHERI, J. L. R.; CARVALHO, C. W. P. CARACTERIZAÇÃO FÍSICA E FÍSICOQUÍMICA DE RIZOMAS E AMIDO DO LÍRIO-DO-BREJO (Hedychium coronarium). Pesq. Agropec. Trop., Goiânia, v. 40, n. 2, p. 159-166, abr./jun. 2010.

[2] ASSIS, A. F. S.; ANASTÁCIO, F. M. O.; SILVA, M. D. B.; AMARANTE, C. B.; NEVES, P. A. O. F. G. DETERMINAÇÃO DO TEOR DE METAIS EM CHÁS DE PLANTAS MEDICINAIS. Enciclopédia Bioesfera, v. 11, n. 1, 2015.

[3] BANIHANI, S. A. Ginger and testosterone. Biomolecules, v. 8, n. 4, p. 119, 2018.

[4] BHATT, N. et al. Ginger: A functional herb. Food as Medicine, p. 51-71, 2013.

[5] BRASIL. RDC № 10, de 9 de março de 2010. Dispõe sobre a notificação de drogas vegetais junto à Agência Nacional de Vigilância Sanitária (ANVISA) e dá outras providências, 2010.

[6] DABAGUE, I.C.M. et al. Teor e composição de óleo essencial de rizomas de gengibre (Zingiber officinale Roscoe) após diferentes períodos de secagem. Rev. bras. plantas med. v.13, n.1, p.79-84, 2011.

[7] EBRAHIMZADEH-ATTARI, V. et al. A systematic review of the anti-obesity and weight lowering effect of ginger (Zingiber officinale Roscoe) and its mechanisms of action. Phytotherapy Research, v. 32, n. 4, 2017.

[8] FERREIRA, G. D. et al. TINTURA DE MULUNGU (Erythrina velutina): PREPARO E CARACTERIZAÇÃO DE PARÂMETROS DE QUALIDADE. Journal of Biology \& Pharmacy and Agricultural Management, v. 17, n. 1, 2020.

[9] GOMES, P. R. B. et al. Avaliação físico-química do óleo essencial Zingiber officinale Roscoe (Gengibre). Revista Cubana de Farmácia, p. 50, 2016.

[10] GONZAGA, D. S. de O. M.; RODRIGUES, V. G. Gengibre Zingiber officinale Roscoe. Porto Velho: Embrapa Rondônia, Folder, 2001.

[11] HUbingeR, S. Z.; SALGADO, H. R. N.; MOREIRA, R. R. D. Controles físico, físico-químico, químico e microbiológico dos frutos de Dimorphandra mollis Benth., Fabaceae. Rev. bras. farmacogn., João Pessoa, v. 19, n. 3, p. 690-696, 2009.

[12] JAY, J.M. Modern food microbiology. 6th ed. Maryland: Aspen, 2000.

[13] LI, H. et al. Ginger for health care: An overview of systematic reviews. Complementary therapies in medicine, v. 45, p. 114-123, 2019.

[14] LORENZI, H.; MATOS, F. J. A. Plantas Medicinais no Brasil: nativas e exóticas. Nova Odessa, Instituto Plantarum, 2002.

[15] MELLO, J.C.P.; PETROVICK, P.R. Quality control of Baccharis trimera (Less) DC (Asteraceae) hydroalcoholic extracts. Acta Farm Bonaer, v. 19, n. 3, p. 211-216, 2000.

[16] NICÁCIO, G. L. S. et al. Breve revisão sobre as propriedades fitoterápicas do Zingiber officinale: 0 gengibre. Sinapse Múltipla, v. 7, n. 2, p. 74-80, 2018. 
[17] NIKKHAH-BODAGH, M.; MALEKI, I.; HEKMATDOOST, A. Ginger in gastrointestinal disorders: a systematic review of clinical trials. Food Sci. \& nutri., v. 7, n. 1, p. 96-108, 2019.

[18] PEDRO, F. G. G.; ARRUDA, G. L.; OLIVEIRA, J. C.; SANTOS, A. D.; SIGARINI, K.S.; HERNANDES, T.; VILLA, R. D.; OLIVEIRA, A. P. Composição centesimal e mineral de plantas medicinais comercializadas no mercado do Porto de Cuiabá, Mato Grosso, Brasil. Rev. Bras. Pl. Med., Campinas, v.18, n.1, supl. I, 2016.

[19] PEREIRA, R.C.A.; BEZERRA, M.G.A.; RODRIGUES, T.H.S. Cultivo de Gengibre em Região Litorânea do Ceará. Comunicado técnico da Embrapa, Sebrae, Fortaleza, CE, 2012.

[20] PINHEIRO, D. S. et al. Análise físico-química e quimiométrica de polpa de Bacaba (Oenocarpus Bacaba). Ciência e Tecnologia de Alimentos, 1ํㅡ. Ed. Belo Horizonte: Editora Poisson, v. 7, p. 8-15, 2020.

[21] PRATO, T. S. Influência da secagem sobre compostos medicinais e de pungência do gengibre. $2010.87 \mathrm{f}$. Dissertação (mestrado) - Universidade Estadual Paulista, Instituto de Biociências, Letras e Ciências Exatas, 2010. Disponível em: <http://hdl.handle.net/11449/90778>. Acesso em 08 de agosto de 2020.

[22] RIBEIRO, R. V. et al. Ethnobotanical study of medicinal plants used by Ribeirinhos in the North Araguaia microregion, Mato Grosso, Brazil. Journal of ethnopharmacology, v. 205, p. 69-102, 2017.

[23] RODRIGUES, M. L.; LIRA, R. K. Perfil Fitoquímico e Biológico do Extrato Hidroalcoólico dos Rizomas do Gengibre (Zingiber officinale Roscoe). Revista de Saúde e Biologia, Paraná, v. 8, n. 1, p. 44-52, 2013.

[24] SACCHETTI, G. Comparative evaluation of 11 essential oils of different origin as functional antioxidants, antiradicals and antimicrobials in foods. Food Chemistry, v. 91, p. 621-32, 2004.

[25] SANTOS, U. V.; SANTOS, B. S.; SILVA, G. F.; CONSTANT, P. B. L.; SANTOS, J. A. B. AVALIAÇÃO DE POTENCIAL DE ERVAS MEDICINAIS: CAPIM-LIMÃO (Cymbopogon citratus D.C.), CHÁ VERDE (Camellia sinensis L.) E HIBISCO (Hibiscus sabdariffa L.) PARA OBTENÇÃO DE CHÁS SOLÚVEIS. Revista GEINTEC - ISSN: 2237-0722. São Cristóvão/SE - 2014. Vol. 4/n. 4/ p.1399-1408. D.O.I.: 10.7198/S2237-0722201400040013

[26] SILVA, B. C.; SILVA, F.; MICHELIN, D. C. Avaliação da qualidade de amostras de Camellia sinensis (L.) Kuntze (Theaceae) comercializadas no município de Araras-SP. Journal of Basic and Applied Pharmaceutical Sciences, v. 34, n. $2,2013$.

[27] SOARES, A.L.; FARIAS, M.R. Qualidade de insumos farmacêuticos ativos de origem natural. In: SIMÕES, C.M.O.; SCHENKEL, E.P.; MELLO, J.C.P.; MENTZ, L.A.; PETROVICK, P.R. Farmacognosia: do produto natural ao medicamento. Artmed Editora, cap.8, p.83-105, 2017.

[28] SOUSA, L.S et al. Prospective study on the properties of therapeutic Zingiber officinale (ginger) with emphasis on antimicrobial action. Revista Gestão, Inovação e Tecnologias, v. 3, p. 427-436, 2014.

[29] USDA. United States Department of Agriculture. National Agriculture Library. National Nutrient Database for Standard Reference. Disponível em: <http://www.nal.usda.gov/fnic/foodcomp/search/>. Acesso em 01 de agosto de 2020.

[30] WEHMUTH FILHO, E. CARACTERIZAÇÃO QUANTO AO POTENCIAL EROSIVO DE CHÁS PRONTOS PARA CONSUMO E HERBAIS. 2016. 30p. TCC (Graduação em Odontologia) - Universidade Federal de Santa Catarina, Departamento de Odontologia. 


\section{Capítulo 3}

Extração e caracterização de amido de diferentes fontes vegetais: Uma alternativa para materiais biodegradáveis a base de amido

\section{Dayane Gonzaga Domingos}

Beatriz Lima Santos Klienchen Dalari

Ana Silvia de Lima Vielmo

Juliana Barden Schallemberger

Daiana Cardoso de Oliveira

Resumo: 0 amido é uma das substâncias mais comuns, dentre as que existem naturalmente. As fontes mais comuns são os cereais, as raízes e os turbéculos. $\mathrm{Na}$ indústria alimentícia, o amido pode ser usado para melhorar as propriedades reológicas dos alimentos. A realidade sobre os grânulos de amido, com identidade própria, segundo as origens, não corresponde ao número de aplicações disponíveis para esta importante matéria prima, atingindo os mais diferentes setores industriais. Neste sentido, o presente trabalho teve como objetivo extrair e caracterizar quimicamente e reologicamente os amidos obtidos de três diferentes espécies vegetais: banana (Musa spp), batata-doce (Ipomoea batatas (L.) Lam.) e mandioca (Manihot esculenta Crantz). Os resultados revelam que os amidos apresentam propriedades únicas e promissoras de acordo com a sua origem vegetal.

Palavras Chave: Amido. Mandioca. Banana. Batata doce. 


\section{INTRODUÇÃO}

Atualmente, na indústria alimentícia, a utilização de matérias-primas de baixo custo e fácil disponibilidade como o amido, vem sendo bastante explorada, para elaboração de novos produtos, os quais podem ser encontrados em diferentes fontes vegetais. 0 amido é um polímero natural e biodegradável usado por muitas plantas como reserva de energia. É também o segundo material de biomassa mais abundante na natureza (LE CORRE; BRAS; DUFRESNE, 2010). Segundo Sullivan- Trainor (2013), o amido é uma das principais fontes de carboidratos de plantas, sendo um dos polímeros naturais mais abundantes. E na dieta humana, se caracteriza como um alimento essencial e imprescindível como fonte de energia.

O amido é um material polimérico macromolecular que desempenha um papel importante com morfologias, estruturas e propriedades variadas, que determinam sua utilidade, havendo ainda, grande interesse das indústrias em encontrar novas fontes de amido com propriedades novas e únicas (GUO, 2018). De acordo com Hoyos-Leyva e colaboradores (2017), é de extrema importância compreender a estrutura e composição do amido, pois a proporção de amilose e amilopectina presente nesse polímero influenciam a organização da estrutura granular, no tamanho e na funcionalidade do amido, o qual essa proporção é variável de acordo com a fonte de obtenção e do grau de maturação da planta.

0 amido presente nas culturas de raízes e tubérculos são importantes fontes de carboidratos e fornecem energia para diferentes populações variando de acordo com o país. Evidencia-se a importância dessas culturas observando a sua produção anual global, que segundo Chandrasekara e Kumar (2016) é de aproximadamente 836 milhões de toneladas, o qual a mandioca, batata e batata doce representam $90 \%$ da produção total de tubérculos e raízes tuberosas.

Os amidos são amplamente aplicados como agente espessante, estabilizador, geleificante, de volume, de ligação ou de retenção de água para vários produtos alimentícios (LIU; LIU, 2020). Além do setor alimentício nos últimos anos muitos estudos vêm se concentrando em polímeros naturais como amido, com o objetivo de criar novos materiais com as propriedades desejadas (NEVORALOVÁ et al., 2019). O motivo de interesse é pelo baixo custo que os amidos oferecem para a produção de novos polímeros biodegradáveis, além de poderem ser processados com equipamentos convencionais de processamento de plásticos, dispensando a necessidade de novos equipamentos (JIANG et al., 2020).

Por possuírem propriedades de formação de filme, que ao ser combinadas biocompatibilidade e comestibilidade tornam os amidos candidatos ideais para a produção de filmes para diversos fins (KOCHKINA; LUKIN, 2020). Além disso podem ser utilizados em materiais de embalagens biodegradáveis, revestimentos para cobertura agrícola, membranas para aplicação farmacêutica, eletrólitos para aplicação em dispositivos eletroquímicos (VALENCIA-SULLCA et al., 2018; MAITRA; SINGH, 2018; BRANDELERO et al., 2019; SHUKUR; KADIR, 2015).

A batata-doce (Ipomoea batatas) é uma cultura alimentar de importância global, após arroz, trigo, batata, milho e mandioca (DING et al., 2020). A batata-doce contém nutrientes essenciais como carboidratos,

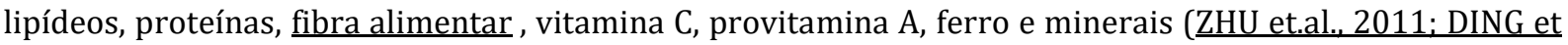
al., 2020). 0 amido de batata doce ainda é explorado para produzir macarrão, lanches, panificação e alimentos de confeitaria (WANG et al., 2020).

A banana verde (Musa paradisiaca) é uma fonte interessante de amido (ACEVEDO-GUEVARA et al., 2018). A banana é uma importante cultura alimentar extensivamente cultivada em regiões tropicais e subtropicais ao redor do mundo (PÉREZ-SIRA, 1997), e é rica em carboidratos, vitamina B, vitamina C, potássio, magnésio e outros elementos minerais (BI et al., 2017). Segundo dados do IBGE (2015), a maior parte da produção brasileira de bananas é consumida in natura e cerca de $2,5 \%$ a $3,0 \%$ da produção é industrializada. No entanto, as bananas são um tipo de fruto perecíveis, levando a sérias perdas econômicas durante o período de maturação, levando a uma perda de 10 a $15 \%$ das bananas colhidas, não podendo ser vendidas, mas como uma solução viável, podem ser usadas como matéria-prima para extração de amido (BI et al., 2017).

A mandioca (Manihot esculenta Crantz) é uma planta de origem tropical e nativa da América do Sul e de acordo com Tironi et al. (2015), caracterizada por sua boa adaptabilidade a diversos ambientes, rusticidade e baixa exigência de fertilidade do solo. Sendo assim, representa a terceira maior fonte de alimento nas regiões tropicais, após o arroz e o milho (FAOSTAT, 2020). A extração de amido de mandioca envolve a raspagem das raízes da mandioca, seguida pela separação das fibras, depois a desidratação do amido e a secagem do produto (PADI; CHIMPHANGO et al., 2020). De acordo com Zhu (2015) o rendimento da extração do amido da mandioca varia de acordo com o período de colheita e o cultivar. 
A realidade sobre os grânulos de amido, com identidade própria, segundo as origens, não corresponde ao número de aplicações disponíveis para esta importante matéria prima, atingindo os mais diferentes setores industriais (VERSINO; URRIZA; GARCÍA, 2019; OYEYINKA et al., 2020; BI et al., 2017; WANG et al., 2020). Nesse contexto, o presente trabalho teve como objetivo extrair e caracterizar quimicamente e reologicamente os amidos obtidos de três diferentes espécies vegetais: banana (Musa spp), batata-doce (Ipomoea batatas (L.) Lam.) e mandioca (Manihot esculenta Crantz), quanto ao seu pH, umidade, teor de cinzas, teor de proteínas, densidade, teor de lipídeos, poder de inchamento e índice de solubilização.

\section{MATERIAIS E MÉTODOS}

\subsection{EXTRAÇÃO DOS AMIDOS}

0 processo de extração do amido da batata doce (variedades Brazlândia Roxa e Beauregard) e da mandioca (variedades Mandin e Mandin Branca) foram realizados de forma similar. Inicialmente os tubérculos foram lavados com água da torneira, descascados e cortados em pedaços pequenos (1 a $2 \mathrm{~cm})$. Em seguida pequenos pedaços foram moídos em água destilada usando um liquidificador de laboratório em uma proporção 2:1 de água para tubérculo. Após a moagem, a pasta foi passada através de um pano de nylon para remover fibras e outras impurezas, produzindo a pasta de amido. 0 líquido resultante do processo foi então colocado em repouso em um tanque de decantação. 0 sobrenadante foi descartado, e a camada de amido inferior foi seco em estufa com circulação de ar a $45{ }^{\circ} \mathrm{C}$ por 24 horas.

Já as bananas verdes, das variedades nanica e caturra, foram descascadas manualmente e imediatamente imersas na solução com metabissulfito de sódio (200 ppm) e solução de $\mathrm{NaOH}(0,2 \%)$ e deixado em repouso para minimizar o escurecimento enzimático da banana (ROSADO et al., 2020). Após pequenos pedaços foram moídos na mesma solução de repouso usando um liquidificador de laboratório. Após a moagem, a pasta foi passada através de um pano de nylon para remover fibras e outras impurezas, produzindo a pasta de amido. 0 líquido resultante do processo foi então colocado em repouso em um tanque de decantação. 0 sobrenadante foi descartado, e a camada de amido inferior foi seco em estufa com circulação de ar a $45^{\circ} \mathrm{C}$ por 24 horas.

\subsection{CARACTERIZAÇÃO}

A medida do pH foi realizada por diluição de $25 \mathrm{~g}$ da amostra em $50 \mathrm{~mL}$ de água destilada, seguido de agitação magnética. Após, o valor de pH foi medido em pHmetro. As análises de umidade (AOAC 925.09), cinzas (AOAC 923.03), lipídeos (AOAC 920.85) e proteínas ( $\mathrm{N}$ x 6,25) (AOAC 920.87) foram realizadas segundo metodologias da Association of Official Analytical Chemists (AOAC, 2005; OLIVEIRA, 2012). A densidade absoluta dos grânulos foi determinada pelo método do picnômetro, por deslocamento do xileno a $30^{\circ} \mathrm{C}$, segundo Schoch e Leach (1964).

0 poder de inchamento e a solubilidade foram determinados de acordo com metodologia adaptada descrito por Leach, Mccowen e Schoch (1959) e Bezerra et al. (2013). Aproximadamente $1 \mathrm{~g}$ da amostra $\left(\mathrm{P}_{1}\right)$ e $40 \mathrm{~mL}$ de água destilada foram colocados em tubos de centrífuga previamente pesados, deixados a uma temperatura constante de $50,60,70,80$ e $90{ }^{\circ} \mathrm{C}$ por aproximadamente 30 minutos. Posteriormente seguiu-se com centrifugação, separando o sobrenadante e seu volume medido (V), $10 \mathrm{~mL}$ foram colocados em uma placa de petri previamente pesada. A amostra na placa foi seca em estufa a $65{ }^{\circ} \mathrm{C}$ por 12 horas e o resíduo foi calculado pela diferença de peso (R). Os tubos de centrifugação foram pesados e calculou-se a diferença de peso da amostra no tubo após centrifugação $\left(\mathrm{P}_{2}\right)$. 0 poder de inchamento $(\mathrm{PI})$ e o índice de solubilidade (IS) foram calculados de acordo com as Equações 1 e 2, respectivamente.

$$
\begin{aligned}
& \mathrm{PI}\left(\mathrm{g} \mathrm{g}^{-1}\right)=\left(\frac{\mathrm{P}_{2}}{\mathrm{P}_{1}}\right) \\
& \mathrm{IS}(\%)=100 \times \mathrm{V}\left(\frac{\mathrm{R}}{\mathrm{P}_{1}}\right) \times 100
\end{aligned}
$$

Onde:

$\mathrm{P}_{1}$ - Peso inicial da amostra.

$\mathrm{P}_{2}$ - Peso de amostra após secagem na estufa 


\section{$\mathrm{R}$ - Resíduo contido na placa de petri \\ V - Volume do sobrenadantes}

\section{RESULTADOS E DISCUSSÃO}

Os rendimentos em amido para as espécies vegetais mandioca Mandim (MM), mandioca Mandim Branca (MB), batata doce Brazlândia Roxa (BR), batata doce Beauregard (BA), banana nanica (BB) e banana caturra (BC), foram 14,89\%, 17,88\%, 11,57\%, 12,63\%, 17,77\% e 4,87\%, respectivamente. De acordo com estes resultados, a fonte vegetal que apresentou menor rendimento de amido foi o da banana caturra. De acordo com Orsuwan e Sothornvit a banana (Musa spp.) é rica em amido e a extração alcalina tem sido utilizada para obtenção do amido. 0 pH é um parâmetro que tem relação com a natureza do amido, nativo, fermentado ou modificado. Através dos resultados apresentados na Tabela 1, pode-se observar que o valor de $\mathrm{pH}$ da banana e da mandioca apresenta-se mais perto da neutralidade, já o da batata doce apresenta um caráter mais ácido, para as variedades em estudo.

Tabela 1: Valores de pH para os diferentes amidos.

\begin{tabular}{|c|c|}
\hline Fonte Vegatal & $\mathrm{pH}$ \\
\hline MM & 7,01 \\
\hline MB & 6,02 \\
\hline BB & 7,70 \\
\hline BC & 6,51 \\
\hline BR & 5,60 \\
\hline BA & 5,83 \\
\hline
\end{tabular}

A Figura 1 mostra o teor de água e o teor de cinzas dos amidos. Como já era esperado, devido a sua alta higroscopicidade, os amidos apresentaram alta quantidade de água. Em ordem de grandeza o teor de umidade foi $\mathrm{MM}>\mathrm{BA}>\mathrm{MB}>\mathrm{BB}>\mathrm{BC}>\mathrm{BR}$. No que diz respeito a proporção de cinzas a quantidade de cinzas varia nos diferentes amidos, estando todos abaixo de $1 \%$ com variação entre 0,1 e $0,2 \%$ em peso. Estes valores baixos para o teor de cinzas corroboram outros trabalhos encontrados na literatura, como de Lorente-Ayza et al. (2016), que ao avaliarem teor de cinzas de amidos de diferentes fontes vegetais (milho, batata, trigo e ervilha) encontraram valores em torno de 0,17 a $0,71 \%$ de teor de cinzas. Os autores avaliaram os amidos para a aplicação em membranas cerâmicas e enfatizam a importância de se quantificar o teor de cinzas, pondendo este ter influência nas caracteristicas finais da membrana.

Figura 2: Teor de umidade e de cinzas nos diferentes amidos.

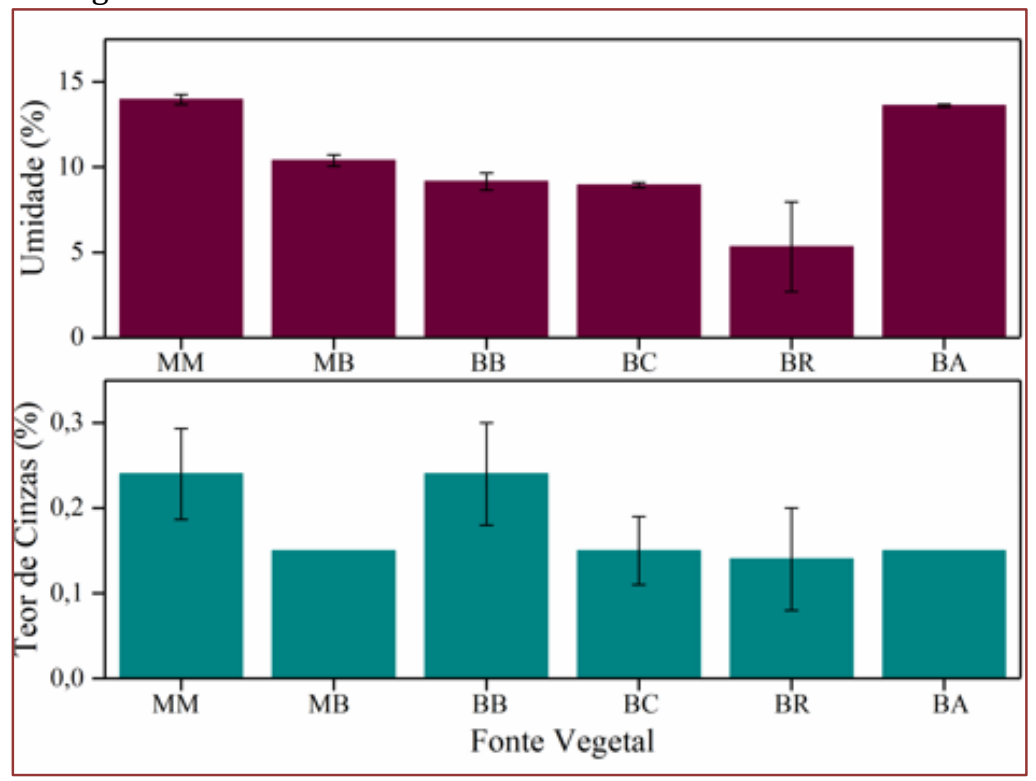


0 amido geralmente é extraído por processos que permitem o carreamento de substâncias contaminantes como proteínas, lipídeos e cinzas. Muito embora em pequenas quantidades no amido, estas substâncias podem interferir nas propriedades físico-químicas e funcionais. Em uma relação contrária a água, as moléculas de baixo peso molecular não alteram a estrutura e densidade dos polímeros, acredita-se que seus efeitos plastificantes estejam relacionados a uma redução significativa no número médio de emaranhados moleculares possibilitando as reorganizações moleculares (FIGUEROA et al., 2016). Desta forma, na Figura 2 pode ser visto os valores obtidos para densidade nos diferentes amidos.

Figura 3: Valores de densidade para os diferentes amidos.

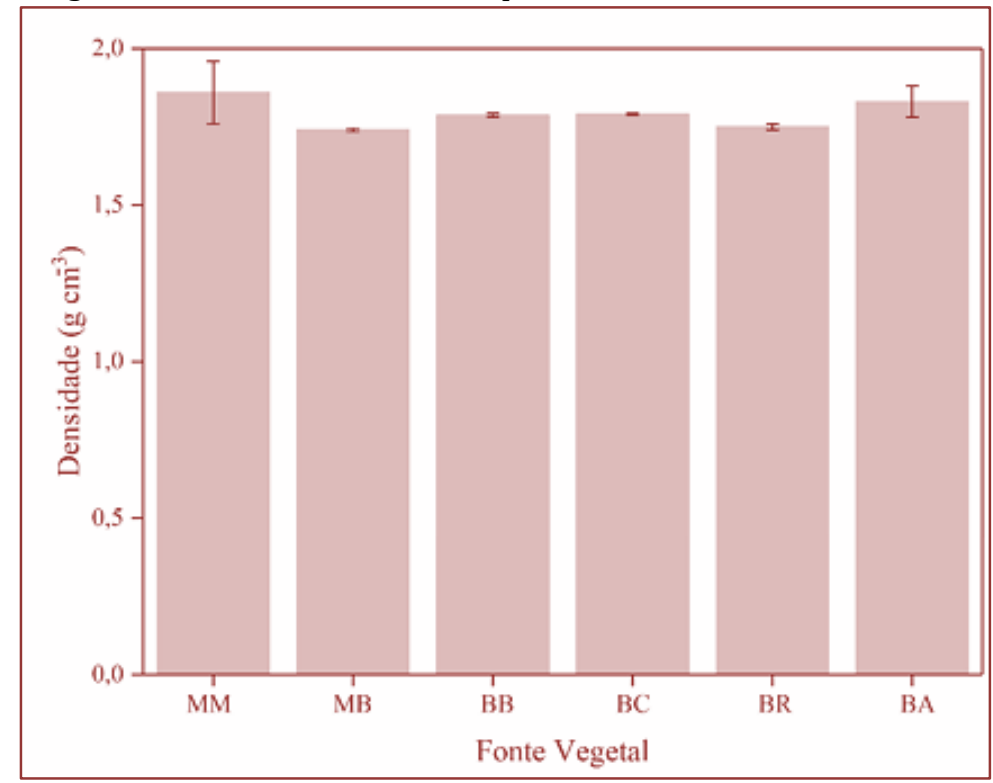

A densidade depende essencialmente de efeitos combinados de fatores inter-relacionados, como a intensidade de interpartículas, forças, tamanho de partícula e número de pontos de contato (GBADAMOSI; OLADEJI, 2013). Conforme os resultados expressos de Figura 2 ambos os amidos apresentaram densidade similar com valores entre 1,74 a $1,87 \mathrm{~g} \mathrm{~cm}^{-3}$, seguindo uma ordem de grandeza de $\mathrm{BB}>\mathrm{MM}>\mathrm{BA}>\mathrm{BC}>\mathrm{BR}>$ MB.

As fontes vegetais aqui analisadas são compostas por diferentes nutrientes, como carboidratos, fonte de vitaminas, proteínas, lipídeos, fonte energética dentre outros. Afim de avaliar a presença de alguns destes constituintes a Figura 3 apresenta os valores encontrados para proteínas e lipídeos nos diferentes amidos. 
Figura 4: Valores de Lipídeos e Proteínas para os diferentes amidos.

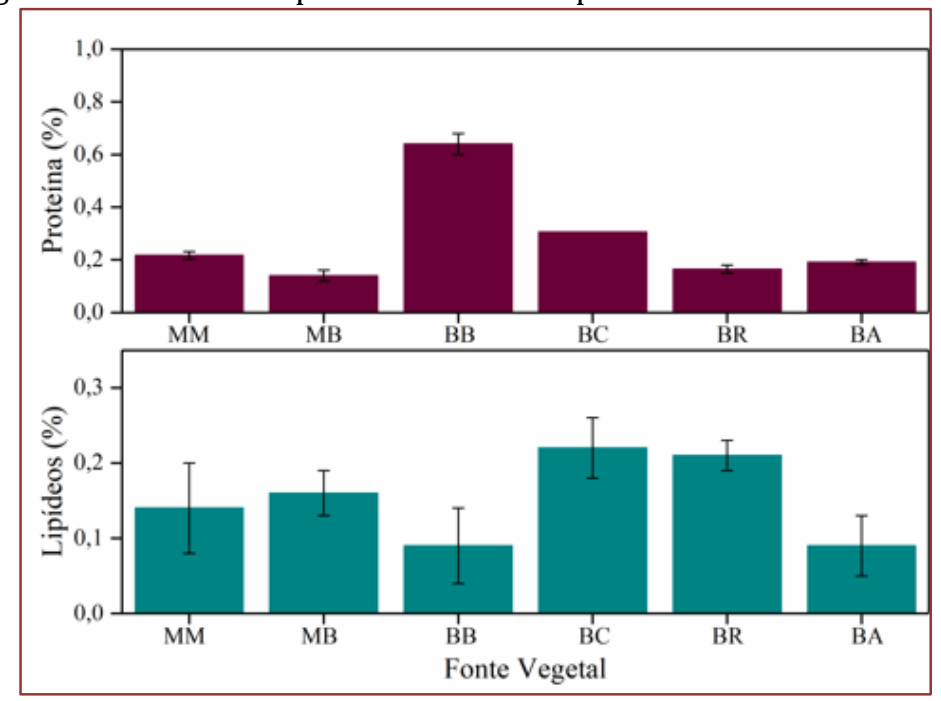

O baixo teor de proteínas para MM e MB já era esperado, uma vez que a composição da raiz de mandioca apresenta em média $82,5 \%$ de amido, 2,7\% de fibras, 0,3\% de matéria graxa, 2,4\% de cinzas, 0,2\% de açúcares redutores e 2,6\% de proteínas (\% em massa seca) (DIAS; LEONEL, 2006). Martinez et al. (2018) relataram o baixo teor de proteína para a mandioca $(0,49-0,9 \%)$, corroborando com os resultados encontrados para MM e MB, relatando que apesar do baixo teor de proteína ainda é possível aplicar para alimentação de animais como fonte de energia (ROJAS et al., 2019). Os valores encontrados para a BB e BC foram similares, contudo, a BB apresentou maior teor de proteínas em relação à BC. De acordo com Andrade et al. (2018), existem diversos fatores que influenciam nas condições proteicas das bananas, como condições climáticas, qualidade do solo, disponibilidade de água e tempo de colheita. Os valores aqui encontrados para a BB e a BC vão de encontro a resultados obtidos por Freitas e Tavares (2005), que chegaram a teores de proteína de 0,24, 0,08\% para Musa AAA-Nanicão, Musa AAB-Terra respectivamente. Com relação a BR e BA apresentaram valores bem similares 0,165 $\pm 0,015$ e 0,191 $\pm 0,009$ respectivamente. De acordo com Quadros et al. (2009) o tipo de cultivar é o principal influenciador no teor de proteínas. Além disso o processo de extração de amidos é um fator que deve ser levado em consideração, sendo que durante o procedimento de extração um percentual de nutrientes pode ficar contido no material fibroso que é descartado.

O mesmo comportamento pode ser observado para os lipídeos, apresentando valores menor que 0,3\% para todas as fontes vegetais. Dos constituintes presentes em menores concentrações, os que mais influenciam as propriedades funcionais dos amidos são os lipídeos (MAIEVES et al., 2011). Chisté et al. (2006) relatam que o teor de lipídeos, assim como outros constituintes, pode variar devido as características intrínsecas das raízes de mandioca. Os valores aqui encontrados para a MM e MB foram similares com aproximadamente 0,14 e $0,16 \%$ para MM e MB respectivamente. Geralmente frutas descascadas apresentam teores de minerais menores se comparados com frutas com casca, devido as paredes celulares apresentarem alto teor de fibras, principalmente celulose insolúvel e hemicelulose (GONDIM et al., 2005; BEZERRA et al., 2013). Isto explica os valores baixos encontrados para a BB e BC. Os valores encontrados para a BR e BA corroboram resultados encontrados na literatura. Quadros et al. (2009) encontrou valores aproximados de 0,05\%. Já Jorge e Lunardi (2005) encontraram0,1\% de lipídios na $c v$. Monalisa.

Como se sabe, os filmes de amido são hidrofílicos devido à composição química do amido (amilose e amilopectina), onde grupos hidroxila e ligações de oxigênio com a água são formados (PELISSARIA et al., 2017). A Figura 4 expressa os resultados de índice de solubilização para os diferentes amidos. Para o IS a $50{ }^{\circ} \mathrm{C}$, o maior foi o do amido BA. A 60 e $70{ }^{\circ} \mathrm{C}$ o amido da MM. A 80 e $90{ }^{\circ} \mathrm{C}$, foi o do amido da BB. Observase, para todos os amidos analisados, que a solubilidade fica mais pronunciada acima de $60{ }^{\circ} \mathrm{C}$, isto porque acima desta temperatura o amido inicia a gelatinização. Durante a gelatinização, a estrutura cristalina do amido é rompida devido ao relaxamento das ligações de hidrogênio e as moléculas de água que interagem com os grupos hidroxilas da amilose e da amilopectina, causando um aumento do tamanho dos grânulos e a solubilização parcial do amido. A solubilidade do amido é resultado da lixiviação da amilose, que se dissocia e se difunde do grânulo de amido (KLEIN et al., 2013). A diminuição da solubilidade do amido é relacionada ao rearranjo interno dos grânulos, que fornece interações mais altas entre os grupos 
funcionais do amido, a formação de aglomerados de amilopectina e a formação de complexos amiloselipídeos (ZAVAREZE; DIAS, 2011).

Figura 5: Índice de solubilização dos amidos em diferentes temperaturas.

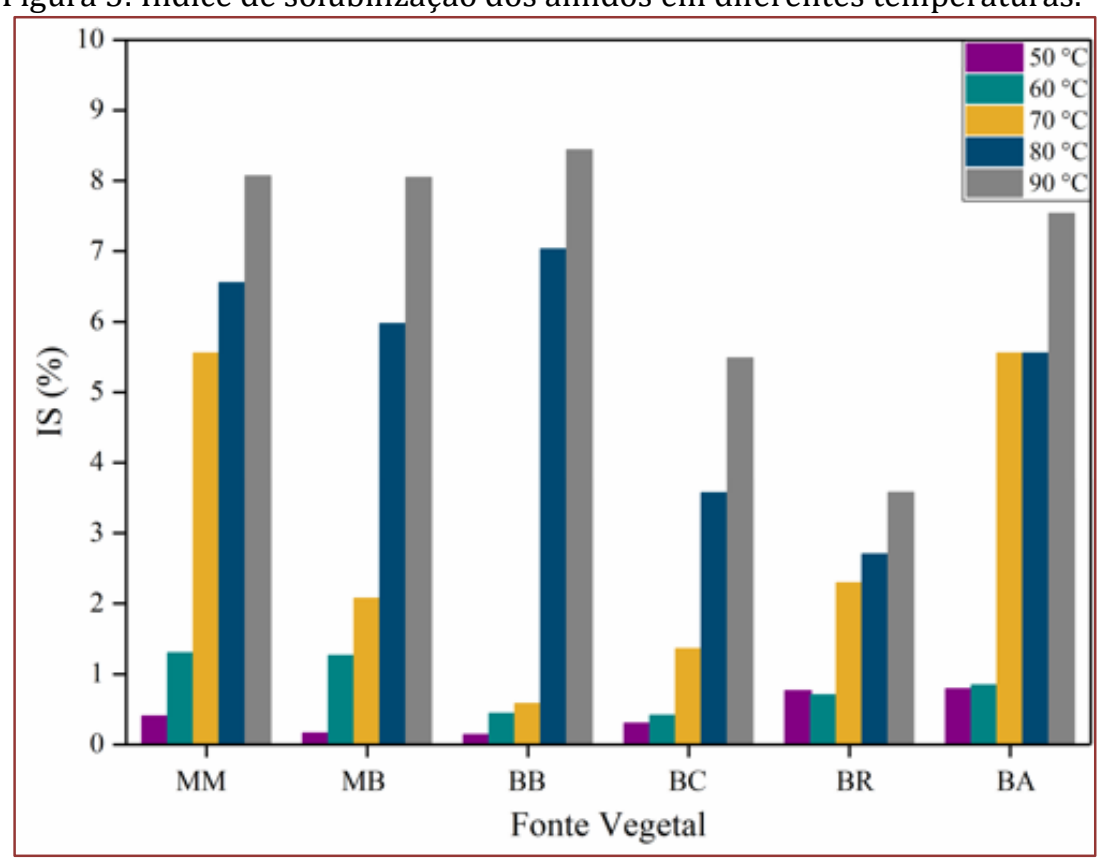

A fraca solubilidade aquosa do amido é conhecida por ser uma restrição limitante para o desenvolvimento de materiais à base de amido (ROSU et al., 2013). Embora o amido seja hidrofílico porque contém uma grande quantidade de grupos hidroxila, o amido é insolúvel em água à temperatura ambiente, apresentando facilidade de retrogradação e alta viscosidade quando é gelatinizado (CHEN; DAI; GAO, 2020; CHEN et al., 2019). Alguns trabalhos vêm sendo desenvolvidos ao longo dos anos na modificação de amidos, a fim de melhorar o comportamento da solubilidade em água (ROSU et al., 2013; MENOLI; BELEIA, 2007; ANGUITA et al., 2006; CHEN et al., 2019).

0 impacto do PI também foi investigado podendo ser visto através da Figura 5.0 maior PI a 50 e $60^{\circ} \mathrm{C}$ foi obtido com o amido da $\mathrm{BB}$, talvez devido ao seu maior teor de cinzas e proteínas. Já a 60,7080 e $90^{\circ} \mathrm{C}$ o maior PI foi o da MM. $\mathrm{O}$ fato do maior PI do amido da MM ocorrer acima de $70{ }^{\circ} \mathrm{C}$ pode estar relacionado com uma maior resistência das ligações de hidrogênio, que mantém o arranjo micelar que é abalado somente após a temperatura de gelatinização, que ocorre para amidos de mandioca acima de $60{ }^{\circ} \mathrm{C}$. $\mathrm{O}$ amido de MM apresenta o maior poder de intumescimento devido provavelmente ao seu maior teor de amilopectina em relação aos outros amidos (KLEIN et al., 2013).

Os amidos são formados por estruturas semicristalinas complexas, compostas principalmente por amilopectina e amilose. Quando são submetidos a aquecimento na presença de um plastificante como a água, o amido passa por um processo denominado gelatinização. Nesta situação o plastificante entra no grânulo de amido, causando o inchamento, a amilopectina cristalina derrete e a ordem arquitetônica molecular é perdida. A temperatura na qual este processo acontece é denominada de gelatinização (VAN DER SMAN; MAUER, 2019). 
Figura 6: Poder de inchamento dos amidos nas diferentes temperaturas.

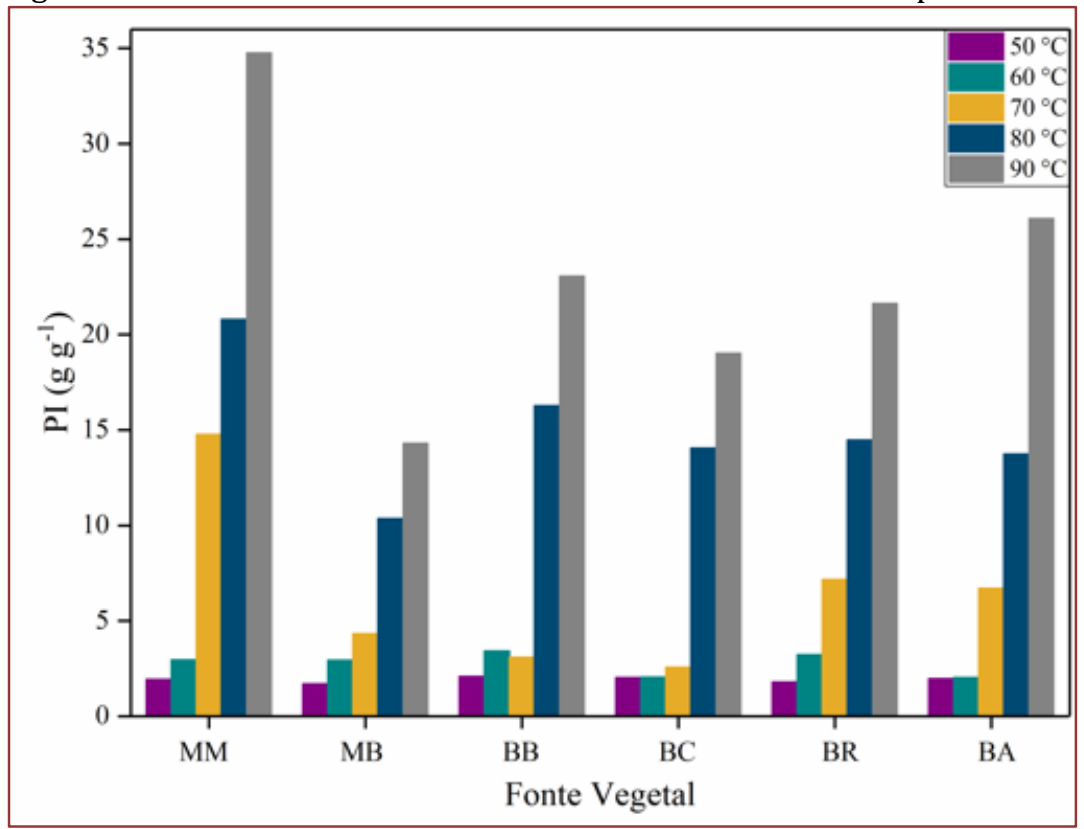

O poder de inchamento é uma propriedade da amilopectina, onde a amilose é considerada um diluente (HOOVER, 2010). A perda no poder de inchamento do amido, pode estar atribuída com o aumento da interação amilose-pectina, ligação intramolecular mais forte, formação de complexos amilose-lipídeos ou até mesmo alteração na matriz cristalina do amido (ZAVAREZE et al., 2011).

\section{CONCLUSÃO}

0 amido em sua forma nativa demonstra uma aplicação limitada na indústria, por isso a necessidade de modificações por processos químicos, físicos ou enzimáticos, a fim de proporcionar propriedades funcionais específicas. Neste estudo, foi possível observar que mesmo amidos de uma mesma espécie vegetal, podem apresentar diferenças físico-químicas e reológicas entre si, o que pode refletir em características funcionais também diferenciadas. 0 amido geralmente é extraído por processos que permitem o carreamento de substâncias contaminantes como proteínas, lipídeos e cinzas. Muito embora em pequenas quantidades no amido, estas substâncias podem interferir nas propriedades físico-químicas e funcionais, como por exemplo a produção de materiais biodegradáveis. 0 maior teor de cinzas e proteínas foi encontrado nos amidos de $\mathrm{BB}$ e $\mathrm{BC}$, enquanto que o maior teor de lipídeos foi encontrado no amido da BC e da BR. $O$ amido da BB foi o que apresentou maior densidade, sendo a menor a do amido da $\mathrm{MB}$, enquanto que os outros amidos apresentaram valores próximos entre si. Os diferentes valores de PI e IS encontrados nos amidos podem indicá-los para diversos processos tecnológicos, otimizando a sua aplicação como matéria-prima de materiais biodegradáveis. Amidos com maior PI podem trazer contribuições no rendimento do produto final, quando forem utilizados como espessante. 


\section{REFERÊNCIAS}

[1] ACEVEDO-GUEVARA, Leonardo et al. Development of native and modified banana starch nanoparticles as vehicles for curcumin. International journal of biological macromolecules, v. 111, p. 498-504, 2018.

[2] ANDRADE, Bruna Andina et al. Produção de farinha de banana verde (Musa spp.) para aplicação em pão de trigo integral. Brazilian Journal of Food Technology, v. 21, 2018.

[3] ANGUITA, M. et al. Study of the effect of technological processes on starch hydrolysis, non-starch polysaccharides solubilization and physicochemical properties of different ingredients using a two-step in vitro system. Animal Feed Science and Technology, v. 129, n. 1-2, p. 99-115, 2006.

[4] ASSOCIATION OF OFFICIAL ANALYTICAL CHEMISTIS (AOAC). Official Methods of Analysis of the AOAC. 18th ed. Gaithersburg, M.D, USA, 2005.

[5] BEZERRA, Carolina Vieira et al. Green banana (Musa cavendishii) flour obtained in spouted bed-Effect of drying on physico-chemical, functional and morphological characteristics of the starch. Industrial Crops and Products, v. 41 , p. 241-249, 2013.

[6] BI, Yu et al. Molecular structure and digestibility of banana flour and starch. Food Hydrocolloids, v. 72, p. 219-227, 2017.

[7] BRANDELERO, Renata Paula Herrera et al. New Approach of Starch and Chitosan Films as Biodegradable Mulching. Revista Virtual de Química, v. 11, n. 3, 2019.

[8] CHANDRASEKARA, A.; KUMAR, T. J. Roots and tuber crops as functional foods: a review on phytochemical constituents and their potential health benefits. International Journal of Food Science. v. 2016, n,1, p.1-15, 2016.

[9] CHEN, Hui et al. The structure and properties of granular cold-water-soluble starch by a $\mathrm{NaOH} /$ urea aqueous solution. International journal of biological macromolecules, v. 141, p. 732-737, 2019.

[10] CHEN, Yun; DAI, Guifang; GAO, Qunyu. Preparation and properties of granular cold-water-soluble porous starch. International Journal of Biological Macromolecules, v. 144, p. 656-662, 2020.

[11] CHISTÉ, Renan Campos et al. Qualidade da farinha de mandioca do grupo seca. Food Science and Technology, v. 26, n. 4, p. 861-864, 2006.

[12] -COTINHO, A. P. C.; CABELLO, C. Caracterização reológica da fécula de mandioca. Revista raízes e amidos tropicais, Botucatu, v.1, outubro, p. 40-48, 2005.

[13] DIAS, Larissa Tavares; LEONEL, Magali. Caracterização físico-química de farinhas de mandioca de diferentes localidades do Brasil. Ciência e agrotecnologia, v. 30, n. 4, p. 692-700, 2006.

[14] DING, Yanyan et al. Study on compatible characteristics of wheat and purple sweet potato starches. Food Hydrocolloids, p. 105961, 2020.

[15] FIGUEROA, Yetzury et al. Effect of sugar addition on glass transition temperatures of cassava starch with low to intermediate moisture contents. Carbohydrate polymers, v. 146, p. 231-237, 2016.

[16] FAO- Food and Agriculture Organization of the United Nations - FAOSTAT.

[17] FREITAS, M. C. J.; TAVARES, D. de Q. Caracterização do grânulo de amido de bananas (Musa AAA-Nanicão e Musa AAB-Terra). Food Science and Technology, v. 25, n. 2, p. 217-222, 2005.

[18] GBADAMOSI, S. O.; OLADEJI, B. S. Comparative studies of the functional and physico-chemical properties of isolated Cassava, Cocoyam and Breadfruit starches. International Food Research Journal, v. 20, n. 5, p. $2273,2013$.

[19] GONDIM, Jussara A. Melo et al. Composição centesimal e de minerais em cascas de frutas. Food Science and Technology, v. 25, n. 4, p. 825-827, 2005.

[20] GUO, K.; LIN, L.; FAN, X.; ZHANG, L.; WEI, C. Comparison of structural and functional properties of starches from five fruit kernels. Food Chemistry, v. 257, p. 75 - 82, 2018.

[21] HOYOS-LEYVA, J. D.; ALONSO-GOMEZ, L.; RUEDA-ENCISO, J.; YEEMADEIRA, H.; BELLO-PEREZ, L.; ALVAREZRAMIREZ, J. Morphological, physicochemical and functional characteristics of starch from Marantha ruiziana Koern, LWT - Food Science and Technology, v.83, n.1, p.150-156, 2017.

[22] INSTITUTO BRASILEIRO DE GEOGRAFIA E ESTATÍSTICA - IBGE Resultados da Produção Agrícola 2015. Disponível em: ftp://ftp.ibge.gov.br/Producao_Agricola/Leva ntamento_Sistematico_da_Producao_Agricol a_[mensal]/Fasciculo/2015/lspa_201501.pdf. Acesso em: maio de 2020

[23] JIANG, Tianyu et al. Starch-based biodegradable materials: Challenges and opportunities. Advanced Industrial and Engineering Polymer Research, v. 3, n. 1, p. 8-18, 2020.

[24] JORGE, Neuza; LUNARDI, Vanessa Martins. Influência dos tipos de óleos e tempos de fritura na perda de umidade e absorção de óleo em batatas fritas. Ciência e Agrotecnologia, v. 29, n. 3, p. 635-641, 2005. 
[25] KLEIN, Bruna et al. Effect of single and dual heat-moisture treatments on properties of rice, cassava, and pinhao starches. Carbohydrate polymers, v. 98, n. 2, p. 1578-1584, 2013.

[26] KOCHKINA, Nataliya E.; LUKIN, Nikolay D. Structure and properties of biodegradable maize starch/chitosan composite films as affected by PVA additions. International Journal of Biological Macromolecules, 2020.

[27] LE CORRE, Déborah; BRAS, Julien; DUFRESNE, Alain. Starch nanoparticles: a review. Biomacromolecules, v. 11 , n. 5, p. 1139-1153, 2010.

[28] LEACH, H. W. Determination of intrinsic viscosity of starches. Cereal Chemistry, v. 40, n.6, p. 593-600, 1963.

[29] LEACH, H. W.; MCCOWEN, D. L.; SCHOCH, T. J. Swelling and solubility patterns of various starches and structure of starch granule. Cereal Chemistry, v. 36, p. 534-544, 1959.

[30] LIU, Keshun; LIU, Qian. Enzymatic determination of total starch and degree of starch gelatinization in various products. Food Hydrocolloids, p. 105639, 2020.

[31] LORENTE-AYZA, M.-M. et al. On the underestimated effect of the starch ash on the characteristics of low cost ceramic membranes. Ceramics International, v. 42, n. 16, p. 18944-18954, 2016.

[32] MAIEVES, Helayne Aparecida et al. Selection of cultivars for minimization of waste and of water consumption in cassava starch production. Industrial Crops and Products, v. 33, n. 1, p. 224-228, 2011.

[33] MAITRA, Jaya; SINGH, Neena. Starch-Chitosan Blend Cross-Linked with Calcium Chloride. In: Advances in Polymer Sciences and Technology. Springer, Singapore, 2018. p. 133-145.

[34] -MARCON, M. J. A; AVANCINI, S. R. P; AMANTE, E. R. Propriedades Químicas e Tecnológicas do Amido de Mandioca e do Polvilho Azedo. Florianópolis: Ed. UFSC, 2007.

[35] MARTINEZ, Daiana G. et al. Ethanol production from waste of cassava processing. Applied Sciences, v. 8, n. 11, p. 2158, 2018.

[36] MENOLI, Adriana V.; BELEIA, Adelaide. Starch and pectin solubilization and texture modification during precooking and cooking of cassava root (Manihot esculenta Crantz). LWT-Food Science and Technology, v. 40, n. 4, p. 744$747,2007$.

[37] NEVORALOVÁ, Martina et al. Controlled biodegradability of functionalized thermoplastic starch based materials. Polymer Degradation and Stability, v. 170, p. 108995, 2019.

[38] OLIVEIRA, Daiana Cardoso. Caracterização e potencial tecnológico de amidos de diferentes cultivares de mandioca (Manihot esculenta Crantz). 2012. 142 f. Dissertação (Programa de Pós-Graduação em Engenharia de Alimentos). Florianópolis, Universidade Federal de Santa Catarina. 2012.

[39] ORSUWAN, Aungkana; SOTHORNVIT, Rungsinee. Development and characterization of banana flour film incorporated with montmorillonite and banana starch nanoparticles. Carbohydrate polymers, v. 174, p. 235-242, 2017.

[40] OYEYINKA, Samson A. et al. Effect of fermentation time on physicochemical properties of starch extracted from cassava root. Food Bioscience, v. 33, p. 100485, 2020.

[41] PADI, Richard Kingsley; CHIMPHANGO, Annie. Commercial viability of integrated waste treatment in cassava starch industries for targeted resource recoveries. Journal of Cleaner Production, p. 121619, 2020.

[42] PELISSARI, Franciele Maria et al. Nanocomposites based on banana starch reinforced with cellulose nanofibers isolated from banana peels. Journal of colloid and interface science, v. 505, p. 154-167, 2017.

[43] PÉREZ-SIRA, Elevina. Characterization of starch isolated from plantain (Musa paradisiaca normalis). StarchStärke, v. 49, n. 2, p. 45-49, 1997.

[44] QUADROS, Diomar Augusto de et al. Composição química de tubérculos de batata para processamento, cultivados sob diferentes doses e fontes de potássio. Food Science and Technology, v. 29, n. 2, p. 316-323, 2009.

[45] ROJAS, Mayerlenis Jimenez et al. Recovery of starch from cassava bagasse for cyclodextrin production by sequential treatment with $\alpha$-amylase and cyclodextrin glycosyltransferase. Biocatalysis and Agricultural Biotechnology, v. 22, p. 101411, 2019.

[46] ROSADO, Carolyne Pimentel et al. Resistant starch from green banana (Musa sp.) attenuates non-alcoholic fat liver accumulation and increases short-chain fatty acids production in high-fat diet-induced obesity in mice. International journal of biological macromolecules, v. 145, p. 1066-1072, 2020.

[47] ROSU, Ana-Maria et al. Synthesis of alkylated potato starch derivatives and their potential in the aqueous solubilization of benzo [a] pyrene. Carbohydrate polymers, v. 93, n. 1, p. 184-190, 2013.

[48] SCHOCH, T. J.; LEACH, H. W. Whole starch and modifidied starches. Determation of absolute density. Liquid displacement. In: WHITLER, R. L.; WOLFRON, M. L. (Ed.). Methods in carbohydrate chemistry. New York: Academic Press, 1964. p. 101-103. v.4. 
[49] SCHONS, A.; STRECK, N. A.; STORCK, L.; BURIOL, G. A.; ZANON, A. J.; PINHEIRO, D. G.; KRAULICH, B. Arranjos de plantas de mandioca e milho em cultivo solteiro e consorciado: crescimento, desenvolvimento e produtividade. Bragantia, v. 68, p.165- 177, 2009.

[50] SHUKUR, M. F.; KADIR, M. F. Z. Hydrogen ion conducting starch-chitosan blend based electrolyte for application in electrochemical devices. Electrochimica Acta, v. 158, p. 152-165, 2015.

[51] SULLIVAN-TRAINOR, M. Starches/glucose, Global markets, MA, 2013.

[52] TIRONI, L. F.; UHLMANN, L. O.; STRECK, N. A.; SAMBORANHA, F. K.; FREITAS, C. P. de O.; SILVA, M. R. Performance of cassava cultivars in subtropical environment. Bragantia, v. 74, n. 1, p. 58-66, 2015

[53] VALENCIA-SULLCA, Cristina et al. Thermoplastic cassava starch-chitosan bilayer films containing essential oils. Food Hydrocolloids, v. 75, p. 107-115, 2018.

[54] VAN DER SMAN, R. G. M.; MAUER, Lisa J. Starch gelatinization temperature in sugar and polyol solutions explained by hydrogen bond density. Food hydrocolloids, v. 94, p. 371-380, 2019.

[55] VERSINO, Florencia; URRIZA, Marina; GARCÍA, María A. Eco-compatible cassava starch films for fertilizer controlled-release. International journal of biological macromolecules, v. 134, p. 302-307, 2019.

[56] WANG, Hongwei et al. Impact of ultrasonication on the aggregation structure and physicochemical characteristics of sweet potato starch. Ultrasonics Sonochemistry, v. 63, p. 104868, 2020.

[57] ZAVAREZE, Elessandra; DIAS, Alvaro Renato Guerra. Impact of heat-moisture treatment and annealing in starches: A review. Carbohydrate Polymers, v. 83, n. 2, p. 317-328, 2011.

[58] ZHU, F.; YANG, X.; CAI, Y.Z.; BERTOFT, E.; CORKE, H. Physicochemical properties of sweetpotato starch. Starch, v. 63 p. $249-259,2011$.

[59] ZHU, Fan. Composition, structure, physicochemical properties, and modifications of cassava starch. Carbohydrate polymers, v. 122, p. 456-480, 2015.

[60] HOOVER, Ratnajothi. The impact of heat-moisture treatment on molecular structures and properties of starches isolated from different botanical sources. Critical reviews in food science and nutrition, v. 50, n. 9, p. 835-847, 2010.

[61] DA ROSA ZAVAREZE, Elessandra et al. Effect of heat-moisture treatment on rice starch of varying amylose content. Food Chemistry, v. 121, n. 2, p. 358-365, 2010. 


\section{Capítulo 4}

Peptídeos bioativos obtidos de produtos lácteos: Uma revisão narrativa

\section{Meire dos Santos Falcão de Lima \\ Amanda Lopes Gueiros \\ Geziane Celina Sátiro \\ Gleidce Nayra André da Silva \\ Karoline Mirella Soares de Souza \\ Ana Lúcia Figueiredo Porto \\ Maria Taciana Holanda Cavalcanti}

Resumo: As proteínas alimentares não fornecem apenas nutrientes, também proporcionam numerosos benefícios através dos peptídeos bioativos que são formados a partir delas. Estes peptídeos atuam em diversas vias bioquímicas específicas, apresentando uma gama de atividades funcionais. Os derivados lácteos por sua vez são fontes muito importantes desses peptídeos bioativos que são derivados das caseínas e proteínas do soro. A presente revisão narrativa tem por objetivo abordar a produção dos peptídeos bioativos de produtos lácteos assim como as bioatividades que os mesmos apresentam. A literatura atual relata que os peptídeos derivados de proteínas de derivados lácteos possuem notáveis atividades multifuncionais na saúde humana. Este campo de pesquisa está crescendo continuamente e os novos estudos devem ser direcionados para a avaliação de efeitos de promoção da saúde in vivo, biodisponibilidade e elucidação dos mecanismos moleculares de ação e em geral possível uso como agentes promotores da saúde em sistemas alimentares.

Palavras-chave: peptídeos bioativos, peptídeos multifuncionais, derivados lácteos, extrato peptídico, atuação na saúde. 


\section{INTRODUÇÃO}

A formação de hábito alimentar é uma ação complexa que sofre interferência de diversas variáveis, por isso estudos contínuos visam agregar benefícios aos produtos que fazem parte da rotina alimentar do consumidor. 0 desenvolvimento de novos produtos também é considerado de grande importância, visto que a relação dieta-saúde representa um desafio para a ciência e a tecnologia de alimentos, principalmente quando se trata de alimentos funcionais (MATEJČEKOVÁ et al., 2017).

Os alimentos funcionais, que prometem ajudar na cura ou na prevenção de doenças, são a nova tendência do poderoso mercado alimentício neste início do século XXI. Entre eles estão os leites fermentados que prometem ajudar na cura ou na prevenção de doenças como as cardiovasculares, certos tipos de câncer, alergias, problemas intestinais etc. Entre os fatores-chave que explicam o êxito dos alimentos funcionais, há a preocupação crescente pela saúde e pelo bem-estar, mudanças na regulamentação dos alimentos e a crescente comprovação científica das relações existentes entre dieta e saúde (BELTRÁN-BARRIENTOS et al., 2016).

A geração de lácteos fermentados é mais uma forma de agregar valor ao leite, pois este é considerado o mais nobre dos alimentos, por sua composição rica em proteína, gordura, carboidratos, sais minerais e vitaminas, proporciona nutrientes e proteção imunológica para o neonato. Além de suas propriedades nutricionais, o leite oferece elementos anticarcinogênicos, presentes na gordura, como o ácido linoleico conjugado, esfingomielina, ácido butírico, $\beta$ caroteno, vitaminas A e D (PARK et al., 2007).

As bactérias contribuem com a produção de ácido lático, que preserva o leite, além de vários outros produtos antimicrobianos, componentes flavorizantes, em adição a outros metabólitos como polissacarídeos extracelulares, aminoácido livres e vitaminas (SATIR; GUZEL-SEYDIM, 2016; LIMA et al., 2017a).

Derivados lácteos fermentados com microrganismos probióticos, por exemplo, podem exercer suas propriedades benéficas através de dois mecanismos: efeitos diretos das células microbianas vivas (probióticos) ou efeitos indiretos através dos metabólitos destas células (biogênicos) (VINDEROLA et al., 2006).

Biogênicos são definidos como componentes alimentares derivados da atividade microbiana que proporcionam benefícios à saúde, sem envolver a microbiota intestinal. Os biogênicos mais importantes dos leites fermentados são peptídeos que não estão presentes antes da fermentação (VINDEROLA et al., 2006).

Peptídeos podem também ser adicionados em alimentos para o enriquecimento do mesmo, seja pela adição de aminoácidos essenciais, ou mesmo, pela adição de propriedades bioativas que o produto não apresentava antes (LIMA et al., 2017b).

Os peptídeos bioativos, na área de alimentos funcionais e suplementos dietéticos, são cada vez mais reconhecidos como ferramentas úteis para melhorar a saúde e prevenir doenças crônicas (UDENIGWE; ALUKO, 2012).

As proteínas alimentares não fornecem apenas nutrientes, mas também proporcionam numerosos benefícios para a saúde através do seu impacto em vias bioquímicas específicas. A maioria dessas atividades é devida a peptídeos criptografados nas sequências de proteínas parentais, que são entregues por digestão, absorvidos intactos pelas células intestinais e transportados para seus órgãos-alvo, onde exercem sua atividade biológica (LAMMI et al., 2019).

Ao longo dos anos, inúmeros peptídeos bioativos foram identificados em hidrolisados proteicos de vários alimentos. As estruturas muito diversificadas explicam a ampla gama de atividades funcionais realizadas pelos peptídeos de alimentos: na verdade, a literatura relata por exemplo, atividades anticancerígenas, anti-inflamatórias, hipotensivas, hipocolesterolêmicas, antidiabéticas, antioxidantes, imunomoduladoras e antibacterianas (CAMPOS et al. 2013; LIMA et al. 2018; LIMA et al. 2017b; SILVA et al. 2012). Nesse campo dinâmico, os peptídeos multifuncionais representam uma área emergente com inúmeras aplicações potenciais (LAMMI et al., 2019). 


\section{METODOLOGIA}

Realizou-se revisão narrativa (ROTHER, 2007) sobre o tema peptídeos bioativos em produtos lácteos a partir dos descritores "peptídeos bioativos" "peptídeos multifuncionais", "derivados lácteos", "extrato peptídico", "atuação na saúde" e seus análogos em inglês. Para ampliar a pesquisa por publicações científicas foi utilizado o cruzamento do termo "AND" com os descritores já citados.

Os textos foram pesquisados nas seguintes bases de dados: Literatura Latinoamericana e do Caribe (LILACS), Scientific Electronic Library Online (SciELO), Biblioteca Virtual de Saúde (BVS), US National Institute of Health $\left(\right.$ PubMed $\left.^{\circledR}\right)$. Também foi consultado a página ScienceDirect ${ }^{\circledR}$. Procurou-se por artigos originais, de revisão e capítulos de livro publicados entre os anos de 2008 a 2018, no entanto, artigos clássicos de anos anteriores também foram contemplados.

O conteúdo dos textos foi organizado em categorias e subcategorias temáticas, nas quais se baseou a estrutura deste artigo.

\section{PEPTÍDEOS BIOATIVOS}

A pesquisa de peptídeos tem sido um importante e diversificado campo de estudo dentro da bioquímica há muitas décadas (ZHANG et al., 2018). Os peptídeos bioativos (PBAs) constituem-se de moléculas pequenas com peso inferior a $10 \mathrm{kDa}$ e podem estar presentes em alimentos como componentes naturais criptografados nas sequências de aminoácidos das proteínas, e são liberados e/ou ativados por hidrólise enzimática, hidrólise microbiana e digestão intestinal (JIN et al., 2016; BASILICATA et al., 2018).

Os PBAs representam uma classe de moléculas muito procuradas na atualidade por pessoas que estão na constante busca por compostos saudáveis capazes de melhorar e manter o estado de bem-estar e para prevenir o aparecimento de patologias degenerativas crônicas (BASILICATA et al., 2018).

Por definição, PBAs são peptídeos derivados de proteínas alimentares que possuem propriedades farmacológicas benéficas além da nutrição normal e adequada (HARTMANN; MEISEL, 2007). Numa revisão, foram relatados vários estudos sobre PBAs utilizando fontes de proteínas marinhas (peixe, salmão, ostra, macroalgas, lulas, ouriço-do-mar, camarão e cavalo-marinho); plantas (soja, lentilhas, grão de bico, ervilha, feijão, aveia, trigo, sementes de cânhamo, canola e linhaça); e animais (proteínas do leite caseína e soro de leite, ovo e músculo da carne) (UDENIGWE; ALUKO, 2012).

A busca e seleção por proteínas alimentares como fontes de PBAs são realizadas com base em dois critérios principais: (1) uso de proteínas abundantes subutilizadas ou subprodutos de alimentos ricos em proteínas e (2) utilização de proteínas contendo sequências peptídicas específicas, ou resíduos de aminoácidos de interesse farmacológico particular (UDENIGWE; ALUKO, 2012). Embora esses critérios sejam individualmente importantes, a combinação das duas abordagens pode levar à seleção estratégica de proteínas que podem produzir altos rendimentos de potentes sequências peptídicas definidas (NIELSEN et al., 2017;UDENIGWE; FOGLIANO, 2017).

A atividade dos PBAs depende de sua composição e da sequência de resíduos de aminoácidos, e alguns deles são conhecidos por exibir propriedades multifuncionais (DE CASTRO; SATO, 2015). Estas moléculas podem exibir, entre outras, propriedades antimicrobiana, antioxidantes, hipotensivas, imunomoduladoras, antitrombóticas ou opióides e, consequentemente, exercer efeitos, atuando nos sistemas nervoso, digestivo, cardiovascular e imunológico. Alguns peptídeos na fase de ensaios clínicos mostraram resultados muito promissores para o tratamento de doenças cardiovasculares, infecciosas e metabólicas (HAFEEZ et al., 2014).

Os PBAs têm importantes vantagens competitivas em relação aos medicamentos tradicionais devido as seguintes razões: 1) Eles têm alta especificidade para os seus tecidos alvo, resultando em pouca ou nenhuma toxicidade, e mesmo baixas concentrações podem ser efetivas. Esta característica é extremamente importante para o tratamento de doenças crônicas; 2) compostos químicos sintéticos que normalmente são usados como as drogas geralmente têm um efeito cumulativo sobre o organismo. As substâncias sintéticas podem representar um problema ambiental devido à sua excreção, ainda na forma ativa. Em contraste, os peptídeos bioativos possuem pouca ou nenhuma acumulação no organismo e são facilmente degradados (DE CASTRO; SATO, 2015).

Em particular, o leite e os produtos lácteos são considerados como a fonte de potentes peptídeos capazes de modular positivamente as funções fisiológicas e metabólicas e, assim, exercer efeitos benéficos sobre saúde humana (CAPRIOTTI et al., 2016). 


\subsection{PEPTÍDEOS BIOATIVOS DE LEITE}

O leite contém aproximadamente 3,5\% de proteína, dos quais $80 \%$ e 20\% correspondem respectivamente a caseína e proteínas de soro de leite. As caseínas são classificadas como $\alpha$-, $\beta$ - e $\kappa$-caseínas e nas proteínas do soro são encontradas $\alpha$-lactoglobulina, $\beta$-lactoglobulina e $\alpha$-lactoalbumina e várias proteínas menores com diferentes tipos de atividades como enzimas, propriedades de ligação mineral e imunoglobulinas (MOHANTY et al., 2016).

Peptídeos bioativos derivados do leite geralmente são compostos de 2-20 aminoácidos por molécula (MOHANTY et al., 2016), salvo em alguns casos que podem consistir em mais de 20, e geralmente são classificados em pequenos peptídeos (menos de 7 aminoácidos, os mais ativos, mas difíceis de analisar por abordagens proteômicas convencionais), peptídeos médios (7-25 aminoácidos) e peptídeos grandes (mais de 25 aminoácidos) (CAPRIOTTI et al., 2016).

A liberação in vivo de PBAs envolve a digestão gastrointestinal (com enzimas digestivas como pepsina, tripsina, quimotripsina e peptidases da borda em escova intestinal) bem como enzimas derivadas da microbiota humana (Figura 1). Por outro lado, a produção in vitro dessa classe de moléculas inclui a hidrólise enzimática da proteína alimentar por enzimas endógenas presentes na matriz alimentar (Figura 1), bem como pela proteólise que ocorre durante o processamento de alimentos ou por ação de culturas "starters" como por exemplo os Lactobacillus spp. ou por enzimas proteolíticas isoladas de microrganismos (SÁNCHEZ-GONZÁLEZ; QUINTERO SAAVEDRA; CHIRALT, 2014).

Figura 1: Hidrolise de proteínas dos derivados lácteos pelo sistema proteolítico de bactérias ácido láticas ou por várias enzimas digestivas durante o processo de digestão, que resulta na liberação de peptídeos bioativos.

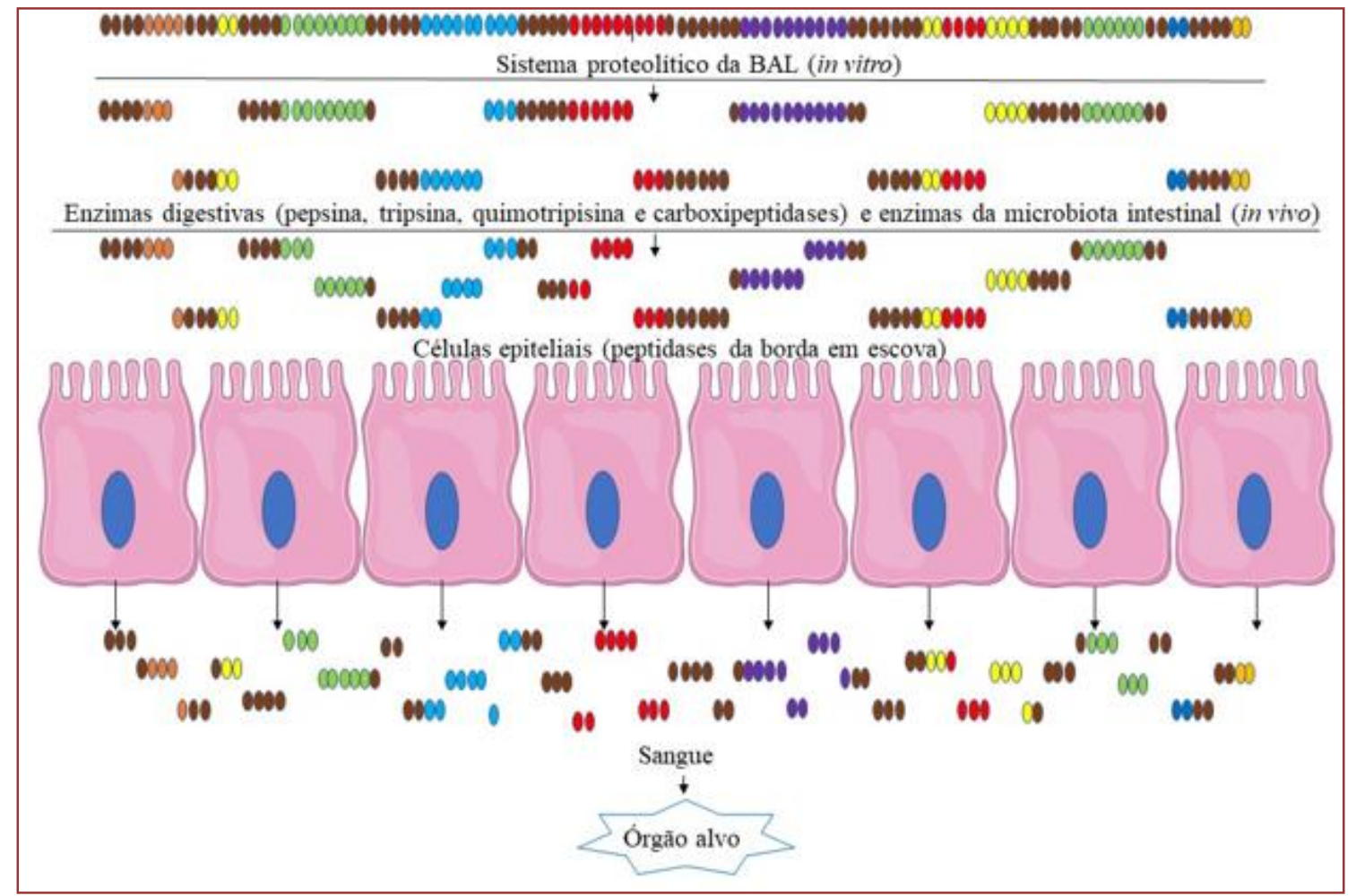

\subsubsection{LIBERAÇÃO DE PEPTÍDEOS BIOATIVOS DO LEITE POR FERMENTAÇÃO}

Como o leite contém apenas pequenas quantidades de aminoácidos e peptídeos curtos, as bactérias ácido láticas dependem de um sistema proteolítico complexo para obter aminoácidos essenciais a partir de caseínas, por exemplo, durante seu crescimento. Este sistema proteolítico especializado compreende três componentes principais (Figura 2): (1) uma proteinase associada à parede celular que está envolvida no primeiro passo da degradação da caseína; (2) sistemas de transporte de peptídeos para permitir a absorção dos peptídeos resultantes, e (3) várias peptidases intracelulares que degradam os peptídeos em fragmentos mais curtose aminoácidos (SAAVEDRA et al., 2013). 
Figura 2: Representação esquemática do sistema proteolítico de bactérias ácido láticas.

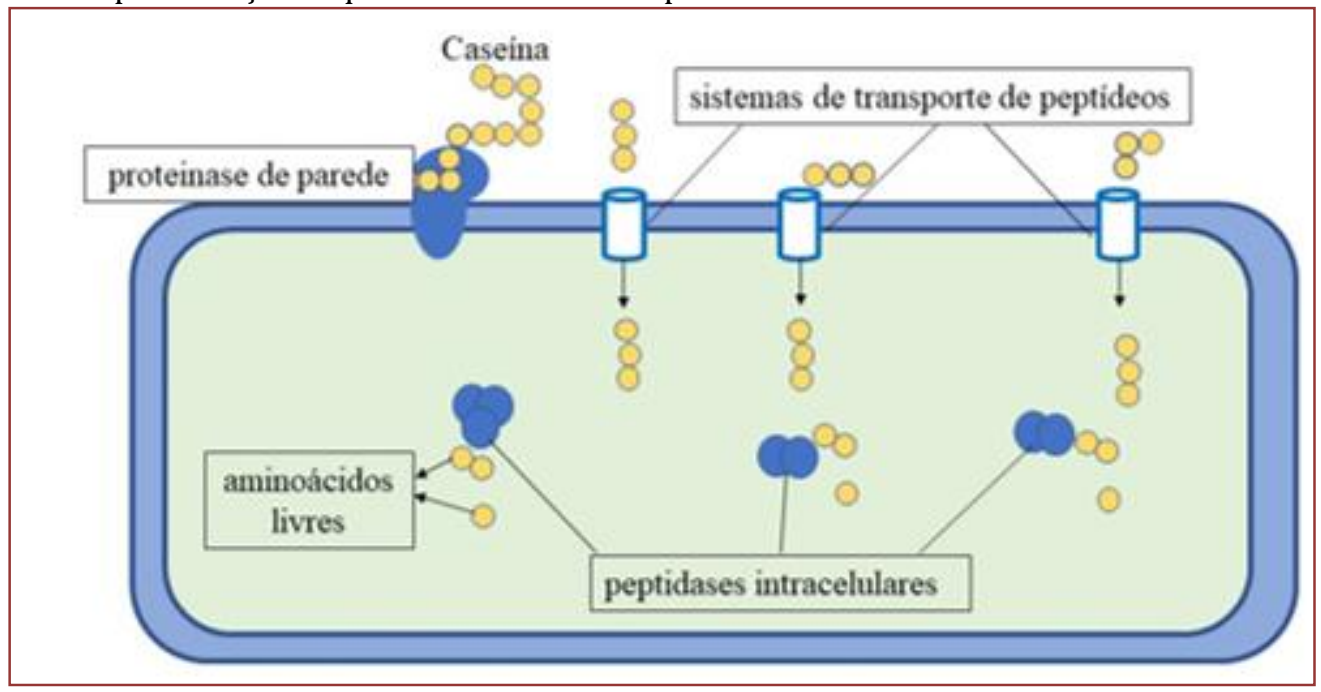

Este sistema proteolítico é necessário para o crescimento da BAL e também contribui para o desenvolvimento de sabor e textura dos produtos fermentados e produção de PBAs (MOHANTY et al., 2016).

Vários peptídeos anti-hipertensivos produzidos durante a fermentação do leite apresentaram uma forte atividade inibitória da Enzima Conversora de Angiotensina I (ECA), uma dipeptidil-carboxipeptidase que desempenha um papel importante na regulação da pressão arterial dentro do sistema renina angiotensina induzindo no sangue aumento de pressão (CHAVES-LÓPEZ et al., 2014).

KEMGANG et al. (2016) produziram um leite fermentado com o probiótico Lactobacillus rhamnosus S1K3, e em seus resultados observação que o consumo deste produto protege ratos de adoecerem depois de serem contaminados por salmonela; eles atribuíram o melhoramento de mecanismos de proteção imune da mucosa intestinal aos peptídeos gerados no leite durante o processo fermentativo.

Peptídeos encontrados em frações menores de 3kDa de leite fermentado por estirpes de L. plantarum apresentaram múltiplas atividades biológicas tais como anti-inflamatórias, anti-hemolíticas, antioxidante, antimutagênica e antimicrobiana (AGUILAR-TOALÁ et al., 2017).

Culturas mistas utilizadas na fermentação de leites também produziram potentes peptídeos bioativos. CHAVES-LÓPEZ et al.,(2014) quando produziram o leite fermentado utilizando bactérias e leveduras isoladas a partir de kumis, encontraram em seus resultados um extrato peptídico com atividade antihipertensiva com $\mathrm{EC}_{50}$ de 30,63 $\mu \mathrm{g} / \mathrm{mL}$.

O kefir como cultura probiotica complexa também tem sido útil na geração de PBAs durante a fermentação de leites. No estudo de LIMA et al. (2018), após a extração da fase aquosa de peptídeos de um leite de ovelha fermentado por grãos de kefir, foi observado que estes extratos apresentaram atividades antioxidantes e antimicrobianas. DALLAS et al. (2016) estudaram o perfil de PBAs formados a partir da fermentação do leite bovino por kefir, em seus resultados identificaram vinte e nove peptídeos funcionais - incluindo funções antibacterianas, anti-hipertensivas, opiáceas e antioxidantes - derivados de $\alpha s 1-, \alpha s 2-$, $\beta$ - e к-caseína. Sete peptídeos funcionais desse estudo também estavam presentes no estudo de EBNER et al. (2015) que avaliaram o efeito do kefir na proteólise de leite bovino; o adicional deste estudo é que nele foram observados os fragmentos peptídicos e suas bioatividades foram encontradas também nos grãos e no leite bovino fresco.

\subsubsection{OBTENÇÃO DE PEPTÍDEOS BIOATIVOS POR SIMULAÇÃO DA DIGESTÃo OU HIDRÓLISE ENZIMÁTICA}

Saber se os peptídeos potencialmente bioativos resistem ao processo de digestão, ou identificar quais novos PBAs são liberados de um determinado produto através da digestão, é importante para o desenvolvimento de novos produtos lácteos com benefícios para a saúde (KOPF-BOLANZ et al., 2014). 
Atividades de PBAs testadas a partir de extratos alimentícios e peptídeos bioativos em experimentos gastrointestinais são duas importantes fatores que precisam ser considerados (JIN et al., 2016). Como exemplo, a lactoquinina, um peptídeo resultante da clivagem da $\beta$-lactoglobulina, $\beta$-Lg $f(142-148)$ que exibiu atividade inibitória in vitro contra a enzima conversora de angiotensina (ECA), demonstrou-se insuficientemente estável contra proteases do trato gastrointestinal. E após a simulação da digestão, a atividade residual anti-ECA foi completamente reprimida quando o peptídeo foi incubado com sangue humano, provando que proteinases e peptidases de soro degradam ainda mais os peptídeos circulantes (PICARIELLO et al., 2013).

Os peptídeos bioativos podem ser liberados durante a digestão gastrointestinal pela ação de enzimas digestivas como a pepsina, tripsina ou quimotripsina. As proteínas dietéticas sofrem desnaturação na presença de ácido clorídrico secretado pelas células parietais do estômago. Este ácido ativa o pepsinogênio e converte-o em sua forma ativa, a pepsina. A pepsina atua em proteínas para metabolizá-las em peptídeos e aminoácidos. A digestão gastrointestinal permite a consequente ação das enzimas presentes no intestino delgado, tais como tripsina ou quimotripsina, que são responsáveis pela hidrólise de proteínas (MOHANTY et al., 2016).

Nas digestões gastrointestinais, as enzimas apresentam certas preferências para as proteínas do leite. Segundo o estudo de JIN et al. (2016) a $\beta$-caseína foi o tipo proteína que liberou mais peptídeos durante a digestão gastrointestinal em um iogurte. 0 número de peptídeos liberados de caseínas foi consistente com o trabalho de DUPONT et al. (2010) que relatam que a ordem de liberação de caseína em ensaios gastrointestinais é $\beta-\mathrm{CN}>\alpha \mathrm{s} 1->\alpha \mathrm{s} 2-\mathrm{CN}>\kappa-\mathrm{CN}$. As enzimas intestinais foram propensas a digerir $\beta-\mathrm{CN}$, enquanto a clivagem da proteína $\kappa-\mathrm{CN}$ é preferida pelas bactérias ácido láticas. A fermentação ajuda na pré-hidrolise da א-CN que não é facilmente hidrolisada nos ensaios gastrointestinais (JIN et al., 2016).

Vários PBAs, como por exemplo os antibacterianos, imunomoduladores, anti-hipertensivo e opióide, são conhecidos por serem liberados das proteínas caseína e/ou do soro de leite por digestão gastrointestinal (HARTMANN; MEISEL, 2007; PICARIELLO et al., 2013; JIN et al., 2016; MOHANTY et al., 2016).

A hidrólise enzimática é uma das técnicas mais rápidas, mais seguras e mais facilmente controlada para a produção de PBAs e pode ser usada para melhorar as propriedades funcionais e biológicas das proteínas, além de agregar valor aos subprodutos com baixo valor comercial (MEIRA et al., 2012; CORRÊA et al., 2014; BRANDELLI; DAROIT; CORRÊA, 2015).

As proteases catalisam a hidrólise de ligações peptídicas em proteínas e podem atuar sobre as ligações éster e amida. Todas as proteases têm um certo grau de especificidade para o substrato, geralmente com base na sequência de aminoácidos que circundam diretamente a ligação que é clivada (UDENIGWE; FOGLIANO, 2017).

A especificidade enzimática e as condições de hidrólise ( $\mathrm{pH}$, temperatura, tempo) influenciam o tamanho e as sequências de aminoácidos nas cadeias peptídicas, bem como a quantidade de aminoácidos livres, que podem afetar a atividade biológica dos hidrolisados (SARMADI; ISMAIL, 2010).

Na revisão de SAAVEDRA et al. (2013) foi citado um peptídeo de 25 aminoácidos derivado da digestão da lactoferrina por pepsina, que apresentou uma excelente atividade antimicrobiana. A digestão da $\alpha$ lactalbumina por pepsina, tripsina ou quimotripsina resulta na produção de PBAs com ambas as atividades imunomoduladoras e antimicrobianas contra bactérias, vírus e fungos.

0 composto bioativo derivado do soro de leite é o tripeptídeo Ile-Pro-Ala, liberado da hidrólise de $\beta$ lactoglobulina, que pode atuar como inibidor de dipeptidil peptidase-4, reduzindo os níveis de glicose e estimulando a insulina (BRANDELLI; DAROIT; CORRÊA, 2015). Outros tripeptídeos derivados da $\beta$-caseína Ile-Pro-Pro e Val-Pro-Pro, por ação de uma protease encontrada em L. helveticus, apresentaram capacidade anti-hipertensiva quando testados em ratos naturalmente hipertensos (MIYAZAKI et al., 2017).

\section{CONSIDERAÇÕES FINAIS}

A literatura atual mostra que os peptídeos derivados de proteínas de derivados lácteos possuem notáveis atividades multifuncionais relevantes para o auxiliar na saúde humana. Esta área de pesquisa está crescendo continuamente com a descoberta de novos alvos de doenças moleculares. Embora existam muitas informações sobre os vários PBAs derivados de proteínas alimentares, as pesquisas devem ser direcionados para a avaliação de efeitos de promoção da saúde in vivo, biodisponibilidade e farmacocinética em indivíduos humanos, elucidação dos mecanismos moleculares de ação e em geral possível uso como agentes promotores da saúde em sistemas alimentares. 


\section{REFERÊNCIAS}

[1] AGUILAR-TOALÁ, J. E.; SANTIAGO-LÓPEZ, L.; PERES, C. M.; PERES, C.; GARCIA, H. S.; VALLEJO-CORDOBA, B.; GONZÁLEZ-CÓRDOVA, A. F.; HERNÁNDEZ-MENDOZA, A. Assessment of Multifunctional Activity of Bioactive Peptides Derived from Fermented Milk by Specific Lactobacillus plantarum Strains. Journal of Dairy Science, v. 100, n. 1, p. 6575, 2017.

[2] BASIliCATA, M. G.; PEPE, G.; SOMMElla, E.; OSTACOlO, C.; MANFRA, M.; SOSTO, G.; PAGANO, G.; NOVELlinO, E.; CAMPIGLIA, P. Peptidome Profiles and Bioactivity Elucidation of Buffalo-Milk Dairy Products after Gastrointestinal Digestion. Food Research International, v. 105, p. 1003-1010, 2018.

[3] BELTRÁN-BARRIENTOS, L. M.; VALLEJO-CÓRDOBA, B.; TORRES-LLANEZ, M. J.; et al. Invited review: Fermented milk as antihypertensive functional food. Journal of Dairy Science, v. 99, n. 6, p. 4099-4110, 2016.

[4] BRANDELLI, A.; DAROIT, D. J.; CORRÊA, A. P. F. Whey as a Source of Peptides with Remarkable Biological Activities. Food Research International, v. 73, p. 149-161, 2015.

[5] CAMPOS, J. F.; SILVA, R. A. DA; PORTO, A. L. F.; et al. Biotechnological richness of the northeastern semi-arid region: antioxidant activity of casein hydrolysates from Moxotó goat milk (Capra hircus Linnaeus, 1758) obtained by papain action. Food Science and Technology, v. 33, n. 3, p. 513-520, 2013.

[6] CAPRIOTTI, A. L.; CAVALIERE, C.; PIOVESANA, S.; SAMPERI, R.; LAGANÃ , A. Recent Trends in the Analysis of Bioactive Peptides in Milk and Dairy Products. Analytical and Bioanalytical Chemistry, v. 408, n. 11, p. 2677-2685, 2016.

[7] CHAVES-LÓPEZ, C.; SERIO, A.; PAPAREllA, A.; MARTUSCELli, M.; CORSETTI, A.; TOFALO, R.; SUZZI, G. Impact of Microbial Cultures on Proteolysis and Release of Bioactive Peptides in Fermented Milk. Food Microbiology, v. 42, p. 117-121, 2014.

[8] CORRÊA, A. P. F.; DAROIT, D. J.; FONTOURA, R.; MEIRA, S. M. M.; SEGALIN, J.; BRANDELLI, A. Hydrolysates of Sheep Cheese Whey as a Source of Bioactive Peptides with Antioxidant and Angiotensin-Converting Enzyme Inhibitory Activities. Peptides, v. 61, p. 48-55, 2014.

[9] DAllaS, D. C.; CITERnE, F.; TIAN, T.; SILVA, V. L. M.; KALANETRA, K. M.; FRESE, S. A.; ROBINSON, R. C.; MILLS, D. A.; BARILE, D. Peptidomic Analysis Reveals Proteolytic Activity of Kefir Microorganisms on Bovine Milk Proteins. Food Chemistry, v. 197, p. 273-284, 2016.

[10] DE CASTRO, R. J. S.; SATO, H. H. Biologically Active Peptides: Processes for Their Generation, Purification and Identification and Applications as Natural Additives in the Food and Pharmaceutical Industries. Food Research International, v. 74, p. 185-198, 2015.

[11] DUPONT, D.; MANDALARI, G.; MOLLÉ, D.; JARDIN, J.; ROLET-RÉPÉCAUD, O.; DUBOZ, G.; LÉONIL, J.; MILLS, C. E. N.; MACKIE, A. R. Food Processing Increases Casein Resistance to Simulated Infant Digestion. Molecular Nutrition and Food Research, v. 54, n. 11, p. 1677-1689, 2010.

[12] HAFEEZ, Z.; CAKIR-KIEFER, C.; ROUX, E.; PERRIN, C.; MICLO, L.; DARY-MOUROT, A. Strategies of Producing Bioactive Peptides from Milk Proteins to Functionalize Fermented Milk Products. Food Research International, v. 63, p. 71-80, 2014.

[13] HARTMANN, R.; MEISEL, H. Food-Derived Peptides with Biological Activity: From Research to Food Applications. Current Opinion in Biotechnology, v. 18, n. 2, p. 163-169, 2007.

[14] JIN, Y.; YU, Y.; QI, Y.; WANG, F.; YAN, J.; ZOU, H. Peptide Profiling and the Bioactivity Character of Yogurt in the Simulated Gastrointestinal Digestion. Journal of Proteomics, v. 141, p. 24-46, 2016.

[15] KEMGANG, T. S.; KAPILA, S.; ShAnMUgAM, V. P.; REDDI, S.; KAPILA, R. Fermented Milk with Probiotic Lactobacillus rhamnosus S1K3 (MTCC5957) Protects Mice from Salmonella by Enhancing Immune and Nonimmune Protection Mechanisms at Intestinal Mucosal Level. Journal of Nutritional Biochemistry, v. 30, p. 62-73, 2016.

[16] KOPF-BOLANZ, K. A.; SCHWANDER, F.; GIJS, M.; VERGÈRES, G.; PORTMANN, R.; EGGER, L. Impact of Milk Processing on the Generation of Peptides during Digestion. International Dairy Journal, v. 35, n. 2, p. 130-138, 2014.

[17] LAMMI, C.; AIELLO, G.; BOSCHIN, G.; ARNOLDI, A. Multifunctional peptides for the prevention of cardiovascular disease: A new concept in the area of bioactive food-derived peptides. Journal of Functional Foods, v. 55, n. January, p. 135-145, 2019.

[18] LIMA, M. S. F.; SOUZA, K. M. S.; ALBUQUERQUE, W. W. C.; et al. Saccharomyces cerevisiae from Brazilian kefirfermented milk: An in vitro evaluation of probiotic properties. Microbial Pathogenesis, v. 110, p. 670-677, 2017a.

[19] LIMA, M. S. F.; SILVA, R. A.; LIMA FILHO, J. L.; et al. Queijo de coalho artesanal : fonte alternativa de peptídeos antimicrobianos Artisanal " coalho" cheese : alternative source of antimicrobial peptides. Brazilian Journal of Food Tecnhology, v. 20, p. e2016193, 2017b. 
[20] LIMA, M. S. F.; SILVA, R. A.; SILVA, M. F.; et al. Brazilian Kefir-Fermented Sheep's Milk, a Source of Antimicrobial and Antioxidant Peptides. Probiotics and Antimicrobial Proteins, v. 10, n. 3, p. 446-455, 2018.

[21] MATEJČEKOVÁ, Z.; LIPTÁKOVÁ, D.; VALÍK, L. Functional probiotic products based on fermented buckwheat with Lactobacillus rhamnosus. LWT - Food Science and Technology, v. 81, p. 35-41, 2017.

[22] MEIRA, S. M. M.; DAROIT, D. J.; HELFER, V. E.; CORRÊA, A. P. F.; SEGALIN, J.; CARRO, S.; BRANDELLI, A. Bioactive Peptides in Water-Soluble Extracts of Ovine Cheeses from Southern Brazil and Uruguay. Food Research International, v. 48, n. 1, p. 322-329, 2012.

[23] MIYAZAKI, H.; NAKAMURA, T.; OHKI, K.; NAGAI, K. Effects of the Bioactive Peptides Ile-Pro-Pro and Val-ProPro upon Autonomic Neurotransmission and Blood Pressure in Spontaneously Hypertensive Rats. Autonomic Neuroscience, v. 208, p. 88-92, 2017.

[24] MOHANTY, D. P.; MOHAPATRA, S.; MISRA, S.; SAHU, P. S. Milk Derived Bioactive Peptides and Their Impact on Human Health - A Review. Saudi Journal of Biological Sciences, v. 23, n. 5, p. 577-583, 2016.

[25] NIELSEN, S. D.; BEVERLY, R. L.; QU, Y.; DALLAS, D. C. Milk Bioactive Peptide Database: A Comprehensive Database of Milk Protein-Derived Bioactive Peptides and Novel Visualization. Food Chemistry, v. 232, p. 673-682, 2017.

[26] PARK, Y. W.; JU, M.; RAMOS, M.; HAENLEIN, G. F. W. Physico-chemical characteristics of goat and sheep milk. Small Ruminant Research, v. 68, p. 88-113, 2007.

[27] PICARIEllo, G.; MAMONE, G.; NITRIDE, C.; ADDEO, F.; FERRANTI, P. Protein Digestomics: Integrated Platforms to Study Food-Protein Digestion and Derived Functional and Active Peptides. TrAC - Trends in Analytical Chemistry, v. 52, p. 120-134, 2013.

[28] ROTHER, E.T. Revisão sistemática X revisão narrativa (Editorial). Acta Paulista de Enfermagem. v. 20, n. 6., p.5-6, 2007.

[29] SAAVEDRA, L.; HEBERT, E. M.; MINAHK, C.; FERRANTI, P. An Overview Of "omic" analytical Methods Applied in Bioactive Peptide Studies. Food Research International, v. 54, n. 1, p. 925-934, 2013.

[30] SÁNCHEZ-GONZÁLEZ, L.; QUINTERo SAAVEDRA, J. I.; CHIRALT, A. Antilisterial and Physical Properties of Biopolymer Films Containing Lactic Acid Bacteria. Food Control, v. 35, n. 1, p. 200-206, 2014.

[31] SARMADI, B. H.; ISMAIL, A. Antioxidative Peptides from Food Proteins: A Review. Peptides, v. 31, n. 10, p. 1949-56, 2010.

[32] SATIR, G.; GUZEL-SEYDIM, Z. B. How kefir fermentation can affect product composition? Small Ruminant Research, v. 134, p. 1-7, 2016.

[33] SILVA, R. A.; LIMA, M. S. F.; VIANA, J. B. M.; et al. Can artisanal "coalho" cheese from Northeastern Brazil be used as a functional food? Food Chemistry, v. 135, n. 3, p. 1533-1538, 2012.

[34] UDENIGWE, C. C.; ALUKO, R. E. Food Protein-Derived Bioactive Peptides: Production, Processing, and Potential Health Benefits. Journal of Food Science, v. 71, n. 1, p. R11-R24, 2012.

[35] UDENIGWE, C. C.; FOGLIANO, V. Food Matrix Interaction and Bioavailability of Bioactive Peptides: Two Faces of the Same Coin? Journal of Functional Foods, v. 35, p. 9-12, 2017.

[36] VINDEROLA, G.; PERDIGON, G.; DUARTE, J.; et al. Effects of the oral administration of the exopolysaccharide produced by Lactobacillus kefiranofaciens on the gut mucosal immunity. Cytokine, v.36, n.5-6, p.254-260, 2006.

[37] ZHANG, R.-Y.; THAPA, P.; ESPIRITU, M. J.; MENON, V.; BINGHAM, J.-P. From Nature to Creation: Going around in Circles, the Art of Peptide Cyclization. Bioorganic \& Medicinal Chemistry, v. 26, n. 6, p. 1135-1150, 2018. 


\section{Capítulo 5}

Fenomenologia na proteção de vasos sanguíneos por controle da viscosidade do sangue

\section{Matheus Guisoni Pereira \\ Klívia Faria Finzer \\ José Roberto Delalibera Finzer \\ Ricardo Amâncio Malagoni}

Resumo: 0 sangue consiste em suspensão constituída pelo plasma, uma fase aquosa contínua contendo sais, açúcar e proteínas e uma fase discreta, que inclui os eritrócitos, leucócitos e plaquetas. 0 plasma comporta-se como um fluido newtoniano, e o sangue como não-newtoniano. 0 trabalho tem o objetivo de descrever a fenomenologia do escoamento do sangue pela artéria aorta $\mathrm{Na}$ modelagem inclui-se a presença de proteínas no sangue sendo quantificado o fator de consistência e o fator de comportamento do sangue. Efetuando-se um balanço de forças em um vaso sanguíneo, obtém-se a tensão na parede em função da perda de pressão que possibilita obter a velocidade em uma posição radial do vaso sanguíneo e a vazão do sangue. 0 perfil de velocidade é obtido e efetuado ajuste a uma equação. A viscosidade aparente é quantificada em 10,4 mPas. Descreve-se que se a velocidade no centro do vaso aumentar devido a uma diminuição do diâmetro por problemas de depósitos, a viscosidade aparente irá diminuir assim como a tensão na parede, e o efeito na aorta é minimizado. 0 trabalho explica o porquê na ocorrência de obstruções parciais, a influência nas paredes é amenizada. Faz-se uma abordagem sobre influências da escassez de oxigênio no sangue e na formação de coágulos por agentes externos como o Covid-19.

Palavras-chave: Comportamento reológico; Viscosidade do sangue; Transporte de oxigênio; Vasos sanguíneos. 


\section{INTRODUÇÃO}

Jean Leonard Marie Poiseuille (1797 - 1869) foi um físico e fisiologista francês, natural de Paris. Estudou durante um ano na École Plytechnique, em Paris e em 1828 com um trabalho denominado Recherches sur la vigor du coeur aortique recebeu o grau D.Sc. Gotthilf Heinrich Ludwig Hagen (1797 - 1884), natural de Konigsberg, Alemanha; o qual atuou como físico e engenheiro hidráulico, em 1839, publica um artigo sobre o escoamento de água em tubos cilíndricos, cujos resultados eram parecidos com os de Poiseuille (Sutera e Skalak, 1993).

Fenomenologicamente para viscosidade e densidades constantes a equação do movimento consiste na equação de Navier-Stokes, Equação (1), a qual indica que um elemento de volume, movendo-se com um fluido, é acelerado devido às forças que atuam sobre o mesmo (Bird et al., 2002). A equação representa que a massa por unidade de volume vezes aceleração é igual às forças de pressão, viscosas e a gravitacional, todas por unidade de volume.

$$
\rho \frac{D \mathbf{v}}{D t}=-\nabla p-[\nabla \cdot \boldsymbol{\tau}]+\rho \mathbf{g}
$$

Do trabalho dos pesquisadores citados, com base fenomenológica na Equação (1) originou-se uma expressão matemática para mensurar a taxa volumétrica de escoamento em regime laminar de fluidos em tubos circulares conhecida como equação de Hagen-Poiseuille (Equação 2), quando a energia potencial é desprezível (Fraiha et al., 2010). Na equação, v é o vetor velocidade do elemento de fluido; p é a pressão; $\boldsymbol{\tau}$ é o tensor tensão, $\rho$ é a densidade do fluido e $\mathbf{g}$ a aceleração da gravidade. 0 regime laminar se caracteriza pela não mistura das camadas do fluido em escoamento (Bird et al., 2002).

$$
Q=\frac{\pi \cdot \Delta P \cdot R^{4}}{8 \cdot \mu \cdot L}
$$

sendo: $Q$ a vazão $\left(\mathrm{m}^{3} / \mathrm{s}\right) ; \Delta P$ a perda de pressão $(\mathrm{Pa}) ; R$ e $L$ são o raio e o comprimento do tubo (m); $\mu$ a viscosidade (Pa.s).

\section{FLUÍDOS NÃO NEWTONIANOS: REOLOGIA DO SANGUE}

O sangue é uma suspensão constituída por uma fase aquosa contínua (plasma) contendo sais, açúcares, proteínas e uma fase discreta, que incluem os eritrócitos (glóbulos vermelhos), que constituem a vasta maioria (mais de 99,5\%) dos particulados, leucócitos (glóbulos brancos do sangue) e plaquetas. 0 plasma é um fluido Newtoniano, com uma viscosidade entre 1,16 e $1,35 \mathrm{cP}$ a $37^{\circ} \mathrm{C}$. Ao contrário do plasma, o sangue tem um comportamento não-newtoniano, principalmente devido à presença de glóbulos vermelhos, conforme mostra a Figura 1. 
Figura 1 - Representação esquemática do sangue e seus constituintes.

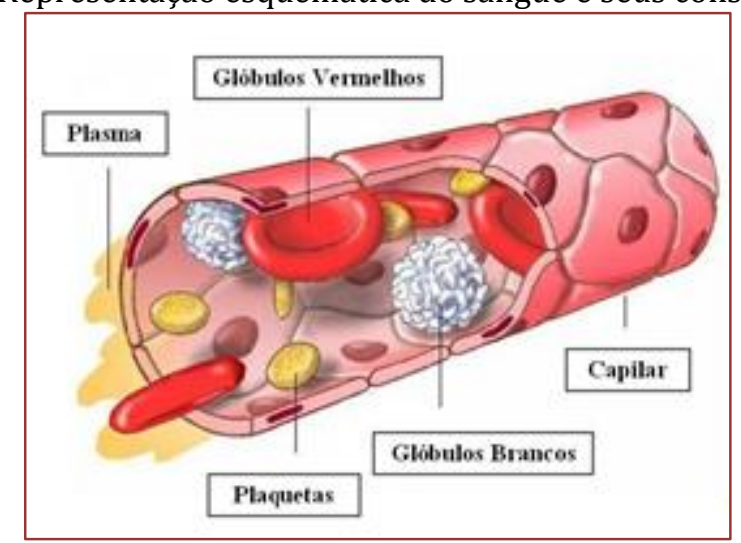

\section{MATERIAL E MÉTODOS}

A tensão aplicada ao sangue em escoamento é modelada com uso da lei da Potência conforme a Equação (3).

$$
\tau=k \cdot(d v / d r)^{n}
$$

sendo: $\tau$ é a tensão aplicada; $k$ o fator de consistência e $n$ o fator de comportamento do sangue.

O comportamento dos fluidos é apresentado na Figura 2, destacando-se a curva da lei de Potência (acima da linha de cor verde, fluido newtoniano) que rege o comportamento do sangue (pseudoplástico). Sendo: $\dot{\gamma}=d v / d r$ a derivada da velocidade do sangue em relação à posição radial.

Figura 2 - Comportamento de fluidos não-newtonianos (a reta de cor verde consiste no comportamento newtoniano).

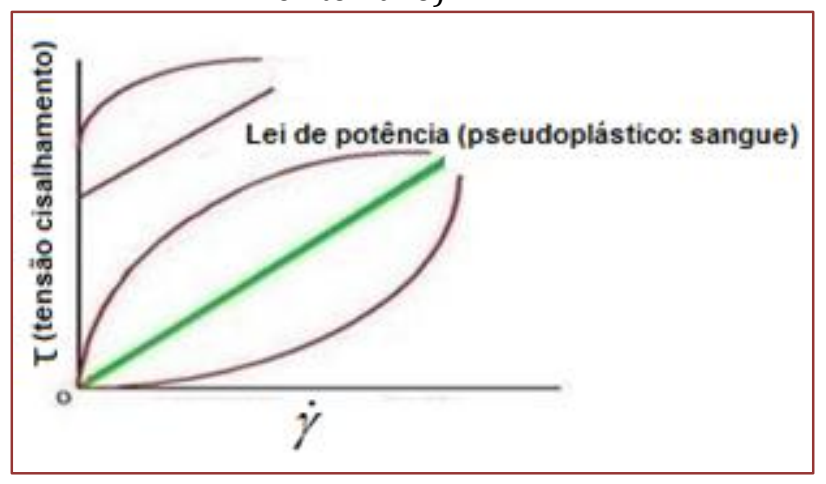

Skelland (1967) mostra que a viscosidade aparente é quantificada pela Equação (4): (Pereira et al., 2020).

$$
\mu_{\text {aparente }}=k \dot{\gamma}^{n-1}
$$


Conforme mostrado por Santos (2009), os fatores de comportamento do fluido e de consistência podem ser correlacionados de acordo com as Equações (5), (6) e (7), o que possibilita o cálculo da viscosidade aparente em mPa's.

$$
\begin{aligned}
& k=c_{1} e^{c_{2} h} \\
& n=c_{3} \cdot h \\
& c_{1}=c_{1}^{*} e^{\left(c_{4} \cdot P / h^{2}\right)}
\end{aligned}
$$

sendo: $\quad c_{1}^{*}=0,00797(\mathrm{~Pa} \cdot \mathrm{s})^{\mathrm{n}} ; c_{2}=17,167 ; \mathrm{c}_{3}=0,651 ; \mathrm{c}_{4}=0,00795(\mathrm{~Pa} \cdot \mathrm{s})^{\mathrm{n}} ; P$ consiste na diferença da proteína total no sangue menos a albumina, na situação normal igual a 0,0325 e $h$ refere-se ao hematócrito, ou seja, a porcentagem total de hemácias (glóbulos vermelhos) em relação ao plasma, sendo seu valor médio de $45 \%$.

\subsection{TENSÃO NA PAREDE DOS VASOS E ESQUEMA DO CORAÇÃO}

Efetuando-se um balanço de forças em um vaso sanguíneo, obtém-se a tensão na parede em função da perda de pressão por atrito $\left(\Delta P_{f}\right)$, conforme a Equação (8).

$$
\tau_{\mathrm{w}}=\mathrm{D} \cdot \Delta \mathrm{P}_{\mathrm{f}} / 4 \cdot \mathrm{L}
$$

A velocidade em uma posição radial no vaso sanguíneo é quantificada pela Equação (9).

$$
v=\left[\frac{\Delta P_{f}}{2 \cdot k \cdot L}\right]^{1 / n} \cdot \frac{n}{n+1}\left[R^{\frac{n+1}{n}}-r^{\frac{n+1}{n}}\right]
$$

sendo: $L$ e $R$ o comprimento e o raio do vaso; $r$ consiste na distância do centro do vaso até um ponto genérico (ver Figura 3).

A vazão do fluido não-newtoniano que segue o modelo da Potência é quantificada pela Equação (10).

$$
\frac{Q}{\pi \cdot R^{3}}=\frac{n}{3 \cdot n+1}\left(\frac{\tau_{w}}{k}\right)^{1 / n}
$$

A Figura 4 situa a aorta no coração a qual possui comprimento e diâmetro médio de 0,05 e 0,025 m, respectivamente. 
Figura 3 - Detalhes de escoamento em um vaso.

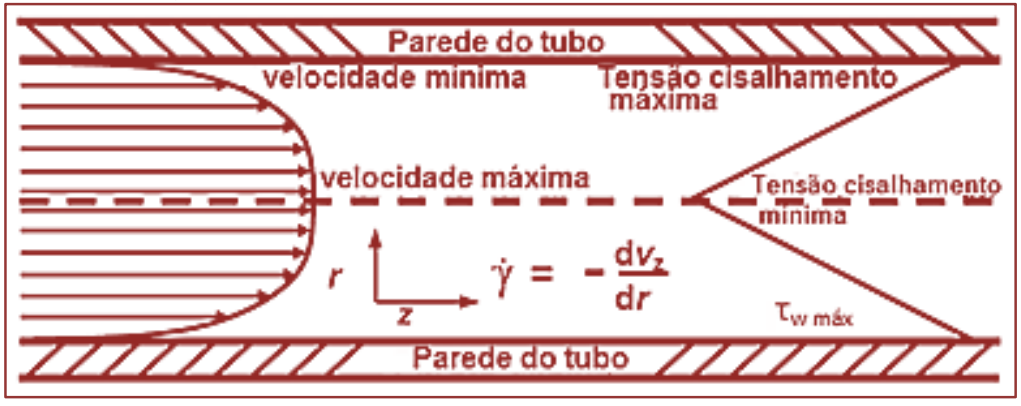

Figura 4 - Representação esquemática dos principais orifícios do coração.

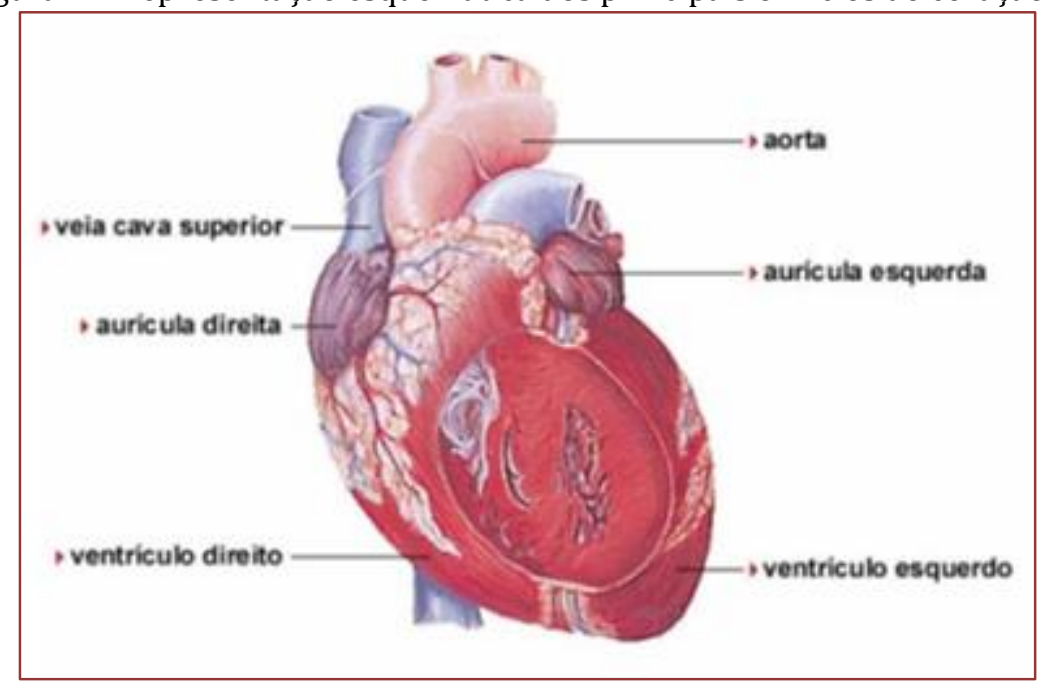

\subsection{MECANISMO DE GERAÇÃO DE HEMÁCIAS (GLÓBULOS VERMELHOS)}

0 oxigênio consiste em $21 \%$ do ar, que também é dominante na crosta terrestre, sendo um elemento essencial na maioria das células vivas. Três prêmios Nobel de Medicina foram atribuídos a pesquisadores que estudam a respiração com oxigênio. Em 1922, Otto Fritz Meyerhof recebeu metade do prêmio por seu trabalho. Nove anos depois, em 1931, Otto Heinrich Warburg Corneille identificou uma enzima necessária para a respiração celular. Mais tarde, na mesma década, Jean François Heymans recebeu o prêmio de 1938 por seu trabalho de regulamentação da respiração. Agora, em 2019, William G. Kaelin Jr., Sir J. Peter Ratcliffe e Gregg L. Semenza foram premiados, por descobrir como as células reconhecem e se adaptam às mudanças nas concentrações de oxigênio no organismo (GILMAN, 2019).

O oxigênio está presente na respiração das pessoas que são completamente dependentes do oxigênio para converter alimento em energia. Mas os níveis de oxigênio variam no corpo, particularmente durante exercício físico ou quando as pessoas se encontram em altitudes elevadas ou depois que um corte interfere no fornecimento de sangue. Quando níveis de oxigênio caem, as células são forçadas a se adaptarem rapidamente. A habilidade do nosso corpo de "sentir" o nível do oxigênio pode dar origem à produção de novos glóbulos vermelhos. Os cientistas descobriram que uma proteína detecta a privação de oxigênio e com isso provoca o aumento na produção de glóbulos vermelhos (BBC, 2019). Watanabe (2019) efetua um esquema simplificado do mecanismo (Figura 5). 
Figura 5. Como o oxigênio é regulado no organismo (Watanabe, 2019)

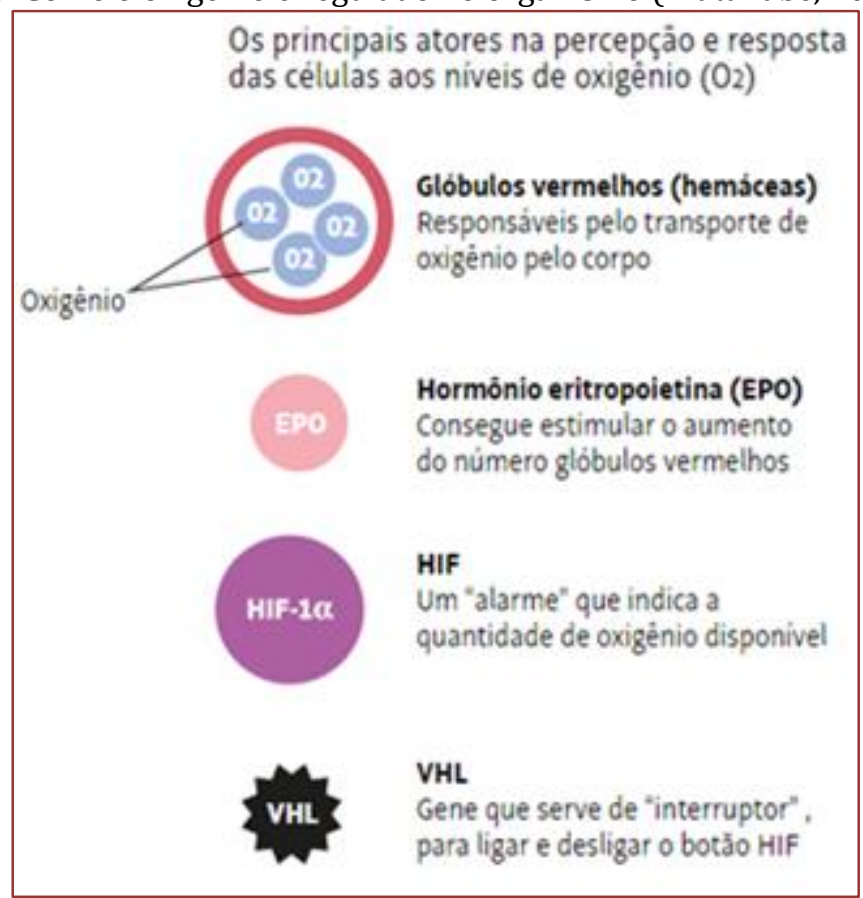

Quando os níveis de oxigênio são baixos (hipóxia), o HIF-1 $\alpha$ é protegido da degradação e se acumula no núcleo. Em níveis normais de oxigênio, o HIF-1 $\alpha$ é rapidamente degradado ( Howes e Satyanarayana, 2019).

Na atualidade, Alguns pacientes graves de Covid-19 não sentem falta de ar, mesmo quando os níveis de oxigênio no sangue já estão bem baixos. Isso faz com que a doença passe despercebida no início e quando o paciente chega ao hospital a situação está tão crítica que ele logo precisa ser entubado.

Uma das hipóteses que explica esse comportamento estranho no corpo é a formação de coágulos nos pulmões. O sangue forma pequenos sólidos que servem como "tampão" quando algum vaso sanguíneo é rompido. Isso geralmente ajuda a estancar sangramentos, mas ele também pode causar trombose, que é quando esses coágulos bloqueiam o escoamento do sangue pelos vasos.

No caso da Covid-19 (Figura 6), cada vez mais estudos mostram que a doença pode causar esses trombos em pacientes que evoluem para quadros mais graves. Isso explicaria por que a pessoa não sente falta de ar, mesmo já estando com níveis baixos de oxigênio: o ar entra e sai normalmente do pulmão, mas o oxigênio não chega onde é necessário, por conta da falta de irrigação (ROSSINE, 2020). Medicamentos precisos podem evitar a ocorrência da formação de coágulos evitando, assim, ação deste complicador no escoamento sanguíneo. A Figura 6 mostra a influência da invasão das células que revestem os vasos sanguíneos (Zorzetto, 2020).

Substâncias que diminuem a viscosidade podem atuar na melhoria do quadro, caso não exista indicação contrária, uma taça de vinho pode ser salutar e atenuar o problema até que a ação do vírus seja suprimida. 
Figura 6. Influência de coágulos em vasos sanguíneos (Zorzetto, 2020).

CÉREBRO -
Algumas pessoas com Covid-19
apresentam isquemia cerebral
e inflamação do sistema
nervoso central, além
de sintomas como tontura,
delírio e convulsōes

\section{RESULTADOS E DISCUSSÃO}

A viscosidade do sangue pode ser determinada utilizando o valor padrão de vazão do sangue pela artéria aorta de $5 \mathrm{~L} / \mathrm{min}$. Ao utilizar as Equações (5) a (7), obtém-se: $n=0,70705$ e $k=18,035$ Pa's $\mathrm{s}^{0.70705}$ (Pereira et al., 2020).

Utilizando-se a Equação (10), obtém-se o valor para a tensão na parede da artéria aorta, sendo $\tau_{w}=326 \mathrm{~Pa}$.

Do balanço de forças, calcula-se a perda de pressão na aorta pela Equação (8), em que $\Delta \mathrm{P}=2608 \mathrm{~Pa}$. A velocidade do sangue no centro da aorta pode ser determinada pela Equação (9), como: Vmáx $=0,75 \mathrm{~m} / \mathrm{s}$. Portanto, o gradiente de velocidade entre o centro e a parede da artéria pode ser calculado, considerando o fato que para $r=\mathrm{R}$ (raio da aorta) a velocidade do sangue é nula, admitindo comportamento linear.

$$
\frac{d v}{d r}=\frac{0-v_{\operatorname{máx}}}{0,0125-0}=-60 \mathrm{~s}^{-1}
$$

Seguindo-se ao cálculo da viscosidade do fluído, utilizando a Equação (4), tem-se:

$$
\mu_{\text {aparente }}=18,0035 \cdot 60^{0,70705-1} \quad \mu_{\text {apar }}=5,43 \mathrm{mPa} \cdot \mathrm{s}
$$

Efetuando-se uma simulação, se a velocidade no centro do vaso aumentar devido a uma diminuição do diâmetro, por problemas de depósitos ou alterações nas paredes (ver Figura 7), como redução em 10\% do diâmetro do vaso, obtém-se com procedimento similar ao anterior: $\tau_{w}=427 \mathrm{~Pa}$. 
Figura 7 - Vaso sanguíneo parcialmente obstruído.

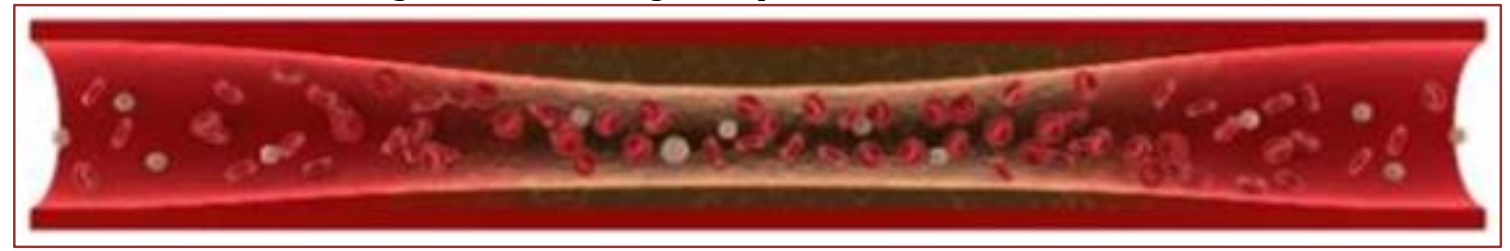

A Equação (9) possibilita obter: $v_{\text {máximo }}=0,97 \mathrm{~m} / \mathrm{s}$, e o uso da Equação 4 possibilita o cálculo da viscosidade aparente do sangue para a situação simulada, sendo: $\mu_{\text {aparente }}=4,90 \mathrm{mPa} \cdot \mathrm{s}$. Portanto: A viscosidade aparente irá diminuir, minimizando o efeito do aumento da tensão na parede do vaso sanguíneo.

\subsection{TRATAMENTO MATEMÁTICO DOS DADOS}

Na seção anterior, a avalição da tensão na parede foi efetuada considerando uma aproximação para a tangente à curva de escoamento do sangue na aorta. Contudo, o correto é obter a equação da velocidade de escoamento em função do raio e calcular o coeficiente angular para a parede da aorta.

Então, utilizando a Equação 9 para a posição radial a $25 \%$ da parede do tubo, tem-se: $R=0,00625 \mathrm{~m}$, e pode-se obter a velocidade do sangue naquela posição radial.

$$
u=\left[\frac{2608}{2 \cdot 18,0035 \cdot 0,05}\right]^{1 / 0,70705} \cdot \frac{0,70705}{1,70705}\left[0,125^{\frac{1,70705}{0,70705}}-0,00625^{\frac{1,70705}{0,70705}}\right]=0,25 \mathrm{~m} / \mathrm{s}
$$

Os resultados da velocidade em função da posição radial são mostrados na Tabela 1.

Tabela 1 - Perfil de velocidade do sangue no segmento de aorta.

\begin{tabular}{|c|c|c|c|c|c|}
$\begin{array}{c}\text { Velocidade do } \\
\text { sangue, } v(\mathrm{~m} / \mathrm{s})\end{array}$ & 0 & 0,25 & 0,75 & 0,25 & 0 \\
\hline $\begin{array}{c}\text { Posição radial, } r \\
(\mathrm{~m})\end{array}$ & $-0,0125$ & $-0,00625$ & 0 & 0,00625 & 0,0125 \\
\hline
\end{tabular}

O perfil de velocidade do sangue no segmento de aorta é mostrado na Figura 8. 
Figura 8 - Perfil de velocidade do sangue escoando no segmento de aorta.

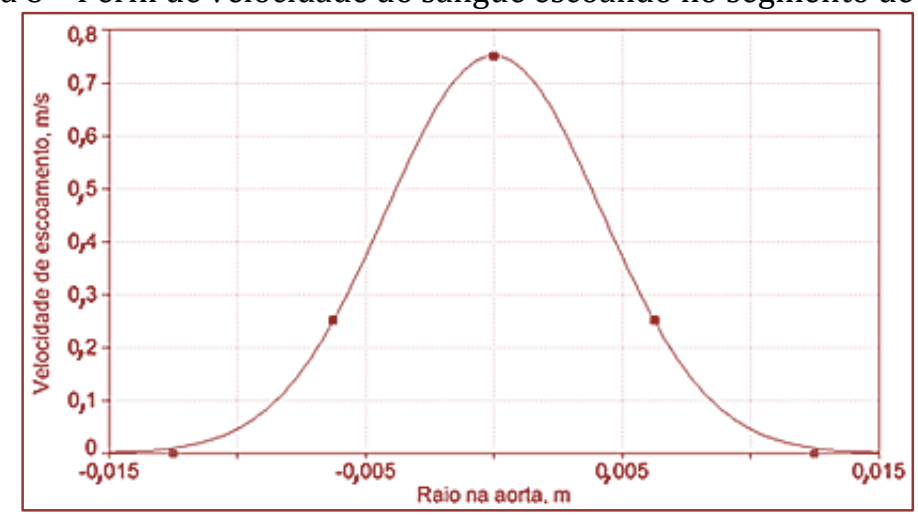

0 ajuste de uma equação matemática aos pontos do perfil de velocidade gerou a Equação (11).

$$
\ln v=-0,2877-28124 r^{2}
$$

Para obtenção da viscosidade aparente do sangue, necessita-se da grandeza do coeficiente angular da curva em $r=0$, ou seja, $\dot{\gamma}$. Portanto, segundo Abramowitz e Stegun (1972):

$$
\frac{d}{d r}\left(e^{u}\right)=e^{u}\left(\frac{u}{e} \cdot \frac{d e}{d r}+\ln e \cdot \frac{d u}{d r}\right) \quad \text { e }\left.\quad \frac{d}{d r}\left(e^{u}\right)\right|_{r=R}=e^{a+b \cdot R^{2}} \ln e \cdot 2 R \cdot b
$$

Substituindo os valores: $\left.\frac{d}{d r}\left(e^{u}\right)\right|_{r=R}=e^{-0,2877-281240,0125^{2}} \ln e \cdot 2 \cdot(-0,0125) \cdot(-28124)=6,54$

Substituindo na Equação (10):

$$
\mu_{\text {aparente }}=k \dot{\gamma}^{n-1}=18,0035 \cdot(6,54)^{-0,293}=10,4 \mathrm{mPas}
$$

A qual é 1,9 vezes maior do que a viscosidade aparente calculada com a sistemática simplificada na Seção 4 .

\section{CONCLUSÃO}

Este trabalho indica, fenomenologicamente, o comportamento do sangue ao escoar pela aorta e serve de subsídio para explicar, o porquê na ocorrência de obstruções parciais, a influência no escoamento é minimizada devido à diminuição da viscosidade do sangue ao aumentar a tensão de cisalhamento. A viscosidade aparente do sangue variou de 5,43 mPa.s para 4,90 mPa.s na ocorrência de $10 \%$ de obstrução do diâmetro do vaso, conforme tratamento simplificado. Ao utilizar o perfil de velocidade verdadeiro verifica-se que a viscosidade aparente é 1,9 vezes maior do que a viscosidade aparente calculada com a sistemática simplificada. Apesar da proteção fenomenológica devido ao comportamento reológico do sangue, coágulos devido a doenças e aumento de glóbulos vermelhos nas condições que exigem mais oxigênio atuam no sentido de atenuar o efeito defensivo automático e influências externas expressivas devem, então, ser eliminadas, além disso, não exagerar em atividades que exigem muito oxigênio. 


\section{AGRADECIMENTOS}

Os autores agradecem à Uniube (Universidade de Uberaba) e à Fundação de Amparo a Pesquisa do Esta do de Minas Gerais - FAPEMIG pelo apoio disponibilizado para realização desta publicação.

\section{REFERÊNCIAS}

[1] ABRAMOWITZ, M.; STEGUN, I. Handbook of mathematical functions. New York: Dover Publications. 1964. $1046 \mathrm{p}$.

[2] BBC. Nobel de Medicina: Cómo las células perciben el oxígeno, la investigación por la que William Kaelin, Peter Ratcliffe y Gregg Semenza ganaron el premio. Redacción BBC News Mundo. 7 outubro. 2019.

[3] BIRD, R.B., STEWART, W. E, e LIGHTFOOT, E .N. Fenômenos de Transporte, 2ª edição, Rio de janeiro: LTC, 2004. 838 p.

[4] FRAIHA, M., BIAGI, J. D., FERRAZ, A. C. O., SVERZUT, C. Projeto e construção de reômetro capilar para caracterização de alimentos para animais. Ciência Rural, v.40, n.9, p.1998-2004, 2010.

[5] GILMAN, N. V. Analyses of the 2019 Nobel Prize in physiology or medicine: molecular machinery for cellular oxygen level response. Science \& Technology Libraries. v.39, n.1, p. 1-27. 2020.

[6] HOWES, L, SATYANARAYANA, M. Three researchers who uncovered how cells respond to oxygen awarded 2019 Nobel Prize in Physiology or Medicine. Chemical \& Engineering News. 7 october. 2019.

[7] PEREIRA, M. G., J. R. D. FINZER, R. A. MALAGONI. Avaliação reológica do escoamento do sangue. Brazilian Journal of Development. V.5,. N.4, P.3042-3050, 2019.

[8] ROSSINI, M.C. Covid-19 nem todos os pacientes com os pulmões seriamente comprometidos sentem falta de ar. Super Interessante. 5 junho. 2020.

[9] SANTOS, N. A. A. Estudo da reologia de fluidos análogos ao sangue. Porto: Universidade do Porto. Fundação para a Ciência e Tecnologia (FCT), 2009. 85 p.

[10] SKELLAND, A. H. P. Non-newtonian flow and heat transfer. New York: John Wiley. 1967. 469 p.

[11] SUTERA, S. P.; SKALAK, R. The history of Poiseuille's law. Annu. Rev. Fluid Mech., v. 25, p. 1-19, 1993.

[12] WATANABE, P. Nobel de medicina vai para estudos sobre células e oxigênio. Folha de São Paulo: Ciência. 8 outubro. 2019.

[13] ZORZETTO, R. Uma doençã assustadora. Pesquisa FAPESP. v.21, n.291. p. 21-24. 


\section{Capítulo 6}

\section{Avaliação dos compósitos $\mathrm{CuFe}_{2} \mathrm{O}_{4} / \mathrm{Bioch} a r$ e $\mathrm{ZnFe}_{2} \mathrm{O}_{4} /$ Biochar na degradação de rodamina $B$ via processo foto-Fenton}

\section{Jandira Leichtweis \\ Nicoly Welter \\ Siara Silvestri \\ Yasmin Vieira \\ Bruna Machado Sanini \\ Elvis Carissimi}

Resumo: Nesse estudo, ferritas $\mathrm{CuFe}_{2} \mathrm{O}_{4}$ e $\mathrm{ZnFe}_{2} \mathrm{O}_{4}$ foram suportadas em biochar para utilização como fotocatalisadores aprimorados no processo foto-Fenton, visando a degradação do corante rodamina B. As amostras preparadas foram caracterizadas por difração de raios-X, microscopia eletrônica de varredura acoplada a analisador por energia dispersiva e espectroscopia de reflectância difusa na faixa do ultravioleta e visível. Todas as caracterizações demonstraram que ambas ferritas foram suportadas uniformemente na superfície do biochar, confirmando a formação dos compósitos. Os testes de degradação iniciais demonstraram que $\mathrm{CuFe}_{2} \mathrm{O}_{4}$ e $\mathrm{ZnFe}_{2} \mathrm{O}_{4}$ puras degradaram aproximadamente 35 e 21\% do corante rodamina B após 60 minutos de reação. Enquanto isso, os compósitos $\mathrm{CuFe}_{2} \mathrm{O}_{4}$ /biochar e $\mathrm{ZnFe}_{2} \mathrm{O}_{4}$ /biochar promoveram um significativo aumento na degradação do corante, 87 e $85 \%$ respectivamente. Esse aumento na eficiência de degradação está atrelado a menor energia de band gap dos compósitos em relação as ferritas puras, resultando em menor recombinação dos pares elétron/lacuna. Dessa forma, os resultados evidenciam que os compósitos fotocatalisadores produzidos são uma alternativa eficaz para remoção de poluentes orgânicos em águas residuais.

Palavras-Chave: Resíduo de biomassa, biochar, ferrita, compósito, poluente orgânico. 


\section{INTRODUÇÃO}

Para a sobrevivência da humanidade, é de suma importância que as águas sejam protegidas. 0 rápido desenvolvimento da indústria aprimorou a forma de vida da população, entretanto, também é a causa de poluição das águas (HUANG et al., 2020). As águas residuais descarregadas pelas indústrias têxtil, de impressão e tingimento são uma das principais fontes de poluição da água com corantes. Como resultado disso, a existência de corantes no ecossistema é bem aparente, afetando o sistema de fotossíntese (GUO et al., 2020; OUACHTAK et al., 2020).

Dentre os poluentes em efluentes lançados pela indústria têxtil está a rodamina B, pertencente a classe dos xantenos. A rodamina B é um corante catiônico altamente solúvel em água, amplamente utilizado em tintas, têxteis, papel, indústrias de couro e processamento de alimentos e pedras semi-preciosas (LIN; LIN, 2017). Entretanto, a água residual contendo rodamina B pode apresentar cor esteticamente desagradável, sendo visível mesmo em baixa concentração, elevada toxicidade crônica, neurotoxicidade e carcinogenicidade para seres humanos, animais e vida aquática (TARIQ et al., 2020; ZHANG et al., 2020; ZHOU et al., 2019).

Existem diversos métodos para extrair corantes orgânicos de águas residuais, como adsorção (XIAO et al., 2020), biossorção (SELVAKUMAR; RANGABHASHIYAM, 2019), reator biológico (YANG et al., 2020), fotocatálise (HEIDARPOUR et al., 2020), eletro-Fenton (ZHANG et al., 2020), foto-Fenton (VAN VIET et al., 2020) entre outros. Dentre esses processos, podemos destacar os processos de oxidação avançada (POA), que são uma série de tecnologias alternativas emergentes para a remoção de contaminantes orgânicos, devido à formação de radicais altamente reativos e não seletivos. Uma das espécies características geradas nos POAs é o radical hidroxila $\left(\bullet \mathrm{OH}, \mathrm{E}_{0}=2,7 \mathrm{~V}\right)$, que pode efetivamente degradar, e até mesmo mineralizar, vários corantes orgânicos (VAN VIET et al., 2020; ZHOU et al., 2019).

Entre os POAs, o processo foto-Fenton (PFF) tem sido objeto de diversos estudos, baseando-se na produção de radicais $\bullet \mathrm{OH}$ pela combinação simultânea de $\mathrm{H}_{2} \mathrm{O}_{2}$, fotocatalisador a base de ferro, $\mathrm{pH}$ próximo a 2,8 e uma fonte de irradiação UV-vis (BORBA et al., 2019). Estudos recentes destacam as ferritas como bons fotocatalisadores do PFF sob luz visível, devido à sua excelente propriedade magnética, estabilidade química e reduzida energia de band gap (WANG et al., 2020b; LAI et al., 2019; WANG et al., 2019). Com base nessas características mencionadas, as ferritas tem potencial para ser um bom fotocatalisador, no entanto, por si só, sua eficiência fotocatalítica não é muito alta, devido a rápida recombinação dos pares eletrônicos elétron/lacuna fotogerados. Devido a isso, muitos pesquisadores vem estudando o suporte de fotocatalisadores em diferentes materiais para formar um compósito capaz de reduzir a recombinação e a energia de band gap (LEICHTWEIS; SILVESTRI; CARISSIMI, 2020; NAWAZ et al., 2020).

Recentemente, a biomassa pirolisada, conhecida como biochar, tem despertado o interesse entre os pesquisadores por seu baixo custo, ampla disponibilidade e abundantes grupos funcionais de superfície que podem promover o efeito catalítico (LAI et al., 2019). Sendo assim, o objetivo desse estudo foi suportar as ferritas de cobre e zinco $\left(\mathrm{CuFe}_{2} \mathrm{O}_{4}\right.$ e $\mathrm{ZnFe}_{2} \mathrm{O}_{4}$, respectivamente) em biochar, caracterizar os compósitos formados e aplicar o PFF para remover o corante rodamina B de águas residuais.

\section{METODOLOGIA}

Os compósitos foram sintetizados pelo método sol-gel. Inicialmente, foi adicionado 2,02 g de nitrato de ferro a $25 \mathrm{~mL}$ de água destilada e $0,604 \mathrm{~g}$ de nitrato de cobre ou de zinco a $25 \mathrm{~mL}$ de água destilada. Em seguida, as soluções foram misturadas com o auxílio de um agitador magnético e foi adicionado $1,458 \mathrm{~g}$ de biochar na mistura. 0 pH foi ajustado para 11-12 com o auxílio de uma solução de hidróxido de sódio (6 M). A solução foi mantida a uma temperatura de reação de $80{ }^{\circ} \mathrm{C}$ durante uma hora e o produto foi arrefecido até à temperatura ambiente. Em seguida, o precipitado foi lavado com água destilada para remover qualquer átomo de impureza e posteriormente seco a $100{ }^{\circ} \mathrm{C}$ e por fim foi moído manualmente para romper os aglomerados. A razão final do compósito obtido foi $\mathrm{CuFe}_{2} \mathrm{O}_{4} /$ Biochar (1:3) e $\mathrm{ZnFe}_{2} \mathrm{O}_{4} /$ Biochar (1:3).

A estrutura cristalina das amostras foi caracterizada por difração de raios-X (DRX) (Difratômetro Rigaku Miniflex 300) utilizando radiação $\mathrm{Cu}-\mathrm{K} \alpha$ a $30 \mathrm{kV}$ e $10 \mathrm{~mA}$, com passo (20) de $0.03^{\circ}$ e um tempo de contagem de $0.3 \mathrm{~s}$ por passo. A análise morfológica dos compósitos foi verificada por microscopia eletrônica de varredura (MEV) utilizando JEOL JSM 7600F com resolução máxima de $5 \mathrm{~nm}$ e operando com uma faixa de tensão de aceleração entre 1-30 kV. Paralelamente à análise morfológica, foi realizada uma análise semiquantitativa da Espectroscopia de Energia Dispersiva (EDS) em diferentes regiões das 
amostras. Os espectros foram obtidos sob condições de vácuo com uma resolução de 137 eV pelo método Synthetic Aperture Focusing Technique (SAFT), usando um sensor OXFORD INCAX-ACT acoplado ao microscópio eletrônico de varredura. Os espectros de absorbância das amostras foram determinados utilizando um 5000 UV-Vis-NIR espectrofotômetro (Varian). A energia de band gap (Eg) das amostras foi calculada pela relação de Tauc através de espectros de reflectância difusa obtidos por espectrofotômetro UV-Vis (Shimadzu).

Foi preparada uma solução de corante de rodamina B em água destilada numa concentração de $10 \mathrm{mg} \mathrm{L}^{-1} \mathrm{e}$ $0 \mathrm{pH}$ da solução foi ajustado para 3. Adicionou-se $1 \mathrm{~g} \mathrm{~L} \mathrm{~L}^{-1}$ do catalisador $\left(\mathrm{CuFe}_{2} \mathrm{O}_{4}, \mathrm{ZnFe}_{2} \mathrm{O}_{4}\right.$, $\mathrm{CuFe}_{2} \mathrm{O}_{4}$ /biochar ou $\mathrm{ZnFe}_{2} \mathrm{O}_{4}$ /biochar) individualmente em $100 \mathrm{~mL}$ de solução. Em seguida, a solução foi agitada magneticamente na ausência de luz para atingir o equilíbrio de adsorção entre corante e catalisador. 0 equilíbrio de adsorção foi obtido quando 3 leituras consecutivas de absorbância coincidiram e se mantiveram constantes com o passar do tempo. 0 equilíbrio foi atingido após 30 min de contato. 0 ponto inicial da reação corresponde ao ponto em que a solução atingiu o equilíbrio de adsorção. Por fim, a reação foi iniciada com a adição de $50 \mu \mathrm{L}$ de $\mathrm{H}_{2} \mathrm{O}_{2}\left(5.0 \times 10^{-5} \mathrm{~mol} \mathrm{~L}^{-1}\right)$ exposta a irradiação da lâmpada, que já estava acesa (por $30 \mathrm{~min}$ ) afim de estabilizar sua intensidade. A intensidade da irradiação que atinge a solução foi medida no início e no final de cada experimento com um luxímetro digital portátil. Os valores medidos mantiveram-se estáveis em $120 \pm 3 \mathrm{~W} \mathrm{~m}{ }^{-2}$. A redução da cor da solução foi medida em espectrômetro UV-Vis no comprimento de onda de absorção máxima da rodamina $\mathrm{B}(\lambda=554 \mathrm{~nm})$. As alíquotas foram coletadas periodicamente a cada 10 minutos por 60 minutos e centrifugadas. Todos os testes foram realizados em triplicata para garantir a reprodutibilidade dos dados experimentais.

\section{RESULTADOS E DISCUSSÃO}

A Fig. 1 mostra os espectros de DRX das amostras. 0 biochar apresentou uma banda típica de material carbonáceo em torno de $2 \theta=26^{\circ}$ (WANG et al., 2020a). A CuFe $\mathrm{O}_{4}$ apresentou todos os picos relatados em estudos anteriores. Os picos de difração em $2 \theta=29,9^{\circ}, 35,6^{\circ}, 38,9^{\circ}, 43,7^{\circ}, 57,7^{\circ}$ e $62,2^{\circ}$ correspondem aos planos cristalográficos (200), (211), (202), (220), (321) e (224), respectivamente (SARAVANAKUMAR et al., 2019). $\mathrm{O}$ compósito $\mathrm{CuFe}_{2} \mathrm{O}_{4}$ /biochar apresentou os principais picos da $\mathrm{CuFe}_{2} \mathrm{O}_{4}$ e os demais não estão visíveis provavelmente devido ao seu suporte no biochar. A $\mathrm{ZnFe}_{2} \mathrm{O}_{4}$ apresentou todos os picos característicos de acordo com o padrão JCPDS no 22-1012, sendo que os picos localizados em $2 \theta=29,9^{\circ}$, $35,3^{\circ}, 42,8^{\circ}, 56,7^{\circ}$ e $62,2^{\circ}$ correspondem aos planos (220), (311), (400), (511) e (440) (ZHU et al., 2020). $\mathrm{O}$ compósito $\mathrm{ZnFe}_{2} \mathrm{O}_{4}$ /biochar apresentou os picos referentes a $\mathrm{ZnFe}_{2} \mathrm{O}_{4}$, contudo com menor intensidade, devido ao suporte no biochar.

Fig. 1 - Difratogramas do biochar, $\mathrm{CuFe}_{2} \mathrm{O}_{4}, \mathrm{CuFe}_{2} \mathrm{O}_{4}$ /biochar, $\mathrm{ZnFe}_{2} \mathrm{O}_{4}$ e $\mathrm{ZnFe}_{2} \mathrm{O}_{4}$ /biochar.

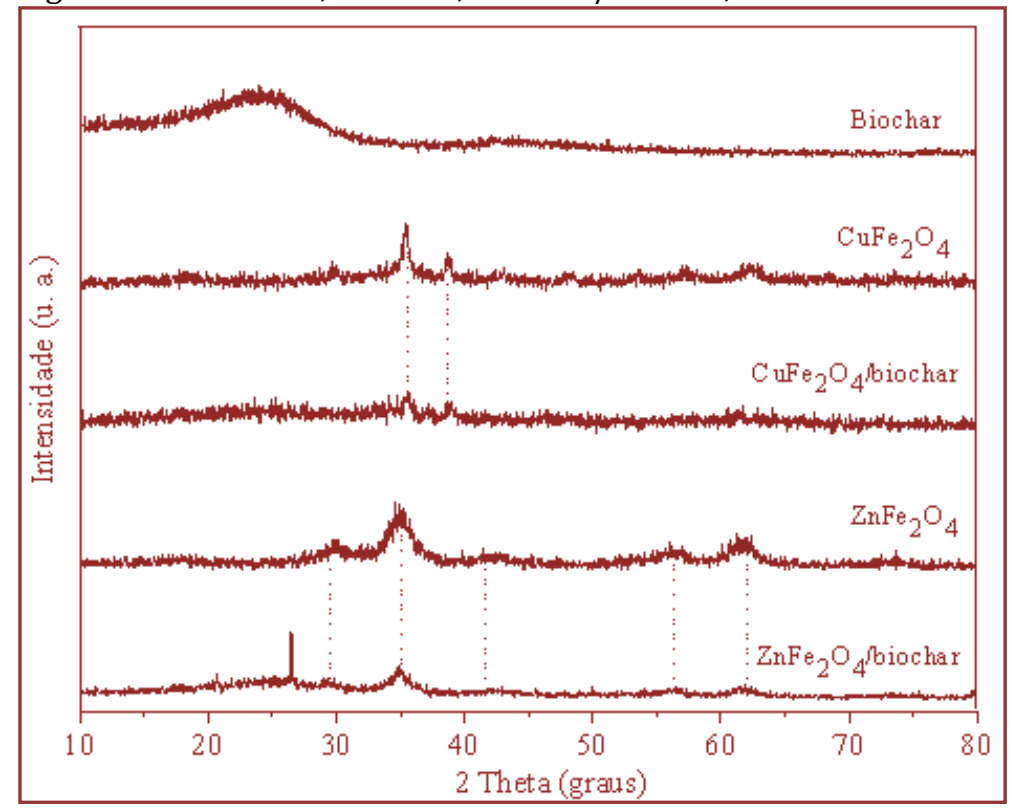

As morfologias dos fotocatalisadores foram identificadas por MEV e podem ser observadas na Fig. 2 . 0 biochar apresentou uma estrutura irregular e porosa, típica desse tipo de material (ver Fig. 2 (a)) (PI et al., 2019). $\mathrm{A} \mathrm{CuFe}_{2} \mathrm{O}_{4}$ e a $\mathrm{ZnFe}_{2} \mathrm{O}_{4}$ apresentaram nanopartículas aglomeradas devido as suas propriedades 
magnéticas (ver Fig. 2 (b e d)). (ATACAN, 2019; ATACAN; TOPALOĞLU; ÖZACAR, 2018) Nas Fig. 2 (c) e (e) fica evidente que as partículas de $\mathrm{CuFe}_{2} \mathrm{O}_{4}$ e $\mathrm{ZnFe}_{2} \mathrm{O}_{4}$ foram uniformemente suportadas com sucesso na superfície do biochar confirmando a formação dos compósitos.

Fig. 2 - Micrografias de (a) biochar, (b) $\mathrm{CuFe}_{2} \mathrm{O}_{4}$, (c) $\mathrm{CuFe}_{2} \mathrm{O}_{4}$ /biochar, (d) $\mathrm{ZnFe}_{2} \mathrm{O}_{4}$ e (e) $\mathrm{ZnFe}_{2} \mathrm{O}_{4} /$ biochar.

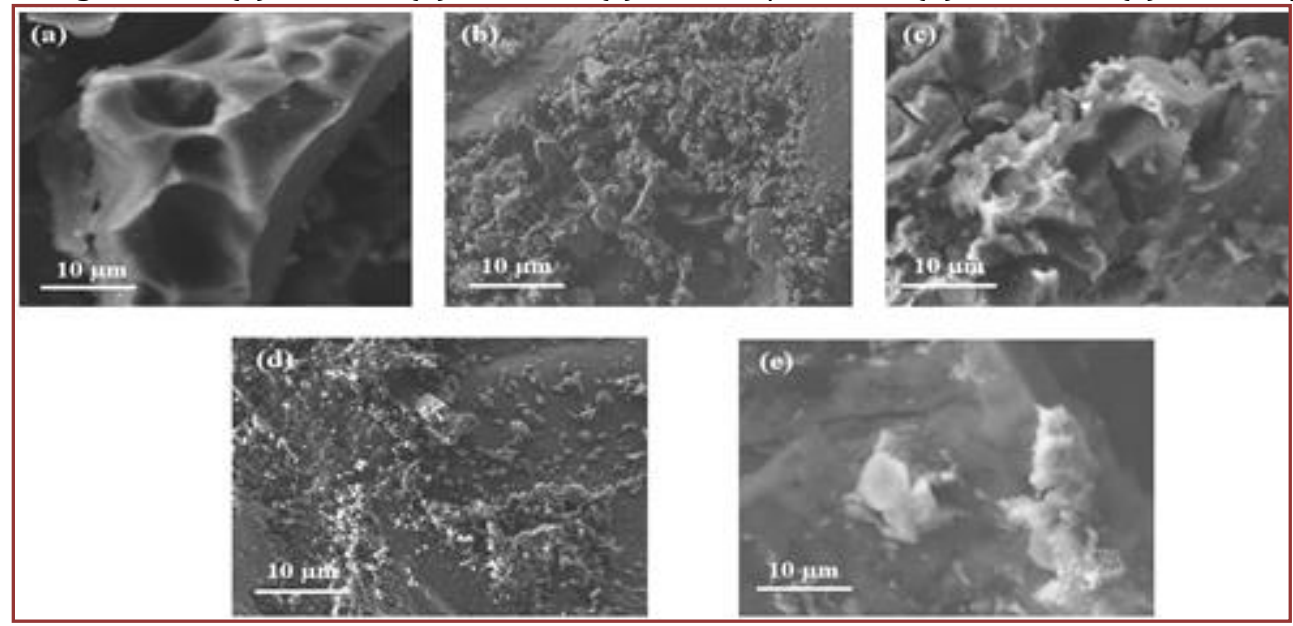

As composições elementares do biochar, da $\mathrm{CuFe}_{2} \mathrm{O}_{4}, \mathrm{CuFe}_{2} \mathrm{O}_{4} /$ biochar, da $\mathrm{ZnFe}_{2} \mathrm{O}_{4}$ e $\mathrm{ZnFe}_{2} \mathrm{O}_{4} /$ biochar foram definidas pela análise EDS. É possível observar na Tabela 1 que na formação dos compósitos, as massas atômicas (\%) de $\mathrm{O}, \mathrm{Fe}, \mathrm{Cu}$ ou $\mathrm{Zn}$ variaram e apareceu ainda, \% de massa atômica de $\mathrm{C}$ (correspondente ao biochar), o que demonstra que tanto a $\mathrm{CuFe}_{2} \mathrm{O}_{4}$, a $\mathrm{ZnFe}_{2} \mathrm{O}_{4}$, quanto o biochar contribuem para a formação dos compósitos fotocatalisadores. Esses resultados corroboram com os resultados do DRX e MEV.

Tabela 1 - Análise de EDS do biochar, $\mathrm{CuFe}_{2} \mathrm{O}_{4}, \mathrm{CuFe}_{2} \mathrm{O}_{4}$ /biochar, $\mathrm{ZnFe}_{2} \mathrm{O}_{4}$ e $\mathrm{ZnFe}_{2} \mathrm{O}_{4}$ /biochar.

\begin{tabular}{|c|c|c|c|c|c|}
\multicolumn{2}{c}{ Amostras } & \multicolumn{5}{c|}{ Massa atômica $(\%)$} \\
\hline Biochar & 69,18 & 30,82 & - & - & - \\
\hline $\mathrm{CuFe}_{2} \mathrm{O}_{4}$ & - & 63,35 & 19,51 & 17,15 & - \\
\hline $\mathrm{CuFe}_{2} \mathrm{O}_{4} /$ biochar & 38.93 & 35,13 & 20,01 & 5,92 & - \\
\hline $\mathrm{ZnFe}_{2} \mathrm{O}_{4}$ & - & 71,28 & 12,91 & - & 15,81 \\
\hline $\mathrm{ZnFe}_{2} \mathrm{O}_{4} /$ biochar & 67.69 & 23,59 & 5,95 & - & 2,77 \\
\hline
\end{tabular}

Na Tabela 2 é possível verificar os valores de energia de band gap. Os compósitos apresentam uma inferior energia de band gap em relação as ferritas puras, fato que confere ao biochar uma redução na energia necessária para gerar o par elétron/lacuna (LEICHTWEIS; SILVESTRI; CARISSIMI, 2020). Este fato está diretamente relacionado a presença grupos funcionais de superfície e dos átomos de carbono do biochar.

Tabela 2 - Espectros de absorbância das amostras $\mathrm{CuFe}_{2} \mathrm{O}_{4}, \mathrm{CuFe}_{2} \mathrm{O}_{4} /$ biochar, $\mathrm{ZnFe}_{2} \mathrm{O}_{4}$ e $\mathrm{ZnFe}_{2} \mathrm{O}_{4} /$ biochar.

\begin{tabular}{|c|c|}
\hline \multicolumn{1}{|c|}{$\mathrm{Amostras}$} & Band gap $(\mathrm{eV})$ \\
\hline $\mathrm{CuFe}_{2} \mathrm{O}_{4}$ & 1,39 \\
\hline $\mathrm{CuFe}_{2} \mathrm{O}_{4} /$ biochar & 1,23 \\
\hline $\mathrm{ZnFe}_{2} \mathrm{O}_{4}$ & 1,67 \\
\hline $\mathrm{ZnFe}_{2} \mathrm{O}_{4} /$ biochar & 1,26 \\
\hline
\end{tabular}

A Fig. 3 apresenta a degradação do corante rodamina B, onde observa-se que por fotólise, a degradação do corante foi insignificante. $\mathrm{A} \mathrm{CuFe}_{2} \mathrm{O}_{4}$ e a $\mathrm{ZnFe}_{2} \mathrm{O}_{4}$ puras degradaram cerca de 38 e $21 \%$ do corante rodamina B após 60 minutos de PFF. Por outro lado, os compósitos $\mathrm{CuFe}_{2} \mathrm{O}_{4}$ /biochar e $\mathrm{ZnFe}_{2} \mathrm{O}_{4} /$ biochar degradaram 87 e $85 \%$ do corante em 60 minutos de PFF, respectivamente. Esse aumento na eficiência de remoção está atrelado ao fato dos compósitos apresentarem menor energia de band gap em relação as ferritas puras (ver Tabela 2) e ainda, devido ao suporte das ferritas no biochar proporcionar a diminuição da recombinação entre os pares elétron/lacuna (LEICHTWEIS; SILVESTRI; CARISSIMI, 2020). 
Fig. 3 - Degradação do corante rodamina B, condições experimentais: Luz visível, pH 3, $50 \mu \mathrm{L} \mathrm{de} \mathrm{H}_{2} \mathrm{O}_{2}, 1 \mathrm{~g}$ $\mathrm{L}^{-1}$ de catalisador, e $10 \mathrm{mg} \mathrm{L}^{-1}$ de rodamina $\mathrm{B}(100 \mathrm{~mL})$.

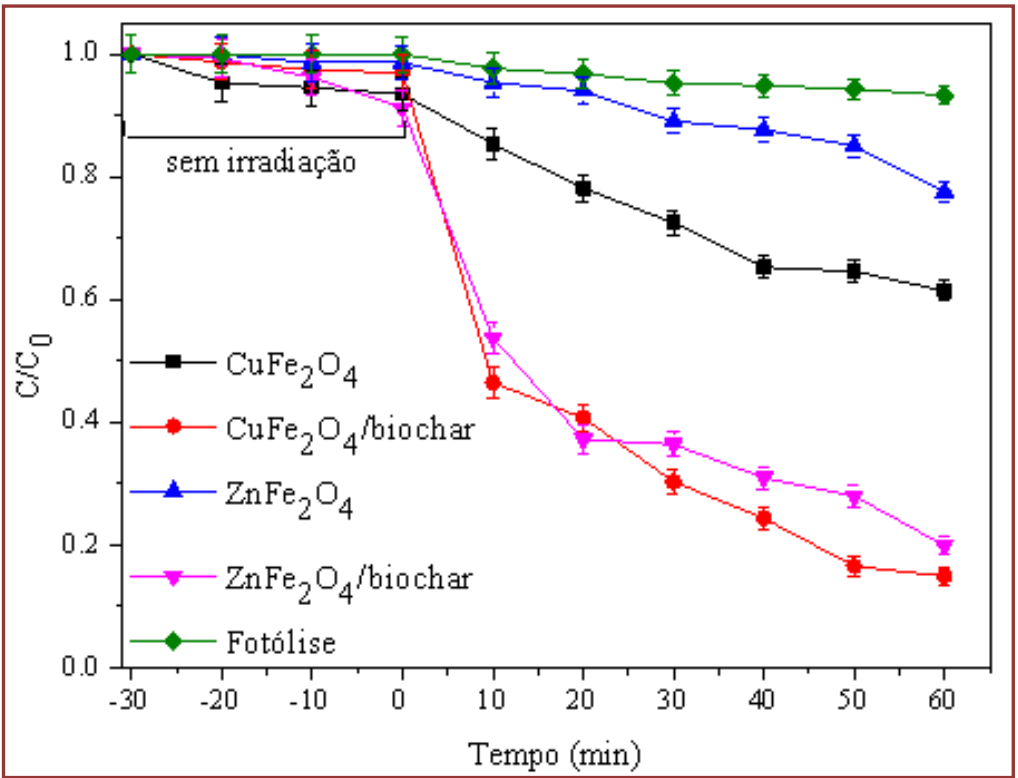

A constante de velocidade da reação PFF de degradação da rodamina $\mathrm{B}$ com $\mathrm{CuFe}_{2} \mathrm{O}_{4} /$ biochar foi ligeiramente superior em relação ao $\mathrm{ZnFe}_{2} \mathrm{O}_{4}$ /biochar (Fig. 4). Sendo as ferritas muito semelhantes em diversas características físico-químicas, ambas com estrutura cristalina tipo espinélio, grupo espacial fd3m, ambos íons metálicos com carga $2+\left(\mathrm{Cu}^{2+}\right.$ e $\left.\mathrm{Zn}^{2+}\right)$, o que as difere é uma pequena variação no comprimento da ligação metal-oxigênio, Cu-O (0,57 ̊̊) e Zn-O (0,58 Å). Onde um menor comprimento de ligação, ou seja, onde os átomos estão mais próximos, o processo de transferência de carga no compósito é facilitado, fato que favorece as reações foto-Fenton.

Fig. 4 - Cinética de degradação do corante rodamina B, condições experimentais: Luz visível, pH 3, $50 \mu \mathrm{L}$ de $\mathrm{H}_{2} \mathrm{O}_{2}, 1 \mathrm{~g} \mathrm{~L}^{-1}$ de catalisador, e $10 \mathrm{mg} \mathrm{L}^{-1}$ de rodamina $\mathrm{B}(100 \mathrm{~mL})$.

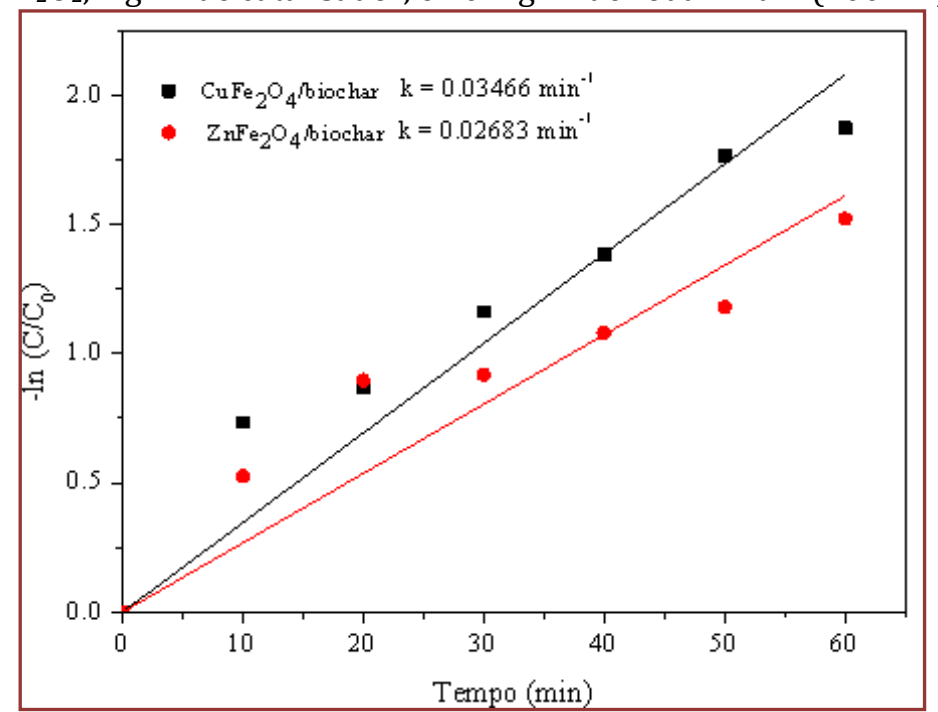




\section{CONCLUSÕES}

As caracterizações comprovaram que as ferritas $\mathrm{CuFe}_{2} \mathrm{O}_{4}$ e $\mathrm{ZnFe}_{2} \mathrm{O}_{4}$ foram distribuídas uniformemente na superfície do biochar, confirmando a formação do compósito. Os testes de degradação via PFF demonstraram que as ferritas puras degradaram cerca de 38 e $21 \%\left(\mathrm{CuFe}_{2} \mathrm{O}_{4}\right.$ e $\mathrm{ZnFe}_{2} \mathrm{O}_{4}$, respectivamente) do corante rodamina B após 60 minutos de PFF. Por outro lado, após a formação do compósito, houve um significativo aumento na degradação do corante. A $\mathrm{CuFe}_{2} \mathrm{O}_{4}$ /biochar degradou $87 \%$ e a $\mathrm{ZnFe}_{2} \mathrm{O}_{4}$ /biochar degradou $85 \%$ do corante rodamina B em 60 minutos de PFF. Esse significativo aumento da eficiência pode estar relacionado a menor energia de band gap dos compósitos em comparação as ferritas puras e da diminuição recombinação dos pares elétron/lacuna devido a presença do biochar. Em relação aos compósitos, o $\mathrm{CuFe}_{2} \mathrm{O}_{4}$ /biochar foi ligeiramente superior na degradação do corante devido a uma maior aproximação dos átomos na estrutura do compósito.

\section{AGRADECIMENTOS}

Os autores agradecem o apoio financeiro concedido pela CAPES, Bolsista CAPES/BRASIL no 88882.427561/2019-01 e no 88887.492412/2020-00, e, ao auxílio financeiro do Projeto Swindon-Exceed (No.: 57521339) apoiado pelo DAAD (Governo da Alemanha).

\section{REFERÊNCIAS}

[1] ATACAN, $\mathrm{K} . ~ \mathrm{CuFe}_{2} \mathrm{O}_{4} /$ reduced graphene oxide nanocomposite decorated with gold nanoparticles as a new electrochemical sensor material for L-cysteine detection. Journal of Alloys and Compounds, v. 791, p. 391-401, 30 jun. 2019.

[2] ATACAN, K.; TOPALOĞLU, B.; ÖZACAR, M. New CuFe204/amorphous manganese oxide nanocomposites used as photocatalysts in photoelectrochemical water splitting. Applied Catalysis A: General, v. 564, p. 33-42, 25 ago. 2018.

[3] BORBA, F. H. et al. Pollutant removal and acute toxicity assessment (Artemia salina) of landfill leachate treated by photo-Fenton process mediated by oxalic acid. Journal of Water Process Engineering, v. 28, p. 159-168, 1 abr. 2019.

[4] GUO, N. et al. Preparation of Fe203 nanoparticles doped with In203 and photocatalytic degradation property for rhodamine B. Optik, v. 201, p. 163537, 1 jan. 2020.

[5] HEIDARPOUR, $H$. et al. Enhanced decolorization of rhodamine B solution through simultaneous photocatalysis and persulfate activation over Fe/C3N4 photocatalyst. Chemical Engineering Research and Design, v. 153, p. 709-720, 1 jan. 2020.

[6] HUANG, M. et al. Preparation of three-dimensional flower-like Fe- $\mathrm{Bi}(\mathrm{OH}) 3$ nanocomposites and the photocatalytic properties for degradation of Rhodamine B in presence of visible light. Optik, v. 216, p. 164876, 1 ago. 2020 .

[7] LAI, C. et al. Fabrication of novel magnetic MnFe204/bio-char composite and heterogeneous photo-Fenton degradation of tetracycline in near neutral pH. Chemosphere, v. 224, p. 910-921, 1 jun. 2019.

[8] LEICHTWEIS, J.; SILVESTRI, S.; CARISSIMI, E. New composite of pecan nutshells biochar-ZnO for sequential removal of acid red 97 by adsorption and photocatalysis. Biomass and Bioenergy, v. 140, p. 105648, 1 set. 2020.

[9] LIN, K.-Y. A.; LIN, J.-T. Ferrocene-functionalized graphitic carbon nitride as an enhanced heterogeneous catalyst of Fenton reaction for degradation of Rhodamine B under visible light irradiation. Chemosphere, v. 182, p. 5464, 1 set. 2017.

[10] NAWAZ, M. et al. Photo-Fenton reaction for the degradation of sulfamethoxazole using a multi-walled carbon nanotube-NiFe2O4 composite. Chemical Engineering Journal, v. 382, p. 123053, 15 fev. 2020.

[11] OUACHTAK, $\mathrm{H}$. et al. Experimental and molecular dynamics simulation study on the adsorption of Rhodamine B dye on magnetic montmorillonite composite $\gamma$-Fe203@Mt. Journal of Molecular Liquids, v. 309, p. 113142, 1 jul. 2020. 
[12] PI, Z. et al. Persulfate activation by oxidation biochar supported magnetite particles for tetracycline removal: Performance and degradation pathway. Journal of Cleaner Production, v. 235, p. 1103-1115, 20 out. 2019.

[13] SARAVANAKUMAR, B. et al. Electrochemical performances of monodispersed spherical CuFe204 nanoparticles for pseudocapacitive applications. Vacuum, v. 168, p. 108798, 1 out. 2019.

[14] SELVAKUMAR, A.; RANGABHASHIYAM, S. Biosorption of Rhodamine B onto novel biosorbents from Kappaphycus alvarezii, Gracilaria salicornia and Gracilaria edulis. Environmental Pollution, v. 255, p. 113291, 1 dez. 2019.

[15] TARIQ, M. et al. Removal of Rhodamine B dye from aqueous solutions using photo-Fenton processes and novel Ni-Cu@MWCNTs photocatalyst. Journal of Molecular Liquids, v. 312, p. 113399, 15 ago. 2020.

[16] VAN VIET, P. et al. Visible-light-induced photo-Fenton degradation of rhodamine B over Fe203-diatomite materials. Journal of Science: Advanced Materials and Devices, 27 jul. 2020.

[17] WANG, K. et al. Aqueous $\mathrm{Cr}(\mathrm{VI})$ removal by a novel ball milled Fe0-biochar composite: Role of biochar electron transfer capacity under high pyrolysis temperature. Chemosphere, v. 241, p. 125044, 1 fev. 2020 a.

[18] WANG, T. et al. An integration of photo-Fenton and membrane process for water treatment by a PVDF@CuFe204 catalytic membrane. Journal of Membrane Science, v. 572, p. 419-427, 15 fev. 2019.

[19] WANG, X. et al. Pt enhanced the photo-Fenton activity of ZnFe204/ $\alpha$-Fe203 heterostructure synthesized via one-step hydrothermal method. Journal of Colloid and Interface Science, v. 561, p. 793-800, 1 mar. $2020 \mathrm{~b}$.

[20] XIAO, W. et al. Preparation and evaluation of an effective activated carbon from white sugar for the adsorption of rhodamine B dye. Journal of Cleaner Production, v. 253, p. 119989, 20 abr. 2020.

[21] YANG, S. et al. Enhancement on the removal of Rhodamine B (RhB) by means of the Enlarged Anode Electric Biological (EAEB) reactor. Chemosphere, v. 245, p. 125566, 1 abr. 2020.

[22] ZHANG, Y. et al. Kinetic study of the degradation of rhodamine B using a flow-through UV/electro-Fenton process with the presence of ethylenediaminetetraacetic acid. Chemosphere, v. 240, p. 124929, 1 fev. 2020.

[23] ZHOU, P. et al. Removal of Rhodamine B during the corrosion of zero valent tungsten via a tungsten speciescatalyzed Fenton-like system. Journal of the Taiwan Institute of Chemical Engineers, v. 100, p. 202-209, 1 jul. 2019.

[24] ZHU, J. et al. Ionic liquid assisted multi-heteroatom doping in core-shell ZnFe204@rG0 with highly reversible lithiation/delithiation kinetics. Journal of Alloys and Compounds, p. 156593, 1 ago. 2020. 


\section{Capítulo 7}

\section{Síntese de chalconas}

\section{Heriberto Rodrigues Bitencourt}

Andrey Moacir do Rosario Marinho

Antonio Pedro da Silva Souza Filho

José Ciríaco Pinheiro

Maria das Graças Cardoso Tavares

Ossalin de Almeida

Rômulo Augusto Feio Farias

Resumo: As chalconas são substâncias pertencentes a classe dos flavonoides, são bastante estudadas tanto do ponto de vista químico como do ponto de vista biológico, possuem várias atividades, tais como, anticancerígena, anti-inflamatória, leishmanicida e outras. Neste trabalho, relata-se a síntese e a caracterização de duas chalconas: 2hidróxi-chalcona (acetofenona condensando com 2-hidróxi-benzaldeído) e chalcona (acetofenona condensando com benzaldeído), utilizando a reação de condensação de Claisen-Schmidt, com rendimento de 55,3\% e 55,7\%, respectivamente, sendo identificadas utilizando RMN, IV e a Espectrometria de massas.

Palavras-Chave: Chalconas; Reação de Condensação; Síntese Orgânica. 


\section{INTRODUÇ̃̃OO}

As chalconas são quimicamente definidas como cetonas $\alpha, \beta$-insaturadas (enonas), com o esqueleto 1,3diaril-prop-2-en-1-ona, pertencentes a classe dos flavonoides (Figura 1), como uma de suas subclasses, consideradas como intermediárias essenciais, tanto na biossíntese como na síntese. Diferentemente dos flavonoides as chalconas não possuem o anel pirânico, que é formado pela ciclização da hidroxila localizada na posição 2 ' das chalconas (NAKANISHI et al., 1975).

Figura 1 - Estrutura química da classe dos flavonóides.

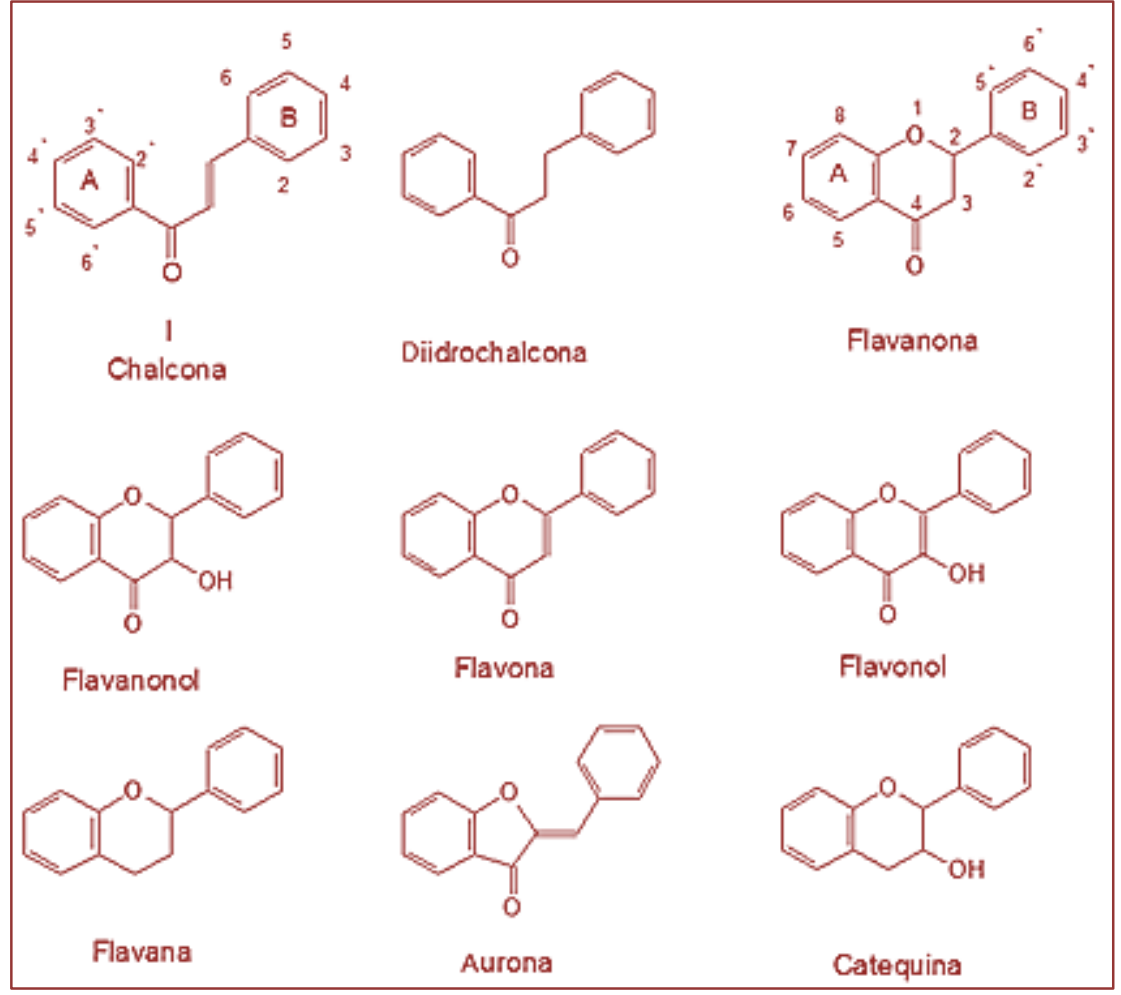

Várias atividades biológicas são atribuídas às chalconas e derivados, entre elas destacam-se algumas como, a atividade antiviral de 4'-etóxi-2'-hidróxi-4,6'-dimetóxichalcona a qual é bastante ativa contra cepas do rinovírus, que estão associadas aos resfriados (ISHITSUKA et al., 1982a). Tal chalcona foi obtida após modificações na estrutura química da flavona 4',5-di-hidróxi-3,3',7-trimetóxiflavona, isolada de Agastache rugosa KUNTZE, que apresenta potente atividade contra o picornavírus (ISHITSUKA et al., 1982b). Já a 2',4'-di-hidróxi-6-metóxi-chalcona, isolada de Boesenberg rotunda (L.) (Zongiberaceae) possui a capacidade de inibir a protease NS3 do vírus da dengue (DEN-2) (KIAT et al., 2006). Para as chalconas isoladas de Millettia leucantha (Leguminosae) foi relatada atividade moderada contra o vírus do herpes simples (PHRUTIVORAPONGKUL et al., 2003). A inibição da replicação de HIV-1 em linfócitos-H9 de camundongos foi obtida com a 2-metóxi-3-metil-4,6-diidróxi-5-(3'-hidróxi)cinamoil-benzaldeído (WU et al., 2003) e com a 2-hidróxi-3-metóxi-chalcona (DENG et al., 2006) que também possui atividade contra o vírus da influenza (Infl A) (LALL; HUSSEIN; MEYER, 2006).

As atividades anti-protozoárias são relatadas, tanto para a forma epimastigota (forma flagelada encontrada na corrente sanguínea do hospedeiro), quanto para a forma promastigota (forma flagelada infectante) (LUNARDI et al., 2003), utilizando chalconas conformacionalmente restritas (LARSEN et al., 2005), chalconas ferrocênicas (WU et al., 2006; WU; WILAIRAT; GO, 2002), chalconas tipo retinóide (VALLA et al., 2006) e chalconas quinolínicas (DOMINGUEZ et al., 2001). Dentre os parasitas estudados encontram-se: Leishmania major, L. donovani, L. amazonensis, Plasmodium falciparum, Tripanossoma cruzi (BOECK et al., 2006; PIÑERO et al., 2006; LIU et al., 2003). 
Já foram citadas diversas propriedades anti-inflamatórias para as chalconas, e os possíveis mecanismos de ações, ocorrem pela: (i) inibição da liberação de $\beta$-glucuronidase e lisozima e de neutrófilos estimulados com formil-Met-Leu-Phe/citocalasina B; (ii) inibição dos efeitos da formação de óxido nítrico, em microglias estimuladas com lipopolissacarídeo (LPS), agindo como seqüestradores de óxido nítrico (HERENCIA et al., 2002); (iii) supressão da expressão da enzima ciclooxigenase-2 (COX-2) (KO et al., 2003); (iv) supressão da biossíntese da Interleucina-1 (IL-1) (HERENCIA et al., 1999a). Estudos in vitro de uma série de dimetil-amino-chalconas (ROJAS et al., 2002a), fluoro-chalconas (ROJAS et al., 2002b) e derivados (HERENCIA et al., 1999b), demonstraram a atividade inibitória da produção de $\mathrm{PGE}_{2}$ e NO, produzidos por macrófagos RAW 264.7 estimulados por LPS, sendo que a 2'6'-dimetóxi-4-dimetil-aminochalcona apresentou atividade inibitória de $\mathrm{NO}$ dependente da concentração com valores de $\mathrm{IC}_{50}$ igual a $0,7 \mu \mathrm{M}$, e via oral, na dose de $25 \mathrm{mgKg}^{-1}$, inibiu significativamente a formação de edema, utilizando como modelo de inflamação a indução pela carragenina em rato. A atividade dessa substância não afeta a viabilidade celular, evidenciada pela redução mitocondrial de MTT após 24hs de tratamento, indicando que eles não são citotóxicos, podendo levar a importante e promissor agente anti-inflamatório.

As atividades antibacterianas das chalconas e de seus derivados contra microrganismos Gram positivos são freqüentemente maior do que contra bactérias Gram negativas, no entanto, alguns análogos também podem inibir o crescimento de microrganismos Gram negativos. Já foram relatadas inibições para as bactérias: Micrococcus luteus, Bacillus subtilis, Staphylococcus aureus, Escherichia coli, Staphylococcus epidermidis e Mycobacterium tuberculosis, dentre outras (ALCARÁZ et al., 2000; LIN et al., 2002).

Atividade antiproliferativa utilizando culturas celulares in vitro, demonstraram a ação contra tumores malignos em diferentes linhagens celulares como: células do câncer da próstata, PC-3 e DU-145 (DELMULLE et al., 2006); HGC-27 (câncer gástrico) (SHIBATA, 1994); HeLa (carcinoma cervical) (YE et al., 2004); MCF-7 (câncer de mama) (MODZELEWSKA et al., 2006 e HSU et al., 2006); K562 e HL-60 (leucemia) (SAYDAM et al., 2003); NCI-H460 (câncer de pulmão) (PHRUTIVORAPONGKUL et al., 2003), contra células L929 mesmo em concentrações de $0,5 \mathrm{mg} / \mathrm{mL}$ e sendo algumas com atividade antitumoral in vivo em tumor ascítico em ratos (ANTO et al., 1995). Outras atividades citotóxicas in vitro contra nove tipos de linhas de células de tumores humanos incluindo, carcinoma epidermóide do nasofaringe (KB), osteosarcoma (Hos), melanoma (SKMEL-2) glioblastoma (U87-MG), câncer ovariano (1A9), entre outros, são relatados (XIA et al., 2000).

Outras atividades contra fungos dermatófitos (LÓPEZ et al., 2001), proteção das células do trato gastroduodenal (DE LA ROCHA et al., 2003), antimitótica (EDWARDS; STEMERICK; SUNKARA, 1990), atividade antiplaquetária de 2',4',6'-triidróxichalconas (ZHAO et al., 2005), atividade alelopática (BITENCOURT; SANTOS; SOUZA FILHO, 2007) e atividade herbicida (TANG e FOSTER, 1980), são também relatadas.

Visando a obtenção de substâncias com melhores atividades biológicas, foram realizadas modificações químicas como substituições nos anéis A e B (ALSTON; FRY, 2004; CESARIN-SOBRINHO; NETTOFERREIRA; BRAZ FILHO, 2001; YAMIN et al. 1998); mudança dos anéis para piperidinas (LIU; GO, 2006), quinolina (DE LEON et al. 2003) e adamantano (ANDERSON; KAMAIMARI, 2005); preparação de oximas (TSANG et al. 2005); fotodimerizações (CESARIN-SOBRINHO; NETTO-FERREIRA, 2002); epoxidação (AMARESH; PERUMAL, 1995; BERKESSEL et al., 2006; BERNINI et al., 2004; PATONAY; TÓTH; ADAM, 1993), adição de hidrogênio (KROHN; STEINGRÖVER; RAO, 2002) e halogênio (KIM et al., 1993) na dupla ligação carbono-carbono; e as isomerizações E/Z, que também são relatadas (BOWDEN; DUAH; RANSON, 1991).

A formulação metodológica convencional de síntese dessas substâncias é a reação do tipo condensação aldólica que requer, a presença de uma base catalítica, solvente e aquecimento, o tempo de reação pode variar de 3 a 24 horas dependendo dos substituintes dos anéis aromáticos. 0 Rendimento do produto obtido pode ser quantitativo ou moderado.

Inicialmente, o catalisador básico remove o hidrogênio alfa à carbonila da cetona (acetofenona), formando assim um carbânion, que pode ser estabilizado por ressonância. A reação continua pelo ataque nucleofílico do carbânion ao carbono da carbonila do aldeído, com a formação de um intermediário tetraédrico (íon alcóxido), que sofre protonação, dando uma $\beta$-hidróxi-cetona que perde uma molécula de água, originando a chalcona, neste tipo de reação, ocorre uma condensação seguida de eliminação de uma molécula de água (Figura 2). 
Figura 2 - Equação química da condensação de Claisen-Schmidt em meio básico.

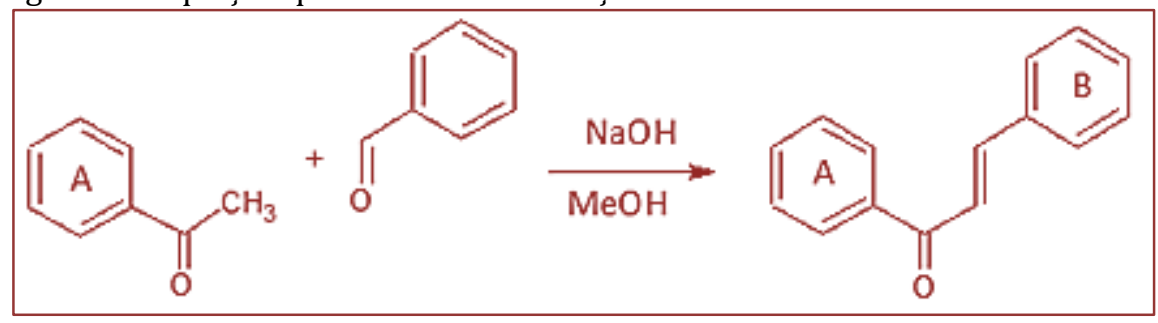

A condensação aldólica é uma reação utilizada na formação de ligação carbono - carbono, sendo que a reação entre aldeídos e cetonas em presença de solução básica fornece cetonas $\alpha, \beta$-insaturada, e é chamada de condensação de Claisen-Schmidt. Apesar da condensação entre dois aldeídos diferentes ser possível, ela é freqüentemente impraticável, uma vez que, haverá condensação cruzada e autocondensação. Assim, em uma condensação aldólica mista, há quatro possíveis produtos, sendo neste caso de uso limitado. Entretanto, quando um dos dois compostos carbonilados não possuir hidrogênios- $\alpha$ e não poder formar íons enólicos (benzaldeídos substituídos) e o outro composto carbonilado (cetona ou aldeído) possuir uma carbonila pouco reativa frente às reações de adições, para impedir a autocondensação (metil-cetonas preferencialmente substituídas- acetofenonas), as condensações aldólicas mistas podem funcionar muito bem (SOLOMONS; FRYHLE, 2002). Vários catalisadores básicos são relatados para a promoção dessas reações, como as hidrotalcitas de Al-Mg (CLIMENT et al., 2004), hidróxido de Bário (IGLESIAS; MARINAS; SINISTERRA, 1987) e hidróxido de lítio (BHAGAT et al., 2006), bem como, na ausência de solvente, água ou álcool (PALLEROS, 2004) e com o uso de ultra-som (CALVINO, 2006).

Neste trabalho, as reações de condensações aldólicas foram realizadas utilizando-se como material de partida, benzaldeídos (salicilaldeído e benzaldeído) que não possuem hidrogênios- $\alpha$ e acetofenona, como catalisador, hidróxido de sódio(50\%), metanol como solvente e agitação (HULL, 2001; HATHAWAY, 1987).

\section{METODOLOGIA}

\subsection{EQUIPAMENTOS UTILIZADOS:}

Espectrômetro de ressonância magnética nuclear Varian Mercury DX-300 e Espectrômetro de massas Waters Acquity TQD (Pós-Graduação em Química/ UFPA); espectrofotômetro de IV Thermo Electron Corporation modelo Nicolet 4700 FT-IR (Lacen-Eletronorte).

\subsection{REAGENTES E SOLUÇÕES}

Os reagentes utilizados foram das marcas Aldrich, Vetec ou Nuclear, todos PA.

\subsection{PROCEDIMENTO DE OBTENÇÃO DAS SUBSTÂNCIAS}

\section{(2E)-1-fenil-3-(2-hidróxi-fenil)-prop-2-en-1-ona (1; Figura 3; 2-HIDRÓXI-CHALCONA):}

Em frasco Erlenmeyer de $250 \mathrm{~mL}$ foi adicionado, $20 \mathrm{~mL}$ de $\mathrm{MeOH}, 10 \mathrm{~mL}$ de $\mathrm{NaOH} 50 \%, 6 \mathrm{~mL}$ de acetofenona ( $\sim 50 \mathrm{mmol})$ e por último $5,2 \mathrm{~mL}$ de aldeído salicílico $(\sim 50 \mathrm{mmol})$. Essa mistura foi mantida em agitação (T.a.) por cerca de $3 \mathrm{~h}$ e armazenada por 24 hs. Posteriormente, foi feita a acidificação utilizando ácido acético à $20 \%$ e armazenada em freezer para formação de um sólido que então foi submetido a filtração e lavagem com água. 0 sólido resultante caramelo amarelado foi recristalizado em metanol. Pf. 143-149ํㅡ (MeOH) (IRIE; WATANABE, 1980). Fornecendo 6,2g da substância 1 (Rendimento de 55,3\%).

RMN-1 ${ }^{-1}\left(300 \mathrm{MHz} ; \mathrm{CDCl}_{3}\right) \delta:$ 7,60 (dd, 1H, J=1,5Hz, J=7,5Hz; H-6), 6,90 (d, 1H, J=7,5Hz; H-3), 6,97 (dd, 1H, $\mathrm{J}=7,5 \mathrm{~Hz}, \mathrm{~J}=7,8 \mathrm{~Hz} ; \mathrm{H}-5$ ), 7,28 (ddd, $1 \mathrm{H}, \mathrm{J}=7,8 \mathrm{~Hz}, \mathrm{~J}=7,5 \mathrm{~Hz}, \mathrm{~J}=1,5 \mathrm{~Hz} ; \mathrm{H}-4$ ), 8,15 (d, 1H, J=16Hz; H-7), 7,70 (d, $1 \mathrm{H}, \mathrm{J}=16 \mathrm{~Hz} ; \mathrm{H}-8$ ), 8,03 (dt, 2H, J=0,9Hz, J=8Hz; H-2' e H-6'), 7,50 (dd, 2H, J=8Hz, J=8Hz; H-3' e H-5' ), 7,57 $\left(\mathrm{tt}, 1 \mathrm{H}, \mathrm{J}=8 \mathrm{~Hz}, \mathrm{~J}=0,9 \mathrm{~Hz} ; \mathrm{H}-4^{\prime}\right)$. 
RMN-13C (75MHz; CDCl $)$ ): 121,8 (C1), 156,9 (C2), 116,2 (C3), 131,7 (C4), 119,9 (C5), 129,4 (C6), 141,4 (C7), 128,2 (C8), 192,1 (C9), 138,2 (C1'), 128,4 (C2'), 128,4 (C3`), 132,5 (C4`), 128,4 (C5`), 128,4 (C-6').

IV (KBr): 3215, 2725, 1638, 1596, 1582, 1459, 1346, 1300, 1022, 858, 748 $\mathrm{cm}^{-1}$.

EM: $m / z=224,4\left(7 \% ;[M-H]^{+}\right)$e $105\left(100 \%, A_{1}{ }^{+}\right)$.

Figura 3 - Estrutura química da 2-HIDRÓXI-CHALCONA.

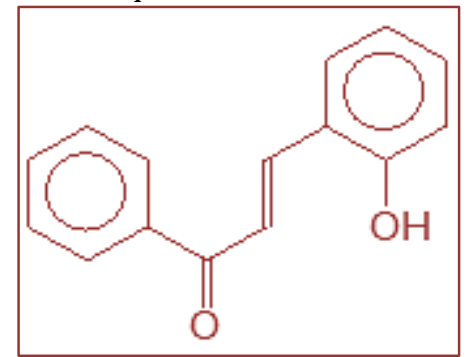

(2E)-1,3-Bis-fenil-prop-2-en-1-ona (2; Figura 4; CHALCONA):

Em frasco Erlenmeyer de $250 \mathrm{~mL}$ foi adicionado, $20 \mathrm{~mL}$ de $\mathrm{MeOH}, 10 \mathrm{~mL}$ de $\mathrm{NaOH} 50 \%, 6 \mathrm{~mL}$ de acetofenona $(\sim 50 \mathrm{mmol})$ e por último $5,4 \mathrm{~mL}$ de benzaldeído $(\sim 50 \mathrm{mmol})$. Essa mistura foi mantida em agitação (T.a.) por cerca de $3 \mathrm{~h}$ e armazenada por $24 \mathrm{hs}$. Posteriormente, foi armazenada em freezer para formação de um sólido que então foi submetido a filtração e lavagem com água. 0 sólido resultante amarelo pálido foi recristalizado em metanol. Pf. 53,5-54으 $\mathrm{C}(\mathrm{MeOH})$ (IRIE; WATANABE, 1980; ANNAPOORNA; RAO; SETHURAM, 2002). Fornecendo 5,8g da substância 2 (Rendimento de 55,7\%).

Figura 4 - Estrutura química da chalcona.

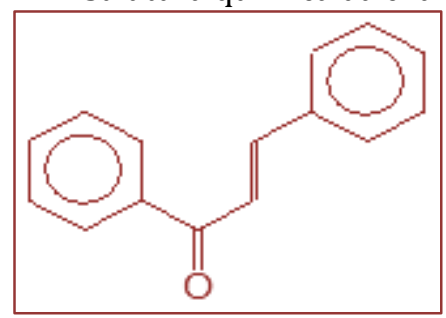

RMN-1 ${ }^{-1}\left(300 \mathrm{MHz} ; \mathrm{CDCl}_{3}\right) \delta: 7,65$ (dd, J=7,1Hz e J=2,3Hz, 2H; H-2 e H-6), 7,42 (dd, J=7,1Hz e J=7,1Hz, 2H; H-3 e H-5), 7,42 (dd, J=7,1Hz e J=2,3Hz; H-4), 7,81 (d, 1H, J= 16Hz; H-7), 7,54 (d, 1H, J= 16Hz; H-8), 8,02 (dd, J=7,0Hz e J=1,6Hz, 2H; H-2' e H-6'), 7,51(tt, J=7,0Hz e 1,6Hz, 2H; H-3' e H-5'), 7,59 (tt, J=7,0Hz e $\mathrm{J}=1,6 \mathrm{~Hz}, 1 \mathrm{H} ; \mathrm{H}-4^{\prime}$ ).

RMN-13C (75MHz; CDCl $)$ ): 134,8 (C1), 128,9 (C2), 128,6 (C3), 132,7 (C4), 128,6 (C5), 128,9 (C6), 144,8 (C7), 122,0 (C8), 190,5 (C9), 138,1 (C1'), 128,4 (C2'), 128,4 (C3`), 130,5 (C4'), 128,4 (C5'), 128,4 (C-6').

IV (KBr): 3082, 3025, 1663, 1606, 1574, 1496, 1447, 1335, 1309, 1033, 844, 752 $\mathrm{cm}^{-1}$.

EM: $\mathrm{m} / \mathrm{z}=209,26\left(76 \% ;[\mathrm{M}-\mathrm{H}]^{+}\right)$e $131\left(100 \%, \mathrm{~B}^{+}\right)$. 


\section{DISCUSSÃO DOS RESULTADOS}

\subsection{CARACTERIZAÇÃO DAS SUBSTÂNCIAS}

Uma das principais características do espectro de RMN de hidrogênio das chalconas é o sistema $A B$, relativo à $\mathrm{H}-7$ e $\mathrm{H}-8$, que se apresentam como um dubleto $\mathrm{J} \sim 16 \mathrm{~Hz}$, indicando a conformação trans entre esses hidrogênios, além dos demais sinais. Com relação ao espectro de carbono-13, pode-se inferir que os principais picos são os relativos ao carbono da carbonila (C-9, 190ppm) e os relativos aos carbonos olefínicos (C-7; 144ppm e C-8; 122ppm), bem como os demais picos do espectro.

No espectro de infravermelho a principal característica é a banda correspondente ao estiramento da carbonila que ocorre entre 1668-1638 $\mathrm{cm}^{-1}$, dependendo dos substituintes dos anéis aromáticos.

Segundo HarboRne (1975), na espectroscopia de massas, as chalconas e derivados apresentam picos referentes aos íons $\mathrm{M}^{+},[\mathrm{M}-\mathrm{H}]^{+}$e $\left[\mathrm{M}-\mathrm{CH}_{3}\right]^{+}$(no caso de p-metóxi-chalconas) e picos referentes à fragmentos estruturalmente informativos derivados da quebra da ligação vizinha ao grupo carbonila (Figura 5). A intensidade relativa de íons designados por $\mathrm{A}_{1}^{+}$e $\mathrm{B}_{1}{ }^{+}$, e outros íons derivados destes, dependem do padrão de substituição.

\section{Identificação da Substância 1:}

No espectro de RMN de hidrogênio de 1 , os sinais relativos de H-7 (8,15ppm) e H-8 (7,70ppm), apresentam-se como um dubleto do tipo $\mathrm{AB}$, com acoplamento de $16 \mathrm{~Hz}$, indicando a conformação trans entre esses hidrogênios. Com relação ao espectro de carbono-13, podem ser identificados os sinais relativos aos carbonos da carbonila (C-9; 192,1ppm) e carbonos olefínicos (C-7; 141ppm e C-8; 129ppm). No espectro de infravermelho a banda correspondente ao estiramento da carbonila em $1638 \mathrm{~cm}^{-1}$. Com base no espectro de massas é possível observar o pico referente ao íon molecular (M+1) com m/z de 225,4 (7\%) que corresponde a massa molar $(224 \mathrm{~g} / \mathrm{mol})$, coincidindo com a fórmula molecular $\mathrm{C}_{15} \mathrm{H}_{12} \mathrm{O}_{3}$, também, pode-se identificar o pico referente ao íon $\mathrm{A}_{1}{ }^{+} \mathrm{com} \mathrm{m} / \mathrm{z}$ de 105 (100\%). Com base nesses dados e os reagentes utilizados, a fórmula estrutural proposta para a substância 1 , está de acordo com a figura 3.

Figura 5 - Esquema de fragmentação das chalconas

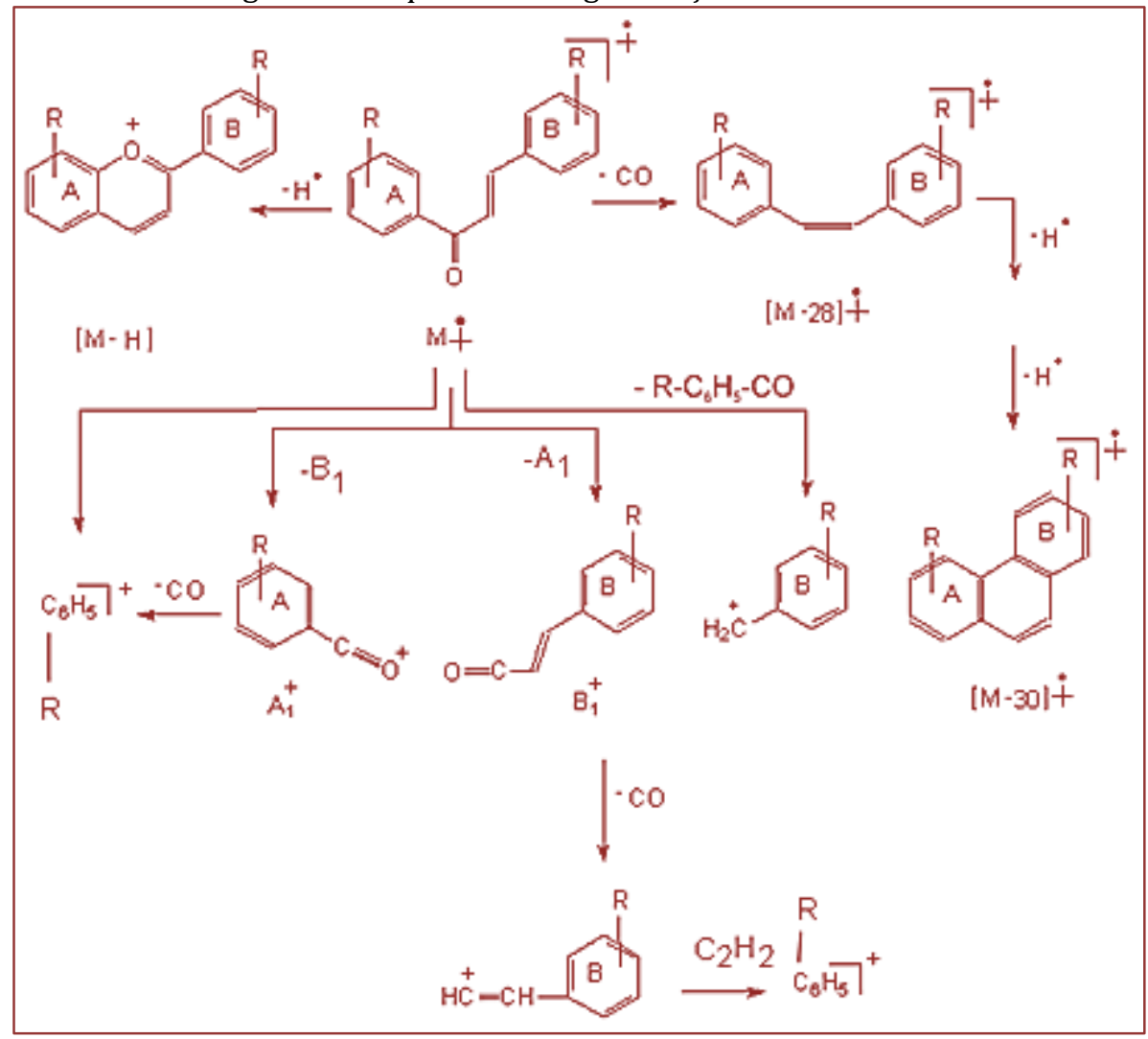




\section{Identificação da Substância 2:}

No espectro de RMN de hidrogênio de $\underline{2}$, os sinais relativos de H-7 (7,81ppm) e H-8 (7,54ppm), apresentam-se como um dubleto do tipo $\mathrm{AB}$, com acoplamento de $16 \mathrm{~Hz}$, indicando a conformação trans entre esses hidrogênios. Com relação ao espectro de carbono-13, podem ser identificados os picos relativos aos carbonos da carbonila (C-9; 190,5ppm) e dos carbonos olefínicos (C-7; 144,8ppm e C-8; $122 \mathrm{ppm}$ ). No espectro de infravermelho a banda correspondente ao estiramento da carbonila em $1663 \mathrm{~cm}^{-}$ 1. Com base no espectro de massas é possível observar o pico referente ao íon molecular $(\mathrm{M}+1) \mathrm{com} \mathrm{m} / \mathrm{z}$ de 209,2 (76\%) que corresponde a massa molar $(208 \mathrm{~g} / \mathrm{mol})$, coincidindo com a fórmula molecular $\mathrm{C}_{15} \mathrm{H}_{12} \mathrm{O}$, também, pode-se identificar o pico referente ao íon $\mathrm{B}_{1}{ }^{+}$com m/z de 131 (100\%). Com base nessa discussão e os reagentes utilizados, a fórmula estrutural proposta para a substância 2 , está de acordo com a figura 4.

\section{CONCLUSÃO}

A síntese de chalconas em meio básico é o método mais indicado para a obtenção dessas substâncias, tendo o cuidado de quando a mistura reacional possuir hidroxila fenólica deve ser feita a acidificação. A reação de condensação, também pode ser realizada em meio ácido.

Com relação à identificação, o método de escolha é a Ressonância magnética nuclear de Hidrogênio (RMN${ }^{1} \mathrm{H}$ ), no qual os sinais relativos dos hidrogênios $\alpha$ e $\beta$ à carbonila devem apresentar uma constante de acoplamento trans $(\sim 16 \mathrm{~Hz})$, sendo complementado com as demais técnicas de identificação.

\section{REFERÊNCIAS}

[1] ALCARÁZ, L. E.; BLANCO, S. E.; PUIG, O. N.; TOMÁS, F.; FERRETI, F. H. Antibacterial activity of flavonoids against methicillin-resistant Staphylococcus aureus strains. J. Theor. Biol. v. 205, n. 2, p. 231-240, 2000.

[2] ALSTON, J.; and FRY, A. J. Substituent effects on the Reduction potentials of Benzalacetophenones (chalcones) Improved Substituent Constants for Such Correlations. Eletrochimica Acta. v. 49, n. 3, p. 455-459, 2004.

[3] AMARESH, R. R.; PERUMAL, P. T. Ring Opening of Chalcone Epoxides with Vilsmeier Reagent. Tetrah. Lett. v. 36, n. 40, p. $7287-7288,1995$.

[4] ANDERSON, G. L.; KAMAIMARI, T. A.-R. Treatment of breast cancer involves administering 1-adamantyl chalcones to a host optionally in combination with a carrier. Patent Number: US6864264-B1 (08 Mar 2005).

[5] ANNAPOORNA, S. R.; RAO, M. P.; SETHURAM, B. Multiple substituent effects on 13C chemical shifts in phenylstyryl ketones: Applicability of interactive free energy relationship. Indian J. Chem. Sect A. v. 41, n. 7. p. 13411345, 2002.

[6] ANTO, R. J.; SUKUMARAN, K.; KUTTAN, G.; RAO, M. N. A.; SUBbARAJU, V. and KUTTAN, R. Anticancer and antioxidant activity of synthetic chalcones and related compounds. Cancer Lett. v. 97, n. 1, p. 33- 37, 1995.

[7] BERKESSEL, A.; KOCH, B.; TONIOLO, C.; RAINALDI, M.; BROXTERMANN, Q. B. And KARPTEIN, B. Asymmetric enone epoxidation by short solid-phase bound peptides: Further evidence for catalyst helicity and catalytic activity of individual peptide strands. Peptide Sci. v. 84, n. 1, p. 90-96, 2006.

[8] BERNINI, R.; MINCIONE, E.; CORATTI, A.; FABRIZI, G.; BATTISTUZZI, G. Epoxidation of Chromones and Flavonoids in Ionic Liquids. Tetrah. v. 60, n. 4, p. 967-971, 2004.

[9] BHAGAT, S.; SHARMA, R.; SAWANT, D. M.; SHARMA, L.; CHAKRABORT, A. K.; LiOH.H $\mathrm{H}_{2} \mathrm{O}$ as a novel dual activation catalyst for highly efficient and easy synthesis of 1,3-diaryl-2-propenones by Claisen-Schmidt condensation under mild conditions. J. Mol. Catal. A: Chem. v. 244, n. 1-2, p. 20-24, 2006.

[10] BITENCOURT, H. R.; SANTOS, L. S.; SOUZA FILHO, A. P. S. Atividade alelopática de chalcona sintética, de seus precursores e de cetonas e aldeídos relacionados. Planta daninha. v. 25, n. 4, p. 747-753, 2007.

[11] BOECK, P.; FALCÃO, C. A. B.; LEAL, P. C.; YUNES, R. A.; CECHINEL FILHO, V.; TORRES SANTOS, E. C.; ROSSIBERGMANN B. Synthesis of chalcone analogues with increased antileishmanial. Bioorg. Med. Chem. v. 14, n. 5, p. 1538$1545,2006$.

[12] BOWDEN, K.; DUAH, C. K.; RANSON, R. J. Reactions in strongly basic media. Parte 10. Base-catalyzed isomerization of Z- to E- substituted chalcones. J. Chem. Soc., Perkins Trans. 2: Phys. Org. Chem. v. 1, p. 109-112, 1991.

[13] CALVINO, V.; PICALLO, M.; LÓPEZ-PEINADO, A. J.; MARTÍN-ARANDA, R. M.; DURÁN-VALLE, C. J. Ultrasound accelerated Claisen-Schmidt condensation: A green route to chalcones. Apll. Surf. Sci. v. 252, n. 17, p. 6071-6074, 2006. 
[14] CESARIN-SOBRINHO, D. e NETTO-FERREIRA, J. C. Fotoquímica de Chalconas Fluoradas no Estado Sólido. Quím. Nova. v. 25, n. 1, p. 62-68, 2002.

[15] CESARIN-SOBRINHO, D.; NETTO-FERREIRA, J. C.; BRAZ FILHO, R. Efeito da Substituição por Átomos de Flúor no Equilíbrio Conformacional de Chalcona. Quím. Nova. v. 24, n. 5, p. 604-611, 2001.

[16] CLIMENT, M. J.; CORMA, A.; IBORRA, S.; and VELTY, A. Activated hydrotalcites as Catalysts for Synthesis of Chalcones of Pharmaceutical Interest. J. Catal. v. 221, n. 2, p. 474-482, 2004.

[17] DE LA ROCHA, N.; MARIA, A. O.; GIANELLO, J. C.; PELZER, L. Cytoprotective effects of chalcones from Zuccagnia punctata and melation on grastroduodenal tract in rats. Pharmacol. Res. v. 48, n. 1, p. 97-99, 2003.

[18] DE LEON, E. J.; ALCARAZ, M. J.; DOMINGUEZ, J. N.; TERENCIO, M. C. A New chloroquinolinyl chalcone derivative as inhhibitor of inflammatory and immune response in mice and rats. J. Pharm. Pharmacol. v. 55, n.9, p. 1313-1321, 2003.

[19] DELMUlle, L.; BEllahCÈNE, A.; DHOOGE, W.; COMHAIRE, F.; ROELENS, F.; HUVAERE, K.; HEYERICK, A.; CASTRONOVO, V.; DE KEKULEIRE, D. Anti-proliferative preoperties of prenylated flavonoids from hops (Humulus lupulus L.) in human prostate cancer cell lines. Phytomedicine. v. 13, n. 9-10, p. 732-734, 2006.

[20] DENG, J.; KELLEY, J. A.; BARCHI, J. J.; SANCHEZ, T.; DAYAM, R.; POMMIER, Y.; NEAMATI, N. Mining the NCI antiviral compounds for HIV-1 integrase inhibitors. Bioorg. Med. Chem. v. 14, n. 11, p. 3785-3792, 2006.

[21] DOMINGUEZ, J. N; CHARRIS, J. E.; LOBO, G.; DOMINGUEZ N. G.; MORENO, M. M.; RIGGIONE, F.; SANCHEZ, E.; OLSON, J.; ROSENTHAL, P. J. Synthesis of quinolinyl chalcones and evaluation of their antimalarial activity. Eur. J. Med. Chem. v. 36, n. 6, p. 555-560, 2001.

[22] EDWARDS, M. L.; STEMERICK, D. M.; SUNKARA, P. S. Chalcones: a new class of antimitotic agentes. J. Med. Chem. v. 33, n. 7, p. 1948-1954, 1990.

[23] HARBORNE, J. B. The flavonoids- Part I. Ed. Chapman and Hall. London, p. 525, 1975.

[24] HATHAWAY, B. A. An Aldol Condensation Experiment Using a Number of Aldehydes and Ketones. J. Chem. Educ. v. 64, n. 4, p. 367-368, 1987.

[25] HERENCIA, F.; FERRÁNDIZ, M. L.; UBEDA, A.; DOMÍNGUEZ, J. N.; CHARRIS, J. E.; LOBO, G. M.; ALCARAZ, M. J. Synthesis and anti-inflammatory activity of chalcone derivatives. Bioorg. Med. Chem. Lett. v. 8, n. 10, p. 1169-1174, 1999a.

[26] HERENCIA, F.; FERRÁNDIZ, M. L.; UBEDA, A.; DOMÍNGUEZ, J. N.; CHARRIS, J. E.; LOBO, G. M.; ALCARAZ, M. J. Novel anti-inflammatory chalcone derivatives inhibit the induction of nitric oxide synthase and cyclooxygenase-2 in mouse peritoneal macrophages. FEBS Lett. v. 453, n. 1-2, p. 129-134, 1999 b.

[27] HERENCIA, F.; LÓPEZ-GARCIA, M. P.; UBEDA, A.; FERRÁNDIZ, M. L. Nitric oxide-scavenging properties of some chalcone derivatives. Nitric Oxide: Biology and Chem. v. 6, n. 2, p. 242-246, 2002.

[28] HSU, Y. L.; KUO, P. L.; TZENG, W. S.; LIN, C. C. Chalcone inhibits the proliferation of human breast cancer cell by blocking cell cycle progression and inducing apoptosis. Food and Chem. Toxicol. v. 44, n. 5, p. 704-713, 2006.

[29] HULL, L. A. The Dibenzalacetone Reaction Revisited. J. Chem. Educ. v. 78, n. 2, p. 226-227, 2001.

[30] IGLESIAS, M.; MARINAS, J. M.; and SINISTERRA, J. V. $\mathrm{Ba}(\mathrm{OH})_{2}$ as Catalyst in Organic Reactions- Part XVIContribution to the Study of the Michael Addition Mechanism to Chalcone in Interfacial Solid- Liquid Conditions. Tetrah. v. 43, n. 10, p. 2335-2342, 1987.

[31] IRIE, K. and WATANABE, K.-I. Aldol Condensations with Metal (II) Complex Catalysts. Bull. Chem. Soc. Jpn., v. 53, n. 5, p. 1366-1371, 1980.

[32] ISHITSUKA, H.; NINOMIYA, Y. T.; OHSAWA, C.; FUJIU, M. AND SUHARA, Y. Direct and Specific Inactivation of Rhinovirus by chalcone Ro 09-0410. Ant. Agen. Chem. v. 22, n. 4, p. 617-621, 1982a.

[33] ISHITSUKA, H.; OHSAWA, C.; OHIWA, T.; UMEDA, I. SUHARA, Y. Antipicornavirus flavone Ro 09-0179. Ant. Agen. Chem. v. 22, n. 4, p. 611-616, 1982b.

[34] KIAT, T. S.; PIPPEN, R.; YUSOF, R.; IBRAHIM, H.; KHALID, N.; RAHMAN, N. A. Inhibitory activity of cyclohexenyl chalcone derivatives and flavonoids of fingerroot, Boesenbergia rotunda (L.), towards dengue-2 virus NS3 protease. Bioorg. Med. Chem. Lett. v. 16, n. 12, p. 3337-3340, 2006.

[35] KIM, K. M.; CHUNG, K. H.; KIM, J. N.; RYU, E. K. A Facile synthesis of $\alpha$-chloro enones by oxidative chlorination. Synthesis. v. 3, p. 283-284, 1993.

[36] KO, H.-H.; TSAO, L.-T.; YU, K.-L.; LIU, C.-T.; WANG, J.-P. And LIN, C.- N. Structure-activity relationship studies on chalcone derivatives: the potent inhibition of chemical mediators release. Bioorg. Med. Chem. Lett. v. 11, n. 1, p. 105-111, 2003. 
[37] KROHN, K.; STEINGRÖVER, K.; RAO, M. S. Isolation and Synthesis of Chalcones with Different Degrees of Saturation. Phytochem. v. 61, n. 8, p. 931-936, 2002.

[38] LALL, N.; HUSSEIN, A. A.; MEYER, J. J. M. Antiviral and antituberculous activity of Helichrysum melanacme constituents. Fitoterapia. v. 77, n. 3, p. 230-232, 2006.

[39] LARSEN, M.; KROMANN, H.; KHARAZMI, A.; NIELSEN, S. F. Conformationally restricted anti-plasmodial chalcones. Bioorg. Med. Chem. Lett. v. 15, n. 21, p. 4858-4861, 2005.

[40] LIN, Y.- M.; ZHOU, Y.; FLAVIN, M. T.; ZHOU, L.-M.; NIE, W.; CHEN, F.-C. Chalcones and flavonoids as antituberculosis agents. Bioorg. Med. Chem. v. 10, n. 8, p. 2795-2802, 2002.

[41] LIU, M.; WILAIRAT, P.; CROFT, S. L.; LAY-CHOO, A.; GO, M.-L. Structure-activity relationship of antileishmanial and antimalarial chalcones. Bioorg. Med. Chem. v. 11, n. 13, p. 2729-2738, 2003.

[42] LIU, X. and GO, M.-L. Anti-proliferative properties of piperidinyl chalcones. Bioorg. Med. Chem. v. 14, n. 1, p. 153-163, 2006.

[43] LÓPEZ, S. N.; CASTELLI, M. V.; ZACCHINO, S. A.; DOMINGUEZ, J. N.; LOBO, G.; CHARRIS-CHARRIS, J.; CORTÉS, J. C. G.; RIBAS, J. C.; DEVIA, C.; RODRIGUEZ, A. M.; ENRIZ, R. D. In vitro antifungal evaluation and structure-activity relationships of a new series of chalcone derivatives and synthetic analogues, with inhibitory properties against polymers of the fungal cell wall. Bioorg. Med. Chem. v. 9, n. 8, p. 1999-2013, 2001.

[44] LUNARDI, F.; GUZELA, M.; RODRIGUES, A. T.; UMEDA, I.; CORREA, R.; EGER-MAGRICH, I.; STEINDEL, M. S.; GRISARD, E. C.; ASSREUY, J.; CALIXTO, J. B.; SANTOS, A. R. S. Trypanocidal and leishmanicidal properties of substitution-containing chalcones. Ant. Agen. Chem. v. 47, n. 4, p. 1449-1451, 2003.

[45] MODZElEWSKA, A.; PETTIT, C.; ACHATANTA, G.; DAVIDSON, N. E.; HUANG, P. and KHAN, S. R. Anticancer activities of novel chalcone and bis-chalcone derivatives. Bioorg. Med. Chem. v. 14, n. 10, p. 3491-3495, 2006.

[46] NAKANISHI, K.; GOTO, T.; ITÔ, S.; NATORI, S.; and NOZOE, S. Natural Products Chemistry, Kodansha Ltda \& Academic Press, Inc. v. 2, p. 218-231, 1975.

[47] PALLEROS, D. R. Solvent-free synthesis of chalcones. J. Chem. Educ. v. 81, n. 9, p. 1345-1347, 2004.

[48] PATONAY, T.; TÓTH, G.; and ADAM, V. A Convenient and General Synthesis of Trans-3-hydroxyflavanones from Chalcones by Dimethyldioxirane Epoxidation and Subsequent Base-catalyzed Cyclization. Tetrah. Lett. v. 34, n. 32, p. 5055-5058, 1993.

[49] PHRUTIVORAPONGKUL, A.; LIPIPUN, V.; RUANGRUNGSI, N.; KIRTIKARA, K.; NISHIKAWA, K.; MARUYAMA, S.; WATANABE, T.; ISHIKAWA, T. Studies on the Chemical Constituents of Stem Bark of Millettia leucantha: isolation of new chalcones with cytotoxic, anti-herpes Simplex Virus and anti-inflammatory activities. Chem. Pharm. Bull. v. 51, n. 2, p. 187-190, 2003.

[50] PIÑERO, J.; TEMPORAL, R. M.; SILVA-GONÇALVES, A. J.; JIMÈNEZ, I. A.; BAZZOCCHI, I. L.; OLIVA, A.; PERERA, A.; LEON, L. L.; VALLADARES, B. New administration model of trans-chalcone biodegradable polymers for the treatment of experimental leishmaniasis. Acta Tropica v. 98, n. 1, p. 56-65, 2006.

[51] ROJAS, J.; DOMÍNGUEZ, J. N.; CHARRIS, J. E.; LOBO, G.; PAYÁ, M.; FERRÁDIZ, M. L. Synthesis and inhibitory activity of dimetilamino-chalcone derivatives on the induction of nitric oxide synthase. Eur. J. Med. v. 37, p. 699-705, 2002a.

[52] ROJAS, J.; PAYÁ, M.; DOMÍNGUEZ, J. N.; FERRÁDIZ, M. L. The synthesis and effect of fluorinated chalcone derivatives on nitric oxide production. Bioorg. Med. Chem. Lett. v. 12, n. 15, p. 1951-1954, 2002b.

[53] SAYDAM, G.; AYDIN, H. H.; SAHIN, F.; KUCUKOGLU, O.; ERCIYAS, E.; TERZIOGLU, E.; BUYUKKECCEI, F.; OMAY, S. B. Cytotoxic and inhibitory effects of 4,4'-dihydroxi chalcone (RVC-588) on proliferation of human leukemic HL-60 cells. Leukemia Res. v. 27, n. 1, p.57-64, 2003.

[54] SHIBATA, S. Anti-tumorigenic chalcones. Stem Cells. v. 12, n. 1, p. 44-52, 1994.

[55] SOLOMONS, T. W. G.; FRYHLE, C. B. Química Orgânica 2. 7. ed. Rio de Janeiro: LTC, 2002.

[56] TANG, D. Y. and FOSTER, A. M. 1-Phenyl-3-tri:fluorophenyl-2-propanone prodn. - from tri-fluoromethyl benzaldehyde and acetophenone, useful as herbicide intermediate. Patent $\mathrm{N}$ o US4229378, 1980.

[57] TSANG, K. Y.; SINHA, S.; LIU, X.; BHAT, S.; CHANDRARATINA, R. A new disubstituted chalcone chalcone oximes, useful for preventing or treating retinoid poisoning, are retinoid receptor RAR-gamma antagonists. Patent Numbers: W02005066115-A2 (21 Jul 2005); US2005165095-A1 (28 Jul 2005).

[58] VALLA, A.; VALLA, B.; CARTIER, D.; LE GUILLOU, R.; LABIA, R.; FLORENT, L.; CHARNEAU, S.; SCHREVEL, J.; POTIER, P. New syntheses and potential antimalarial activities of new 'retinoid-like chalcones`. Eur. J. Med. Chem. v. 41, n. 1, p. 142-146, 2006. 
[59] WU, J.-H.; WANG, X.-H.; YI, Y.-H.; LEE, K.-H. Anti-AIDS agents 54. A potent anti-HIV Chalcone and Flavonoids from Genus Desmos. Bioorg. Med. Chem. Lett. v. 13, n. 10, p. 1813-1815, 2003.

[60] WU, X.; TIEKINK, E. R. T.; KOSTETSKI, I.; KOCHERGINSKY, N.; TAN, A. L. C.; KHOO, S. B.; WILAIRAT, P.; GO, M.L. Antiplasmodial activity of ferrocenil chalcones: investigations into the role of ferrocene. Eur. J. Pharm. Sci. v. 27, n. 23 , p. $175-187,2006$.

[61] WU, X.; WILAIRAT, P.; GO, M.-L. Antimalarial Activity of ferrocenyl chalcones. Bioorg. Med. Chem. Lett. v. 12, n. 17 , p. 2299-2302, 2002.

[62] XIA, Y.; YANG, Z.-Y.; XIA, P.; BASTOW, K. F.; NAKANISHI, Y.; LEE, K.-H. Antitumor agents. Part 202: Novel 2'amino chalcones: design, synthesis and biological evaluation. Bioorg. Med. Chem. Lett. v. 10, n. 8, p. 699-701, 2000.

[63] YAMIN, L. J.; GASUL, E. I.; BLANCO, S. E.; and FERRETTI, F. H. Synthesis and Structure of 4-X-Chalcones. J. Mol. Struc. (Teoch.). v. 428, n. 1-3, p. 167-174, 1998.

[64] YE, C.-L.; LIU, J.-W.; WEI, D.-Z.; LU, Y.-H.; QIAN, F. In vitro anti-tumor activity of 2',4'-dihydroxy-6'-methoxy3',5'-dimethylchalcone against six established human cancer cell lines. Pharmacol. Res. v. 50, n. 5, p. 505-510, 2004.

[65] ZHAO, L.-M.; JIN, H.-S.; SUN, L.-P.; PIAO, H.-R.; QUAN, Z.-S. Synthesis and evaluation of antiplatelet activity of trihydroxychalcone derivatives. Bioorg. Med. Chem. Lett. v. 15, n. 22, p. 5027-5029, 2005. 


\section{Capítulo 8}

\section{Desenvolvimento e avaliação da qualidade físico- química de sabonete em barra a base de óleo de coco (Cocos nucifera)}

\section{Keliane Gonçalves Costa}

Josefa Renalva de Macêdo Costa

Flavia Scigliano Dabbur

Resumo: 0 sabão é um dos produtos de higiene mais antigos utilizados pelo homem. Dentre os óleos de origem vegetal utilizados para a obtenção de produtos cosméticos o óleo de coco (Cocos nucifera), tem ganhado destaque devido à sua rica composição química formada por ácidos graxos. 0 objetivo deste trabalho foi desenvolver um sabonete em barra utilizando somente o óleo de coco como matéria-prima saponificável, amostra manipulada (AM) e posteriormente avaliar as características físico-químicas do produto acabado fazendo comparação a uma formulação comercial semelhante (AC). Os sabonetes foram produzidos de acordo com a técnica a frio (Cold process). Foram testados três diferentes fabricantes de óleo de coco bem como diferentes proporções das matérias-primas na formulação, visando reduzir o quantitativo de hidróxido de sódio no produto. Das seis formulações desenvolvidas uma foi escolhida para a realização dos testes comparativos por apresentar melhor consistência, aspecto e pH. Os testes físicoquímicos foram realizados em triplicata, sendo eles: características organolépticas (cor, odor e aspecto); perda de peso durante a estocagem; perda de massa por amolecimento; resistência à água; resistência à exposição luminosa; formação de rachaduras; avaliação de pH; formação de espuma e estabilidade preliminar. Neste estudo foi possível obter saponificação com menor quantitativo de hidróxido de sódio na formulação. As amostras $\mathrm{AM}$ e AC se mostraram equivalentes nos testes realizados exceto nos testes que exigiram imersão da amostra em água por um período superior a $24 \mathrm{~h}$ onde a AM apresentou desgaste superior a AC.

Palavras-Chave: Sabões. Cosméticos. Cocos nucifera. Óleo de coco. Controle de Qualidade. 


\section{INTRODUÇÃO}

O sabão é utilizado desde a antiguidade, no entanto, não se sabe ao certo suas origens, acredita-se que o mesmo foi descoberto por meio do contato da gordura animal com as cinzas geradas em fogueiras de sacrifícios realizadas por povos ancestrais, de acordo com uma antiga lenda romana estes sacrifícios aconteciam no Monte Sapo, onde a gordura e as cinzas ao se misturarem formavam uma pasta que ao cair da chuva era arrastada chegando até as margens do rio Tibre, as mulheres que lavavam roupas ali passaram a perceber que o contato desta pasta com as roupas as tornavam mais brancas (PEREIRA, 2012; ROMEU, 2013).

De acordo com Prates (2006), o uso farmacêutico do sabão encontra-se descrito no tratado médico Ébers Papyrus (datado de aproximadamente 1.500 A.C.). Este tratado descreve a formação de um material a partir da combinação de óleos animal e vegetal com sais alcalinos semelhantes ao sabão, que era utilizado para a tratar as doenças da pele bem como para a higiene pessoal.

O sabonete é uma evolução do sabão, formado a partir da reação de saponificação que se dá através da junção química de compostos graxos com um álcali na presença de água, tem em sua formulação matériasprimas de melhor qualidade, e seu processo de fabricação é mais rigoroso, resultando assim em um produto de qualidade superior (MERCADANTE; ASSUMPÇÃO, 2010; MARCHEZAN et al., 2014).

Classificado como cosmético de uso externo o sabonete pode conter em sua composição substâncias naturais ou sintéticas, sendo utilizado principalmente para realizar a limpeza, perfumar, corrigir odores, alterar a aparência, e manter em bom estado as diversas partes do copo humano (BRASIL, 2004). Este se encontra na lista de risco grau I (risco mínimo), para produtos a serem utilizados na pele (BRASIL, 2015).

Além disso, situa-se entre os produtos de higiene pessoal mais consumidos no Brasil, os sabonetes ocupam lugar de destaque entre as principais categorias de cosméticos exportados; em janeiro de 2019 foram US\$ 7,4 milhões (ABIHPEC, 2019).

De acordo com Gonçalves e Henkes (2016), o mercado de cosméticos vem evoluindo e sofrendo mudanças, vive atualmente o que se denomina de "onda verde". Seguindo os padrões de exigência de um público cada vez mais preocupado em consumir de forma consciente, os cosméticos produzidos com matérias-primas de origem vegetal têm ganhado notoriedade, pois atendem aos mesmos requisitos éticos de estilo de vida adotados por grande parte dos consumidores que prezam pela saúde e sustentabilidade do meio ambiente (FLOR; MAZIN; FERREIRA, 2019).

Para Moraes (2007) o nível de aceitação dos sabonetes está diretamente relacionado as experiências sensoriais percebidas pelo usuário durante e após o uso do mesmo, visto que os cinco sentidos são a chave das sensações e podem induzir o sistema cerebral a uma maior produção de endorfinas proporcionando a sensação de bem-estar e consequentemente uma melhor experiência com o uso do produto.

A substituição da gordura animal pela gordura vegetal nas formulações cosméticas permite a fabricação de sabonetes mais leves e delicados capazes de promover simultaneamente a limpeza e a proteção da pele conferindo também uma melhor aceitabilidade sensorial. (BARBIZAN; FERREIRA; DIAS, 2013).

Desta maneira, os óleos vegetais extraídos de diferentes plantas oleaginosas podem ser utilizados além da indústria alimentícia, na indústria cosmética estendendo seus benefícios também pra formulações de uso externo (MARTINS; SANTOS, 2015).

Dentre os óleos de origem vegetal que podem ser utilizados para a obtenção de produtos cosméticos está o óleo de coco. A espécie Cocos nucifera é originária do Cabo Verde, e foi introduzida no Brasil, em 1553, pelos portugueses na época da colonização do país. Largamente utilizado na indústria alimentícia o óleo de coco passou a ser utilizado também na indústria cosmética, devido a sua rica composição, contendo $47 \%$ de ácido láurico, $18 \%$ de ácido mirístico, $7 \%$ de ácido cáprico, $9 \%$ de ácido palmítico, $9 \%$ de ácido caprílico, $5 \%$ de ácido oleico, $2 \%$ de ácido esteárico, $2 \%$ de ácido linoleico, $1 \%$ de ácido capróico (RIBEIRO, 2017).

Na pele o óleo de coco promove a nutrição principalmente para peles ressecadas visto que é composto $100 \%$ por ácidos graxos e lipídios, constitui assim uma barreira protetora que mantem por mais tempo a umidade na pele, proporcionando força e flexibilidade aos tecidos conjuntivos (MAJEWSKI, 2017). 
É necessário que haja um controle específico para um adequado processo de desenvolvimento de cosméticos. De acordo com o Guia de Controle de Qualidade de Produtos Cosméticos publicado pela Agência Nacional de Vigilância Sanitária (ANVISA), o controle de qualidade pode ser definido como:

[...] o conjunto de atividades destinadas a verificar e assegurar que os ensaios necessários e relevantes sejam executados e que o material não seja disponibilizado para uso e venda até que ele cumpra com a qualidade preestabelecida. O Controle de Qualidade não deve se limitar às operações laboratoriais, mas abranger todas as decisões relacionadas à qualidade do produto. É de responsabilidade das empresas fabricantes e importadoras submeter os produtos cosméticos ao Controle de Qualidade (BRASIL, 2007, p. 20).

O controle de qualidade é um processo em que são realizadas várias atividades a fim de monitorar toda a cadeia de fabricação avaliando vários pontos referentes ao produto em todas as etapas da fabricação, bem como no produto acabado. Esse acompanhamento é necessário para que seja possível garantir a segurança e eficácia do produto (BRASIL, 2007).

Considerando o uso do sabonete em larga escala em território Nacional, onde o público cada vez mais preocupado em consumir produtos de origem vegetal é crescente (MARQUES, 2014). Torna-se relevante a pesquisa a fim de desenvolver um produto contendo maior quantitativo de ingredientes de origem vegetal e estável físico-quimicamente, para aplicação tópica.

O objetivo deste trabalho foi desenvolver uma base para sabonete em barra utilizando óleo de coco como matéria-prima saponificável, bem como realizar a avaliação das características físico-químicas desta formulação frente a um sabonete comercial, visando oferecer uma colaboração no campo da cosmetologia para ampliar a aplicação de óleos vegetais no desenvolvimento de formulações com maior porcentagem de matérias-primas naturais.

\section{MATERIAL E MÉTODO}

Trata-se de uma pesquisa experimental, desenvolvida nos laboratórios Magistrais e de Controle de Qualidade de Produtos Farmacêuticos da Farmácia Escola do CESMAC, no período de 2019.1 a 2020.1.

A amostra foi um sabonete em barra desenvolvido com ingredientes comprados em fornecedores idôneos (Tabela 1). Uma marca de sabonete comercial contendo óleo de coco foi adquirida por compra direta no mercado local, para a realização dos testes comparativos, estes foram realizados em triplicata a fim de garantir maior confiabilidade aos resultados.

Tabela 1. Descrição da lista de ingredientes do sabonete comercial com INCI name e respectiva função.

\begin{tabular}{|l|l|l|}
\multicolumn{2}{c|}{ Matérias-primas } & \multicolumn{2}{c|}{ Função } \\
\hline Seboato de sódio & Sodium tallowate & Surfactante/Tensoativo \\
\hline Cocoato de sódio & Sodium palm kernelate & Surfactante/Emulsificante \\
\hline Água & Aqua & Solvente \\
\hline Glicerina & Glycerin & Umectante/Solvente \\
\hline Cloreto de sódio & Sodium chloride & Adjuvante/Viscosidade \\
\hline Hidróxido de sódio & Sodium hydroxide & Tampão/Desnaturante \\
\hline EDTA tetrasódico & Tetrasodium edta & Quelante \\
\hline Ácido etidrônico & Etidronic acid & Quelante \\
\hline FBA351 & Disodium distyrylbiphenyl disulfonate & Surfactante/Controle de viscosidade \\
\hline Butilhidroxitolueno (BHT) & Butylated hydroxytoluene & Antioxidante \\
\hline Dióxido de titânio & Titanium dioxide & Corante \\
\hline Óleo de coco & Cocus nucifera (coconut) oil & MP saponificável \\
\hline Fragrância & Parfum, coumarin & Odorizante \\
\hline
\end{tabular}

Fonte INCI name: EUROPEAN COMMISSION, 2006; Autor, 2020. 


\subsection{PROCEDIMENTOS}

\subsubsection{DESENVOLVIMENTO DAS FORMULAÇÕES DO SABONETE BASE COM ÓLEO DE COCO}

Para manipular a formulação do sabonete foi necessário determinar os óleos ou gorduras que foram utilizados em sua composição. Os critérios que embasaram essa decisão foram às propriedades de cada óleo ou gordura a ser utilizada. Uma vez escolhido o óleo, sendo ele o óleo de coco, que de acordo com Mercadante e Assumpção (2010) se faz necessário realizar o cálculo estequiométrico para encontrar a quantidade ideal de hidróxido de sódio a ser utilizada a fim de obter a reação de saponificação. Para óleo de coco o fator utilizado foi de 0,1910 .

Foram realizados testes, a partir deste cálculo 19,1g de $\mathrm{NaOH}$ para $100 \mathrm{~g}$ do óleo de coco. As formulações foram realizadas visando reduzir o quantitativo de $\mathrm{NaOH}$ na formulação sem comprometer a saponificação. Abaixo segue cálculo:

Óleo de coco $=420$ g. Onde $420 \mathrm{~g} \mathrm{x} \mathrm{0,1910=80,22} \mathrm{g} \mathrm{foram} \mathrm{necessárias} \mathrm{80,22} \mathrm{g} \mathrm{de} \mathrm{hidróxido} \mathrm{de} \mathrm{sódio} \mathrm{para}$ saponificar $420 \mathrm{~g}$ do óleo de coco.

\subsubsection{CONTROLE FÍSICO-QUÍMICO DA MATÉRIA PRIMA}

\subsubsection{TESTE DO ÍNDICE DE ACIDEZ DOS ÓLEOS}

0 índice de acidez é um método aplicável a óleos brutos e refinados, vegetais e animais e gorduras animais, que mede a quantidade de ácidos graxos livres contidos no óleo que foram liberados da molécula de glicerol, a partir da relação entre o número, em miligramas, de hidróxido de potássio necessário para neutralização os ácidos livres presentes em uma grama de amostra do óleo, desta forma é possível verificar a acidez do produto analisado. Esse parâmetro é um dos indicativos do grau de degradação dos óleos, que também pode ter a ver com a forma de extração (VASCONCELOS, 2002; INSTITUTO ADOLFO LUTZ, 2008).

0 índice de acidez foi realizado inicialmente pesando $2 \mathrm{~g}$ da amostra líquida em frasco erlenmeyer de 125 $\mathrm{mL}$, foram adicionados $25 \mathrm{~mL}$ de solução de éter-álcool (2:1) neutra e duas gotas da solução indicadora fenolftaleína. Titulou-se com solução de hidróxido de sódio 0,1 M até o aparecimento da coloração rósea e está persistindo por 30 segundos. Após os procedimentos foram realizados os cálculos utilizando a fórmula:

\section{Índice de acidez $=\mathrm{V} \times \mathrm{F} \times 5,61 \div \mathrm{P}$}

Onde:

$$
\begin{aligned}
& \text { V = Volume }(\mathrm{mL}) \text { de solução de hidróxido de sódio } 0,1 \text { M gasto na titulação } \\
& F=\text { Fator da solução de hidróxido de sódio } \\
& \mathrm{P}=\text { Peso da amostra }
\end{aligned}
$$

Fonte: INSTITUTO ADOLFO LUTZ, 2008.

\subsection{FORMULAÇÕES}

A Tabela 2 mostram as formulações em cada uma das seis formulações testadas.

Foram adquiridos três tipos de óleo de coco, sendo um óleo de coco obtido artesanalmente (A) e dois do tipo comercial extra virgem de dois fornecedores diferentes, que foram nomeados B e C. 
Tabela 2. Descrição das quantidades das matérias-primas utilizadas para cada formulação.

\begin{tabular}{|c|c|c|c|c|c|c|c|c|c|}
\hline \multirow{2}{*}{$\begin{array}{l}\text { Matérias-primas } \\
\text { (MP) }\end{array}$} & \multirow{2}{*}{ Fornecedor } & \multirow{2}{*}{ Função } & \multirow{2}{*}{ INCI } & \multicolumn{6}{|c|}{ Formulações (\%) } \\
\hline & & & & 1 & 2 & 3 & 4 & 5 & 6 \\
\hline $\begin{array}{c}\text { Óleo de coco } \\
\text { artesanal }\end{array}$ & A & $\begin{array}{c}\text { MP } \\
\text { saponificável }\end{array}$ & $\begin{array}{l}\text { Cocos nucifera } \\
\text { oil }\end{array}$ & 80 & 60 & - & & & \\
\hline $\begin{array}{l}\text { Óleo de coco } \\
\text { extra virgem }\end{array}$ & B & $\begin{array}{c}\text { MP } \\
\text { saponificável }\end{array}$ & $\begin{array}{l}\text { Cocos nucifera } \\
\text { oil }\end{array}$ & & & 60 & 60 & & \\
\hline $\begin{array}{l}\text { Óleo de coco } \\
\text { extra virgem }\end{array}$ & $\mathrm{C}$ & $\begin{array}{c}\text { MP } \\
\text { saponificável }\end{array}$ & $\begin{array}{l}\text { Cocos nucifera } \\
\text { oil }\end{array}$ & & - & & & 60 & 60 \\
\hline $\begin{array}{l}\text { Hidróxido de } \\
\text { sódio }\end{array}$ & & $\begin{array}{c}\text { Agente } \\
\text { saponificante }\end{array}$ & $\begin{array}{c}\text { Sodium } \\
\text { Hydroxide }\end{array}$ & 19 & 19 & 15 & 10 & 10 & 10 \\
\hline $\begin{array}{c}\text { Butil- } \\
\text { hidroxitolueno }\end{array}$ & & Antioxidante & $\begin{array}{c}\text { Butylated } \\
\text { hydroxytoluene }\end{array}$ & 0,05 & 0,05 & 0,05 & 0,05 & 0,05 & 0,05 \\
\hline $\begin{array}{l}\text { Lauril sulfato de } \\
\text { sódio }\end{array}$ & & $\begin{array}{c}\text { Agente } \\
\text { espumante }\end{array}$ & $\begin{array}{l}\text { Sodium Lauryl } \\
\text { Sulfate }\end{array}$ & 3 & 3 & 3 & 3 & 3 & \\
\hline Água purificada & & Solvente & Aqua & qsp & qsp & qsp & qsp & qsp & qsp \\
\hline
\end{tabular}

Fonte INCI name: EUROPEAN COMMISSION, 2006; Autor, 2020.

\subsubsection{PROCEDIMENTO DE PREPARO DO SABONETE}

Os sabonetes foram produzidos de acordo com a técnica a frio (Cold process), onde as gorduras e a solução alcalina são misturadas em proporções equivalentes em um misturador para que ocorra a saponificação, a emulsão formada neste processo é colocada numa estrutura de resfriamento, onde a saponificação é efetivada (MOTTA, 2007).

O ponto de partida para a fabricação dos sabonetes se deu, a partir da determinação da quantidade de hidróxido de sódio necessária ao processo sendo esta, baseada no índice de saponificação do óleo de coco. 0 procedimento foi realizado em três fases que são elas:

Fase I: Pesou-se o $\mathrm{NaOH}$, e ele foi transferido para um béquer contendo água purificada, agitou-se lentamente até completa dissolução. Nesta fase mesmo sendo denominado um processo a frio a solução formada a partir da água e $\mathrm{NaOH}$ gera aquecimento e resfria naturalmente a medida em que a reação ocorre.

Fase II: Pesou-se o óleo de coco o qual foi transferido para béquer, após resfriamento da Fase I a $40{ }^{\circ} \mathrm{C}$, verteu-se a mesma sobre a Fase II, agitando-se com auxílio de um bastão de vidro.

Fase III: Procedeu-se com a mistura utilizando um agitador mecânico de alta velocidade durante dez minutos. Foram testados dois tipos de mistura com equipamentos e tempos distintos foram eles: Batedeira por um período de uma hora e mixer por um período de dez minutos, mantendo-se a agitação até obtenção de uma forma cosmética com consistência semissólida. A seguir, distribuiu-se rapidamente a massa obtida no molde para sabonetes com capacidade aproximada de $50 \mathrm{~g}$. As amostras permaneceram em temperatura ambiente nos moldes por 7 dias para ganhar forma, após esse período as amostras foram desenformadas e protegidas da luz para evitar mudanças de coloração e em local seguro para evitar a quebra das barras por um período de 40 dias. Desta forma o sabonete se torna mais compacto e liso além de ganhar cor definitiva à medida que a água evapora e o processo de saponificação se completa. Neste processo o sabonete ganha cor definitiva à medida que a água evapora e a saponificação se completa, tornando-se mais compacto e liso (BARBIZAN; FERREIRA; DIAS, 2013).

\subsection{ANÁLISES FÍSICO-QUÍMICAS}

\subsubsection{ANÁLISES FÍSICAS (ASPECTO) PARA ESCOLHA DA MELHOR FORMULAÇÃO}

Para escolha da formulação que melhor atendia os parâmetros físicos de um sabonete, foram verificados o aspecto de todas as seis formulações desenvolvidas. Foram reprovadas as bases que não estavam dentro desses critérios sendo caracterizadas como: base amolecida, endurecida ressecada, levemente ressecada, translúcida. 


\subsubsection{ANÁLISES FÍSICO-QUÍMICAS DO PRODUTO ACABADO FRENTE A AMOSTRA COMERCIAL}

Após os 40 dias a amostra manipulada e a comercial foram submetidas aos testes de características organolépticas (cor, odor, aspecto), teste de perda de massa durante a estocagem, perda de massa/amolecimento, teste de resistência a água (água absorvida), resistência a exposição luminosa, formação de rachaduras, determinação do $\mathrm{pH}$, formação de espuma e estabilidade preliminar (DIEZ; CARVALHO, 2000; BRASIL, 2004; BRASIL, 2007; BARBIZAN; FERREIRA; DIAS, 2013; TESCAROLLO et al.; 2015; SOUZA et al.; 2016).

\subsubsection{CARACTERÍSTICAS ORGANOLÉPTICAS}

São testes utilizados para avaliar as características de um produto, detectáveis pelos órgãos dos sentidos: aspecto, cor, odor e tato. Fornecem parâmetros que permitem avaliar, de imediato, o estado da amostra em estudo por meio de análises comparativas, com o objetivo de verificar alterações, possibilitando o reconhecimento primário do produto (BRASIL, 2004; BRASIL, 2007).

Cor: a análise da cor pode ser realizada por meio visual (colorimetria visual) onde se compara visualmente a cor da amostra com a cor de um padrão. Será efetuada sob a condição de luz "branca" natural ou artificial. A amostra do produto pode ser classificada segundo os seguintes critérios: normal, sem alteração; levemente modificada; modificada; intensamente modificada.

Odor: a amostra e o padrão de referência, acondicionados no mesmo material de embalagem, devem ter seu odor comparado diretamente através do olfato e pode ser classificada segundo os seguintes critérios: normal, sem alteração; levemente modificada; modificada; intensamente modificada.

Aspecto: Observou-se visualmente as características da amostra, verificando se ocorreram modificações macroscópicas em relação ao padrão estabelecido. Esta deve permanecer íntegra durante todo o teste mantendo seu aspecto inicial em todas as condições, exceto em temperaturas elevadas, freezer ou ciclos em que pequenas alterações são aceitáveis. 0 aspecto pode ser descrito como homogêneo, heterogêneo, transparente, opaco, leitoso. A amostra pode ser classificada segundo os seguintes critérios: normal, sem alteração; alterado, mudança de forma, volume ou aparência visual da amostra (BRASIL, 2004).

\subsubsection{PERDA DE PESO - DURANTE ESTOCAGEM}

Tem como objetivo avaliar a perda de massa das amostras simulando as condições normais de uso. Foram avaliadas 3 barras de sabões, as quais ficaram armazenadas sem embalagem e expostas sob temperatura ambiente $25^{\circ} \mathrm{C}$, simulando as condições normais de uso. Foram determinadas as massas iniciais e massas após 7, 14, 21 e 28 dias (SOUZA et al., 2016).

\subsubsection{PERDA DE MASSA / AMOLECIMENTO}

Para medir a taxa de desgaste (perda de massa) 3 (três) barras foram pesadas (m1), imersas em um recipiente contendo $250 \mathrm{~mL}$ de água purificada e deixadas em repouso por um período de 24 horas a 25 ㅇ. A. Após este período, as barras foram retiradas e pesadas novamente $(\mathrm{m} 2)$ sendo colocadas sobre papel toalha por 2 horas e, posteriormente, retiradas as partes amolecidas até que se verificasse a área sólida. Após esse procedimento a barra resultante foi pesada novamente $(\mathrm{m} 3)$. A partir da diferença entre a massa inicial (m1) e massa final (m3) foram calculadas as porcentagens de perda de massa. Este ensaio apresenta um caráter qualitativo sendo usadas faixas comparativas de acordo com os seguintes critérios: Faixa I: \% Perda de Massa e 0 - 10; Faixa II: \% Perda de Massa e 10 - 20; Faixa III: \% Perda de Massa e 21 - 30; Faixa IV: \% Perda de Massa e 31 - 40 (BARBIZAN; FERREIRA; DIAS, 2013).

\subsubsection{RESISTÊNCIA À ÁGUA (ÁGUA ABSORVIDA)}

Para medir a água absorvida (resistência à água), 3 (três) barras foram pesadas (m1), imersas em um recipiente contendo $250 \mathrm{~mL}$ de água purificada e mantidas em repouso por um período de 24 horas sob temperatura ambiente. 
Em seguida, as amostras foram retiradas e após eliminação do excesso de água foi realizada nova pesagem (m2). A diferença entre a massa inicial (m1) e massa final (m2) foi calculada para encontrar o teor de água absorvida (SOUZA et al., 2016).

\subsubsection{RESISTÊNCIA A EXPOSIÇÃO LUMINOSA}

0 teste de resistência a exposição luminosa foi efetuado a fim de verificar possíveis alterações nas barras analisadas, mantendo-se a metade da barra exposta à luz natural e a outra metade coberta com papel alumínio, para isto foram verificadas possíveis alterações na cor, odor e aspecto do produto, comparandose a parte exposta à parte coberta. 0 teste foi realizado sob temperatura ambiente. As amostras foram avaliadas visualmente por um período de 21 dias (BARBIZAN; FERREIRA; DIAS, 2013).

\subsubsection{FORMAÇÃO DE RACHADURAS}

Três barras foram penduradas em um suporte e imersas até a metade, dentro de béqueres contendo 500 $\mathrm{mL}$ de água purificada. As barras permaneceram parcialmente imersas por um período de 24 horas em temperatura ambiente. Após este período as barras foram retiradas da água e pesadas, após o procedimento as barras permaneceram suspensas para secagem ao ar livre por 30 horas no mesmo suporte. A avaliação das amostras foi realizada visualmente a fim de verificar a formação de rachaduras, sendo estas classificadas como: muito leves (espessura do cabelo), leves (fina superfície), médias (evidente superfície/interface), maiores (toda superfície) e largas (fendas) (DIEZ; CARVALHO, 2000; TESCAROLLO et al., 2015).

\subsubsection{PH}

O pH foi determinado por imersão direta de pHmetro em uma solução a 10 \% do sabonete diluído em água purificada (BRASIL, 2007).

\subsubsection{FORMAÇÃO DE ESPUMA}

Para a realização desse teste foi utilizada, água purificada a temperatura de $25 \stackrel{\circ}{\circ} \mathrm{C}$, sendo esta utilizada para preparar as soluções das amostras do sabonete diluído na concentração a $2 \%$. 0 procedimento foi realizado transferindo $50 \mathrm{~mL}$ da solução preparada para proveta de $100 \mathrm{~mL}$. A proveta foi invertida 10 vezes, em movimentos sincronizados. Logo após essa operação determinou se a altura da espuma formada, foram realizadas mais duas determinações com intervalos de 5 minutos. Os valores obtidos com a formulação manipulada e comercial em estudo foram comparados com os valores das alturas de uma solução padrão de lauril sulfato de sódio preparado nas mesmas condições das amostras (SOUZA et al., 2016).

\subsubsection{ESTABILIDADE PRELIMINAR}

Consiste na realização do teste na fase inicial do desenvolvimento do produto, utilizando-se diferentes formulações de laboratório e com duração reduzida. Emprega-se condições extremas de temperatura com o objetivo de acelerar possíveis reações entre seus componentes e o surgimento de sinais que devem ser observados e analisados conforme as características específicas de cada tipo de produto. 0 estudo não tem a finalidade de estimar a vida útil do produto, mas sim de auxiliar na triagem das formulações. Amostras em barras, foram armazenadas em diferentes condições controladas de temperatura e umidade relativa (UR), em refrigerador $\left(5^{\circ} \mathrm{C}\right.$ e $55 \%$ UR), temperatura ambiente $\left(25^{\circ} \mathrm{C}\right.$ e $75 \%$ de UR) e em estufa $\left(40{ }^{\circ} \mathrm{C}\right.$ e $60 \%$ UR). Os testes foram realizados semanalmente, por um período de 28 dias e os parâmetros avaliados foram: aspecto, odor e coloração (BRASIL, 2004; TESCAROLLO et al., 2015). 


\section{RESULTADOS E DISCUSSÃO}

Para Peixoto (1998) existem vários fatores que podem influenciar no índice de acidez de um óleo, como a qualidade da matéria-prima, seu grau de maturação, infestações por microrganismos, o modo de obtenção do óleo que pode ser produzido de forma mecânica e/ou com o uso de solvente além do processo de refino ou mistura também podem ser a causa de alterações nos valores deste índice.

A resolução no 270/2005/MS estabelece uma faixa de segurança acerca dos níveis máximos permitidos de acidez para os diversos tipos de óleos e gorduras, indicando assim as características mínimas de qualidade que são estabelecidas para esses produtos. Para óleos e gorduras refinados (exceto azeite de oliva refinado e óleo de bagaço de oliva refinado): máximo 0,6 $\mathrm{mg} \mathrm{KOH/g}$ e para óleos prensados a frio e não refinados: máximo 4,0 mg KOH/g (BRASIL, 2005).

Desta maneira o índice de acidez é um dado importante na avaliação do estado de conservação do óleo visto que um processo de decomposição, seja por hidrólise, oxidação ou fermentação altera quase sempre a concentração dos íons hidrogênio na amostra podendo o tornar inviável para o uso (INSTITUTO ADOLF LUTZ, 2008).

As amostras de óleo extra virgem testadas permaneceram na faixa de acidez permitida, no entanto a amostra de óleo artesanal mostrou um índice de acidez, superior aos outros óleos analisados ultrapassando a faixa estabelecida pela resolução $(4,0 \mathrm{mg} \mathrm{KOH} / \mathrm{g})$ (Tabela 3), este pode ter sido um fator que contribuiu negativamente no resultado da saponificação nas bases para sabonete 1 e 2 testadas, visto que com o índice de acidez mais alto este demanda maior quantidade de álcali para que seja realizada a saponificação (BRASIL, 2005).

Tabela 3. Resultados do teste de índice de acidez do óleo de coco de diferentes fornecedores.

\begin{tabular}{|c|c|c|}
\hline Tipo de óleo & \multicolumn{1}{c|}{ Fornecedor } & \multicolumn{1}{c|}{ Resultado (IA) } \\
\hline Artesanal & $\mathrm{A}$ & $\mathrm{IA}=8,220$ \\
\hline Extra virgem & $\mathrm{B}$ & $\mathrm{IA}=0,337$ \\
\hline Extra virgem & $\mathrm{C}$ & $\mathrm{IA}=0,519$ \\
\hline
\end{tabular}

Fonte: Dados da pesquisa (2020).

Foram desenvolvidas e testadas seis formulações para sabonete base utilizando como matéria-prima saponificável o óleo de coco de extração artesanal (A), extra virgem comercial (B) e (C). A técnica utilizada foi a de saponificação a frio (Cold Process) onde os óleos e a solução alcalina foram misturados em proporções equivalentes.

A técnica de saponificação Cold Process é uma forma de produzir sabonetes através da mistura do óleo escolhido com um álcali a fim de gerar uma reação química denominada saponificação. Este método foi escolhido devido à algumas vantagens sobre outras técnicas para a produção de sabões, permite produzir um sabonete de boa qualidade onde o produto resultante é mais delicado e compacto (PUTON, 2019).

0 processo não submete a massa a altas temperaturas, desta forma evita-se principalmente a degradação das propriedades do óleo utilizado, nessa reação além da formação do sabão é gerada a glicerina e está permanece na base conferindo propriedades benéficas ao produto final, permitindo assim uma limpeza mais suave e hidratante, diferente do que ocorre nos processos industriais onde a glicerina formada durante o processo de saponificação é retirada pelo seu alto valor de mercado (PUTON, 2019).

Inicialmente não foram obtidos resultados satisfatórios com as formulações onde foram utilizados óleo de coco natural e extra virgem do fornecedor B mesmo após realizados vários ajustes na quantidade dos princípios ativos da formulação, e testadas diferentes formas de mistura. As problemáticas apresentadas foram determinadas pelas análises físico-químicas.

Os resultados dessas análises prévias demonstraram que, a formulação 1 e 2, apresentaram base amolecida com odor desagradável, a formulação 3 mostrou-se endurecida e ressecada com presença de grânulos, a formulação 4 apresentou base amolecida translúcida com visível excesso de óleo, a formulação 5 se mostrou endurecida, mas levemente ressecada com grânulos. A partir destes resultados a formulação 6 foi desenvolvida realizando a diminuição do hidróxido de sódio e retirada do lauril sulfato de sódio, visto que este permanecia tornando a base mais áspera e com grânulos. 
Nas formulações testadas, além de diferentes concentrações das matérias-primas foram testados alguns tipos de mistura, utilizando equipamentos e tempos de agitação diferentes (Tabela 4). Foi possível verificar que o misturador mais eficiente para esse processo é o agitador mecânico de alta velocidade, possivelmente porque incorpora mais ar a massa formando uma mistura semi-sólida mais rapidamente. A formulação 6 foi a de escolha, pois permaneceu com boa saponificação e bom aspecto para dar continuidade aos testes físico-químicos.

Tabela 4. Tipo de misturador utilizado e resultados obtidos nas formulações teste.

\begin{tabular}{|c|c|c|l|}
\hline Formulação & Equipamento & Tempo (minutos) & \multicolumn{1}{c|}{ Resultado } \\
\hline 1 & Batedeira & 60 & Base amolecida \\
\hline 2 & Batedeira & 60 & Base amolecida \\
\hline 3 & Batedeira & 60 & Base endurecida ressecada \\
\hline 4 & Batedeira & 10 & Base amolecida translucida com visível excesso de óleo \\
\hline 5 & Mixer & 10 & Base endurecida e levemente ressecada \\
\hline 6 & Mixer & 10 & Base endurecida com bom aspecto \\
\hline
\end{tabular}

De acordo com o Guia de Controle de Qualidade de Produtos Cosméticos (BRASIL, 2007), o controle de qualidade e as observações da conformidade das especificações são requisitos necessários para que seja possível garantir a segurança, eficácia e qualidade do produto. Desta forma após ser realizado o desenvolvimento da formulação ideal, procedeu-se com a realização dos testes comparativos frente a um sabonete comercial contendo óleo de coco (Tabela 5).

Tabela 5. Resultados dos ensaios físico-químicos dos sabonetes manipulado e comercial.

\begin{tabular}{|c|c|c|}
\hline $\begin{array}{c}\text { TESTES } \\
\text { Ensaios organolépticos }\end{array}$ & Amostra manipulada (AM) & Amostra comercial (AC) \\
\hline Cor & Branca & Branca \\
\hline Odor & Característico de coco & Característico de sabonete neutro \\
\hline Apecto & Homogêneo/ opaco & Homogêneo/ opaco \\
\hline \multicolumn{3}{|l|}{ Perda de peso durante estocagem (g) } \\
\hline Tempo 0 & $15,63 \pm 0,0444$ & $15,60 \pm 0,3333$ \\
\hline 7 dias & $15,50 \pm 0,0666$ & $15,36 \pm 03111$ \\
\hline 14 dias & $15,33 \pm 0,0444$ & $15,33 \pm 0,2888$ \\
\hline 21 dias & $15,40 \pm 0$ & $15,33 \pm 0,2888$ \\
\hline 28 dias & $15,30 \pm 0$ & $15,33 \pm 0,2888$ \\
\hline Perda $(\mathrm{g})$ & $0,33 \pm 0,0444 / 2,11 \%$ & $0,26 \pm 0,0888 / 1,66 \%$ \\
\hline Perda de Massa por amolecimento & \multirow[b]{2}{*}{ Total dissolução após 24 h (Faixa IV) } & \multirow[b]{2}{*}{ Perda de 37,33 \% (Faixa IV) } \\
\hline $\begin{array}{c}\text { Faixa I: } \% 0 \text { - } 10 \text {; Faixa II: } \% 10-20 \text {; Faixa III: } \% \\
21-30 \text {; Faixa IV: } \% 31-40\end{array}$ & & \\
\hline Resistência a água & Total dissolução após 24 h & Aumento de $76,79 \%$ \\
\hline Resistência a exposição luminosa & Alteração leve no odor após 21 dias & $\begin{array}{c}\text { Alteração leve no odor após } 21 \\
\text { dias }\end{array}$ \\
\hline \multirow{2}{*}{$\begin{array}{l}\text { Formação de rachaduras } \\
\text { pH }\end{array}$} & Total dissolução após 24 h & Rachaduras leves \\
\hline & $\mathrm{pH} 9,89 \pm 0,04\left(20,8{ }^{\circ} \mathrm{C}\right)$ & $10,29 \pm 0,05\left(20,8^{\circ} \mathrm{C}\right)$ \\
\hline
\end{tabular}

Fonte: Dados da pesquisa (2019).

Nos ensaios organolépticos, a amostra manipulada (AM) e amostra comercial (AC) apresentaram coloração branca, sem brilho, as barras se mostraram duras com poucas descamações e aspecto homogêneo e opaco. As amostras apresentaram resultados equivalentes quanto a cor e aspecto, diferindo apenas no item análise de odor onde a AM apresentou odor característico de óleo de coco e a AC apresentou odor característico de sabão comum, este resultado se deu provavelmente pela quantidade dos outros ingredientes presentes na $\mathrm{AC}$ visto que na AM os únicos ingredientes utilizados foram o óleo de coco e o hidróxido de sódio. 
Através dos resultados obtidos no teste de perda de peso durante a estocagem foi possível avaliar a perda de massa das amostras simulando as condições normais de armazenagem ao longo de 28 dias onde, as variações de peso observadas nas amostras foram analisadas a cada sete dias e expressos em termos da média das três amostras com desvio padrão e também em percentual. A perda foi de $2,11 \%$ na $\mathrm{AM}$ e $1,66 \%$ de perda na AC. A evaporação em maior quantidade na AM pode estar relacionada com a maior quantidade de óleo vegetal na composição da AM podendo ser fator desencadeante de uma maior volatilidade no produto e consequente perda de peso (BARBIZAN; FERREIRA; DIAS, 2013).

Os sabonetes, de maneira geral, após deixados sobre uma superfície com resíduo de água como ocorre em saboneteiras, tendem a absorver a água presente no recipiente levando a formação de um material gelatinoso, resultado do amolecimento da barra, este amolecimento da barra está diretamente ligado ao desgaste do sabonete e como consequência em uma menor durabilidade do produto. 0 desgaste será maior ou menor de acordo com a formulação do produto (DIEZ; CARVALHO, 2000).

0 desgaste das amostras foi analisado através do teste de perda de massa por amolecimento utilizando as amostras AM e AC, a fim de verificar a quantidade de massa resultante na barra após $24 \mathrm{~h}$ submersa em água. Após este período a AM apresentou total dissolução da formulação não sendo possível avaliar o valor da perda em relação ao tempo, já na AC a perda foi de 37,33 \% sendo classificada como (Faixa IV), visto que a perda de massa ficou entre 31-40 \%. Com esse teste foi possível observar o alto grau de desgaste da AM pois apresentou dissolução antes do período de análise e alto grau de desgaste também na AC visto que classificado como faixa IV, apresentou grande índice de perda de massa, sendo este um fator negativo pois determina nessas condições um menor tempo de duração do produto.

No teste de resistência a água foi verificada a quantidade água absorvida pela amostra em um período de $24 \mathrm{~h}$ a AM apresentou total dissolução após o período de submersão em água e a AC obteve um aumento de 76,79 \% em relação ao seu peso inicial. Foi possível observar que a AC não se dissolveu, mas absorveu bastante água tornando a barra amolecida.

Como descrito por Moraes (2007), a partir dos anos 1970 ocorreram mudanças no mercado mundial dos sabonetes, onde a utilização de formulações com base $100 \%$ sintética passou a ser sistemática, atendendo ao apelo do consumidor que opta por formulações que ofereçam maior ação hidratante e emoliente para a pele, estes requisitos passaram a ser referência de mercado onde foram criadas várias opções técnicas de formulações sintéticas podendo ser combinadas ou não partindo da na utilização de frações especiais de triglicérides de ácidos graxos (TAG) ou de sistemas de lipídeos (SLs), a fim de manter a estabilidade da composição e trazer benefícios funcionais diversos ao produto. Desta forma as bases sintéticas tendem a se tornar amolecidas não dissolvendo rapidamente em contato com a água devido a substâncias inclusive derivadas da gordura animal presentes nessas formulações.

Os resultados do teste para avaliar a resistência à exposição luminosa demonstraram que as partes expostas não apresentaram alterações quanto a coloração, ou aspecto, no entanto foi possível observar um leve odor não característico nas amostras AM e AC quando comparadas com as barras não expostas.

Desta forma, foi possível verificar a necessidade de um acondicionamento em embalagens que ofereçam proteção contra a incidência de luz, para evitar possíveis alterações de odor nas barras, pois estas modificações podem impactar diretamente na experiência olfativa com o uso do produto gerando resultados negativos na aceitabilidade desse produto pelo consumidor (TESCAROLLO et al., 2015).

Para Diez e Carvalho (2000) tanto a composição, como o processo de fabricação, são fatores desencadeantes na ocorrência de rachaduras em sabonetes, desta forma o teste de formação de rachaduras é importante no processo de aprovação de uma nova formulação para sabonete, visto que o aparecimento de rachaduras torna o produto pouco atrativo tanto visualmente como sensorialmente, este processo pode ocorrer devido à falta de componentes umectantes na formulação promovendo assim o ressecamento da barra quando exposto em condições habituais de uso.

No teste de formação de rachaduras as barras referentes as formulações AM e AC, permaneceram parcialmente submersas por um período de $24 \mathrm{~h}$ e logo após foram penduradas no mesmo suporte para secagem por um período de 30 horas. Como ocorrido nos testes anteriores a AM apresentou total dissolução após $24 \mathrm{~h}$ parcialmente submersa não sendo possível observar a formação de rachaduras, já na $\mathrm{AC}$ as barras apresentaram rachaduras finas em sua superfície, esta foi classificada como rachaduras (leves) visto que as rachaduras se apresentaram finas e superficiais. 
A determinação do $\mathrm{pH}$ tem suma importância nos testes a serem realizados em produtos cosméticos pois determina a eficácia e segurança do produto, além de estar relacionada com a compatibilidade dos componentes da formulação (BARBIZAN; FERREIRA; DIAS, 2013). No presente estudo o pH foi determinado através da verificação de solução a $10 \%$ de cada formulação, os resultados foram os seguintes, a AM pH 9,89 e AC 10,29. De acordo com a recomendação do guia de controle de qualidade em produtos cosméticos, Brasil (2007), o pH ideal para sabonetes em barra deve estar no máximo em torno de 10,4 (exceto em casos de sabonetes líquidos neutros), as amostras testadas AM e AC permaneceram dentro do limite permitido, não ultrapassando a faixa de $\mathrm{pH}$ aceitável para sabonetes em barra.

A Tabela 6 mostra os resultados do teste de formação de espuma na amostra desenvolvida e na comercial comparado à solução padrão que foi utilizado o Lauril éter sulfato de sódio.

Tabela 6. Resultados do teste de formação de espuma.

\begin{tabular}{|c|c|c|c|}
\hline Formação de espuma & AM & $\mathrm{AC}$ & Solução Padrão \\
\hline Tempo 0 & Ultrapassou $100 \mathrm{~mL}$ & $65 \mathrm{~mL}$ & Ultrapassou $100 \mathrm{~mL}$ \\
\hline 5 minutos & Ultrapassou $100 \mathrm{~mL}$ & $62 \mathrm{~mL}$ & $75 \mathrm{~mL}$ \\
\hline 10 minutos & Ultrapassou $100 \mathrm{~mL}$ & $60 \mathrm{~mL}$ & $65 \mathrm{~mL}$ \\
\hline
\end{tabular}

No teste de formação de espuma foi possível observar diferença significativa entre as soluções AM, AC e Padrão, visto que a solução da $\mathrm{AM}$ inicialmente mostrou bastante espuma sendo esta densa, permanecendo estável até o término do teste, a AC, mostrou espuma densa, no entanto com volume significativamente inferior, este reduziu pouco de acordo com o tempo da análise, já a solução padrão mostrou inicialmente espuma alta e densa, mas rapidamente baixou seu nível e tornou-se menos densa.

0 aumento de espuma na amostra AM pode ser devido à adição do óleo com seus ácidos graxos livres, visto que não foi utilizado nenhum tensoativo na formulação, já na AC, a pouca formação de espuma pode estar relacionada com as outras substâncias presentes na formulação deixando a espuma pesada e instável, tendo seu nível minimizado rapidamente (BIGHETTI, 2008).

0 teste de estabilidade preliminar buscou verificar o comportamento das amostras em diferentes condições de armazenamento por um período de 28 dias. Conforme demonstrado no Quadro 1, ao longo dos 28 dias de análise as amostras AM e AC não apresentaram mudanças no aspecto, odor e coloração, quando armazenados em temperatura ambiente e refrigerador, no entanto ao serem armazenados em estufa a uma temperatura de $40^{\circ} \mathrm{C}$, as amostras apresentaram alteração na cor tornando-se levemente amareladas a partir do décimo quarto dia, aos 28 dias de análise a AC apresentou leve odor não característico quando comparado a AM.

Quadro 1. Resultados do teste de estabilidade preliminar onde foram avaliadas as alterações em aspecto, odor e coloração.

\begin{tabular}{|c|c|c|c|c|c|c|c|c|c|c|}
\hline \multirow[t]{2}{*}{ ANÁLISES } & $\begin{array}{c}\text { T0 } \\
\text { (inicial) }\end{array}$ & \multicolumn{3}{|c|}{ T 7dias } & \multicolumn{3}{|c|}{ T 14 dias } & \multicolumn{3}{|c|}{ T 28 dias } \\
\hline & & $\begin{array}{c}5 \\
{ }^{\circ} \mathrm{C}\end{array}$ & $\begin{array}{l}25 \\
{ }^{\circ} \mathrm{C}\end{array}$ & $\begin{array}{l}45 \\
{ }^{\circ} \mathrm{C}\end{array}$ & $\begin{array}{c}5 \\
{ }^{\circ} \mathrm{C}\end{array}$ & $\begin{array}{l}25 \\
{ }^{\circ} \mathrm{C}\end{array}$ & $\begin{array}{l}45 \\
{ }^{\circ} \mathrm{C}\end{array}$ & $\begin{array}{c}5 \\
{ }^{\circ} \mathrm{C}\end{array}$ & $\begin{array}{l}25 \\
{ }^{\circ} \mathrm{C}\end{array}$ & $\begin{array}{l}45 \\
{ }^{\circ} \mathrm{C}\end{array}$ \\
\hline \multicolumn{11}{|l|}{$\begin{array}{c}\text { AMOSTRA } \\
\text { AM }\end{array}$} \\
\hline ASPECTO & $\mathrm{H}$ & $\mathrm{H}$ & $\mathrm{H}$ & $\mathrm{H}$ & $\mathrm{H}$ & $\mathrm{H}$ & $\mathrm{H}$ & $\mathrm{H}$ & $\mathrm{H}$ & $\mathrm{H}$ \\
\hline COR & BO & BO & BO & BO & BO & BO & BO & BO & BO & BO \\
\hline ODOR & CC & CC & CC & CC & CC & CC & AC & CC & CC & AC \\
\hline \multicolumn{11}{|l|}{$\begin{array}{c}\text { AMOSTRA } \\
\text { AC }\end{array}$} \\
\hline ASPECTO & $\mathrm{H}$ & $\mathrm{H}$ & $\mathrm{H}$ & $\mathrm{H}$ & $\mathrm{H}$ & $\mathrm{H}$ & $\mathrm{H}$ & $\mathrm{H}$ & $\mathrm{H}$ & $\mathrm{H}$ \\
\hline COR & BO & BO & BO & BO & BO & BO & AC & AC & BO & AC \\
\hline ODOR & $\mathrm{CSC}$ & CSC & $\mathrm{CSC}$ & $\mathrm{CSC}$ & $\mathrm{CSC}$ & CSC & $\mathrm{AO}$ & CSC & $\mathrm{AO}$ & $\mathrm{AO}$ \\
\hline
\end{tabular}

Legenda: (H) homogêneo, BO Branco opaco, CC Característico de coco, (CSC) Característico de sabão comum, (AO) Alteração em odor, (AC) Alteração na coloração (SA) sem alteração.

Fonte: Dados da pesquisa (2019). 
De acordo com os resultados obtidos, houveram diferenças nos testes físicos uma vez que a AM apresentou rápida e total dissolução, antes do período de análise nos testes que exigiram imersão em água, pois em sua formulação somente havia os ingredientes saponificáveis (óleo de coco - material graxo) em maior quantidade e material saponificante (álcali) quando comparado a formulação comercial. Desta forma foi possível observar que a amostra manipulada se mostra com menos teor de aditivos químicos que retardam a sua dissolução em relação a amostra comercial.

A formulação manipulada busca atender um padrão de consumo crescente no Brasil e no mundo, onde o consumidor tem priorizado utilizar produtos com maior quantidade de ativos naturais pois além de contribuírem para a saúde e sustentabilidade do meio ambiente tem a proposta de promover a conscientização e a beleza livre de crueldade, não realizando testes em animais (FLOR; MAZIN; FERREIRA, 2019).

No Brasil, bem como em muitos países, não há uma regulamentação oficial para produtos cosméticos naturais e orgânicos, porém existem organizações que definem regras e padrões próprios, emitindo certificações para produtos cosméticos que atendam aos conceitos estabelecidos para cada categoria. Todo o processo é levado em consideração desde a origem das matérias-primas até a sua degradação. No entanto muitos fabricantes ainda acabam explorando esse "apelo verde", utilizando em seus produtos concentrações mínimas de matéria-prima de origem natural, (muitas vezes concentrações inferiores a 1 \%). Desta forma é possível observar o interesse meramente mercadológico em explorar um conceito atual de produto ideal, não atendendo a real proposta vinculada ao "cosmético verde" (FLOR; MAZIN; FERREIRA, 2019).

\section{CONCLUSÃO}

Nas condições experimentais do presente estudo, conclui-se que o objetivo proposto foi atingido através da produção de um sabonete utilizando o óleo de coco como única matéria-prima saponificável empregando a técnica a frio (Cold Process), obtendo um sabonete com características organolépticas adequadas e bom desemprenho nos testes físico-químicos e ainda com uso de menor quantitativo de hidróxido de sódio na formulação.

Os testes realizados permitiram verificar as características físico-químicas da amostra produzida frente a comercial, além de diferenças importantes quanto aos resíduos gerados após desgaste total das barras em água. Desta forma, verificou-se que produtos formulados com matérias-primas naturais tendem a gerar menos resíduos com seu desgaste minimizando, assim a contaminação e impactos causados ao meio ambiente após seu descarte.

É fundamental que uma nova proposta de sabonete além de atender aos requisitos impostos pelo consumidor atual como benefício funcional e preocupação ambiental, também venha a agregar valor emocional ao produto, visto que a aceitação por parte do usuário está diretamente ligada as experiências sensoriais percebidas durante o uso o tornando-o mais propício a aceitação do item em questão. Desta maneira torna-se relevante estudos de avaliação sensorial desta nova formulação a fim de complementar o desenvolvimento do produto para possível comercialização.

\section{REFERÊNCIAS}

[1] ABIHPEC. Associação brasileira da indústria de higiene pessoal, perfumaria e cosméticos. Boletim de Estatísticas de Comércio Exterior. São Paulo: Departamento de Comunicação \& Marketing da ABIHPEC, 2019. Disponível em: https://www.adipec.com.br/assets/pdf/bece-abihpec-01-2019.pdf. Acesso em: 02 mar. 2020.

[2] BARBIZAN, F.; FERREIRA, E. C.; DIAS, I. L.T. Sabonete em barra produzido com Óleo de oliva (Olea europea L.) como proposta para o desenvolvimento de cosméticos verdes. Biofar. Rev. Biol. Farm., Campina Grande, v.9, n. 1, p. 116-127, maio 2013. Disponível em: https://pt.scribd.com/document/266368247/Sabonete-Em-Barra-ProduzidoCom-de-Oleo-de-Oliva-1. Aceso em: 26 nov. 2019.

[3] BIGHETTI, A. E et al. Desenvolvimento de sabonete em barra com óleo de buriti (Mauritia Flexuosa L.). Infarma, São Paulo, v.20, n. 5/6, 2008. Disponível em: http://revistas.cff.org.br/infarma/article/view/203. Acesso em: 23 abril 2020.

[4] BRASIL. Ministério da Saúde. Agência Nacional de vigilância sanitária. Guia de Estabilidade de Produtos Cosméticos: Série Qualidade em Cosméticos. Brasília: ANVISA, 2004. Disponível em: http://portal.anvisa.gov.br/documents/106351/107910/Guia+de+Estabilidade+de+Produtos+Cosm\%C3\%A9ticos/4 9cdf34c-b697-4af3-8647-dcb600f753e2. Acesso em: 10 dez. 2019. 
[5] BRASIL. Ministério da Saúde. Agência Nacional de vigilância sanitária. Resolução RDC № 270, de 22 de setembro de 2005 - Aprova o regulamento técnico para óleos vegetais, gorduras vegetais e creme vegetal. Brasília: ANVISA, 2005. Disponível em: http://bvsms.saude.gov.br/bvs/saudelegis/anvisa/2005/rdc0270_22_09_2005.html. Acesso em: 15 jan. 2020.

[6] BRASIL. Ministério da Saúde. Agência Nacional de vigilância sanitária. Guia de Controle de Qualidade de Produtos Cosméticos: Uma Abordagem sobre os Ensaios Físicos e Químicos. Brasília, DF: ANVISA, 2007. Disponível em: https://www.crq4.org.br/downloads/guia_cosmetico.pdf. Acesso em: dez. 2019.

[7] BRASIL. Ministério da Saúde. Agência Nacional de Vigilância Sanitária. Resolução RDC № 07, de 10 de fevereiro de 2015- Dispõe sobre os requisitos técnicos para a regularização de produtos de higiene pessoal, cosméticos e perfumes e dá outras providências. Brasília: ANVISA, 2015. Disponível em: http://bvsms.saude.gov.br/bvs/saudelegis/anvisa/2015/rdc0007_10_02_2015.pdf. Acesso em: 15 fev. 2020.

[8] DIEZ, M. A; CARVALHO, G. S. C. Aditivos para sabonetes em barra. Oxiteno S/A Indústria e comércio. São Paulo, 2000. Disponível em: https://document.onl/documents/aditivos-para-sabonetes.html Acesso em: 24 mar. 2020.

[9] EUROPEAN COMMISSION. Official Journal of the European Union: amending Decision 96/335/EC establishing an inventory and a common nomenclature of ingredients employed in cosmetic products, Brussels: COMMISSION, 9 feb. 2006, p 528. Disponível em: https://ec.europa.eu/growth/tools-databases/cosing/. Acesso em: 30 mar. 2020.

[10] FLOR, J.; MAZIN, M. R.; FERREIRA, L.A. Cosméticos Naturais, Orgânicos e Veganos. Cosmetics \& Toiletries Brasil, São Paulo, v.31 n. 3, p.30-36, maio/jun 2019. Disponível em: https://www.cosmeticsonline.com.br/artigo/87. Acesso em 05 mar. 2020

[11] GONÇALVES, J. S.; HENKES, J. A. Produção de cosméticos de forma mais sustentável. R. Gest. Sust. Ambiente, Florianópolis, v. 5, n. 1, p. $473 \quad$ - $\quad 488$, abr./set. 2016. Disponível em: https://www.researchgate.net/publication/318220094_PRODUCAO_DE_COSMETICOS_DE_FORMA_MAIS_SUSTENTA VEL. Acesso em: 07 mar. 2020.

[12] INSTITUTO ADOLFO LUTZ. Métodos físico-químicos de análise de alimentos. São Paulo, v. 1 n.1, p.11020, 2008. Disponível

http://www.ial.sp.gov.br/resources/editorinplace/ial/2016_3_19/analisedealimentosial_2008.pdf. Acesso em: 06 abr. 2020.

[13] MAJEWSKI, A. Óleo de coco e suas propriedades. Farmacêuticas consultoria. São Paulo, 29 maio 2017.Disponível em: https://www.farmaceuticas.com.br/oleo-de-coco-e-suas-propriedades/ Acesso em: 29 mar. 2020.

[14] MARChEZAN, M. P. et al. Produção de sabonetes sólidos com óleo usado e essência de cravo-da-índia. REGET/UFSM, Santa Maria, v. 18 n. 1, p.577-582, abr. 2014. Disponível em: https://periodicos.ufsm.br/reget/article/view/12684/pdf. Acesso em: 08 mar. 2020.

[15] MARQUES, A. A. Avaliação comparativa das propriedades físico-químicas de sabonetes sólidos de baixo e de alto custo. 2014. 45f. Trabalho de Conclusão de Curso (Graduação) Universidade Estadual da Paraíba. Campina Grande, 2014. Disponível em: http://dspace.bc.uepb.edu.br/jspui/bitstream/123456789/3800/1/PDF\%20\%20Amanda\%20Agostinho\%20Marques.pdf. Acesso em: 19 fev. 2020.

[16] MARTINS, J. S.; SANTOS, J. C. O. Estudo comparativo das propriedades do óleo de coco obtido pelos processos industrial e artesanal. In: ERQ. 5o Encontro Regional de Química \& 4o Encontro Nacional de Química, 2015, Mossoró/RN. Anais Blucher Proceedings. São Paulo: Blucher LTDA, 2015. P. 526. Disponível em: http://www.proceedings.blucher.com.br/article-details/estudo-comparativo-das-propriedades-de-leo-de-cocoobtido-pelos-processos-industrial-e-artesanal-22108. Acesso em: 01 mar. 2020.

[17] MERCADANTE, R.; ASSUMPÇÃO, L. Massa base para sabonetes: fabricando sabonetes sólidos. Projeto Gerart VII Revisão 2010, UNIOESTE-Paraná, p.1-15, 2010. Disponível em: http://cantinhodaunidade.com.br/wpcontent/uploads/2014/03/apostila7.pdf. Acesso em: 28 ago. 2019.

[18] MORAES, L. Sabonetes: Inovando no Desenvolvimento com Tecnologia. Cosmetics \& Toiletries Brasil, São Paulo, v. 19, p. 62-71, dez. $2007 . \quad$ Disponível https://www.academia.edu/33349737/Artigo_C_and_T196_p\%C3\%A1gs Acesso em: 02 mar. 2020.

[19] MOTTA, E. F. R. O. Dossiê Técnico: Fabricação de produtos de higiene pessoal. SBRT, REDETEC. Rede de Tecnologia do Rio de Janeiro, p.11-15, maio 2007. Disponível em: http://www.respostatecnica.org.br/. Acesso em: 13 fev. 2020.

[20] PEIXOTO, E. R. M.; SANTANA, D. M. N.; ABRANTES, S. Avaliação dos índices de identidade e qualidade do azeite de oliva - proposta para atualização da legislação brasileira. Ciênc. Tecnol. Aliment., Campinas v. 18 n. 4, p. dez. 1998. 
https://www.scielo.br/scielo.php?script=sci_arttext\&pid=S010120611998000400017\&lng=pt\&nrm=iso\&tlng=pt. Acesso em: 26 maio 2019.

[21] PEREIRA, F. S. G. Sabões e detergentes, Processos químicos industriais, Instituto Federal de Educação, Ciência e Tecnologia de Pernambuco - IFPE, p. 2-14, 2012. Disponível em: https://www.researchgate.net/publication/317506551_Soaps_and_Detergents_In_Portuguese_Saboes_e_Detergentes. Acesso em: 25 nov. 2019

[22] PUTON, V. Sabonetes Naturais com os benefícios da aromaterapia. [E-book] Florianópolis: Instituto Ekanta. 2019. Disponível

https://ekanta.net/cursos?gclid=CjwKCAjwgdX4BRB_EiwAg808Hb6FCI9BLkJ62u9zWZeUctJJyhDwtg30yPr3042YbyaDn_NINmxNxoC0dQQAvD_BwE. Acesso em: jan. 2020.

[23] PRATES, M. M. Determinação de propriedades físico-químicas de sabões comerciais em barra para controle de qualidade. 203 f. Trabalho de Conclusão de Curso (Bacharelado) -Universidade Federal de Santa Catarina, Florianópolis, 2006. Disponível em: https://core.ac.uk/download/pdf/30385448.pdf. Acesso em: 25 nov. 2019.

[24] RIBEIRO, L. G. T. A verdade científica sobre um superalimento funcional denominado óleo de coco. Brazilian Journal of Surgery and Clinical Research - BJSCR, São Paulo, v.18, n.3, p. 109-117, maio 2017. Disponível em: https://www.mastereditora.com.br/periodico/20170502_235155.pdf. Acesso em: 27 ago. 2019.

[25] ROMEU, C. C. Comparação do desempenho ambiental de dois sabonetes cosméticos utilizando a técnica da ACV. Biblioteca digital USP. São Paulo, p.141, 2013. Disponível em: https://teses.usp.br/teses/disponiveis/3/3137/tde-26062014-155702/pt-br.php. Acesso em: 15 jun. 2019.

[26] SOUZA, R. C. V. et al. Sabonete vegetal: desenvolvimento, avaliação da qualidade e aceitabilidade sensorial. Revista Interfac EHS- Saúde Meio Ambiente e Sustentabilidade, Campinas, v. 12, n. 1, p. 144-154, 2016. Disponível em: http://www3.sp.senac.br/hotsites/blogs/InterfacEHS/edicao-atual/. Acesso em: 10 nov. 2019.

[27] TESCAROLLO, I. L et al. Proposta para avaliação da qualidade de sabão ecológico produzido a partir do óleo vegetal residual. REGET/UFSM, Santa Maria, v.19, n. 3, p. 871-880, dez. 2015. Disponível em: https://periodicos.ufsm.br/reget/article/viewFile/17782/pdf. Acesso em: 25 nov. 2019.

[28] VASCONCELOS, A. F. F. GODINHO, O. E. S. Uso de métodos analíticos convencionados no estudo da autenticidade do óleo de copaíba. Quím. Nova, São Paulo, v.25, n.6, dez. 2002. Disponível em: https://www.scielo.br/scielo.php?script=sci_arttext\&pid=S0100-40422002000700002\&lng=pt Acesso em: 26 maio 2019. 


\section{Capítulo 9}

Caracterização e aplicação da casca de Citrus Reticulada como um eficiente adsorvente para remoção de contaminante emergente em solução líquida

\section{Matias Schadeck Netto \\ Isadora Argenta Preigschadt \\ Raíssa da Cunha Bevilacqua \\ Evandro Stoffels Mallmann \\ Guilherme Luiz Dotto \\ Edson Luiz, Foletto}

Resumo: Neste trabalho, a casca da bergamota (Citrus Reticulada), um resíduo agroindustrial de ampla disponibilidade, foi empregada como adsorvente do corante Violeta Cristal em solução aquosa. A casca de bergamota foi inicialmente caracterizada por difração de Raio-X, Espectroscopia no Infravermelho com Transformada de Fourier e determinação do Ponto de carga zero. Para determinação das melhores condições de pH e dosagem de adsorvente para a realização dos experimentos cinéticos e confecção das isotermas de adsorção, um planejamento experimental do tipo Delineamento Composto Central Rotacional $\left(2^{2}\right)$ foi realizado, o qual indicou um $\mathrm{pH}$ de 9 e uma dosagem de adsorvente de $0,5 \mathrm{~g} \mathrm{~L}^{-1}$. Os dados cinéticos foram melhores ajustados pelo modelo de pseudo-segunda ordem, enquanto que as isotermas de adsorção foram melhores descritas pelo modelo de Langmuir, apresentando a casca de bergamota uma capacidade máxima teórica de adsorção de $460 \mathrm{mg} \mathrm{g}^{-1}$. Desse modo, devido à alta capacidade de adsorção associada com a rápida cinética, a casca de bergamota pode ser considerada um adsorvente em potencial para remoção de corantes.

Palavras-chave: Adsorção, Citrus Reticulada, resíduo, corante, planejamento experimental. 


\section{INTRODUÇÃO}

A contaminação dos recursos naturais, em especial o sistema hídrico, vem sendo foco de muitas pesquisas na atualidade, pois tem se apresentado como um grande problema na sociedade moderna. A água é uma das principais fontes de sobrevivência atuando diretamente nas atividades industriais, agricultura e geração de energia (VINCENTIN, 2017). 0 setor têxtil é destaque quando comparado aos demais setores geradores de efluentes industriais. Seus efluentes podem possuir alta demanda de oxigênio, sólidos suspensos e coloração forte, considerados complexos, estando presentes os corantes que possuem difícil remoção(AKAR; AKAR; ÇABUK, 2009). Devido a isso, têm-se uma busca justificável por técnicas aplicáveis no tratamento desses resíduos.

A presença de corante no meio ambiente ocorre pelo tratamento inadequado dos efluentes industriais carregados destes contaminantes. Em corpos líquidos, os corantes diminuem a taxa de reoxigenação da água, diminuindo a atividade fotossintética afetando toda a biota aquática, pois dificulta a penetração dos raios solares. Em seres humanos a contaminação por corantes também pode acarretar em problemas no fígado e rins, juntamente com o sistema excretor e circulatório (DOTTO et al., 2011; WANG et al., 2016).

Os corantes possuem em sua fórmula vários anéis aromáticos, podendo ser naturais ou sintéticos. Dentro de um conjunto de requerimentos ideais, os corantes devem ser estáveis à luz, ao processo de lavagem com água, além de apresentar fixação uniforme nas fibras do substrato (GEADA, 2006). 0 corante violeta cristal é composto de misturas de tetrametila, pentametila e hexametila pararosanilinas, sendo possível criar diferentes versões através da mistura desses compostos, com diversos tons de violeta no corante final (PELCZAR; REID; CHAN, 1980). Quanto mais metilado o composto (que possui mais grupos metila ligados), mais azul profundo a cor final será. 0 principal uso do violeta cristal é no tingimento têxtil na cor púrpura, e dar tons violeta profundo em pinturas e tinta de impressão. É também largamente utilizado nas tintas de canetas esferográficas azuis.

Dentre as técnicas conhecidas está o processo de adsorção, o qual é amplamente utilizado para a remoção de corantes em soluções aquosas, pois além de apresentar alta eficiência de remoção, apresenta como vantagem a facilidade de operação e a possibilidade da utilização de adsorventes de baixo custo (DAS; KARAN; BHATTACHARJEE, 2017).

Vários resíduos agroindustriais têm sido usados como adsorventes de baixo custo para remoção de diversos tipos de poluentes em águas, tais como cacto palmatória (GEORGIN et al., 2019), caroço de abacate (NETTO; FAVARIN, 2019), sementes de araticum (FRANCO et al., 2020), fibra de sisal (VARGAS et al., 2020), casca de Ipê-amarelo (HERNANDES et al., 2019), fibras de piaçava (MARQUES et al., 2019), casca de arroz (FRANCO et al., 2017), casca de laranja (SIVARAJ; NAMASIVAYAM; KADIRVELU, 2001), casca de limão (KUMAR, 2007), entre outros.

Neste trabalho, avaliou-se a utilização da casca de bergamota (Citrus Reticulada) para a remoção do corante violeta cristal. Esse é um resíduo sem valor agregado e normalmente utilizado para compostagem, chás ou farinhas. A bergamota, também conhecida como tangerina, consiste de uma fruta cítrica de cor alaranjada e sabor adocicado, sendo considerada uma antiga espécie selvagem, nativa da Ásia. É facilmente encontrada no Brasil, e normalmente é colhida entre os meses de maio a agosto, mas a safra pode ir de abril a setembro, sendo um adsorvente renovável, não poluente, de fácil produção e de baixo custo, além de conter alto grau de porosidade. Estimativas do IBGE indicam que o Brasil produziu, em 2015, cerca de 1 milhão de toneladas de tangerina, em aproximadamente 50 mil hectares (IBGE., 2015).

\section{MATERIAS E MÉTODOS}

\subsection{OBTENÇÃO DA CASCA DE BERGAMOTA}

As bergamotas do tipo Poncã (Citrus Reticulada) foram colhidas em uma propriedade rural no interior do município de Coronel Barros, Rio Grande do Sul. Elas foram descascadas, e o fruto foi utilizado para consumo humano. As cascas foram secas incialmente a uma temperatura de $80^{\circ} \mathrm{C}$ durante $24 \mathrm{~h}$. Após esse período, as cascas foram trituradas em um moedor de café e passadas em uma peneira de 30 mesh, com um diâmetro de partícula de aproximadamente $0,6 \mathrm{~mm}$. Após a moagem e peneiramento, a casca foi submetida a um tratamento térmico a $110{ }^{\circ} \mathrm{C}$ durante $3 \mathrm{~h}$ para a remoção de água e alguns compostos voláteis que poderiam interferir no processo de adsorção. Na Figura 1 é mostrado o sólido após o processo de tratamento térmico, o qual foi utilizado na adsorção do corante Violeta cristal em meio líquido. 
Figura 1. Casca de bergamota utilizada nos experimentos de adsorção.

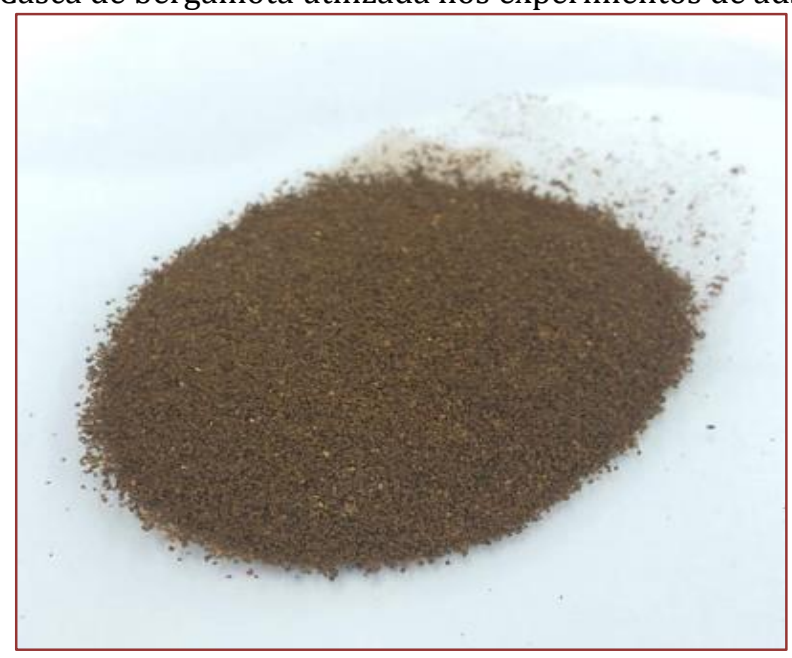

\subsection{CARACTERIZAÇÃO DO ADSORVENTE}

Para a determinar os grupos funcionais presentes na casca de bergamota e investigar a composição do adsorvente, evidenciando quais os principais grupos que podem ser responsabilizados pela adsorção do corante Violeta Cristal, foi utilizada a Espectrofotometria no Infravermelho com Transformada de Fourier (FTIR), uma vez que as ligações químicas de cada molécula vibram em frequências específicas. Para isso foi utilizado um espectrofotômetro Shimadzu (IR Prestige 21) com o método da pastilha de KBr, em uma faixa do espectro de 4500 a $450 \mathrm{~cm}^{-1}$. A cristalinidade do material foi determinada através da difração de Raios-X utilizando um equipamento Rigaku (modelo Miniflex 300), nas condições de análise de radiação $\mathrm{Cu}-K \alpha(\lambda=1.54051 \AA ̊ \Omega)$ e fonte de energia com $10 \mathrm{~mA}$ e $30 \mathrm{kV}$, com tamanho de passo de $0,03^{\circ}$ e tempo de contagem de 0,5 segundos por passo.

$\mathrm{O}$ ponto de carga zero da casca de bergamota foi determinado, uma vez que representa o $\mathrm{pH}$ no qual a superfície do material apresenta carga neutra. $\mathrm{O}$ fator $\mathrm{pH}$ é extremamente importante em processos adsortivos, uma vez que, um pH de trabalho na adsorção maior que o ponto de carga zero do material, é responsável por carregar a superfície do adsorvente negativamente, favorecendo a adsorção por atração eletrostática de moléculas carregadas positivamente. Quando a adsorção ocorre em um pH menor que o ponto de carga zero do material, a adsorção de moléculas carregadas negativamente é favorecida. Para determinação do ponto de carga zero da casca de bergamota, 12 frascos contendo $20 \mathrm{~mL}$ de uma solução 0.1 molar de cloreto de sódio tiveram seus pHs ajustados de 1 a 12. Em seguida, 20 mg de cascas moída foram colocadas em cada frasco que foram deixados sob agitação a $150 \mathrm{rpm}$ em temperatura ambiente por $24 \mathrm{~h}$. Após esse período, o $\mathrm{pH}$ de cada frasco foi determinado, e o valor de variação do $\mathrm{pH}(\Delta \mathrm{pH}, \mathrm{pH}$ inicial $\mathrm{pH}_{\text {final }}$ ) foi calculado. $\mathrm{O}$ valor do ponto de carga zero é determinado graficamente quando $\Delta \mathrm{pH}=0$, em um gráfico $\Delta \mathrm{pH} \times \mathrm{pH}$ inicial (NETHAJI et al., 2010).

\subsection{PROCEDIMENTO EXPERIMENTAL}

0 corante Violeta cristal (número CAS: 8004-87-3; fórmula estrutural: $\mathrm{C}_{24} \mathrm{H}_{28} \mathrm{~N}_{3} \mathrm{Cl}$; massa molar: 393,6 g/mol; comprimento de onda de máxima absorbância: $590 \mathrm{~nm}$ ) foi adquirido junto empresa Êxodo química (Brasil), onde uma solução estoque de $1000 \mathrm{mg} / \mathrm{L}$ foi preparada com água destilada, a qual foi utilizada para a elaboração das soluções de concentração requerida nos estudos cinéticos e isotérmicos por diluição. A fórmula estrutural do corante Violeta cristal é mostrado na Figura 2. 
Figura 2. Estrutura molecular do corante Violeta cristal.

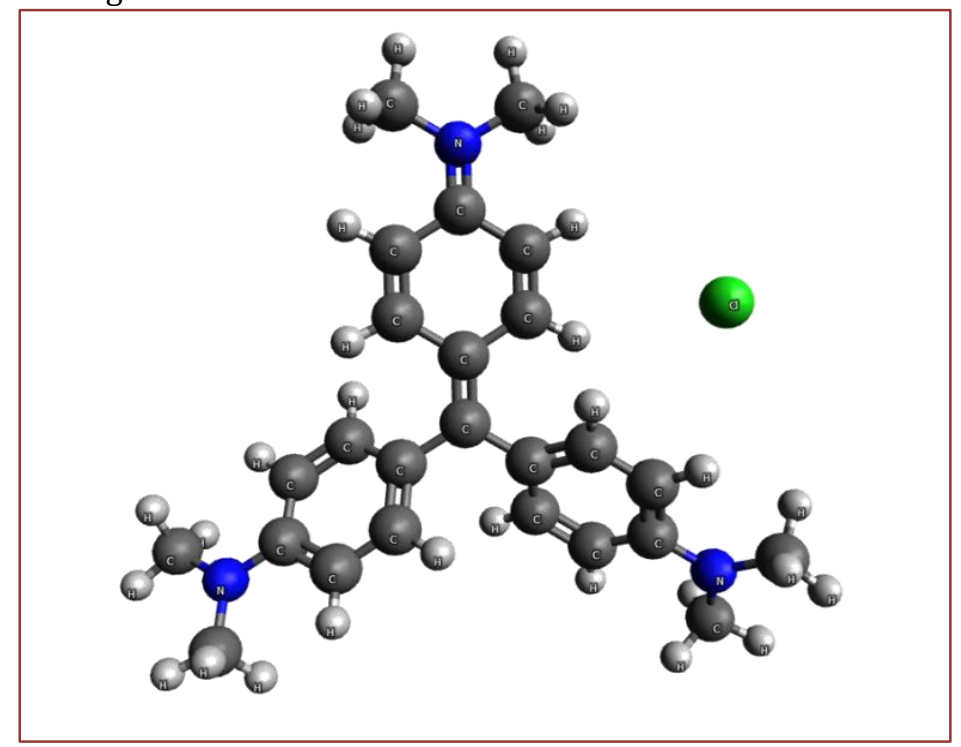

Todos os experimentos foram conduzidos em batelada, utilizando um banho termostatizado da marca Dubnoff (SL-157), com agitação de $150 \mathrm{rpm}$. O volume de solução utilizado foi de $50 \mathrm{~mL}$. Após cada ensaio de adsorção, a casca de bergamota foi separada por centrifugação, e a concentração de corante remanescente na fase líquida foi analisada utilizando um espectrofotômetro Biospectro SP-22 (Brasil). Uma varredura espectrofotométrica foi previamente realizada para determinar o comprimento de onda de absorbância máxima (590 nm) do Violeta cristal. Posteriormente, foi construída uma curva de calibração padrão de absorbância versus concentração de corante.

\subsection{PLANEJAMENTO EXPERIMENTAL}

Para a determinação do pH e dosagem de adsorvente para realização dos experimentos de adsorção visando a máxima remoção de corante juntamente com a máxima capacidade de adsorção da casca de bergamota, foi realizado um planejamento experimental do tipo delineamento composto central rotacional $\left(2^{2}\right)$. $0 \mathrm{pH}$ foi variado 4,18 a 9,82. Essa faixa de $\mathrm{pH}$ foi escolhida devido ao fato do corante Violeta cristal ser catiônico, e pHs básicos são indicados para a adsorção de moléculas carregadas positivamente (SALLEH et al., 2011). A faixa de dosagem de adsorvente estudada variou em torno de $1 \mathrm{~g} \mathrm{~L}$ ${ }^{1}\left(0,5 \mathrm{~g} \mathrm{~L}^{-1}\right.$ a $\left.1,5 \mathrm{~g} \mathrm{~L}^{-1}\right)$ que é a comumente usada em processos de adsorção. 0 tempo de contato entre adsorbato escolhido foi de duas horas, e a concentração inicial de corante foi de $50 \mathrm{mg} \mathrm{L}^{-1}$. Ao final da adsorção, a função resposta Remoção (\%) foi calculada através da Equação 1, e a função resposta Capacidade de Adsorção no Equilíbrio, foi determinada pela Equação 2.

$$
\begin{aligned}
& R(\%)=\left\{\left(C_{i}-C_{f}\right) / C_{i}\right\} * 100 \% \\
& q_{e}=\left(C_{i}-C_{f}\right) *(V / m)
\end{aligned}
$$

Onde, $C_{i}$ e $C_{f}$ são as concentrações de corante iniciais e finais $\left(\mathrm{mg} \mathrm{L}^{-1}\right)$, respectivamente; $V$ é o volume de solução (L); $m$ (g) é a massa de adsorvente.

\subsection{CINÉTICA DE ADSORÇÃo}

0 efeito do tempo na adsorção foi verificado através da cinética de adsorção. 0 estudo cinético permite determinar a capacidade de adsorção no tempo $t$, a taxa de remoção de corante e o tempo de equilíbrio de adsorção. A cinética de adsorção foi realizada com uma concentração inicial de corante de $100 \mathrm{mg} \mathrm{L}^{-1}$, onde alíquotas foram retiradas em tempos pré-definidos de 5, 10, 15, 20, 30, 45, 60, 90, 120 e 180 minutos, e a concentração residual de corante na fase líquida foi determinada. Uma dosagem de 
adsorvente de $0,5 \mathrm{~g} \mathrm{~L}^{-1}$ e um pH de 9 foram utilizados, condições estas advindas do planejamento experimental. 0 modelo de Pseudo-primeira ordem (PPO) (Eq. 3) (LAGERGREN, 1898), e o modelo de Pseudo-segunda ordem (PSO) (Eq. 4) (HO; MCKAY, 1998) foram utilizados para descrever a cinética de adsorção. A capacidade de adsorção no tempo $t$ foi estimada pela Eq.5.

$$
\begin{aligned}
& q_{t}=q_{1} *\left\{1-\exp \left(-k_{1} * t\right)\right\} \\
& q_{t}=t /\left\{\left[1 /\left(k_{2} *{q_{2}}^{2}\right)\right]+\left(t / q_{2}\right)\right\} \\
& q_{t}=\left(C_{i}-C_{t}\right) *(V / m)
\end{aligned}
$$

Onde, $q_{1}$ e $q_{2}\left(\mathrm{mg} \mathrm{g}^{-1}\right)$ são as capacidades de adsorção teórica do modelo de Pseudo-primeira ordem e Pseudo-segunda ordem, respectivamente. Os termos $k_{1}\left(\mathrm{~min}^{-1}\right)$ e $k_{2}\left(\mathrm{~g} \mathrm{mg}^{-1} \mathrm{~min}^{-1}\right)$ são as constantes de taxa dos modelos de Pseudo-primeira ordem e Pseudo-segunda ordem, respectivamente. 0 termo $t$ é o tempo, e $q_{t}$ é a capacidade de adsorção no tempo $t$. 0 termo $C t\left(\mathrm{mg} \mathrm{L}^{-1}\right)$ representa a concentração de corante no tempo $t$.

\subsection{ISOTERMA DE ADSORÇÃO}

0 estudo das isotermas de adsorção permite determinar a capacidade máxima de adsorção de determinado adsorvente. Para isso, diferentes concentrações inicias de corante foram colocadas em contato com o adsorvente e mantidas sob agitação por um certo tempo. Para a confecção da curva da isoterma foram usadas concentrações inicias de corante de 25, 50, 100, 150 e $200 \mathrm{mg} \mathrm{L}^{-1}$. Foi utilizado um tempo de contato de $3 \mathrm{~h}$, uma dosagem de adsorvente de 0,5 $\mathrm{g} \mathrm{L}^{-1}$ e um pH de 9. Os modelos utilizados para descrever a isoterma de adsorção foram os modelos de Langmuir (Eq. 6) (LANGMUIR, 1918), o modelo de Freundlich (Eq. 7) (FREUNDLICH, 1906) e o modelo de Sips (Eq. 8) (SIPS, 1948).

$$
\begin{aligned}
& q_{e}=q_{m} * k_{l} * C_{e} /\left\{1+\left(k l * C_{e}\right)\right\} \\
& q_{e}=k_{f} *\left\{C_{e} e^{(1 / a)}\right\} \\
& q_{e}=q_{m} *\left(k_{s} * C_{e}\right)^{m} /\left\{1+\left(k_{s} * C_{e}\right)^{m}\right\}
\end{aligned}
$$

Onde, $q_{m}\left(\mathrm{mg} \mathrm{g}^{-1}\right)$ representa a capacidade máxima de adsorção, $k_{l}\left(\mathrm{~L} \mathrm{mg}^{-1}\right), k_{f}\left[\mathrm{mg} \mathrm{g}^{-1}\left(\mathrm{mg} \mathrm{L}^{-1}\right)^{-1 / n f}\right] \mathrm{e}_{s}(\mathrm{~L}$ $\left.\mathrm{mg}^{-1}\right)^{1 / \mathrm{n}}$ são as constantes dos modelos de Langmuir, Freundlich e Sips, respectivamente. 0 termo $C_{e}\left(\mathrm{mg} \mathrm{L}^{-}\right.$ 1) representa a concentração de corante no equilíbrio. 0 termo $m$ de Sips é adimensional, e representa o grau de heterogeneidade do sistema.

\section{RESULTADOS E DISCUSSÃO}

\subsection{CARACTERIZAÇ̃̃O DO ADSORVENTE}

0 resultado de difração de raios-X para a casca de bergamota triturada é mostrado na Figura 3. Através do difratograma, é possível perceber que a casca de bergamota apresenta uma estrutura amorfa devido a ampla faixa de reflexão de 2 theta entre $10^{\circ}$ e $50^{\circ}$. Também é possível perceber a presença de dois pequenos picos localizados em 2 theta igual a $15^{\circ}$ e $20^{\circ}$, os quais podem esta relacionados a presença de celulose cristalina na casca de bergamota (TSOUKO et al., 2015). 
Figura 3. Difração de raios-X da casca de bergamota triturada.

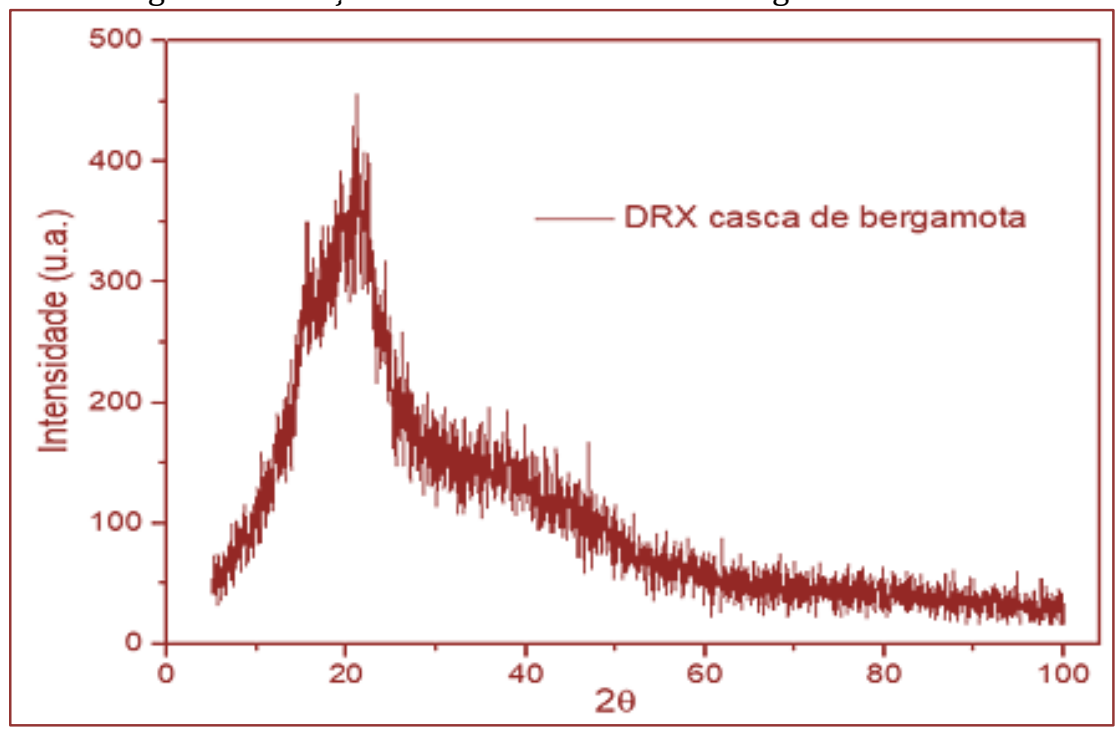

O espectro de infravermelho com transformada de Fourier para a amostra da casca de bergamota triturada é mostrado na Figura 4. Os principais grupos funcionais constituintes da casca de bergamota são álcoois, carbonilas, carboxilas, ésteres, grupos esses característicos de materiais lignocelulósicos. A banda em $3430 \mathrm{~cm}^{-1}$ está associada as vibrações de alongamento da ligação O-H (IRFAN KHAN et al., 2015). A banda em $2927 \mathrm{~cm}^{-1}$ está associada a vibração de alongamento da ligação $\mathrm{C}-\mathrm{H}$ presente na lignina (KUBO; KADLA, 2005). A banda em $1730 \mathrm{~cm}^{-1}$ pode estar associada ao alongamento da ligação $\mathrm{C}=0$ em grupos éster (PROLA et al., 2013). A banda em $1630 \mathrm{~cm}^{-1}$ pode estar relacionada à vibração de alongamento do grupamento $\mathrm{C}=\mathrm{C}$, e de grupos carbonila, que esticam a vibração no anel aromático dos materiais lignocelulósicos (HOSPODAROVA; SINGOVSZKA; STEVULOVA, 2018). A banda em $1440 \mathrm{~cm}^{-1}$ pode estar relacionada a vibração de flexão do grupo $\mathrm{CH}_{2}$ das olefinas presente na hemicelulose e celulose. A banda em $1090 \mathrm{~cm}^{-1}$ corresponde ao alongamento assimétrico das ligações C-O-C da celulose e hemicelulose. A banda em $1079 \mathrm{~cm}^{-1}$ é devida ao alongamento da ligação de C-O do álcool primário da lignina (SILLS; GOSSETT, 2012), enquanto que a banda em $1018 \mathrm{~cm}^{-1}$ está associada ao alongamento da ligação de C-0 na celulose (ALENCAR et al., 2012).

Figura 4. Espectro FTIR da casca de bergamota triturada.

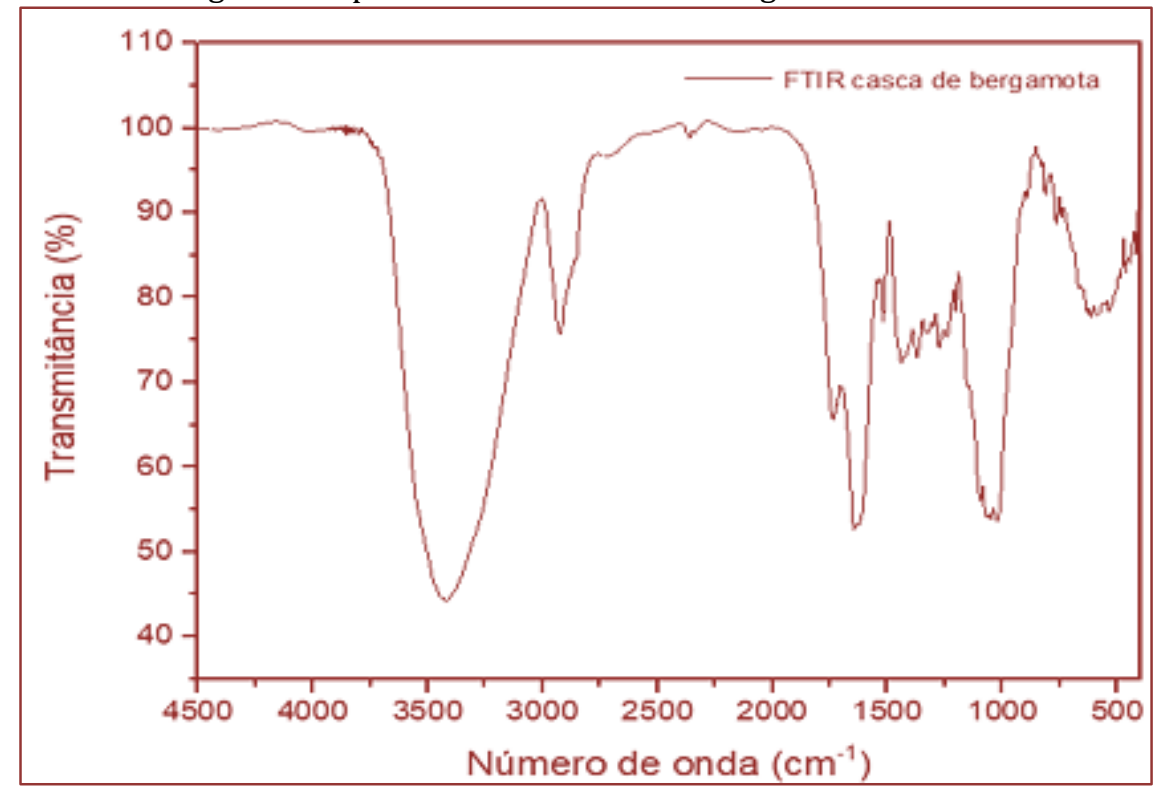


O ponto de carga zero está mostrado na Figura 5. Conforme é possível se observar, o pH no qual a superfície do material apresenta carga neutra corresponde a um pH de 4. Com esse resultado, é possível concluir que um pH de trabalho maior do que 4 favorece a adsorção, uma vez que carrega a superfície do material negativamente, e o corante violeta cristal, por ser catiônico, apresenta carga superficial positiva, sendo atraído pelo adsorvente. Quanto maior for o $\mathrm{pH}$, mais cargas negativas se acumulam na superfície do adsorvente, por isso, uma faixa de trabalho em $\mathrm{pH}$ alcalino foi escolhida para a realização do planejamento experimental.

Figura 5. Diagrama do ponto de carga zero da casca de bergamota.

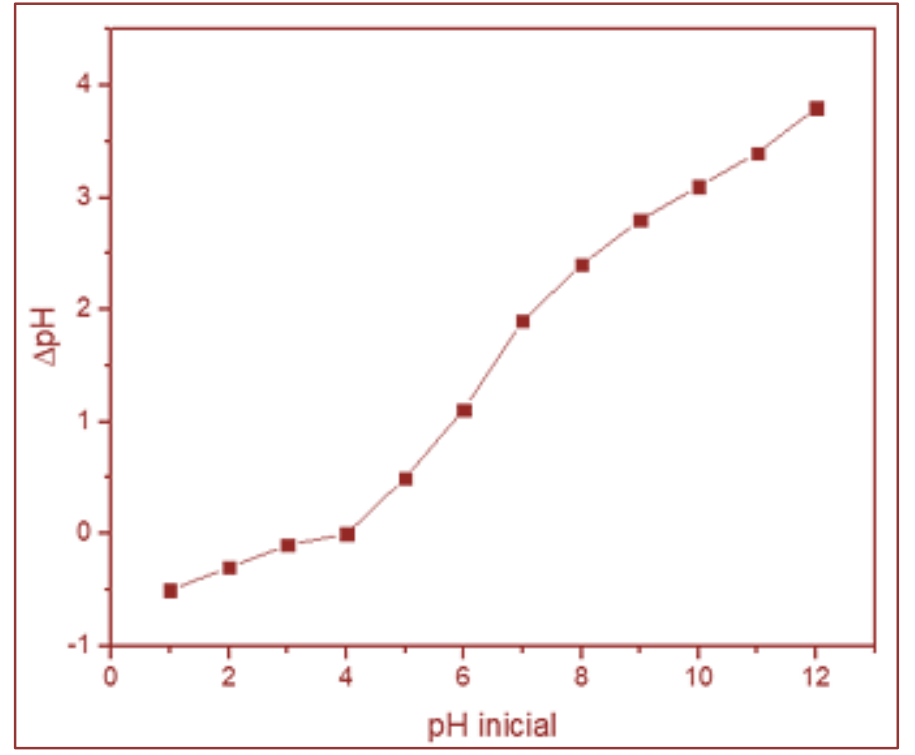

\subsection{PLANEJAMENTO EXPERIMENTAL}

Os resultados do planejamento experimental, com as duas repostas, Remoção $(R, \%)$ e capacidade de adsorção $\left(q_{e}\right)$, e também com os valores reais e codificados das variáveis pH e dosagem de adsorvente, são mostrados na Tabela 1.

\begin{tabular}{|c|c|c|c|c|}
\hline Experimento & $\mathrm{pH}$ & $\begin{array}{c}\text { Dosagem de } \\
\text { adsorvente }\left(\mathrm{g} \mathrm{L}^{-1}\right)\end{array}$ & $R(\%)$ & $q_{e}\left(\mathrm{mg} \mathrm{g}^{-1}\right)$ \\
\hline 1 & $9(1)$ & $1,5(1)$ & 94,61 & 31,71 \\
\hline 2 & $5(-1)$ & $1,5(1)$ & 87,08 & 29,19 \\
\hline 3 & $9(1)$ & $0,5(-1)$ & 82,85 & 83,31 \\
\hline 4 & $5(-1)$ & $0,5(-1)$ & 78,89 & 79,33 \\
\hline 5 & $9,82(1,41)$ & $1,0(0)$ & 94,12 & 47,32 \\
\hline 6 & $4,18(-1,41)$ & $1,0(0)$ & 75,84 & 38,13 \\
\hline 7 & $7(0)$ & $1,705(1.41)$ & 94,39 & 28,04 \\
\hline 8 & $7(0)$ & $0,295(-1.41)$ & 81,94 & 144,47 \\
\hline 9 & $7(0)$ & $1,0(0)$ & 91,07 & 45,79 \\
\hline 10 & $7(0)$ & $1,0(0)$ & 91,38 & 45,94 \\
\hline 11 & $7(0)$ & $1,0(0)$ & 90,77 & 45,64 \\
\hline
\end{tabular}

Pela análise da tabela, é possível perceber que a casca de bergamota apresenta uma alta capacidade de remoção de corante, onde em toda a faixa de pH utilizado, remoções acima de $75 \%$ foram encontradas. É verificado que pHs maiores provocam uma maior remoção de corante, o que era esperado, devido ao valor de ponto de carga zero encontrado, o que também ocorre quando há o aumento da dosagem de adsorvente.

A equação da resposta Remoção (\%) em função das variáveis independentes é mostrada na Equação 9.0 coeficiente de determinação $\left(R^{2}\right)$ desta equação encontrado foi de 0,937 , o que indica um bom ajuste dos 
dados experimentais ao modelo. 0 teste de Fischer comprovou que o modelo é preditivo, sendo o valor de

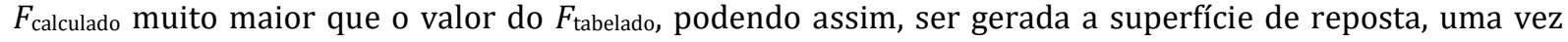
que o valor de $F_{\text {calculado }}$ foi de 14,96, enquanto que o valor de $F_{\text {tabelado }}$ foi de 5,05.

$$
Y=91,07+4,67 X 1-3,23 X 1^{2}+4,70 X 2-1,64 X 2^{2}+0,89 X 1 X 2
$$

Onde, $X 1$ representa a variável independente "pH"; $X 2$ representa a variável independente "dosagem de adsorvente".

A equação que descreve a resposta capacidade de adsorção (qe, $\mathrm{mg} \mathrm{g}^{-1}$ ) é mostrada na equação 10 . 0 coeficiente de determinação $\left(R^{2}\right)$ encontrado foi de 0,945 , também indicando um bom ajuste dos dados experimentais ao modelo. A equação do modelo também foi preditiva, sendo o valor do $F$ calculado de 17,12 , enquanto que o $F$ tabelado foi de 5,05.

$$
\mathrm{Y}=45,83+2,44 \mathrm{X} 1-3,74 \mathrm{X} 1^{2}-33,34 \mathrm{X} 2+18,15 \mathrm{X} 2^{2}-0,36 \mathrm{X} 1 \mathrm{X} 2
$$

As curvas de superfície para as respostas Remoção (\%) e capacidade de adsorção estão mostradas na Figura 6(a) e Figura 6(b), respectivamente.

Figura 6. (a) Curva de superfície para a resposta Remoção (\%) de corante; (b) curva de superfície para a resposta Capacidade de adsorção $\left(q_{e}, \mathrm{mg} \mathrm{g}^{-1}\right)$.

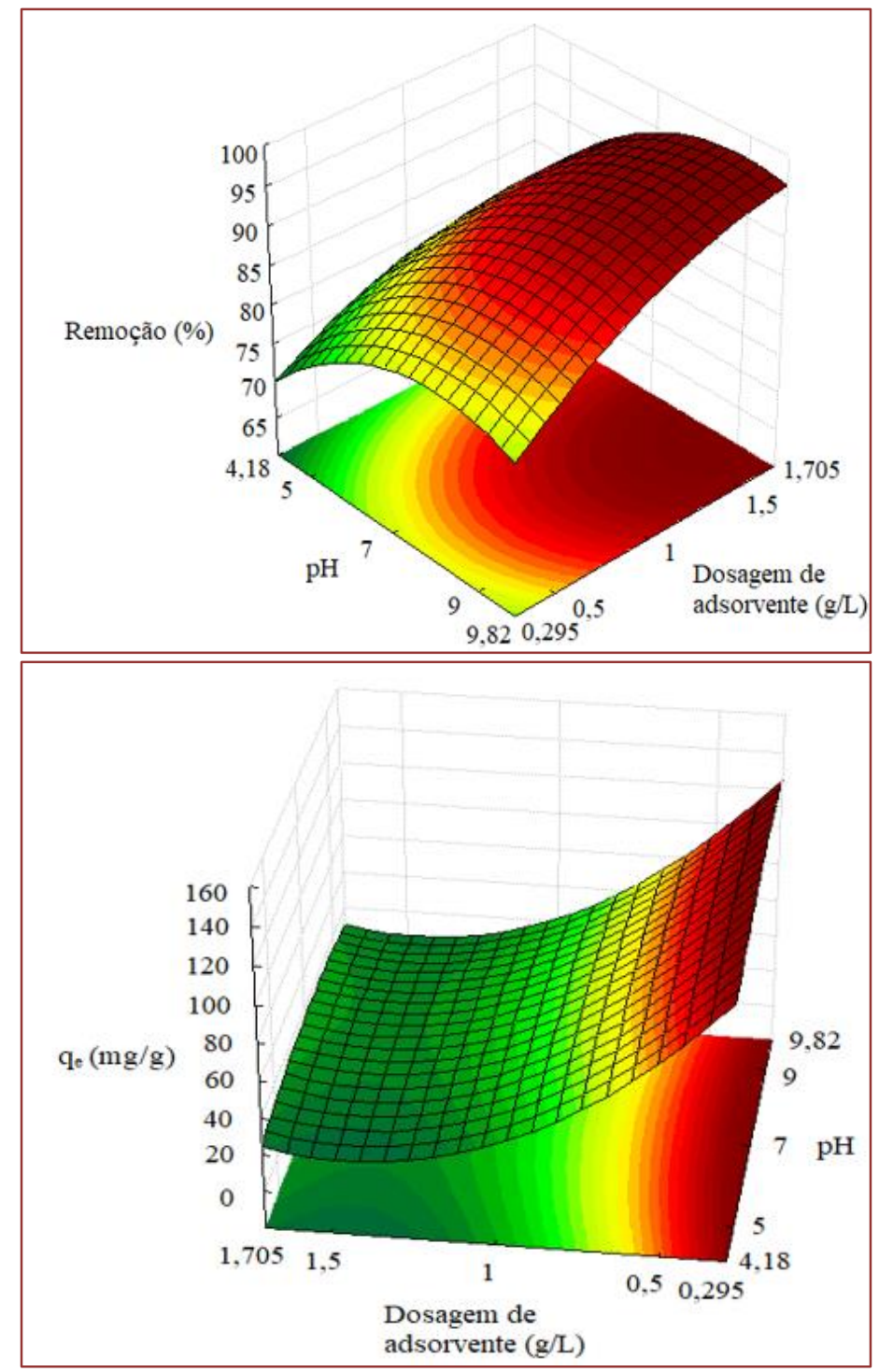


Pela análise da Figura 6(a), é possível perceber que maiores remoções são observadas em maiores valores de pHs e maiores dosagens de adsorvente, o que corrobora com o valor de ponto de carga zero encontrado. A casca de bergamota possui uma boa afinidade com o corante Violeta cristal, uma vez que mais de $95 \%$ é removido do meio aquoso quando a adsorção ocorre em pH básico. Para a resposta capacidade de adsorção $\left(q_{e}, \mathrm{mg} \mathrm{g}^{-1}\right)$, conforme a Figura 6 (b), a variável dosagem de adsorvente apresenta maior relevância no experimento, uma vez que a quantidade de casca de bergamota presente no meio é inversamente proporcional a capacidade de adsorção, conforme a Equação 2. Maiores capacidades de adsorção são encontradas quando a dosagem de adsorvente se aproxima de $0,295 \mathrm{~g} \mathrm{~L}^{-1}$, e por isso, a fim de maximizar a remoção de corante aliado com uma boa capacidade de adsorção, os níveis escolhidos para a realização dos estudos cinéticos e termodinâmicos foi um pH de 9 e uma dosagem de adsorvente de 0,5 g $\mathrm{L}^{-1}$.

\subsection{CINÉTICA DE ADSORÇÃO}

0 ajuste dos dados cinéticos obtidos experimentalmente aos modelos está mostrado na Tabela 2 e na Figura 7. Pela análise da tabela, é possível notar que o modelo de Pseudo-segunda ordem melhor se ajustou aos dados experimentais, uma vez que apresenta os maiores valores de coeficiente de determinação $\left(R^{2}\right)$, coeficiente de determinação ajustado $\left(R^{2} a d j\right)$ e o menor Erro médio relativo $(E M R, \%)$, onde a capacidade máxima teórica no equilíbrio encontrada foi de $171,36 \mathrm{mg} \mathrm{g}^{-1}$.

Tabela 2. Ajuste dos dados cinéticos aos modelos teóricos

\begin{tabular}{|c|c|c|c|}
\multicolumn{4}{|c|}{ Modelo Cinético } \\
\hline$q_{1}$ & 160.1 & $q_{2}$ & 171.36 \\
\hline$k_{1}$ & 0.1758 & $k_{2}$ & 0.0017 \\
\hline$R^{2}$ & 0.938 & $R^{2}$ & 0.984 \\
\hline$R^{2}$ adj & 0.932 & $R^{2}$ adj & 0.982 \\
\hline$E M R, \%$ & 6.98 & $E M R, \%$ & 3.3 \\
\hline
\end{tabular}

Figura 7. Curva cinética para a adsorção de Violeta cristal por casca de bergamota.

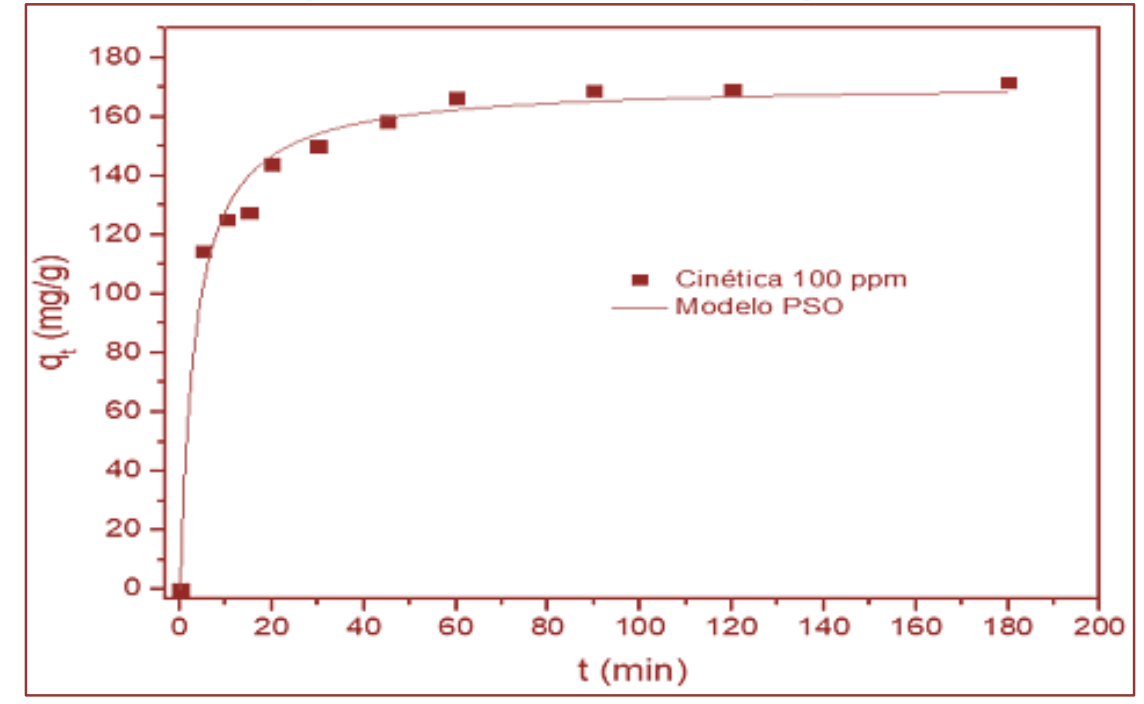

Como pode se perceber na figura 7, a adsorção tende ao equilíbrio já com 90 minutos de experimento, um tempo relativamente curto, e onde em apenas cinco minutos, uma capacidade de adsorção de mais de 110 $\mathrm{mg} \mathrm{g}^{-1}$ é atingida. A taxa de adsorção inicial é alta, uma vez que é grande a disponibilidade de sítios ativos disponíveis na superfície do adsorvente. Conforme o tempo passa, a quantidade de sítios decai, sendo isso, favorável para processos de adsorção, pois o tratamento de efluentes coloridos pode ser realizado com eficiência em curtos intervalos de tempo. 


\subsection{ISOTERMA DE ADSORÇÃO}

Através das isotermas de adsorção, é possível determinar a máxima capacidade de adsorção de determinado adsorvente. Os resultados do ajuste dos dados experimentais aos modelos isotérmicos são mostrados na Tabela 3 e na Figura 8. Pela análise da tabela, os modelos que melhor descrevem a isoterma de adsorção são os modelos de Langmuir e Sips, que apresentaram altos valores de coeficiente de determinação $\left(R^{2}\right)$ e coeficiente de determinação ajustado $\left(R^{2} a d j\right)$. Porém, ao se analisar o Erro médio relativo $(E M R)$, é possível notar que o modelo de Langmuir teve um ajuste levemente superior, uma vez que apresentou um EMR menor que o modelo de Sips.

Tabela 3. Modelos isotérmicos utilizados na adsorção de Violeta cristal por casca de bergamota.

\begin{tabular}{|c|c|c|c|c|c|}
\multicolumn{2}{|c|}{ Langmuir } & \multicolumn{2}{c|}{ Freundlich } & \multicolumn{2}{c|}{ Sips } \\
\hline$q_{m}$ & 460.2 & $k_{f}$ & 44.6 & $q_{s}$ & 503 \\
\hline$k_{l}$ & 0.054 & $a$ & 1.89 & $k_{s}$ & 0.044 \\
\hline$R^{2}$ & 0.999 & $R^{2}$ & 0.989 & $m$ & 1.08 \\
\hline$R^{2}$ adj & 0.998 & $R^{2}$ adj & 0.987 & $R^{2}$ & 0.999 \\
\hline$E M R(\%)$ & 1.69 & $E M R(\%)$ & 10.5 & $R^{2}$ adj & 0.998 \\
\hline & & & & $E M R(\%)$ & 2.42 \\
\hline
\end{tabular}

Figura 8. Isoterma de adsorção do corante Violeta cristal pela casca de bergamota.

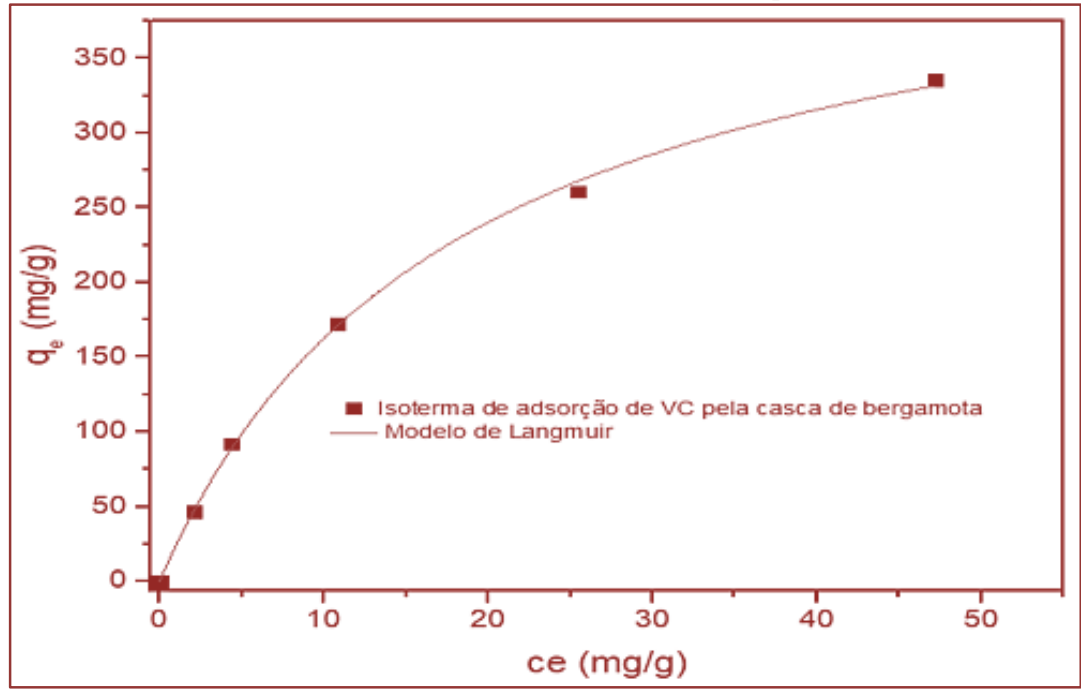

A Figura 8 apresenta a isoterma de adsorção a $25^{\circ} \mathrm{C}$ do corante Violeta cristal pela casca de bergamota. 0 modelo de Langmuir assume que a adsorção ocorre em monocamadas, onde os locais de adsorção têm igual afinidade e energia. A casca de bergamota apresentou capacidade máxima de adsorção teórica de 460,2 $\mathrm{mg} \mathrm{g}^{-1}$ de corante, estando esse alto valor aliado com uma cinética de adsorção relativamente rápida. Isso confere à casca de bergamota, que antes era um material de baixíssimo valor agregado, uma possibilidade de ser usada como adsorvente de corantes em meio líquido.

\section{CONCLUSÕES}

Neste trabalho, foi avaliado a utilização da casca de bergamota como adsorvente de corante em meio líquido. A casca de bergamota foi caracterizada, apresentando um caráter amorfo, onde foi possível perceber os picos constituintes da celulose na amostra. Os diferentes grupos funcionais evidenciados pelo FTIR caracterizam a casca de bergamota como um material lignocelulósico com grupos funcionais que podem auxiliar no aumento da interação entre adsorbato e adsorvente. 0 ponto de carga zero encontrado para a casca de bergamota foi de 4, onde o melhor pH encontrado para a realização dos estudos cinéticos e isotérmicos advindo do planejamento experimental foi $\mathrm{pH}=9$. A melhor dosagem de adsorvente para maximizar a Remoção (\%) e a capacidade de adsorção foi de 0,5 $\mathrm{g} \mathrm{L}^{-1}$. A casca de bergamota apresentou uma rápida cinética, sendo o modelo de Pseudo-segunda ordem aquele que melhor descreveu a cinética de 
adsorção. A isoterma de adsorção foi melhor descrita pelo modelo de Langmuir, onde o adsorvente apresentou capacidade máxima de adsorção de 460,2 $\mathrm{mg} \mathrm{g}^{-1}$ de corante. Sendo assim, a casca de bergamota pode ser considerada um adsorvente alternativo e com grande potencial para a remoção de corantes em meio líquido.

\section{REFERÊNCIAS}

[1] AKAR, S. T.; AKAR, T.; C.ABUK, A. Decolorization of a textile dye, reactive red 198 (RR198), by Aspergillus parasiticus fungal biosorbent. Brazilian Journal of Chemical Engineering, v. 26, n. 2, p. 399-405, 2009.

[2] ALENCAR, W. S. et al. Application of Mangifera indica (mango) seeds as a biosorbent for removal of Victazol Orange 3R dye from aqueous solution and study of the biosorption mechanism. Chemical Engineering Journal, v. 209, p. 577-588, 2012.

[3] DAS, D.; KARAN, C. K.; BHATTACHARJEE, M. Heterotrimetallic coordination polymers for dye adsorption and desorption. Polyhedron, v. 124, p. 51-61, 2017.

[4] DOTTO, G. L. et al. REMOÇ̃̃o DOS CORANTES AZUL BRILHANTE, AMARELO CREPÚSCULO E AMARELO TARTRAZINA DE SOLUÇÕES AQUOSAS UTILIZANDO CARVÃO ATIVADO, TERRA ATIVADA, TERRA DIATOMÁCEA, QUITINA E QUITOSANA: ESTUDOS DE EQUILÍBRIO E TERMODINÂMICA. Quimica Nova, v. 34, n. 7, p. 1193-1199, 2011.

[5] FRANCO, D. S. P. et al. Alternative treatments to improve the potential of rice husk as adsorbent for methylene blue. Water Science and Technology, v. 75, n. 2, p. 296-305, 2017.

[6] FRANCO, D. S. P. et al. Araticum (Annona crassiflora) seed powder (ASP) for the treatment of colored effluents by biosorption. Environmental Science and Pollution Research, 2020.

[7] FREUNDLICH, H. M. F. Over the adsorption in solution. Journal of Physical Chemistry, v. 57, p. 385-471, 1906.

[8] GEADA, O. Remoção de corantes têxteis utilizando resíduos agrícolas da produção de milho. [s.l.] Universidade do Porto, 2006.

[9] GEORGIN, J. et al. Paddle cactus (Tacinga palmadora) as potential low-cost adsorbent to treat textile effluents containing crystal violet. Chemical Engineering Communications, 2019.

[10] HERNANDES, P. T. et al. Adsorptive decontamination of wastewater containing methylene blue dye using golden trumpet tree bark (Handroanthus albus). Environmental Science and Pollution Research, v. 26, n. 31, p. 3192431933, 2019.

[11] HO, Y. S.; MCKAY, G. Kinetic models for the sorption of dye from aqueous solution by wood. Process Safety and Environmental Protection, v. 76, n. 2, p. 183-191, 1998.

[12] HOSPODAROVA, V.; SINGOVSZKA, E.; STEVULOVA, N. Characterization of Cellulosic Fibers by FTIR Spectroscopy for Their Further Implementation to Building Materials. American Journal of Analytical Chemistry, v. 09, n. 06, p. 303-310, 2018.

[13] IBGE., I. B. D. G. E. E. -. Produção agrícola municipal: culturas temporárias e permanentes. [s.l: s.n.].

[14] IRFAN KHAN, M. et al. Simultaneous preparation of nano silica and iron oxide from palm oil fuel ash and thermokinetics of template removal. RSC Advances, v. 5, n. 27, p. 20788-20799, 2015.

[15] KUBO, S.; KADLA, J. F. Hydrogen bonding in lignin: A fourier transform infrared model compound study. Biomacromolecules, v. 6, n. 5, p. 2815-2821, 2005.

[16] KUMAR, K. V. Optimum sorption isotherm by linear and non-linear methods for malachite green onto lemon peel. Dyes and Pigments, v. 74, n. 3, p. 595-597, 2007.

[17] LAGERGREN, S. About the theory of so-called adsorption of soluble substances. Kungliga Svenska Vetenskapsakademiens Handlingar, v. 24, p. 1-39, 1898.

[18] LANGMUIR, I. THE ADSORPTION OF GASES ON PLANE SURFACES OF GLASS, MICA AND PLATINUM. Journal of the American Chemical Society, v. 40, n. 9, p. 1361-1403, 1918.

[19] MARQUES, B. S. et al. Adsorption of a textile dye onto piaçava fibers: kinetic, equilibrium, thermodynamics, and application in simulated effluents. Environmental Science and Pollution Research, v. 26, n. 28, p. 28584-28592, 2019.

[20] NETHAJI, S. et al. Adsorption of Malachite Green dye onto activated carbon derived from Borassus aethiopum flower biomass. Journal of Hazardous Materials, v. 181, n. 1-3, p. 271-280, 2010.

[21] NETTO, M. S.; FAVARIN, N. Effect of Salinity on the Adsorption Behavior of Methylene Blue onto Comminuted Raw Avocado Residue : CCD-RSM Design. 2019. 
[22] PELCZAR, M. J.; REID, R.; CHAN, E. C. S. Microbiologia. 1. ed. São Paulo: [s.n.].

[23] PROLA, L. D. T. et al. Comparison of Jatropha curcas shells in natural form and treated by non-thermal plasma as biosorbents for removal of Reactive Red 120 textile dye from aqueous solution. Industrial Crops and Products, v. 46, p. 328-340, 2013

[24] SALLEH, M. A. M. et al. Cationic and anionic dye adsorption by agricultural solid wastes: A comprehensive review. Desalination, v. 280, n. 1-3, p. 1-13, 2011.

[25] SILLS, D. L.; GOSSETT, J. M. Using FTIR to predict saccharification from enzymatic hydrolysis of alkalipretreated biomasses. Biotechnology and Bioengineering, v. 109, n. 2, p. 353-362, 2012.

[26] SIPS, R. On the structure of a catalyst surface. The Journal of Chemical Physics, v. 16, n. 5, p. 490-495, 1948.

[27] SIVARAJ, R.; NAMASIVAYAM, C.; KADIRVELU, K. Orange peel as an adsorbent in the removal of Acid violet 17 (acid dye) from aqueous solutions. Waste Management, v. 21, n. 1, p. 105-110, 2001.

[28] TSOUKO, E. et al. Bacterial cellulose production from industrial waste and by-product streams. International Journal of Molecular Sciences, v. 16, n. 7, p. 14832-14849, 2015.

[29] VARGAS, V. H. et al. Sisal fiber as an alternative and cost-effective adsorbent for the removal of methylene blue and reactive black 5 dyes from aqueous solutions. Chemical Engineering Communications, v. 207, n. 4, p. 523536, 2020.

[30] VINCENTIN, B. M. Estudo da adsorção de corante têxtil em fibras naturais de bucha vegetal (luffa cylindrica). [s.l.] Universidade Tecnológica Federal do Paraná, 2017.

[31] WANG, Z. B. et al. Retention and separation of 4BS dye from wastewater by the N-TiO2ceramic membrane. Desalination and Water Treatment, v. 57, n. 36, p. 16963-16969, 2016. 


\section{Capítulo 10}

Preparação e caracterização de membrana inorgânica com propriedades para remoção de corante amarelo reativo $B F-3 R$

\section{Fabiana Medeiros do Nascimento Silva}

Rondinele Nunes de Araújo

Antonielly dos Santos Barbosa

Rochelia Silva Souza Cunha

Meiry Glaucia Freire Rodrigues

Resumo: Os corantes exibem as mais diversas aplicações, estes por sua vez podem ser tóxicos e resistentes a muitos processos de tratamento, quando presentes em águas residuais. Pesquisas que envolvam o tratamento desses resíduos tornam-se necessárias, a fim de minimizar impactos causados a partir destes descartes. 0 interesse em processos de separação por membranas ganha cada vez mais destaque no tratamento deste tipo de águas residuais. As membranas inorgânicas apresentam características únicas que as tornam atraentes para aplicação em processos de separação, objeto de interesse desta pesquisa. 0 objetivo desta pesquisa foi preparar uma membrana inorgânica utilizando a argila (Bofe) natural e avaliar a partir da remoção do corante reativo (amarelo BF-3R) sua seletividade. A membrana inorgânica preparada com a argila (Bofe) foi sintetizada a partir da argila Bofe natural policatiônica, que foi peneirada, prensada, compactada e sinterizada. A obtenção da membrana inorgânica preparada com a argila (Bofe) foi confirmada pela análise por Difração de raios X. A caracterização funcional da membrana inorgânica foi realizada a partir da avaliação do fluxo permeado e a capacidade seletiva, não havendo variação do fluxo, mantendo-se constante durante todo o processo de separação e evidenciando-se uma excelente seletividade para o corante amarelo reativo $\mathrm{BF}$ - 3R, acima de $90 \%$ ao longo do processo de separação.

Palavras-Chave: membranas; baixo custo; corante amarelo reativo BF - 3R. 


\section{INTRODUÇÃO}

Os corantes são utilizados há mais de vinte mil anos nas indústrias têxtil, farmacêutica, alimentícia, cosmética, indústria do papel, impressão, couro, plástico, entre outras. Apesar de sua importância nessas aplicações, os corantes podem ser tóxicos e resistentes a muitos processos de tratamento dessas águas residuais. Pesquisas que envolvam o tratamento desses resíduos tornam-se necessárias, a fim de minimizar impactos causados a partir destes descartes (Meireles et al., 2018). Corantes apresentam estruturas complexas, aromáticos tóxicos, não-biodegradáveis, cancerígenos. Estas águas residuais industriais são descartadas com grandes quantidades de corantes em fontes de água próximas as indústrias que, por sua vez, poluem os sistemas aquáticos inteiros (Yagub et al., 2014; Jothirani et al., 2016).

Os corantes reativos são aqueles que contêm um grupo eletrofílico (reativo) capaz de formar ligação covalente com grupos hidroxila das fibras celulósicas, com grupos amino, hidroxila e tióis das fibras protéicas e também com grupos amino das poliamidas, quando, contidos em águas residuais são muito difíceis de tratar, uma vez que são moléculas orgânicas recalcitrantes, resistentes à digestão aeróbia e são estáveis à luz, calor e agentes oxidantes. São diversas as técnicas que vem sendo aplicadas em escala industrial para o tratamento dessas águas residuais contaminadas com corantes, a citar, o carvão ativado, a sílica-gel, a alumina ativada, oxidação de Fenton, degradação eletroquímica, ozonização e as peneiras moleculares estão entre os adsorventes mais utilizados (Crini, 2006; Fardjaouia et al., 2017).

Uma das maiores preocupações ambientais com os corantes é a sua absorção e reflexão da luz solar que entra no corpo aquífero, o que interfere no crescimento de bactérias a níveis insuficientes de degradação biológica na água, resultando em um desequilíbrio ecológico (Unuabonah et al., 2008, Berradi et al., 2019). Além disso, é difícil tratar os efluentes industriais com corantes, devido às suas propriedades inertes e alto investimento em determinados tratamentos. Os efluentes industriais que contêm corantes em alta concentração geram graves problemas de saúde em seres humanos podendo levar a câncer, tumores, icterícia, alergias, irritação da pele e mutações (Bingjie et al., 2013).

Os processos de separação por membrana constituem uma tecnologia econômica e eficiente para o tratamento eficaz de águas residuais de corantes (Cheryan, 1998; Bhattacharya et al., 2010; Alventosa-de Lara et al., 2012; Zebić Avdičević et al., 2017). As tecnologias de membrana têm amplas aplicações na remoção de contaminantes de água potável e de águas residuais. 0 processo de separação por membranas utiliza membranas sintéticas como barreira seletiva, são eles: microfiltração, ultrafiltração, diafiltração, nanofiltração e osmose inversa (Burggraaf e Cot, 1996). Assim, se faz necessário a busca por materiais que possuem características propícias a este processo.

Nas últimas décadas, a membrana cerâmica teve um rápido progresso no tratamento de águas residuais industriais devido às suas propriedades vantajosas em relação à membrana polimérica convencional. As características benéficas das membranas cerâmicas incluem resistência à incrustação, alta permeabilidade, boa capacidade de recuperação, estabilidade química e vida útil longa, que encontraram aplicações com as recentes inovações nos métodos de fabricação e na nanotecnologia. Portanto, as membranas cerâmicas são uma grande promessa para possíveis aplicações no tratamento de água (Samaei et al., 2018; Li et al., 2020).

Os processos de separação por membrana tornaram-se conhecidos devido à sua simplicidade e à sua elevada eficiência de separação seletiva (Mulder, 1997; Hauser, 2011).

Nosso grupo de pesquisa (Laboratório de Desenvolvimento de Novos Materiais-LABNOV) tem publicado uma série de trabalhos sobre a síntese de membranas inorgânicas com a finalidade de tratar diversos efluentes (Scheibler et al., 2014; Mota et al., 2014; Cunha et al., 2014; Barbosa et al., 2015; Barbosa et al., 2015; Silva et al., 2017; Barbosa et al., 2018; Barbosa et al., 2018; Cunha et al., 2018; Barbosa et al., 2019; Barbosa et al., 2019). Este estudo é parte integrante desta linha de pesquisa.

Portanto, processos de baixo custo devem ser investigados para realizar a remoção de corantes, uma vez que é uma prática acessível e sustentável e conduz à universalização deste tipo de tratamento de águas residuais. Uma possível fonte de materiais de baixo custo e com excelentes características adsorventes, que pode conduzir a uma solução bem sucedida, são as argilas. Neste sentido, o objetivo deste trabalho foi avaliar a remoção do corante reativo (amarelo BF-3R) a partir de uma membrana inorgânica preparada com a argila (Bofe). 


\section{METODOLOGIA}

Os experimentos foram desenvolvidos no Laboratório de Desenvolvimento de Novos Materiais (LABNOV), localizado na Unidade Acadêmica de Engenharia Química, no Centro de Ciências e Tecnologia da Universidade Federal de Campina Grande (UAEQ/CCT/UFCG).

Na Figura 1 está apresentada a estrutura química do corante reativo amarelo BF-3R fornecido pela Texpal Química Ltda, Valinhos, São Paulo, Brasil.

Figura 1. Estrutura do corante reativo BF-3R.

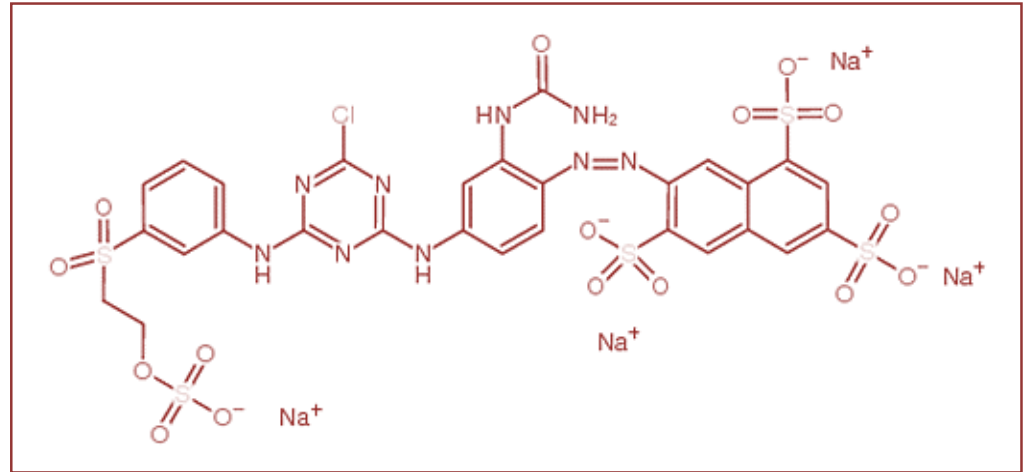

\section{Preparação da Membrana Inorgânica}

Foi preparada uma membrana inorgânica a partir da argila Bofe (fornecida pela Indústria Bentonit União Nordeste (BUN) e pela empresa BENTONISA). A argila Bofe natural policatiônica, foi peneirada em peneira ABNT\#200. Foram pesadas 3 gramas desta argila e colocada em um molde de aço inoxidável onde foi prensada em uma prensa mecânica com 4 toneladas $/ 2$ min, dando origem a membrana inorgânica plana em forma de disco, com as seguintes dimensões: $26 \mathrm{~mm}$ de diâmetro e $4 \mathrm{~mm}$ de espessura. Nesta etapa do processamento se efetua simultaneamente, a conformação e a compactação do pó da argila. Após as membranas prensadas, estas foram levadas a sinterização em forno mufla a $500{ }^{\circ} \mathrm{C}$ sob uma taxa de aquecimento de $5^{\circ} \mathrm{C} /$ min durante 2 horas.

\section{Caracterização}

\section{Difração de raios-X (DRX)}

Os difratogramas foram obtidos utilizando o método de pó, empregando-se um difratômetro Shimadzu XRD-6000 com radiação CuK $\alpha$ tensão de $40 \mathrm{kV}$, corrente de $30 \mathrm{~mA}$, passo de $0,02^{\circ}$, tempo por passo de 1,0 s e velocidade de varredura de $2^{\circ} / \mathrm{min}$, nos intervalos de $2 \theta$ entre $3^{\circ}$ e $50^{\circ}$.

\section{Adsorção Física de $\mathrm{N}_{2}$}

A análise de adsorção física de Nitrogênio foi realizada a $-196^{\circ} \mathrm{C}$ utilizando um equipamento da marca Micromeritcs ASAP 2020 numa faixa de pressão relativa $\left(\mathrm{P} / \mathrm{P}_{0}\right)$ variando entre 0,06 e 0,98.

\section{Remoção do corante em sistema contínuo de separação por membrana}

A separação por membranas é uma das tecnologias de tratamento eficientes para a rejeição do corante das águas residuais. A solução de corante amarelo reativo BF-3R utilizada foi preparada com concentração de $50 \mathrm{mg} / \mathrm{L}(50 \mathrm{ppm}$ ) e corrigida com pH 1, em função dessa argila apresentar maior eficiência de capacidade de remoção nesse pH (Silva et al., 2016). Para obter o pH da solução do corante fixado em 1, foram utilizadas soluções de ácido clorídrico 2 M. Para avaliar o potencial da membrana inorgânica produzida a partir da remoção do corante amarelo reativo BF-3R, a solução do corante foi alimentada ao sistema de separação por membrana, nas condições de temperatura de $25^{\circ} \mathrm{C}$ e pressão de 4 bar. 
0 aparato experimental utilizado, Figura 2, consiste de uma bomba peristáltica - Cole Parmer (bomba de alimentação) e um módulo de permeação de aço inoxidável (onde se encontra a membrana) constituindo o sistema de separação.

Figura 2. Sistema de separação utilizado para avaliação da seletividade da membrana inorgânica (argila Bofe).

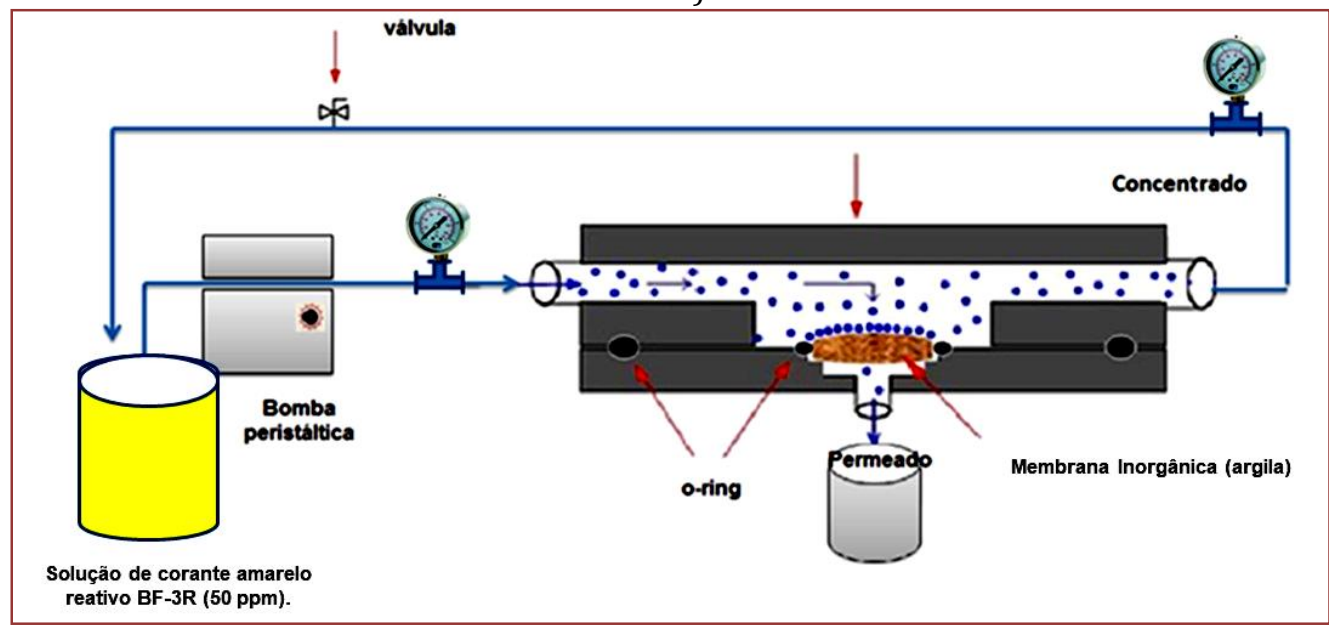

O volume do permeado produzido após a passagem da alimentação no módulo de separação (em regime tangencial), a cada $15 \mathrm{mim}$, durante 75 min, Figura 3, foi recolhido em um Becker e medido, para a possível avaliação do fluxo, conforme a Equação 1:

$$
\mathrm{J}=\mathrm{V} /(\mathrm{A} \cdot \mathrm{t})
$$

Em que: $\mathrm{J}=$ Fluxo $\left(\mathrm{L} / \mathrm{m}^{2} . \mathrm{h}\right) ; \mathrm{V}=$ volume $(\mathrm{L}) ; \mathrm{A}=$ área da membrana $\left(\mathrm{m}^{2}\right) ; \mathrm{t}=$ tempo $(\mathrm{h})$.

Pode-se observar na Figura 3 (fotografia dos volumes permeados) produzidos ao longo de 75 minutos.

Figura 3. Visualização dos permeados utilizando a membrana inorgânica (argila Bofe), nos tempos de 0 à 75 min.

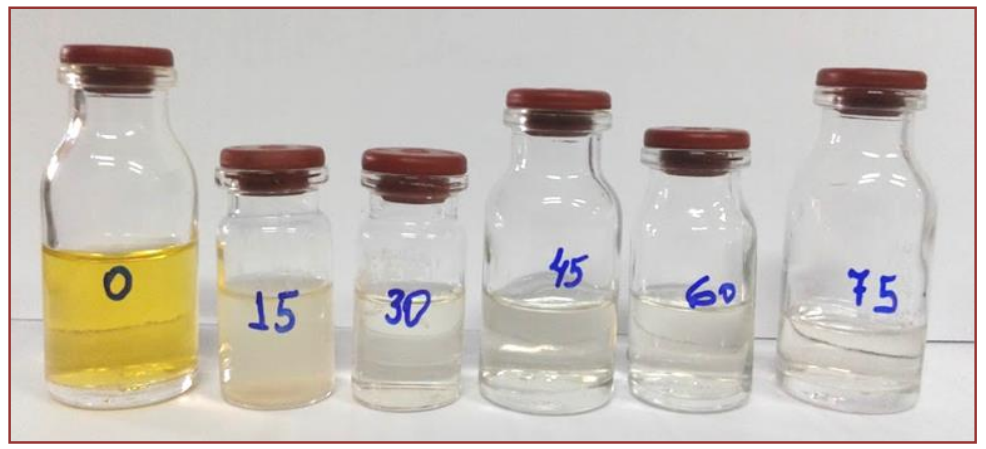


A concentração de corante no permeado foi medida em um Espectrofotômetro de UV - Visível, a fim de avaliar a concentração remanescente do corante após o processo de separação. 0 coeficiente de rejeição (R\%), é exposto na equação 2:

$$
\% R=\left(\frac{C_{0}-C}{C_{0}}\right) * 100
$$

Em que: R\%: Coeficiente de rejeição; $C_{0}$ é a Concentração da solução inicial, em mg/L; C é a Concentração da solução final, em $\mathrm{mg} / \mathrm{L}$.

\section{RESULTADOS E DISCUSSÃO}

\subsection{ARGILA BOFE NATURAL - CARACTERIZAÇÃO}

\section{Difração de Raios-X}

A argila Bofe natural policatiônica natural foi caracterizada a partir da análise por DRX. Identificou-se, Figura 4, que a argila Bofe natural apresenta reflexão em aproximadamente $5,55^{\circ}$, característico do grupo da esmectita (Souza Santos, 1992), com espaçamento basal (d $\mathrm{d}_{001}$ ) de 1,59 nm que é característico de uma montmorilonita hidratada. Outros picos também são observados e referem-se a minerais não esmectíticos como é o caso do quartzo que se apresenta como impureza.

Figura 4. Difratograma de raios X da argila Bofe natural.

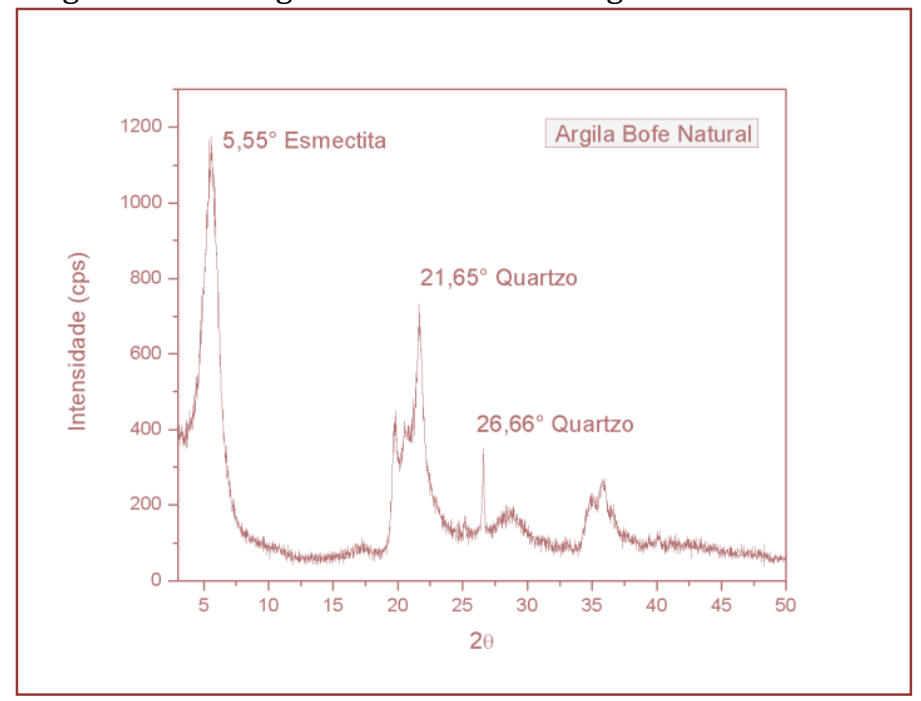

\section{Fisissorção de $\mathrm{N}_{2}$}

Na Tabela 1 são apresentados os resultados das propriedades texturais da argila Bofe.

Tabela 1. Propriedades texturais da argila Bofe.

\begin{tabular}{|c|c|c|c|}
\hline Amostra & $\mathrm{S}_{\text {BET }}\left(\mathrm{m}^{2} / \mathrm{g}\right)$ & $V_{\text {micro }}\left(\mathrm{cm}^{3} / \mathrm{g}\right)$ & $V_{\text {meso }}\left(\mathrm{cm}^{3} / \mathrm{g}\right)$ \\
\hline Argila Bofe & 105 & 0,0120 & 0,1831 \\
\hline
\end{tabular}

Evidencia-se que a argila Bofe natural possui um valor de área superficial específica de $105 \mathrm{~m}^{2} / \mathrm{g}$, valor que se assemelha aos determinados por Rodrigues, 2003 que encontrou para argila vermelha, $103 \mathrm{~m}^{2} / \mathrm{g} \mathrm{e}$ Oliveira et al., 2012 que encontrou uma área específica para argila BSN-03 de 120 m²/g. 
A isoterma de adsorção de $\mathrm{N}_{2}$ da argila Bofe natural está presentada na Figura 5.

Figura 75. Isoterma de Adsorção da argila Bofe natural.

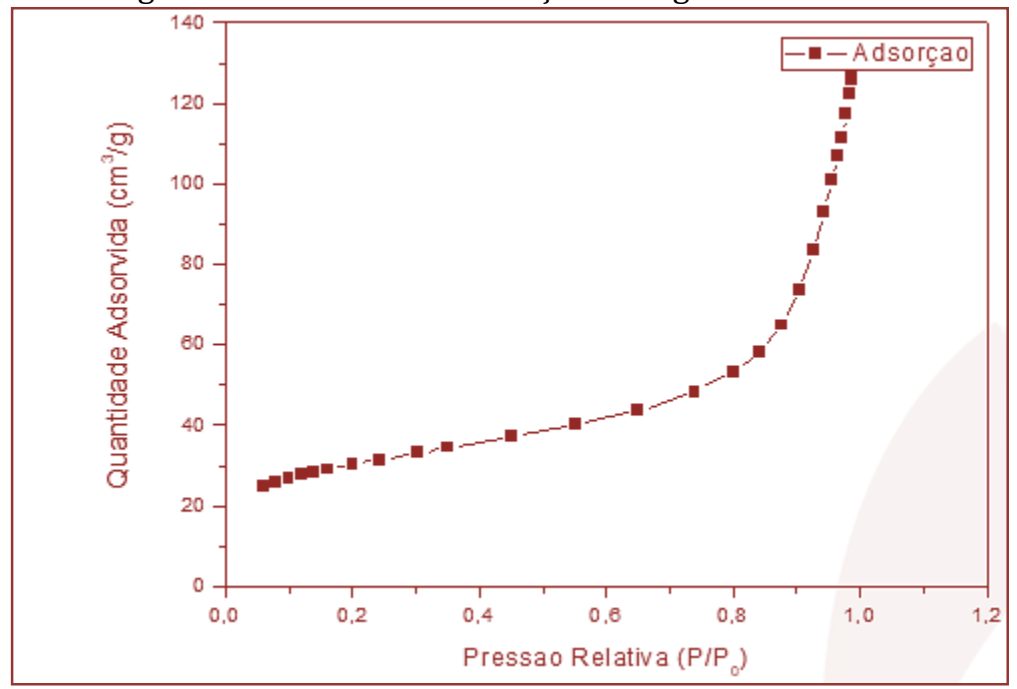

Na Figura 5 está apresentada a forma característica da formação de uma isoterma de adsorção, classificada como tipo II ou isoterma BET, característica da formação de múltiplas camadas de moléculas adsorvidas na superfície sólida. Este tipo de isoterma sigmoidal (forma 'S') é frequentemente encontrada em sólidos não porosos ou com poros maiores que microporos, o que explica os baixos valores de volume microporoso (Ruthven, 1984; Gregg e Sing, 1982). Observa-se também que na região de baixa pressão, de $\mathrm{P} / \mathrm{P} 0=0$ a 0,2 , a adsorção ocorre na superfície externa das partículas e a superfície de microporos, se tais poros (diâmetro 0-2 nm) existem. Em altas pressões relativas $(0,4<\mathrm{P} / \mathrm{P} 0<0,95)$, a adsorção da segunda e terceira camada, ocorre acompanhada pela condensação em mesoporos (4-40 nm). Finalmente, às pressões relativas $>0,95$, a condensação em macroporos (40 nm) ocorre (Bergaya et al., 2006).

\section{MEMBRANA INORGÂNICA (ARGILA BOFE) - CARACTERIZAÇÃo}

\section{Difração de Raios-X}

A membrana inorgânica produzida a partir do processo de conformação, compactação e sinterizacao $\left(500^{\circ} \mathrm{C}\right)$ da argila Bofe natural, foi caracterizada por DRX, Figura 6. Constatou-se uma redução característica do pico da esmectita, assim como um deslocamento, estando refletido em $8,9^{\circ}$ com espaçamento basal de 1,00 nm. Pode-se evidenciar que a estrutura cristalina da argila após compactada, conformada e sinterizada a $500{ }^{\circ} \mathrm{C}$ foi preservada. 
Figura 6. Difratograma de raios X da membrana inorgânica (argila Bofe).

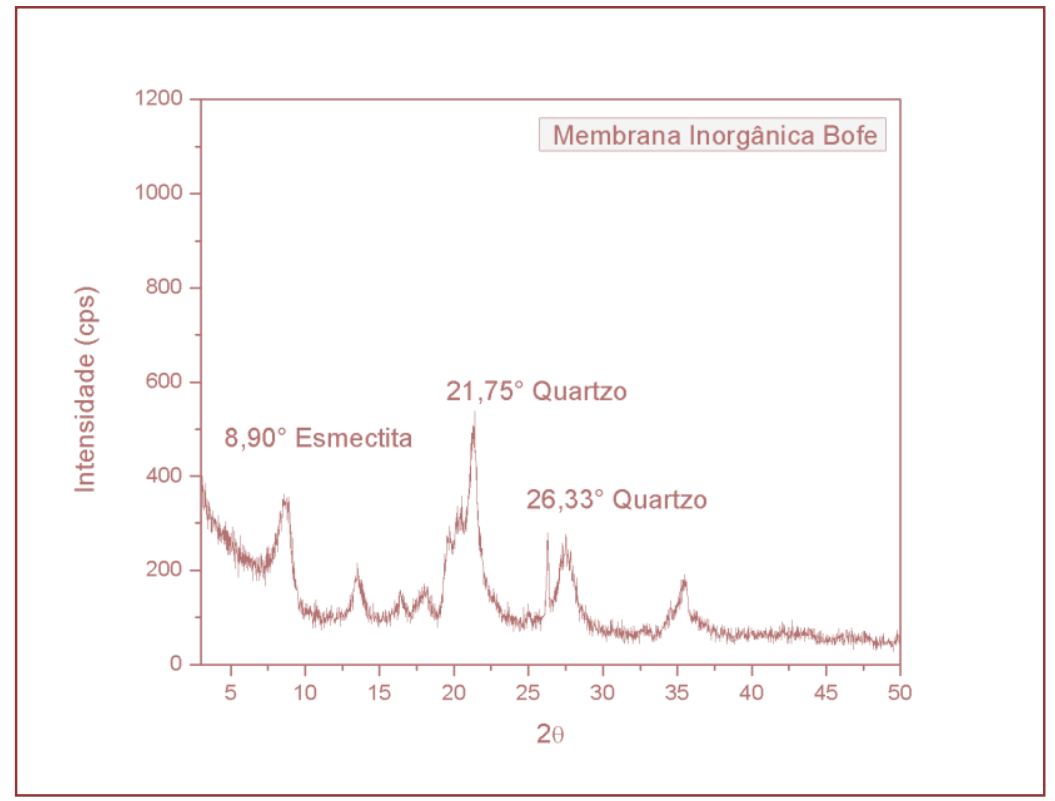

\section{Remoção do corante em sistema contínuo de separação por membrana}

Os percentuais de rejeição do corante amarelo BF-3R na membrana inorgânica foram determinados em amostras coletadas no intervalo de tempo de 0 à 75 minutos e encontram-se ilustrados na Tabela 2.

Tabela 2. Percentuais de rejeição da membrana inorgânica (argila Bofe).

\begin{tabular}{|c|c|c|c|c|c|c|}
\hline \multirow{2}{*}{$\begin{array}{c}\text { Membrana inorgânica } \\
\text { (argila Bofe) }\end{array}$} & $0 \mathrm{~min}$ & $15 \mathrm{~min}$ & $30 \mathrm{~min}$ & $45 \mathrm{~min}$ & $60 \mathrm{~min}$ & $75 \mathrm{~min}$ \\
\cline { 2 - 8 } & 0 & 83,68 & 91,32 & 92,06 & 92,46 & 92,60 \\
\hline
\end{tabular}

Conforme os dados avaliados a partir da análise por espectrofotometria de UV-visível, Tabela 2, dos volumes permeados durante $75 \mathrm{~min}$ totais, com intervalos de $15 \mathrm{~min}$, para o sistema de separação por membrana inorgânica (preparada a partir da argila Bofe), os resultados dos coeficientes de rejeição foram $83,68 \%$ para $15 \mathrm{~min}, 91,32 \%$ para $30 \mathrm{~min}, 92,06 \%$ para $45 \mathrm{~min}, 92,46 \%$ para 60 min e $92,60 \%$ para 75 min. Observa-se um aumento no valor do coeficiente de rejeição com o tempo, atingindo o equilíbrio em 45 min. A partir dos valores obtidos pela técnica por espectrofotometria de UV-visível é possível verificar a excelência no que diz respeito a remoção do corante reativo BF-3R, a partir da membrana inorgânica preparada, assim como, a partir da visualização da Figura 3, confirma-se a eficiência de remoção da membrana.

A membrana inorgânica produzida e avaliada no processo de separação do corante mostrou-se promissora, pois a quantidade de corante no permeado foi menor do que $4 \mathrm{mg} / \mathrm{L}$, apresentando um alto valor de rejeição, quando comparado com outras pesquisas desenvolvidas, com o mesmo corante, de acordo com os dados apresentados na Tabela 2, evidenciando o potencial desta membrana inorgânica. Destaca-se que o sistema qu foi utilizado neste trabalho foi contínuo, enquanto os demais sistemas utilizados nos outros trabalhos da literatura foi batelada. 
Tabela 3. Resultados de materiais utilizadas no processo de remoção do corante amarelo reativo BF-3R.

\begin{tabular}{|c|c|c|c|c|c|}
\hline Material & $\begin{array}{l}\text { Sistema de } \\
\text { separação }\end{array}$ & Corante & $\begin{array}{c}\text { Condições } \\
\text { experimentais }\end{array}$ & $\% \mathrm{R}$ & Ref. \\
\hline $\begin{array}{l}\text { Adsorvente Argila } \\
\text { Bofe }\end{array}$ & batelada & $\begin{array}{c}\text { Amarelo reativo } \\
\text { BF-3R }\end{array}$ & $\begin{array}{c}\mathrm{t}=3 \mathrm{~h} \\
\mathrm{pH}=1 \\
\mathrm{~T}=25^{\circ} \mathrm{C}\end{array}$ & 53,30 & Monteiro, 2016. \\
\hline $\begin{array}{c}\text { Adsorvente } \\
\text { Argila verde lodo }\end{array}$ & batelada & $\begin{array}{c}\text { Amarelo reativo } \\
\text { BF-3R }\end{array}$ & $\begin{array}{c}\mathrm{t}=1 \mathrm{~h} \\
\mathrm{~T}=25^{\circ} \mathrm{C}\end{array}$ & 73,72 & $\begin{array}{l}\text { Queiroz et al., } \\
2016 .\end{array}$ \\
\hline Zeólita ZSM-5 & batelada & $\begin{array}{c}\text { Amarelo reativo } \\
\text { BF-3R }\end{array}$ & $\begin{array}{c}\mathrm{t}=2 \mathrm{~h} \\
\mathrm{pH}=1 \\
\mathrm{~T}=25^{\circ} \mathrm{C}\end{array}$ & 70,78 & Brito et al., 2020 \\
\hline Zeólita SAPO-34 & batelada & $\begin{array}{c}\text { Amarelo reativo } \\
\text { BF-3R }\end{array}$ & $\begin{array}{c}\mathrm{t}=2 \mathrm{~h} \\
\mathrm{pH}=1 \\
\mathrm{~T}=25^{\circ} \mathrm{C}\end{array}$ & 52,93 & Silva et al., 2019 \\
\hline $\begin{array}{c}\text { Membrana } \\
\text { Inorgânica (argila } \\
\text { Bofe) }\end{array}$ & Fluxo contínuo & $\begin{array}{c}\text { Amarelo reativo } \\
\text { BF-3R }\end{array}$ & $\begin{array}{c}\mathrm{t}=1 \mathrm{~h} 15 \mathrm{~min} \\
\mathrm{pH}=1 \\
\mathrm{~T}=25^{\circ} \mathrm{C}\end{array}$ & 92,60 & $* *$ \\
\hline
\end{tabular}

As medidas de fluxo do permeado para a membrana inorgânica (argila Bofe) em função do tempo são mostradas na Figura 7.

Figura 7. Fluxo permeado em função do tempo para a membrana inorgânica (argila Bofe). Condições experimentais: $P$ $=4,0$ bar, Temperatura $=25^{\circ} \mathrm{C}$, tempo $=75$ minutos.

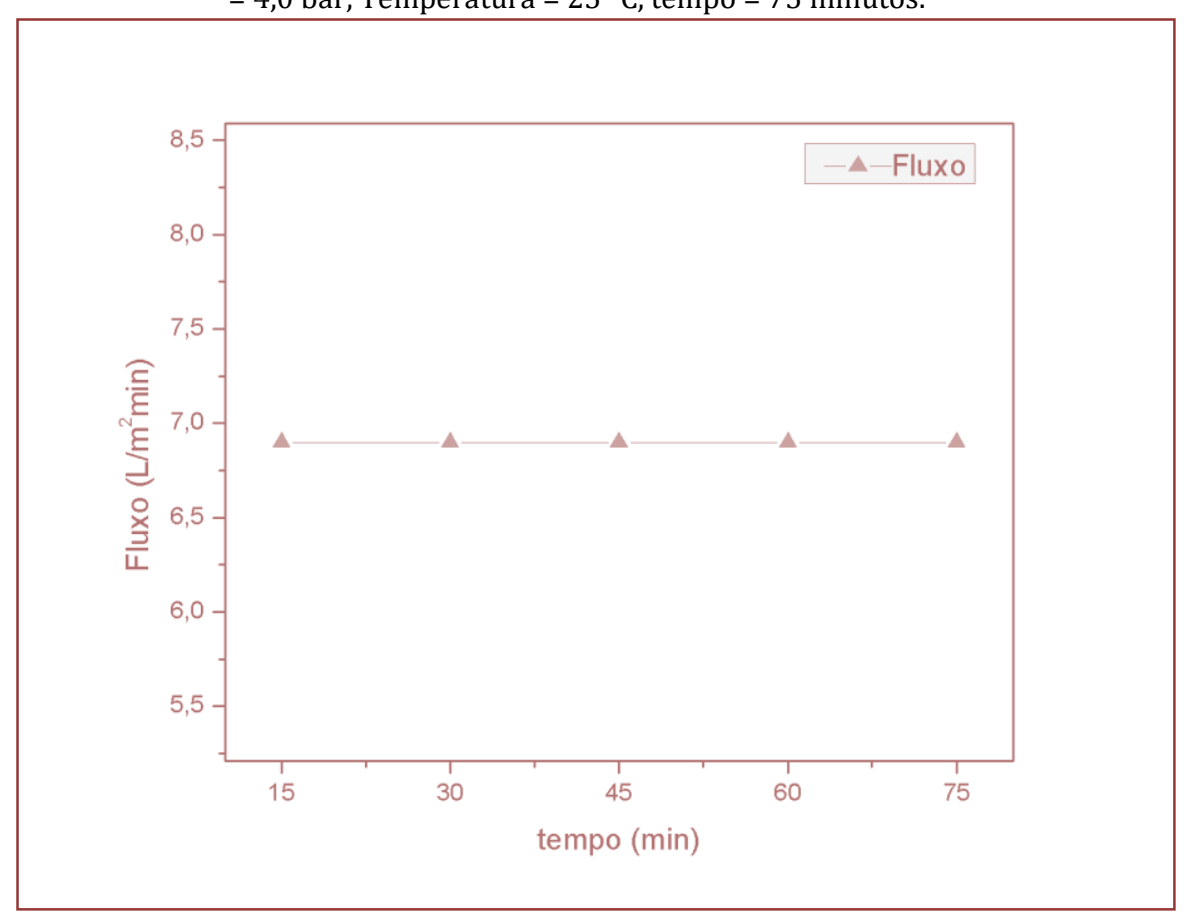

A caracterização funcional de uma membrana é representada a partir da avaliação do fluxo permeado e a capacidade seletiva. A partir do processo de separação por membrana inorgânica, desenvolvido neste trabalho, também foi possível avaliar o fluxo na membrana com o tempo, conforme mostrado na Figura 7. Constata-se que não houve variação do fluxo, mantendo-se constante durante todo o processo de separação. 0 fluxo permeado, para uma dada pressão de operação, deve ser constante com o tempo, pois a independência do fluxo com o tempo é uma indicação da estabilidade mecânica da membrana, da pureza do solvente e da sua baixa interação com o material (Burggraaf e Cot, 1996).

Neste estudo, o fluxo permaneceu em torno de 7,0 L/m².min, utilizando uma pressão de 4,0 bar, temperatura de $25{ }^{\circ} \mathrm{C}$ e um período de 75 minutos evidenciando estabilidade mecânica da membrana inorgânica (argila Bofe). 


\section{CONCLUSÕES}

Neste estudo, a membrana inorgânica de baixo custo foi produzida a partir de argila Bofe que encontra-se em abundância no estado da Paraíba e necessita de temperatura de sinterização inferior quando comparada com outros materiais (alumina, zircônia).

DRX e fisissorção de $\mathrm{N}_{2}$ foram técnicas utilizadas para caracterizar a matéria prima (argila Bofe). Após moagem e peneiramento a membrana inorgânica foi produzida a partir da argila em estado de pó pelo método de prensagem uniaxial. 0 disco resultante foi sinterizado a $500^{\circ} \mathrm{C}$.

Foi realizada a remoção do corante amarelo utilizando a membrana inorgânica de baixo custo e conclui-se que

(i) a membrana apresenta a capacidade de remover o corante amarelo com valor de percentagem de rejeição superior a $92 \%$.

(ii) os resultados evidenciaram que a membrana inorgânica removeu a cor do corante amarelo.

(iii) o processo de separação por membrana de baixo custo é mais eficiente do que o sistema de banho finito (batelada) utilizando outros adsorventes.

\section{AGRADECIMENTOS}

Os autores agradecem à Petrobras pelo apoio financeiro e a Coordenação de Aperfeiçoamento de Pessoa de Nível Superior (CAPES) pelas bolsas concedidas.

\section{REFERÊNCIAS}

[1] Alventosa-deLara E., Barredo-Damas S., Alcaina-Miranda M.I., Iborra-Clar M.I. Ultrafiltration Technology With a Ceramic Membrane for Reactive Dye Removal: Optimization of Membrane Performance. Journal of Hazardous Materials, 209-210, 492- 500, 2012.

[2] Barbosa A.S., Barbosa A.S., and Rodrigues, M.G.F. Contaminants Removal in Wastewater Using Membrane Adsorbents Zeolite Y/Alpha-Alumina. Materials Science Forum, 912, 12-15, 2018. doi:10.4028/www.scientific.net/MSF.912.12

[3] Barbosa A.S., Barbosa A.S., and Rodrigues, M.G.F. Synthesis Of MCM-22 Zeolite Membrane On A Porous Alumina Support. Materials Science Forum, 805, 272-278, 2015. doi:10.4028/www.scientific.net/MSF.805.272

[4] Barbosa A.S., Barbosa A.S., and Rodrigues, M.G.F. Synthesis of zeolite membrane (MCM-22/ $\alpha$-alumina) and its application in the process of oil-water separation. Desalination and Water Treatment, 1-8, 2015. doi: $10.1080 / 19443994.2014 .995719$

[5] Barbosa A.S., Barbosa A.S., and Rodrigues, M.G.F. Y-Type Zeolite Membranes: Synthesis by Secondary by Method and Application in Treatment of Oily Effluents. Materials Science Forum, 958, 23-28, 2019. doi:10.4028/www.scientific.net/MSF.958.23

[6] Barbosa A.S., Barbosa A.S., Barbosa, T.L.A. and Rodrigues, M.G.F. Synthesis of zeolite membrane (NaY/alumina): effect of precursor of ceramic support and its application in the process of oil-water separation. Separation and Purification Technology, 200, 141-154, 2018. https://doi.org/10.1016/j.seppur.2018.02.001

[7] Barbosa, Antonielly S., Rodrigues, Meiry G. F. Tratamento de efluentes oleosos utilizando argila e membrana de baixo custo a base de argila. XXI Congreso Argentino de Catálisis, Santa Fé, Argentina, 2019.

[8] Barbosa, T. L. A., Do Carmo, Edilânia S. Rodrigues, M. G. F. Desenvolvimento de membrana de baixo custo a partir de argila brasileira para tratamento de efluentes oleosos e reuso. XXI Congreso Argentino de Catálisis, Santa Fé, Argentina, 2019.

[9] Bergaya, F.; Theng, B. K. G.; Lagaly, G. Handbook of Clay Science. Elsevier, p. 965, 2006.

[10] Berradi, M., Hsissou, R., Khudhair, M., Assouag, M., Cherkaoui, O., El Bachiri, A., El Harfi, A. Textile finishing dyes and their impact on aquatic environs. Water Research. 5, 11-27, 2019.

[11] Bhattacharya P., Dutta S., Ghosh S., Vedajnananda S., Bandyopadhyay S. Crossflow microfiltration using ceramic membrane for treatment of sulphur black effluent from garment processing industry. Desalination, 261, 67$72,2010$.

[12] Bingjie, L. Dongfeng, W. Guangli, Y. Xianghong, M.. Adsorption of heavy metal ions, dyes and proteins by chitosan composites and derivatives-a review. J. Ocean Univ. China (Oceanic and Coastal Sea Research), 12, 500-508, 2013. 
[13] Brito, L. R. S., Barbosa, T. L. A., Bezerra, J. U. L., Rodrigues, M. G. F. Síntese da zéolita ZSM-5 para ser utilizada como adsorvente na remoção do corante reativo BF-3R: influência do pH. Cap.9, p. 66-78, 2020, Editora Poisson, Belo Horizonte.

[14] Burggraaf, A.J.; Cot, L. Fundamentals of Inorganic Membrane Science and Technology, 1st Edition, Amsterdam, Elsevier,1996.

[15] Cheryan M., Rajagopalan N. Membrane processing of oily streams. Wastewater treatment and waste reduction. Journal of Membrane Science, 151, 13-28, 1998.

[16] Crini, G. Non-conventional low cost adsorbents for dye removal: a review Bioresource Technology, 97, 10611085, 2006.

[17] Cunha R.S.S., Mota J.D., Rodrigues, M.G.F., Leite R.C.N., Carvalho, L.H. Estudo comparativo da modificação de membranas tubulares PEUAPM com adição de argilas organofílicas destinadas a separação de emulsões óleo/água. In: XIV Latin American Symposium on Polymers (SLAP)/XII Ibero American Congress on Polymers (CIP), Porto de Galinhas, PE, Brasil, 2014.

[18] Fardjaouia, Nor-El-Houda., Berrichia, F. Z. E., Ayarib, F. Kaolin-issued zeolite A as efficient adsorbent for Bezanyl Yellow and Nylomine Green anionic dyes. Microporous and Mesoporous Materials. 243, 91-101, 2017.

[19] Gregg, S.J., Sing, K.S.W. Adsorption Surface Area and Porosity, second ed., Academic Press, London, p.154, 1982.

[20] Hauser, P.J., Advances in Treating Textile Effluent. InTech, Rijeka, Croatia. 2011.

[21] Jothirani, R. Kumar, P.S. Saravanan, A. Narayan, A.S. Dutta, A. Ultrasonic modified corn pith for the sequestration of dye from aqueous solution. J. Ind. Eng. Chem., 39, 162-175, 2016.

[22] Li, C., Sun, W., Lu, Z., Ao, X., Li, S. Ceramic nanocomposite membranes and membrane fouling: A review. Water Research. 175, 115-674, 2020

[23] Meireles, G., Daamc, M. A., Sanches, A. L. M., Zanoni, M. V. B., Soares, A. M. V. M., Gravato, C., Oliveira, D. P. Red disperse dyes (DR 60, DR 73 and DR 78) at environmentally realistic concentrations impact biochemical profile of early life stages of zebrafish (Danio rerio). Chemico-Biological Interactions. 292, 94 -100, 2018.

[24] Monteiro, G. S. Adsorção de Corantes Reativos em Meio Aquoso Utlizando Argilas Nacionais. Tese de Doutorado. Programa de Pós-Graduação em Engenharia Química, Universidade Federal de Campina Grande, 2016.

[25] Mota J.D., Cunha R.S.S., Leite R.C.N., Rodrigues M.G.F., Carvalho, L.H., Lima I.N.L. Desempenho de Membrana Sinterizada de PEUAPM na Remoção de Óleo: Efeito da Incorporação de Argila Organofílica. In: XIV Latin American Symposium on Polymers (SLAP)/XII Ibero American Congress on Polymers (CIP), Porto de Galinhas, PE, Brasil, 2014.

[26] Mulder J. Basic Principles of Membrane Technology, Springer, 1997.

[27] Oliveira G.C., Mota M.F., Silva M.M., Rodrigues M.G.F., Laborde H.M. Performance of natural sodium Clay treated with ammonium salt in the separation of emulsified oil in water. Brazilian Journal of Petroleum and Gas, 6, 171-183, 2012.

[28] Queiroz, F. J; Júnior, G. E. L., Barbosa, T. L. A., Rodrigues, M. G. F. Remoção De Corante Amarelo BF-3R utilizando Argila Verde-Lodo como Adsorvente. Anais do Congresso Nacional de Pesquisa e Ensino em Ciências, Paraíba, 2016.

[29] Rodrigues, M. G. F. Physical and catalytic characterization of smectites from Boa-Vista, Paraíba, Brazil. Cerâmica, 49, 146-150, 2003.

[30] Ruthven, D. M. Principals of Adsorption and Adsorption Processes, John Wiley \& Sons, 1984.

[31] Samaei, S. M., Gato-Trinidad, S. Altaee, A. The application of pressure-driven ceramic membrane technology for the treatment of industrial wastewaters - A review, Separation and Purifification Technology, 200, 198-200, 2018.

[32] Scheibler J.R., Santos E. R. F., Barbosa A.S. and Rodrigues, M.G.F. Performance of zeolite membrane (ZSM-5/ $\gamma$ Alumina) in the oil/water separation process. Desalination and Water Treatment, 1-7, 2014. http://dx.doi.org/10.1080/19443994.2014.986536

[33] Silva F.M.N., Lima E.G., Barbosa T.L.A., M.G.F. Rodrigues, In: 13th International Conference on Catalysis in Membrane Reactors, Houston, USA, 2017.

[34] Silva, E. L.; Araújo, I. N.; Oliveira, L. A.; Lima, E. G.; Mota, J. D.; Rodrigues, M. G. F. Estudo comparativo entre as argilas policatiônica (verde dura) e sódica (BSN 02) na remoção de corante em sistema de banho finito. Anais do Encontro Brasileiro sobre Adsorção, Sergipe, 2016.

[35] Silva, F. N. M., Barbosa, T. L. A., Rodrigues, D. P. A., Rodrigues, M. G. F. Síntese da zeólita SAPO-34 e aplicação na remoção do corante reativo amarelo BF-3R. XXI Congreso Argentino de Catálisis, Santa Fé, Argentina, 2019. 
[36] Souza Cunha R.S., Mota J.D., Mota, M.F., M.G.F. Rodrigues, and Machado F. Preparation and Characterization of Tubular Composite Membranes and their Application in Water Flow Measurements. Materials Science Forum, 912, 263-268, 2018. doi. 10.428/www.scientific.net/MSF.912.263

[37] Souza Santos, P. Ciência e Tecnologia de Argilas, v. 1, 2ª Ed., Ed. Edgard Blucher. Vol. 2, 3, 1992.

[38] Unuabonah, E.I. Adebowale, K.O. Dawodu, F.A. Equilibrium, kinetic and sorber design studies on the adsorption of aniline blue dye by sodium tetraborate-modified kaolinite clay adsorbent. Journal of Hazardous Materials, 157, 397-409, 2008.

[39] Yagub, M. T.; Sem, T. K.; Afroze, S.; Ang, H. M. Dye and its removal from aqueous solution by adsorption: A review. Advances in Colloid and Interface Science, 209, 172-184, 2014.

[40] Zebić Avdičević M., Košutić K., Dobrović S. Effect of operating conditions on the performances of multichannel ceramic UF membranes for textile mercerization wastewater reatment. Environ. Technology, 38, 65, 2017. 


\section{Capítulo 11}

\section{Planejamento experimental da remoção de corante amarelo reativo através de argila esmectita}

\section{Luana Araujo de Oliveira \\ Iwalisson Nicolau de Araújo \\ Rochelia Silva Souza Cunha \\ Joseane Damasceno Mota \\ Meiry Glaucia Freire Rodrigues}

Resumo: Os corantes reativos são compostos químicos considerados de alta toxicidade, alérgicos, carcinógenos e mutagênicos, devido a isso seu tratamento é primordial. Dentre os mais comuns tipos de tratamento dos efluentes industriais encontrados está a adsorção. 0 objetivo desse trabalho é realizar um planejamento experimental na remoção do corante amarelo reativo BF-3R através da argila esmectita verde dura natural por uma adsorção pelo banho finito. A argila verde dura natural foi caraterizada através da técnica de Difração de Raios-X (DRX) e Espectroscopia de Fluorescência de Raios X por Energia Dispersiva (FRX-ED). A solução de corante utilizada apresentou concentração de $50 \mathrm{mg} / \mathrm{L} \mathrm{e} \mathrm{pH} \mathrm{1,} \mathrm{e} \mathrm{os} \mathrm{ensaios} \mathrm{de} \mathrm{banho} \mathrm{finito} \mathrm{foram} \mathrm{realizados} \mathrm{seguindo}$ um planejamento fatorial 22 com três pontos centrais, onde as variáveis de entrada foram o tempo de remoção e massa de argila e a resposta foi a percentagem de remoção. Através do software Statistica 7 foi possível obter a equação do modelo matemático para a resposta, a análise de variância, as superfícies de resposta e de contorno, o diagrama de Pareto e o gráfico dos valores preditos versus observados. A partir dessa análise observou que a melhor eficiência de remoção foi com maior tempo de contato da argila com a solução de corante (5 h) e maior massa de argila utilizada (1,5 g).

Palavras-chave: corante reativo, argila esmectita, sorção, tratamento de efluentes, poluição. 


\section{INTRODUÇÃO}

A água é um dos recursos naturais mais importantes da Terra, sendo imprescindível para a geração e manutenção de todas as formas de vida em nosso planeta, com importância em uma ampla gama de atividades, tais como abastecimento público, processos produtivos industriais, agropecuária, recreação, entre outros (PEREIRA e FREIRE, 2005).

A modernização e o estilo de vida urbano enfrentam muitas questões ambientais e, entre elas, a poluição da água é uma das principais causas de desequilíbrio ecológico. Os efluentes industriais descartados com contaminantes como corantes, metais pesados, pesticidas etc. apresentam riscos ambientais e de saúde significativos (KHAN et al., 2020).

Um grande número de indústrias, como têxtil, papel e celulose, impressão, tintas, solventes, entre outros, consomem grandes volumes de água. Os efluentes dessas indústrias podem conter quantidades indesejadas de poluentes, por exemplo, os corantes sintéticos que são amplamente utilizados nas indústrias têxtil, de papel e de impressão (ZOLLINGER, 1987). Os corantes são capazes de reduzir a fotossíntese e causar diferentes graus de toxicidade, mutagênese e carcinogênese nos seres vivos (SANTOS et al., 2020).

Existem muitas desvantagens nos processos convencionais de tingimento reativo na indústria têxtil, por exemplo, o consumo de grande quantidade de água (normalmente 12-15 toneladas de água por tonelada de fibra de algodão) e descarregando muitos efluentes coloridos com alta salinidade, causando poluição ambiental (WANG et al., 2020 e BHATE et al., 2017). Isso porque, durante o processo de tingimento, cerca de $50 \%$ da quantidade de corantes fica disponível nos efluentes que, quando não tratados de forma adequada antes do descarte, são extremamente prejudiciais a vida aquática (MESSINA E SCHULZ, 2006).

Águas residuais contendo corantes orgânicos, especialmente corantes têxteis reativos, são difíceis de degradar devido à sua estrutura aromática complexa e são de natureza tóxica, devido a isso seu tratamento é primordial. Como os corantes possuem resistência à degradação no seu tratamento de efluentes, as técnicas convencionais se tornam complicadas e é necessário um cuidado no despejo nos corpos hídricos (AKSU, 2005 e ROCHA et al., 2015).

Portanto, os corantes orgânicos devem ser removidos adequadamente antes de serem descarregados nos sistemas aquáticos para preservar a saúde humana e o ecossistema. A água contaminada é tratada por vários métodos físico-químicos, como oxidação de Fenton, fotodegradação, coagulação-floculação, adsorção, técnica de membrana, entre outros (YAGUB et al., 2014 e MOHAMMED et al., 2020).

Entre essas técnicas, o processo de adsorção provou ser muito eficiente na remoção de poluentes orgânicos das águas residuais. A adsorção é um fenômeno superficial básico, pelo qual os poluentes são removidos seletivamente de uma solução aquosa, anexando o soluto (adsorbato) a uma superfície sólida (adsorvente). 0 processo de adsorção se dá através da troca entre as moléculas de corante e os cátions inorgânicos presentes nas intercamadas de algumas argilas (GEISEKING E JENNY, 1936).

Comparado a outros processos alternativos, a adsorção é geralmente o método mais viável e adaptável devido ao seu design simples de operação, não suscetibilidade a poluentes, reutilização, alta eficiência, custo inicial relativamente baixo e baixa produção de resíduos (AWAD et al., 2020 e CARVALHO et al., 2014).

Entre as argilas utilizadas como adsorventes destacam-se as argilas esmectíticas, que são argilas constituídas predominantemente por argilominerais esmectíticos. Sua larga aplicabilidade como adsorvente está associada a sua elevada área superficial, elevada capacidade de troca de cátions (CTC), baixo custo, grande disponibilidade e boa inércia química (BARBA, 1997).

Nosso grupo de pesquisa tem desenvolvido diversos estudos na área de tratamento de efluentes contendo corantes reativos utilizando diversos adsorventes. BARBOSA et al. (2018) estudou o tratamento de efluentes têxteis utilizando membrana cerâmica de baixo custo; BARBOSA et al. (2018) e LIMA et al. (2016) avaliaram a descontaminação de efluentes têxteis utilizando argila chocolate B e argila Brasgel, respectivamente; BARBOSA et al. (2015), BARBOSA et al. (2016), LIMA et al. (2016), ROCHA et al. (2017), ROCHA et al. (2016) e SIQUEIRA et al. (2016) realizaram o estudo de remoção de diversos corantes utilizando a argila vermelha como adsorvente; BARBOSA et al. (2018) sinterizou, caracterizou e aplicou membrana zeolítica NaA na remoção do corante reativo azul; LIMA et al. (2014), PAULA et al. (2014) e LIMA et al. (2014) sintetizaram peneiras moleculares como adsorvente na remoção de corantes; ROCHA et al. (2015), ROCHA et al. (2016), ROCHA et al. (2017) e SOUSA et al. (2018) utilizaram diversos tipos de argilas para remoção de corantes; SILVA et al. (2017), SILVA et al. (2018), SILVA et al. (2019), SILVA et al. (2019) e 
SILVA et al. (2019) utilizaram diversos tipos de zeólitas para remoção de corante reativo; Barbosa et al. (2019) e Rodrigues et al. (2019) realizaram a síntese de estruturas metalorgânicas para serem utilizadas na remoção de corante rodamina $B$.

Destaca-se alguns trabalhos, tais como Barbosa et al. (2019) que estudou a remoção do corante reativo vermelho por adsorção utilizando argilas branca e vermelha, realizando experimentos com variação de $\mathrm{pH}$ num intervalo de $1 \mathrm{a}$ 7. Silva et al. (2020) executou o estudo com o objetivo de preparar a zeólita ZSM5 e utilizá-la como adsorvente na remoção do corante reativo amarelo BF-3R, o parâmetro do pH na adsorção foi avaliado a fim de se obter uma melhor eficiência de remoção na cor. Silva et al. (2016) realizou um estudo comparativo entre as argilas policatiônica (verde dura) e sódica (BSN 02) na remoção de corante em sistema de banho finito.

Com a necessidade crescente da otimização de produtos e processos, minimizando custos e tempos, maximizando rendimento, produtividade e qualidade de produtos, dentre outros objetivos, tem levado profissionais a buscarem técnicas sistemáticas de planejamento de experimento. A metodologia do planejamento fatorial, associada à análise de superfícies de respostas, é uma ferramenta fundamentada na teoria estatística, que fornece informações seguras sobre o processo, minimizando o empirismo que envolve técnicas de tentativa e erro (RODRIGUES e IEMMA, 2009).

0 presente trabalho teve como objetivo realizar um planejamento experimental na remoção de corante amarelo reativo BF-3R, utilizando como adsorvente a argila verde dura natural. Para esta finalidade foi utilizado um sistema de banho finito, analisando a influência das variáveis de massa de argila e tempo de experimento, para a resposta de percentagem de remoção.

\section{METODOLOGIA}

\subsection{MATERIAIS}

A argila utilizada para esse estudo foi a argila verde dura natural (VDN), fornecida pela empresa BENTONISA - Betonita do Nordeste S.A., situada no município de Boa Vista/PB.

O corante amarelo reativo BF-3R foi fornecido pela Texpal Química Ltda. O corante cuja estrutura está representada na Figura 1.

Figura 1. Estrutura química do corante amarelo reativo BF-3R.

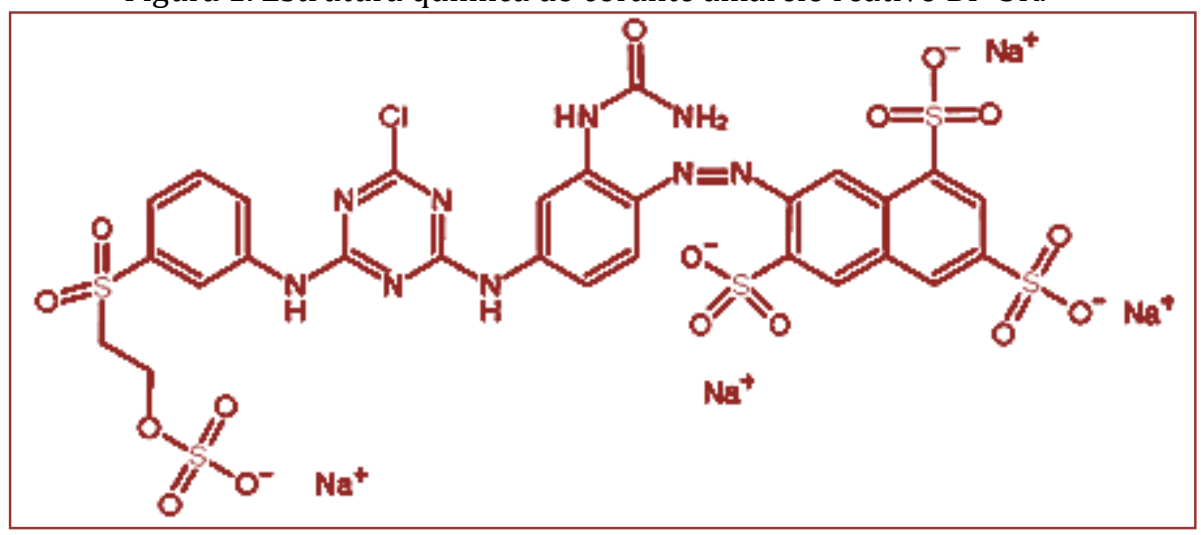

\subsection{DIFRAÇÃO DE RAIOS-X (DRX)}

A argila verde dura natural foi caraterizada através da técnica de difração de raios-X (DRX) através do método do pó, utilizando um difratômetro da marca Shimadzu modelo XRD-6000 com radiação CuK $\alpha$, tensão de $40 \mathrm{kV}$ em corrente de filamento de $30 \mathrm{~mA}$, tamanho do passo de $0,02^{\circ}$, tempo por passo de 1,000 $\mathrm{s}$, com velocidade de varredura de $2^{\circ}(2 \theta) / \mathrm{min}$, com ângulo $2 \theta$ percorrido de 2 a $50^{\circ}$.

\subsection{FLUORESCÊNCIA DE RAIOS X POR ENERGIA DISPERSIVA (FRX-ED)}

A análise química a partir da Fluorescência de Raios X por Energia Dispersiva (FRX-ED) permite identificar e quantificar a composição química global de um sólido. A amostra a ser analisada foi peneirada 
em malha ABNT $\mathrm{N}^{\circ} 200$ (abertura de 0,075 mm). A análise foi realizada com o equipamento da marca Shimadzu modelo 720 .

\subsection{PREPARAÇÃO DA SOLUÇÃO DE CORANTE AMARELO REATIVO BF-3R}

A solução de corante amarelo reativo BF-3R utilizada apresentou concentração de $50 \mathrm{mg} / \mathrm{L}$ e pH 1, devido a essa argila apresentar maior eficiência de capacidade de remoção nesse pH (SILVA et al., 2016). Para obter o pH do meio reacional fixado em 1, foram utilizadas soluções de ácido clorídrico 0,25 M.

\subsection{PLANEJAMENTO EXPERIMENTAL UTILIZADO NO BANHO FINITO}

Para avaliar o potencial da argila VDN na remoção do corante amarelo reativo BF-3R, ensaios de banho finito foram realizados seguindo um planejamento fatorial 22 com três pontos centrais, como exibido na Tabela 1, onde o efeito dos fatores: tempo de remoção $(\mathrm{t})$ e massa de argila $(\mathrm{m})$ foram avaliados. 0 tempo de remoção foi realizado em 1 h (-), 5 h (+) e 3 h (0); e as massas de argilas foram de 0,5 g (-), 1,5 g (+), e $1,0 \mathrm{~g}(0)$. A resposta avaliada foi percentagem de remoção de corante.

A adição de três pontos centrais (0) permite uma estimativa independente do erro a ser obtido, ou seja, não repercutem nas estimativas usuais dos efeitos em um planejamento fatorial $2^{2}$ (MONTGOMERY e RUNGER, 2003).

A análise estatística foi realizada através do software Statistica 7 e sua matriz de experimentos está mostrada na Tabela 1.

Tabela 1. Matriz dos experimentos do banho finito.

\begin{tabular}{|c|c|c|c|}
\hline \multicolumn{2}{|c|}{ Ensaios } & tempo (h) & \%Remoção \\
\hline 1 & $0,5(-1)$ & $1(-1)$ & R1 \\
\hline 2 & $1,5(+1)$ & $1(-1)$ & R2 \\
\hline 3 & $0,5(-1)$ & $5(+1)$ & R3 \\
\hline 4 & $1,5(+1)$ & $5(+1)$ & R4 \\
\hline 5 & $1(0)$ & $3(0)$ & R5 \\
\hline 6 & $1(0)$ & $3(0)$ & R6 \\
\hline 7 & $1(0)$ & $3(0)$ & R7 \\
\hline
\end{tabular}

\subsection{PREPARAÇÃO E REALIZAÇÃO DE ENSAIOS EM SISTEMA BATELADA}

Os ensaios de banho finito foram realizados no shaker orbital da marca CERTOMAT, sob rotação de 200 rpm, onde o conjunto (solução de corante + argila VDN) foi conduzido de acordo com a matriz de planejamento. Após cada período de agitação, as amostras foram filtradas para determinação da quantidade de corante presente no filtrado.

A Figura 2 apresenta os filtrados obtidos no ensaio 1 (0,5 g de argila VDN e 1 hora de agitação) e no ensaio 4 (1,5 g de argila VDN e 5 horas de agitação), após a remoção do corante reativo BF-3R utilizando argila VDN como adsorvente.

Figura 2. Visualização dos filtrados obtidos nos ensaios 1 e 4, respectivamente.

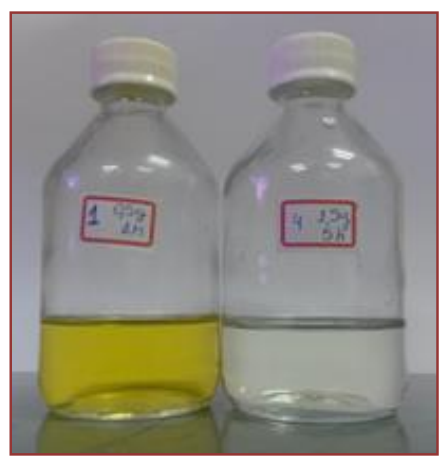




\subsection{DETERMINAÇÃO DA PERCENTAGEM DE REMOÇÃO}

A concentração do corante amarelo reativo BF-3R na solução foi determinada com o auxílio da curva de calibração, obtida por meio da medição da absorbância de diferentes concentrações de soluções desse corante a um comprimento de onda máximo de $427 \mathrm{~nm}$ em um espectrofotômetro (UV-1600 Pró-Análise).

A percentagem de remoção (\%Rem), bem como a capacidade de remoção (qeq) foram obtidas a partir das Equações 1 e 2 (WU et al, 2009), respectivamente:

$$
\% \operatorname{Rem}=\left(\frac{C_{i}-C}{C_{i}}\right) * 100
$$

Em que: \%Rem: percentagem de remoção; $C_{\mathrm{i}}$ : concentração da solução inicial (mg/L); C: concentração da solução final (mg/L).

$$
q_{e q}=\frac{V}{m}\left(C_{i}-C\right)
$$

Em que: qeq: capacidade de remoção (mg do corante/g do adsorvente); V: volume da solução do corante (mL); m: massa do sólido (mg); $C_{\mathrm{i}}$ : concentração inicial (mg/L); C: concentração da solução final (mg/L).

\section{RESULTADOS E DISCUSSÃO}

\subsection{CARACTERIZAÇÃO DA ARGILA VDN}

Na Figura 3 é apresentado o difratograma de raios X da argila VDN.

Figura 3. Difratograma de raios $\mathrm{X}$ da argila VDN

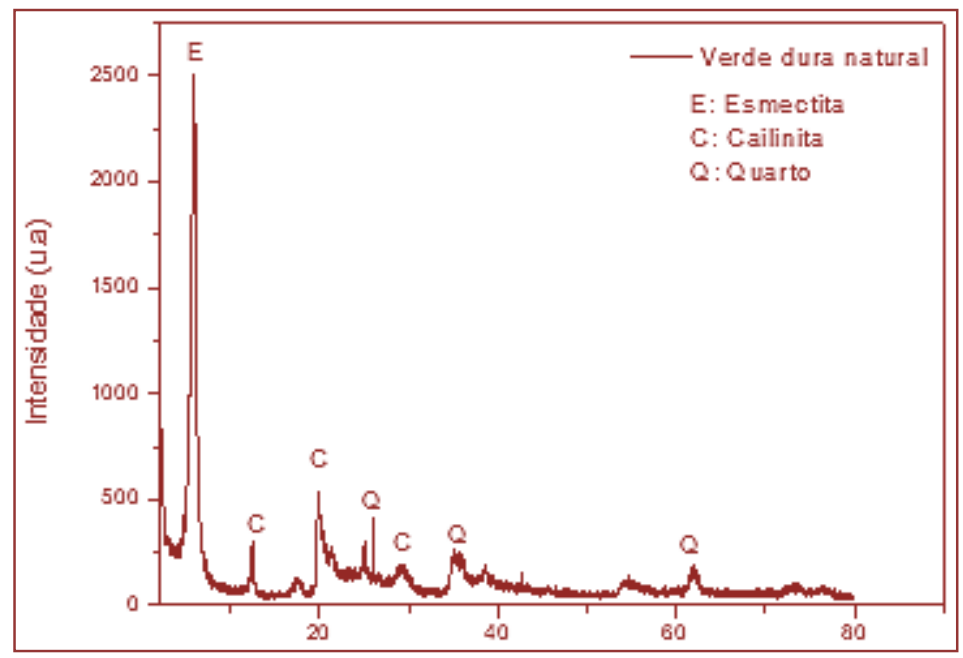

Por meio deste difratograma é possível verificar que a argila VDN apresenta reflexão em aproximadamente $5,7^{\circ}$, característico do grupo da esmectita (SOUZA-SANTOS, 1992; RODRIGUES, 2003; MOTA et al., 2014; QUEIROZ et al., 2010), que corresponde ao espaçamento basal (d001) de 15,5 $\AA$ (1,55 $\mathrm{nm}$ ). Outros picos também são observados e são referentes a minerais não esmectíticos como o quartzo que se apresenta como impureza.

Na Tabela 2, encontra-se apresentada a composição química da argila VDN. 
Tabela 2. Composição química da argila VDN.

\begin{tabular}{|c|c|}
$\begin{array}{c}\text { Composição } \\
\text { química }\end{array}$ & $\begin{array}{c}\text { Argila VDN } \\
(\%)\end{array}$ \\
\hline $\mathrm{SiO}_{2}$ & 52,70 \\
\hline $\mathrm{Al}_{2} \mathrm{O}_{3}$ & 30,26 \\
\hline $\mathrm{MgO}$ & 3,84 \\
\hline $\mathrm{Fe}_{2} \mathrm{O}_{3}$ & 11,39 \\
\hline $\mathrm{CaO}$ & 0,38 \\
\hline $\mathrm{Na}_{2} \mathrm{O}$ & - \\
\hline $\mathrm{TiO}_{2}$ & 0,53 \\
\hline $\mathrm{BaO}_{2}$ & 0,41 \\
\hline $\mathrm{Cr}_{2} \mathrm{O}_{3}$ & 0,16 \\
\hline $\mathrm{NiO}^{\mathrm{SiO}}$ & 0,15 \\
\hline $\mathrm{SO}$ & 0,07 \\
\hline $\mathrm{CuO}$ & 0,03 \\
\hline $\mathrm{ZnO}$ & 0,02 \\
\hline Outros & 0,06 \\
\hline TOTAL & 100 \\
\hline
\end{tabular}

Pela análise dos resultados apresentados na Tabela 2, observa-se que a argila VDN apresenta uma grande quantidade de óxido de alumínio $\left(\mathrm{Al}_{2} \mathrm{O}_{3}\right)$, que juntamente com o óxido de silício $\left(\mathrm{SiO}_{2}\right)$, totaliza um percentual acima de $83 \%$ da composição total. Encontra-se também um teor elevado de óxido de ferro na forma de óxido de ferro III $\left(\mathrm{Fe}_{2} \mathrm{O}_{3}\right)$. 0 magnésio, o cálcio e o bário, estão presentes, geralmente, como óxidos de cátions trocáveis, característicos dos argilominerais nas suas formas naturais. Estes resultados se assemelham com os valores encontrados na literatura para argilas brasileiras (GRIM, 1968 e SOUZA SANTOS, 1992).

\subsection{PROCESSO DE REMOÇÃO DO CORANTE AMARELO}

Os resultados referentes à percentagem de remoção de corante amarelo reativo BF-3R de acordo com o planejamento fatorial utilizando a argila VDN estão mostrados na Tabela 3.

Tabela 3. Resultados obtidos a partir do planejamento fatorial da remoção do corante amarelo reativo BF3R utilizando argila VDN como adsorvente.

\begin{tabular}{|c|c|c|c|}
\hline Ensaios & Massa de argila VDN $(\mathrm{g})$ & tempo $(\mathrm{h})$ & \%Remoção \\
\hline 1 & 0,5 & 1 & 64,26 \\
\hline 2 & 1,5 & 1 & 70,58 \\
\hline 3 & 0,5 & 5 & 95,24 \\
\hline $\mathbf{4}$ & $\mathbf{1 , 5}$ & $\mathbf{5}$ & $\mathbf{9 8 , 0 2}$ \\
\hline 5 & 1 & 3 & 89,52 \\
\hline 6 & 1 & 3 & 89,02 \\
\hline 7 & 1 & 3 & 88,66 \\
\hline
\end{tabular}

A partir da análise da Tabela 3 constata-se que a condição ótima de massa e tempo utilizada nos testes de sorção, com a finalidade de obter a maior remoção (concentração final de corante por g de adsorvente) ocorreu no ensaio 4. Neste ensaio as condições experimentais foram agitação de $200 \mathrm{rpm}$, utilizando 1,5 g de argila VDN e tempo de contato entre a argila VDN e a solução do corante amarelo reativo BF-3R de 5 horas.

Os resultados para a capacidade de remoção (qeq) estão apresentados na Tabela 4 e pode-se pontuar que o maior valor de qeq foi de 3,53 mg do corante amarelo reativo BF-3R/mg argila VDN. 
Tabela 4. Resultados obtidos para capacidade de remoção (qeq) do corante amarelo reativo BF-3R utilizando argila VDN como adsorvente.

\begin{tabular}{|c|c|c|c|}
\hline Ensaios & Massa de argila VDN $(\mathrm{g})$ & tempo $(\mathrm{h})$ & qeq $(\mathrm{mg} / \mathrm{g})$ \\
\hline $\mathbf{1}$ & 0,5 & 1 & 3,21 \\
\hline $\mathbf{2}$ & 1,5 & 1 & 3,53 \\
\hline $\mathbf{3}$ & 0,5 & 5 & 1,59 \\
\hline $\mathbf{4}$ & 1,5 & 5 & 1,63 \\
\hline $\mathbf{5}$ & 1 & 3 & 2,24 \\
\hline $\mathbf{6}$ & 1 & 3 & 2,23 \\
\hline $\mathbf{7}$ & 1 & 3 & 2,22 \\
\hline
\end{tabular}

Na Tabela 5 o valor de remoção obtido no presente trabalho é comparado com valores do mesmo parâmetro obtidos para sorção do corante amarelo reativo BF-3R utilizando diferentes adsorventes.

Tabela 5. Comparação entre valores de qeq da sorção do corante reativo amarelo BF-3R com outros materiais adsorventes.

\begin{tabular}{|c|c|c|c|c|c|c|}
\hline Adsorvente & Condições experimentais & $\begin{array}{c}\text { Massa } \\
(\mathrm{g})\end{array}$ & $\begin{array}{l}\text { tempo } \\
\text { (h) }\end{array}$ & $\mathrm{pH}$ & $\begin{array}{c}\mathrm{q}_{\mathrm{eq}} \\
(\mathrm{mg} / \mathrm{L})\end{array}$ & Referência \\
\hline Argila VDN & $\begin{array}{c}\text { Sistema batelada } \\
\mathrm{C}_{\mathrm{i}}=50 \mathrm{mg} / \mathrm{L} ; \mathrm{T}=25^{\circ} \mathrm{C} \\
\text { shaker }(200 \mathrm{rpm})\end{array}$ & 1,5 & 5 & 1 & 3,530 & Este trabalho \\
\hline $\begin{array}{l}\text { Argila verde- } \\
\text { lodo }\end{array}$ & $\begin{array}{c}\text { Sistema batelada } \\
\mathrm{C}_{\mathrm{i}}=50 \mathrm{mg} / \mathrm{L} ; \mathrm{T}=25{ }^{\circ} \mathrm{C} \\
\text { shaker }(200 \mathrm{rpm})\end{array}$ & 0,5 & 1 & 1 & 3,123 & $\begin{array}{l}\text { Queiroz et al. } \\
\quad(2016)\end{array}$ \\
\hline Zeólita ZSM-5 & $\begin{array}{c}\text { Sistema batelada } \\
\mathrm{C}_{\mathrm{i}}=50 \mathrm{mg} / \mathrm{L} ; \mathrm{T}=25^{\circ} \mathrm{C} ; \text { shaker } \\
(200 \mathrm{rpm})\end{array}$ & & & 1 & 3,164 & Silva et al. (2020) \\
\hline $\begin{array}{c}\text { Zeólita SAPO- } \\
34\end{array}$ & $\begin{array}{c}\text { Sistema batelada } \\
\mathrm{C}_{\mathrm{i}}=50 \mathrm{mg} / \mathrm{L} ; \mathrm{T}=25^{\circ} \mathrm{C} ; \\
\text { shaker }(200 \mathrm{rpm})\end{array}$ & & & 1 & 2,740 & Silva et al. (2019) \\
\hline
\end{tabular}

Constata-se que o valor obtido é superior ao obtido por outros adsorventes. Avaliando a Tabela 5 observase que a utilização da argila VDN é bastante promissora e possui uma alta eficiência.

Através do software Statistica 7 foi possível obter o modelo matemático que relaciona a percentagem de remoção de corante amarelo reativo BF-3R através da argila verde dura natural mostrado na Equação (3). Os coeficientes e os seus respectivos erros padrão em negritos são os estatisticamente significativos ao nível de 95\% de confiança, sendo portanto, a média, a massa de argila e o tempo significativos e a interação massa/tempo não foi significativa.

$\%$ Rem $=(85,04 \pm 0,16)+\left(14,60^{*}\right.$ massa $\left.\pm 0,21\right)+\left(2,27^{*}\right.$ tempo $\left.\pm 0,21\right)-\left(0,88^{*}\right.$ massa ${ }^{*}$ tempo $\left.\pm 0,21\right)$

Na Tabela 6 são apresentados os parâmetros da análise de variância para os ajustes do modelo, podendo verificar se o modelo proposto é significativo, preditivo ou se apresenta falta de ajuste.

Tabela 6. Análise de variância para a resposta de percentagem de remoção.

\begin{tabular}{|c|c|c|c|c|c|c|}
\hline Fonte de Variação & $\begin{array}{l}\text { Soma } \\
\text { Quadrática }\end{array}$ & $\begin{array}{l}\text { Graus de } \\
\text { liberdade }\end{array}$ & $\begin{array}{l}\text { Média } \\
\text { Quadrática }\end{array}$ & $\begin{array}{l}\text { Fcalc } \\
(95 \%)\end{array}$ & $\begin{array}{l}\text { Ftab } \\
(95 \%)\end{array}$ & $\begin{array}{l}\text { Fcalc/ } \\
\text { Ftab }\end{array}$ \\
\hline Regressão & 877,0595 & 3 & 292,3531 & 10,27 & 9,28 & 1,11 \\
\hline Resíduo & 85,3760 & 3 & 28,4586 & & & \\
\hline Falta de ajuste & 85,0030 & 1 & 85,0030 & 455,78 & 18,51 & 24,62 \\
\hline Erro Puro & 0,3731 & 2 & 0,1865 & & & \\
\hline Total & 962,4355 & 6 & & & & \\
\hline \% Variação explicada & 91,13 & & & & & \\
\hline
\end{tabular}


Observa-se que o modelo para resposta de percentagem de remoção do corante amarelo reativo BF-3R é estatisticamente significativo, pois o coeficiente de variação explicada $\left(\mathrm{R}^{2}\right)$ é satisfatório, explicando 91,13\% da variação em torno da média, e também pode-se dizer que o modelo é estatisticamente significativo devido a razão Fcalculado por Ftabelado para a regressão, está acima de 1, ao nível de confiança de $95 \%$.

Mesmo o modelo sendo significativo, ele não é preditivo, pois, a razão Fcalculado por Ftabelado para a regressão não deu maior que 10, portanto o modelo não é significativo para realizar previsões. E pode-se afirmar ainda que o modelo não apresenta falta de ajuste, pois o Fcalculado por Ftabelado para falta de ajuste, está acima de 1.

Devido o modelo ser estatisticamente significativo, pode-se assim, construir a superfície de resposta e as curvas de contorno para análise das faixas ótimas de operação das variáveis de entrada que maximizem a resposta em estudo (BARROS NETO et al., 1995 e RODRIGUES e IEMMA, 2009). A superfície de resposta e as curvas de contorno estão mostradas nas Figuras 4 e 5, respectivamente.

Figura 4. Superfície de resposta para \% de remoção de corante amarelo reativo BF-3R através da argila verde dura em função dos valores codificados.

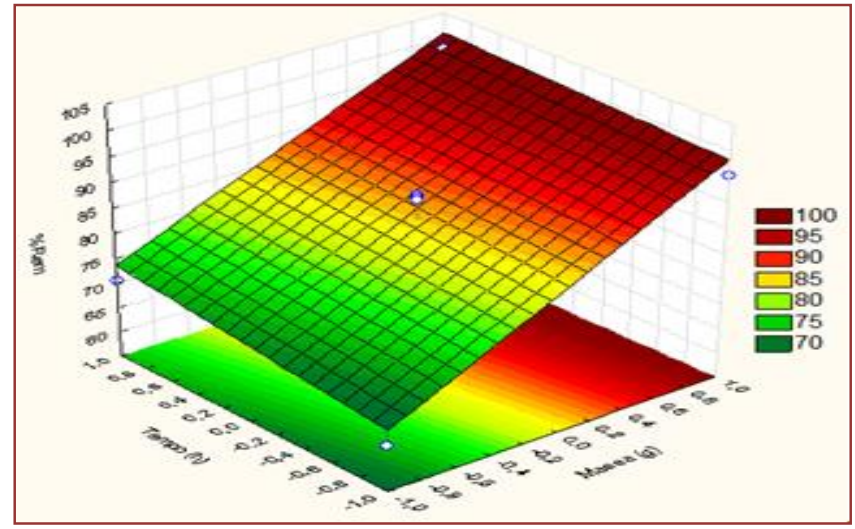

Figura 5. Curvas de contorno para \% de remoção de corante amarelo reativo BF-3R através da argila verde dura em função dos valores codificados.

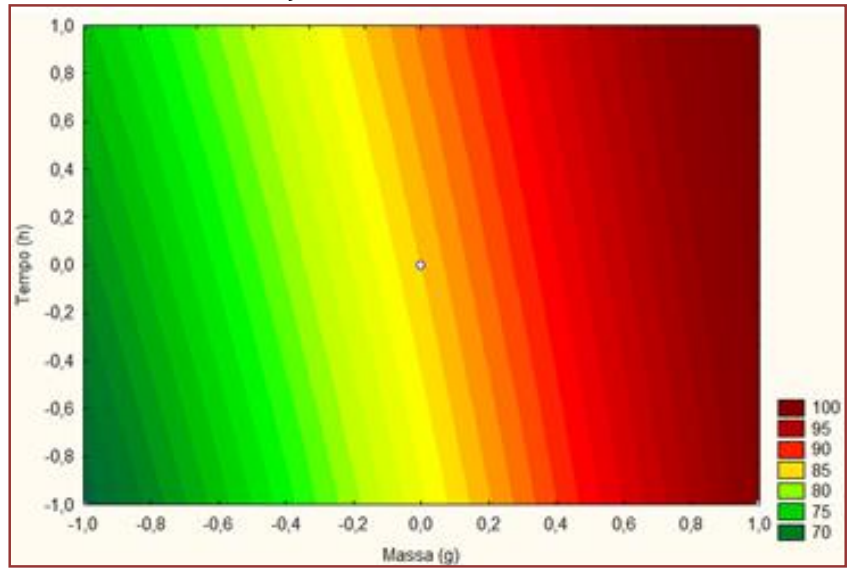

Observando a superfície de resposta e as curvas de contorno é possível visualizar a influência das variáveis do processo na percentagem de remoção, que ficou evidenciado que quanto maior o tempo de contato da argila com a solução de corante e maior a massa de argila utilizada, uma maior eficiência de remoção é obtida.

Outra análise realizada pelo software Statistica 7 foi o diagrama de Pareto, que está mostrado na Figura 6. 
Figura 6. Diagrama de Pareto para as variáveis de entrada do planejamento experimental.

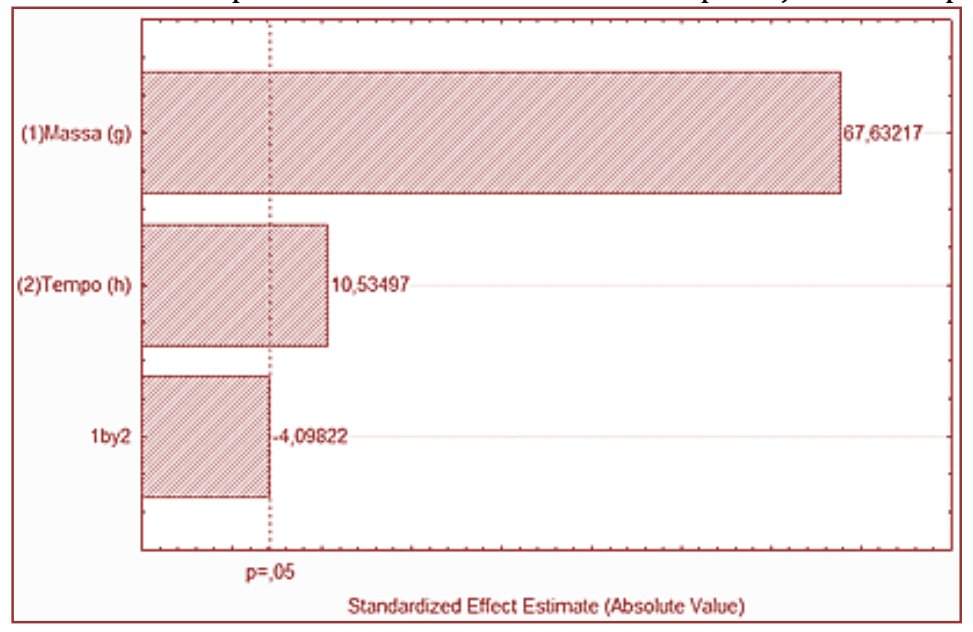

A partir de Figura 6 é possível observar que as variáveis significativas são a massa e o tempo, a interação massa*tempo não foi siginificatica pois apresentou para teste p valor maior que 0,05 .

Na Figura 7 é apresentado o gráfico dos valores preditos versus observados para o percentual de remoção, o qual mostra que os valores observados não ficaram alinhados com os valores preditos, sendo assim o modelo não é predito como também comprovado pelo valor de Fcalculado/Ftabelado não ter sido maior que 10.

Figura 7. Gráfico dos valores preditos versus observados para a resposta percentual de remoção

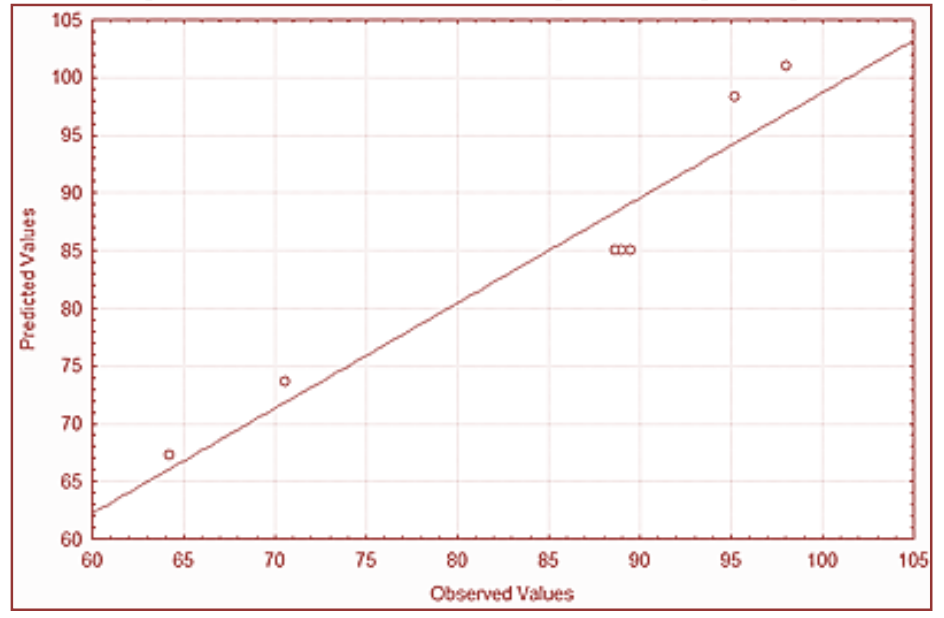

\section{CONSIDERAÇÕES FINAIS}

Baseado no difratograma de raios X da amostra da argila verde natural foi possível concluir que essa argila é uma esmectita, pois possui picos característicos deste grupo.

A argila VDN mostrou-se eficaz para sorção do corante reativo amarelo BF-3R. A otimização do processo sortivo pelo planejamento experimental evidenciou que a melhor condição é para uma maior massa $(1,5$ g) e maior tempo (5 h).

Pela análise de variância (ANOVA) conclui-se que o modelo experimental estudado foi estatisticamente significativo para $95 \%$ de confiança do experimento. 


\section{AGRADECIMENTOS}

Os autores agradecem a Coordenação de Aperfeiçoamento de Pessoa de Nível Superior (Capes), ao Conselho Nacional de Desenvolvimento Científico e Tecnológico (CNPq) pelas bolsas concedidas e a Bentonisa pelo fornecimento da argila.

\section{REFERÊNCIAS}

[1] AKSU, Z. Application of biosorption for the removal of organic pollutants: a review. Process Biochemistry, $\mathrm{v}$. 40, p. 997-1026, 2005.

[2] AWAD, A. M.; JALAB, R.; BENAMOR, A.; NASSER, M. S.; BA-ABBAD, M. M.; EL-NAAS, M.; MOHAMMAD, A. W. Adsorption of organic pollutants by nanomaterial-based adsorbents: An overview. Journal of Molecular Liquids, v. 301, 112335, 2020.

[3] BARBA, A.; BELTRÁN, V.; FELIU, C.; GARCÍA, J.; GINÉS, F.; SÁNCHEZ, E.; SANZ, V. Materias primas para la fabricación de soportes de baldosas cerâmicas. Editora Instituto de Tecnologia Cerámica (ITC), 292p, Espanha, 1997.

[4] BARBoSA, A. S.; ALVES, A. C.; RODRIGUES, M. G. F. Avaliação da Argila Chocolate B (natural e modificada ácida e termicamente) na descontaminação de efluentes têxteis. III Congresso Nacional de Pesquisa e Ensino em Ciências, Campina Grande, Paraíba, 2018.

[5] BARBOSA, A. S.; MONTEIRO, G. DE S.; ROCHA, L. N.; LIMA, E. G.; RODRIGUES, M. G. F. Remoção do corante reativo vermelho por adsorção utilizando argilas branca e vermelha. Revista Gestão e Sustentabilidade Ambiental, v. 8, p. 539-561, 2019.

[6] BARBOSA, A. S.; ROCHA, L. N.; BARBOSA, A. S.; MONTEIRO, G.; RODRIGUES, M. G. F. Argila vermelha utilizada como adsorvente na remoção de corantes reativos. 59ํㅡㄹ Congresso Brasileiro de Cerâmica, Barra dos Coqueiros, Sergipe, 2015.

[7] BARBOSA, A. S.; ROCHA, L. N.; MONTEIRO, G.; RODRIGUES, M. G. F. Análise estatística da remoção de corantes reativos a partir da argila vermelha. I Congresso Nacional de Pesquisa e Ensino em Ciência, Campina Grande, Paraíba, 2016.

[8] BARBOSA, M. E.; BARBOSA, A. S.; RODRIGUES, M. G. F. Tratamento de efluentes têxteis utilizando o processo de separação por membrana cerâmica de baixo custo. III Congresso Nacional de Pesquisa e Ensino em Ciência, Campina Grande, Paraíba, 2018.

[9] BARBoSA, T. L. A., RODRIGUES, D. P. A., RODRIGUES, M. G. F. Síntese da estrutura metalorgânica ZIF-67 e aplicação na remoção do corante rodamina B. XXI Congreso Argentino de Catálisis, Santa Fé, Argentina, 2019.

[10] BARbOSA, T. L. A.; LIMA, E. G.; BARbOSA, A. S.; RodRigUES, M. G. F. Membrana Zeolítica NaA: Síntese, Caracterização e Aplicação na Remoção do Corante Reativo Azul no Tratamento de Águas Residuais da Indústria Têxtil. III Congresso Nacional de Pesquisa e Ensino em Ciências, Campina Grande, Paraíba 2018.

[11] BARROS NETO, B.; SCARMINIO, J.S.; BRUNS, R.E. Planejamento e Otimização de Experimentos. Editora Unicamp, 401p, São Paulo, 1995.

[12] BHATE, P. M.; DEVI, R. V.; DUGANE, R.; HANDE, P. R.; SHAIKH, L.; VAIDYA, S.; MASAND, S. A novel reactive dye system based on diazonium salts. Dyes and Pigments, v. 145, p. 208-215, 2017.

[13] CARVALHO, K. A.; MORAIS, C. J. O.; SILVA, M. L. P.; MOTA, A. L. N.; GOMES, K. K. P. Estudo da remoção de corantes reativos pelo processo de adsorção usando argila Chocobofe in natura. XX Congresso Brasileiro de Engenharia Química, Florianópolis, Santa Catarina, 2014.

[14] GIESEKING, J. E. e JENNY, H. Behavior of polyvalent cations in base exchange. Soil Science, v. 42, p. 273-280, 1936.

[15] GRIM, R. E. Clay mineralogy (International Series in the Earth and Planetary Sciences). Editora McGraw-Hill, 596p, New York, 1968.

[16] KHAN, A. J.; SONG, J.; AHMED, K.; RAHIM, A.; VOLPE, P. L. O.; REHMAN, F. Mesoporous silica MCM-41, SBA-15 and derived bridged polysilsesquioxane SBA-PMDA for the selective removal of textile reactive dyes from wastewater. Journal of Molecular Liquids, v. 298, 111957, 2020.

[17] LIMA, F. S.; BARBoSA, A. S., RODRIGUES, M. G. F. Tratamento de efluentes (corante reativo azul BF-5G) utilizando argila Brasgel como adsorvente. I Congresso Nacional de Pesquisa e Ensino em Ciências, Campina Grande, Paraíba, 2016. 
[18] LIMA, F. S.; ROCHA, L. N., BARBOSA, A. S., RODRIGUES, M. G. F. Estudo da capacidade de remoção do corante reativo vermelho BF-4B em argila Vermelha e Brasgel. I Congresso Nacional de Pesquisa e Ensino em Ciências, Campina Grande, Paraíba, 2016.

[19] LIMA, L. A., MOTA, M. F., MENEZES, V. M. R., RODRIGUES, M. G. F. Síntese da peneira molecular MCM-41 e sua utilização como adsorvente na remoção do corante azul reativo BF-5G. XX Congresso Brasileiro de Engenharia Química, Florianópolis, Santa Catarina, 2014.

[20] LIMA, L. A., PAULA, G. M., RODRIGUES, M. G. F. Síntese da peneira molecular SBA-15 e sua utilização como adsorvente na remoção de corantes. XXIV Congresso Iberoamericando de Catálisis, Mendellin, Colômbia, 2014.

[21] MESSINA, P. V. e SCHULZ, P. C. Adsorption of reactive dyes on titania-silica mesoporous material. Journal of Colloid and Interface Science, v. 299, p. 305-320, 2006.

[22] MOHAMMED, I. A.; JAWAD, A. H.; ABDULHAMEED, A. S.; MASTULIA, M. S. Physicochemical modification of chitosan with fly ash and tripolyphosphate for removal of reactive red 120 dye: Statistical optimization and mechanism study. International Journal of Biological Macromolecules,v. 161, p. 503-513, 2020.

[23] MONTGOMERY, D. C. e RUNGER, G. C. Estatística aplicada e probabilidade para engenheiros. Editora LTC, São Paulo, 463p, 2009.

[24] MOTA, M. F.; RODRIGUES, M. G. F.; MACHADO, F. Oil-water separation process with organoclays: A comparative analysis. Applied Clay Science, v. 99, p. 237-245, 2014.

[25] PAUlA, L. N. R.; PAULA, G. M.; RODRIGUES, M. G. F. Adsorption of reactive blue BF-5G dye on MCM-41 synthesized from chocolate clay. Cerâmica, 2020 (Aceito).

[26] PAULA; L. N. R; PAULA, G. M.; CLERICUZZI, G.; RODRIGUES, M. G. F. Preparação de peneiras moleculares MCM-41: Influência da calcinação na remocão corante reativo azul BF-5G. XXVI Congresso Iberoamericano de Catálise, Coimbra, Portugal, 2018.

[27] PEREIRA, W. S.; FREIRE, R. S. Ferro zero: uma nova abordagem para o tratamento de águas contaminadas com compostos orgânicos poluentes. Química Nova, v. 28, p. 130-136, 2005.

[28] QUEIROZ, F. J. DE; JÚNIOR, G. E. L.; BARBOSA, T. L. A.; RODRIGUES, M. G. F. Remoção de corante amarelo BF3R utilizando argila verde-lodo como adsorvente. I Congresso Nacional de Pesquisa e Ensino em Ciências, Campina Grande, Paraíba, 2016.

[29] QUEIROZ, M. B.; RODRIGUES, S. C. G.; LABORDE, H. M.; RODRIGUES, M. G. F. Swelling of Brazilian Organoclays in Some Solvents with Application in the Petroleum Industry. Materials Science Forum, v. 660, p. 1031-1036, 2010.

[30] ROCHA, L. N.; BARBOSA, A. S.; M. G.; RODRIGUES, M. G. F. Estudo de adsorção de corantes reativos utilizando argila vermelha. 61 Congresso Brasileiro de Cerâmica, Gramado, Rio Grande do Sul, 2017.

[31] ROCHA, L. N.; BARBOSA, A. S.; MONTEIRO, G. S.; BARBOSA, A. S.; RODRIGUES, M. G. F. Influência do pH na remoção de corantes reativos utilizando argilas como adsorventes. 18ํㅡㄹ Congresso Brasileiro de Catálise, Búzios, Rio de Janeiro, 2015.

[32] ROCHA, L. N.; BARBOSA, A. S.; MONTEIRO, G.; RODRIGUES, M. G. F. Cinética de adsorção de corantes utilizando a argila Branca como adsorvente. 19 Congresso Brasileiro de Catálise, Ouro Preto, Minas Gerais, 2017.

[33] ROCHA, L. N.; BARBOSA, A. S.; RODRIGUES, M. G. F. Ensaio de adsorção de dois corantes reativos utilizando argila vermelha. XXI Congresso Brasileiro de Engenharia Química, Fortaleza, Ceará, 2016.

[34] ROCHA, L. N.; BARBOSA, A. S.; RODRIGUES, M. G. F. Remoção do corante vermelho BF-4B em sistema descontínuo utilizando argilas esmectíticas. XI Encontro Brasileiro sobre Adsorção, Aracaju, Sergipe, 2016.

[35] RODRIGUES M. G. F.; TOMAZ, P. F.; RODRIGUES, D. P. A.; BARBOSA, T. L. A. Nova rota de síntese da estrutura metalorgânica ZIF e argila para serem utilizadas na remoção de corante rodamina B. XXI Congreso Argentino de Catálisis, Santa Fé, Argentina, 2019.

[36] RODRIGUES, M. G. F. Physical and catalytic characterization of smectites from Boa-Vista, Paraíba, Brazil, Cerâmica, v. 49, p. 146-150, 2003.

[37] RODRIGUES, M. I. e IEMMA, A. F. Planejamento de experimentos e otimização de processos. Editora Cárita, 358p, Campinas, São Paulo, 2009.

[38] SANTOS, D. H. S.; DUARTE, J. L. S.; TAVARES, M. G. R.; TAVARES, M. G.; FRIEDRICH, L. C.; MEILI, L.; PIMENTEL, W. R. O.; TONHOLO, J.; ZANTA, C. L. P. S. Electrochemical degradation and toxicity evaluation of reactive dyes mixture and real textile effluent over DSA ${ }^{\circledR}$ electrodes. Chemical Engineering and Processing - Process Intensification, v. 153, 107940, 2020.

[39] SILVA, E. L. DA; ARAÚJO, I. N.; OLIVEIRA, L.A. DE; LIMA, E.G.; MOTA, J. D.; RODRIGUES, M. G. F. Estudo comparativo entre as argilas policatiônica (verde dura) e sódica (BSN-02) na remoção de corante em sistema de banho finito. XI Encontro Brasileiro sobre Adsorção, Aracaju, Sergipe, 2016. 
[40] SILVA, F. M. N.; ALVES, A. C.; LIMA, E. G.; RODRIGUES, M. G.F. influencia do pH na adsorção do corante vermelho reativo BF-4B utilizando a zeólita Mordenita. II Congresso Nacional de Pesquisa e Ensino em Ciências, Campina Grande, Paraíba, 2017.

[41] SILVA, F. M. N.; SILVA, L. R. B.,SILVA, E. T. S.; RODRIGUES, M. G. F. Síntese da zeólita mordenita e modificação com CTMABr. Aplicação na remoção do corante Rodamina B. XXI Congreso Argentino de Catálisis, Santa Fé, Argentina, 2019.

[42] SILVA, F. N. M.; BARBOSA, T. L. A.; R., D. P. A.; RODRIGUES, M. G. F. Síntese da zeólita SAPO-34 e aplicação na remoção do corante reativo amarelo BF-3R. XXI Congreso Argentino de Catálisis, Santa Fé, Argentina, 2019.

[43] SILVA, L. R. B.; BARBOSA, T. L. A.; BEZERRA, J. U. L.; RODRIGUES, M. G. F. Zeólita ZSM-5 não modificada e modificada com surfactante CTMABr: aplicação na remoção do corante amarelo BF-3R. 63o Congresso Brasileiro de Cerâmica, Bonito, Mato Grosso do Sul, 2019.

[44] SILVA, L. R. B.; BARBOSA, T. L. A.; BEZERRA, J. U. L.; RODRIGUES, M. G. F. Síntese da Zéolita ZSM-5 para ser utilizada como adsorvente na remoção do corante reativo BF-3R: influência do PH. Processos Químicos e Biotecnológicos - Volume 5, Editora Poisson, p. 66-78, 2020.

[45] SILVA, L. R. B.; SILVA, E. T. S.; RODRIGUES, D. P. A.; BARBOSA, A. S.; RODRIGUES, M. G. F. Remoção do corante reativo amarelo BF-3R utilizando a zeólita ZSM-5 não calcinada. 1ํ Simpósio de Química do CCA/UFPB, Areia, Paraíba, 2018.

[46] SIQUEIRA, F.; ROCHA, L. N.; BARBOSA, A. S.; RODRIGUES, M. G. F. Estudo da capacidade de remoção do corante vermelho BF-4B em argilas vermelha e brasgel. I Congresso Nacional de Pesquisa e Ensino em Ciências, Campina Grande, Paraíba, 2016.

[47] SOUSA, K. F.; BARBOSA, T. L. A.; RODRIGUES, M. G. F. Uso da Argila Policatiônica Verde Dura na Remoção de Corante Reativo (Amarelo BF-3R) em Sistema de Banho Finito. III Congresso Nacional de Pesquisa e Ensino em Ciências, Campina Grande, Paraíba 2018.

[48] SOUZA-SANTOS, P., Ciência e tecnologia de argilas. Editora Edgard Blucher, São Paulo, Brasil, 1992.

[49] WANG, A.; XIA, L.; ZHOU, S.; GUO, H.; WANG, Y.; XU, W. Solvent assisted reactive dyeing of cotton with high exhaustion in the absence of salt. Journal of Cleaner Production, v. 267, 108584, 2020.

[50] WU, F., TSENG, R., HUANG, S., JUANG, R. Characteristics of pseudo-second-order kinetic model for liquidphase adsorption: a mini-review. Chemical Engineering Journal, v. 151, p. 1-9, 2009.

[51] YAGUB, M. T.; SEM, T. K.; AFROZE, S.; ANG, H. M. Dye and its removal from aqueous solution by adsorption: A review. Advances in Colloid and Interface Science, v. 209, p. 172-184, 2014.

[52] ZOLLINGER, H. Colour chemistry: synthesis, properties and applications of organic dyes and pigments. Editora VCH, 637p, 1987. 


\section{Capítulo 12}

Sorção de metal pesado em efluentes sintéticos utilizando minerais argilosos: Bofe e Brasgel

\section{Rochelia Silva Souza Cunha \\ Joseane Damasceno Mota \\ Wellington Siqueira Lima \\ Meiry Gláucia Freire Rodrigues}

Resumo: Este estudo investigou o potencial das argilas Bofe e Brasgel como sorventes no processo de separação do íon metálico chumbo, utilizando-se sistema de banho finito seguindo um planejamento fatorial 22 adicionado com três pontos centrais, tendo como variáveis de entrada: pH e concentrações e como variáveis de saída: percentagem de remoção e capacidade de remoção. 0 objetivo deste trabalho foi caracterizar as argilas Bofe proveniente do município de Boa Vista/PB e Brasgel fornecida pela Bentonit União Nordeste (BUN), por meio das técnicas de Difração de Raios X (DRX), capacidade de troca de cátions (CTC) e Espectrofotometria de Raios-X por Energia Dispersiva (EDX) e avaliar o potencial de sorção das argilas. As combinações das técnicas DRX, CTC e EDX evidenciaram características ao grupo das argilas esmectíticas. No processo de sorção verifica-se uma remoção de 99,97 \% da concentração inicial de chumbo e capacidade de remoção de 3,38 mg para cada grama de argila Bofe, enquanto a argila Brasgel a remoção foi de 99,80 \% e 3,80 mg para cada grama de argila Brasgel. Desta forma, as argilas utilizadas mostraram-se promissoras no tratamento de águas residuais contendo chumbo em efluentes sintéticos.

Palavras-chave: argilas; Bofe; Brasgel; sorção; chumbo. 


\section{INTRODUÇÃO}

A contaminação por metais pesados é um problema ambiental enfrentado em todo o mundo. Eles contaminam principalmente o solo e a água, dos quais entram em outros sistemas, nas plantas e animais afetando assim o homem (Uddin, 2017). Embora a presença de alguns metais pesados, incluindo cobre, ferro, manganês, zinco e molibdênio serem necessários para o metabolismo adequado na vida dos organismos, isto em pequenas quantidades, quando apresentados em elevadas concentrações propiciam sérios riscos à saúde nos seres vivos (Durand, 2012).

Yang et al., (2017) relata que os principais contaminantes de metais pesados no ambiente são: arsênico $(\mathrm{As})$, cádmio $(\mathrm{Cd})$, cromo $(\mathrm{Cr})$, cobre $(\mathrm{Cu})$, chumbo $(\mathrm{Pb})$, mercúrio $(\mathrm{Hg})$, níquel $(\mathrm{Ni})$ e zinco $(\mathrm{Zn})$. A exposição de seres humanos a ambientes contaminados por metais pesados pode ocasionar diversos problemas à saúde como: câncer, doenças de pele, paralisia, perda de dentes, problemas oculares, disfunção renal e pulmonar, dores musculares, articulares e muitas outras complicações, como vem sendo mencionados por Durand (2012) e Uddin (2017).

0 metal pesado chumbo de forma particular possui efeito tóxico por ser carcinogênico, como também pode ocasionar anemia abdominal, dores musculares e articulares, problemas nos rins e pressão alta (Ahmaruzzaman, 2011).

A presença desses metais pesados no meio ambiente é proveniente de vários fatores, sejam naturais como: erupções vulcânicas, rochas intempéries, ou processos antropogênicos, como: agricultura, mineração e industrialização que geram resíduos contendo metais pesados no meio ambiente (Durand, 2012; Yang et al., 2017). Esses resíduos quando não são bem gerenciados, podem levar à liberação de metais pesados no ecossistema através do ar, solo e água (Shahid et al., 2017).

Todos esses aspectos ambientais e preocupações com a saúde levaram nas últimas décadas, diversas pesquisas para encontrar maneiras de remover metais pesados do meio ambiente. Métodos para remoção e recuperação de íons de metais vêm sendo desenvolvidas, incluindo, filtração, precipitação química, sorção, eletrodeposição e os sistemas por membranas (Sdiri et al., 2016).

De todas as tecnologias mencionadas a adsorção/sorção, é a mais utilizada no processo de remoção e recuperação de metais pesados, devido à sua simplicidade de equipamento e operação, além da possibilidade de utilização de um adsorvente sólido para vários ciclos de extração sem perdas na capacidade de extração de metal (Es-sahbany et al., 2019).

Adsorção pode ser definida como a deposição e aderência de espécies de moléculas a uma superfície, como mostrado na Figura 1, que depende de dois parâmetros básicos, incluindo (i) o adsorvente, que é a superfície para as quais moléculas são depositadas, por exemplo, argila e (ii) o adsorvido, essa é a espécie adsorvida que neste caso são os metais (Uddin, 2017).

Figura 1. Representação gráfica do processo de adsorção/sorção de metais pesados por minerais argilosos.

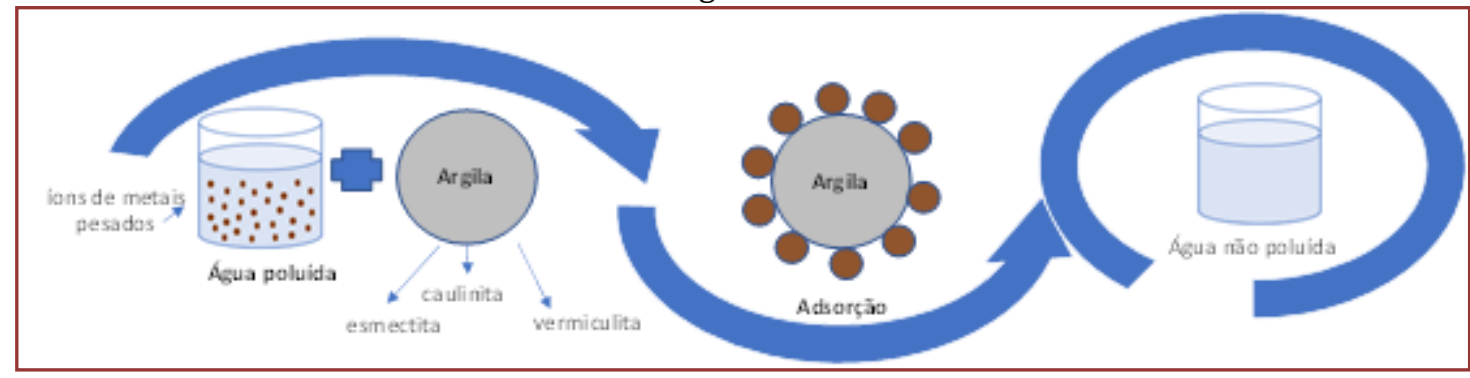

As argilas são aplicadas para diferentes fins, como catalisadores, suportes químicos, coagulantes, sorventes, revestimentos, cosméticos, cerâmica, agentes de perfuração, materiais de construção e aplicações geológicas (Souza Santos, 1992; Bergaya et al., 2006; Aboudi Mana et al., 2017; Yi et al., 2017). Diante de diversas aplicações elas também foram identificadas como adsorventes para metais pesados e outros poluentes (Vaca et al., 2011; Es-sahbany et al., 2019). Isso ocorre porque os minerais de argila possuem grandes área superficial que lhes permitem capturar cátions e ânions por troca iônica e sorção). 
Outra razão na utilização das argilas é que são de baixo custo, fáceis de extrair e não tóxico (tornando-as materiais ecológicos) (Al-Anit e Sarapää, 2008; Uddin, 2017).

A composição das argilas pode variar frequentemente devido à substituição de cátions por raios iônicos semelhantes, no octaedro e folhas tetraédricas, sem alterar a estrutura original do mineral argiloso (Jia et al., 2016).

Como as argilas podem reter metais pesados tanto por sorção ou troca iônica, trabalhos vem sendo desenvolvidos utilizando diversas argilas que provaram ser eficientes na sorção de vários tipos de metais pesados presentes no solo, água e efluentes (Churchman et al., 2006; Stathi et al., 2007; Addy et al., 2012; Es-sahbany et al., 2019).

No Laboratório de Desenvolvimento de Novos Materiais (LABNOV) situado na Universidade Federal de Campina Grande - PB, vários estudos têm sido desenvolvidos na remoção de metais pesados como relatam Mota et al, (2016 - 2017), Lima (2011a), Rodrigues et al, (2004), Patrício (2011), Mota et al, (2014), Silva et al (2015) e Cunha et al., (2015) onde investigaram as melhores formas de tratamentos de efluentes contaminados por metais pesados utilizando diferentes tipos de argilas nacionais e internacionais, naturais e tratadas, como materiais alternativos no uso de adsorventes. Outros trabalhos desenvolvidos podem ser observados na Tabela 1 . Com isto, este trabalho visa caracterizar e avaliar as argilas Bofe e Brasgel e aplicar processo de remoção de chumbo, em sistema de banho finito de acordo com um planejamento fatorial $2^{2}$ com três pontos centrais.

Tabela 1- Pesquisas realizadas no LABNOV sobre o uso de argilas na remoção de metais pesados.

\begin{tabular}{|c|c|c|}
\hline Argilas & Metais & Autores \\
\hline Argilas bentoníticas Primavera & $\mathrm{Cd}^{2+}$ & Silva (2005) \\
\hline Argila Chocolate & $\mathrm{N}^{2+}$ & Vilar (2007) \\
\hline Argila Chocolate & $\mathrm{Ni}^{2+}$ & Vilar et al., (2009) \\
\hline Argilas bentoníticas (Bofe e Verde-Lodo) & $\mathrm{Cu}^{2+} \mathrm{e} \mathrm{Cd}^{2+}$ & Almeida Neto (2007) \\
\hline Verde-Lodo & $\mathrm{Cr}^{3+}$ & Cabral (2009) \\
\hline Brasgel & $\mathrm{Pb}^{2+}$ & Sousa (2009) \\
\hline Argilas nacionais & $\mathrm{Pb}^{2+} \mathrm{e} \mathrm{Zn}^{2+}$ & Lima et al., (2010 - 2012) \\
\hline Argila Brasgel & $\mathrm{Pb}^{2+} \mathrm{e} \mathrm{Zn}^{2+}$ & Patrício (2012) \\
\hline Argilas nacionais: cinza e verde-lodo & $\mathrm{Zn}^{2+}$ & Vasconcelos (2012 - 2013) \\
\hline Chocobofe e Chocolate B & $\mathrm{Cd}^{2+}, \mathrm{Pb}^{2+}, \mathrm{Zn}^{2+}$ & Silva (2015) \\
\hline
\end{tabular}

\section{MATERIAIS E MÉTODOS}

\subsection{MATERIAIS}

Foram utilizadas amostras de argilas denominada Brasgel fornecida pela Bentonit União Nordeste (BUN) e argila Bofe fornecida pela empresa BENTONISA. As argilas foram desagregadas, moídas e passadas em peneira ABNT № 200\# (abertura de 0,075 mm).

\subsubsection{CARACTERIZAÇÃo}

Difratometria de raios $X(D R X)$ :

As amostras foram analisadas por meio do método do pó empregando-se um difratômetro Shimadzu XRD6000 com tubos de raios $X$ de alvo de Cobre $(\lambda=1,5418 \AA ̊)$ nas seguintes condições: tensão de $40 \mathrm{KV}$, corrente de $30 \mathrm{~mA}$, tamanho do passo de 0,02 em 20, tempo de exposição por passo de $1 \mathrm{~s}$ e numa faixa de ângulo $2 \theta$ de $2^{\circ}$ a $45^{\circ}$. 


\section{Capacidade de troca de cátions (CTC):}

O equipamento utilizado para determinação da Capacidade de Troca de Cátions (CTC) das argilas Brasgel e Bofe em sua forma natural foi um destilador Kjeldahl (modelo MA - 036 PLUS). 0 procedimento de análise das amostras foi o mesmo método utilizado por Mota (2014).

\section{Espectrofotometria de Raios-X por Energia Dispersiva (EDX):}

A análise química a partir do EDX permite identificar e quantificar a composição química global de um sólido. As amostras foram homogeneizadas, peneiradas a malha 200 mesh (abertura de 0,075 mm). A análise foi realizada com o equipamento da marca Shimadzu (modelo 720), no Laboratório de caracterização da Unidade Acadêmica de Engenharia de Materiais (UAEMa/UFCG).

\subsection{PLANEJAMENTO EXPERIMENTAL}

Foi adotado o planejamento experimental fatorial, pois possibilita analisar os efeitos de dois tipos de fatores no experimento. 0 objetivo foi verificar se existe efeito significativo entre a concentração inicial e 0 $\mathrm{pH}$. Foi adotado o planejamento fatorial $2^{2}$ com triplicata no ponto central. $\mathrm{E}$ os efeitos adotados foram concentração $\left(10,30\right.$ e 50 mg. $\left.\mathrm{L}^{-1}\right)$ e pH $(3,4$ e 5). A matriz de entrada de dados e os sinais para os efeitos fatoriais estão apresentados na Tabela 2. A partir do planejamento, foi possível identificar as melhores respostas dos fatores. A adição dos três pontos centrais permite obter uma estimativa independente do erro a ser obtido, ou seja, não repercutem nas estimativas usuais dos efeitos em um planejamento fatorial $2^{2}$ de acordo com Montgomery (1996).

Tabela 2. Matriz de ensaios do planejamento fatorial $2^{2}$.

\begin{tabular}{|c|c|}
\hline \multicolumn{2}{|c|}{ Variáveis } \\
Concentração de chumbo em solução $\left(\mathrm{mg} / \mathrm{L}^{-1}\right)$ & $(-1)=10 ;(0)=30 ;(+1)=50$ \\
\hline $\mathrm{pH}$ da solução & $(-1)=3 ;(0)=4 ;(+1)=5$ \\
\hline
\end{tabular}

\subsection{SORÇÃO EM SISTEMA DE BANHO FINITO}

De acordo com a matriz de planejamento foram preparadas soluções (efluentes sintéticos) na concentração de chumbo a 10,30 e $50 \mathrm{mg}^{-\mathrm{L}^{-1}}$ em que foi utilizado o sal de nitrato de chumbo $(\mathrm{Pb}$ $\left.\left(\mathrm{NO}_{3}\right)_{2} \cdot 6 \mathrm{H}_{2} \mathrm{O}\right)$ - VETEC. Para ajuste de $\mathrm{pH}$ das soluções foram utilizadas soluções de ácido clorídrico $(\mathrm{HCl})$ e hidróxido de sódio $(\mathrm{NaOH})$ diluídas a $3 \%$.

Os ensaios de sorção constaram da dispersão de $0,5 \mathrm{~g}$ de argila em contato com $50 \mathrm{~mL}$ da solução contendo o efluente nas concentrações de 10,30 e 50 mg. $\mathrm{L}^{-1}$, com ajuste de $\mathrm{pH}$ de 3,0; 4,0 ou 5,0 a cada $1 \mathrm{~h}$. $0 \mathrm{pH}$ desempenha um papel importante no processo de sorção de cátions de metais pesados por minerais argilosos, pois afeta o comportamento de cátions de metais pesados (Churchman et al., 2006). As dispersões ficaram sob agitação mecânica constante de 200 rpm utilizando o equipamento Shaker durante $5 \mathrm{~h}$. Ao final deste período, foi realizada uma filtração e o filtrado seguiu para análise.

Para determinação da quantidade de chumbo presente nas amostras, foi utilizado o método de espectrofotometria de absorção atômica, que determina o teor de metal presente na fase líquida. Este método foi escolhido por ser relativamente preciso rápido e ainda pelo fato de se utilizar pequenas quantidades de amostra. A percentagem de remoção (\%Rem) e a Capacidade de Remoção em equilíbrio $\left(\mathrm{q}_{\mathrm{eq}}\right)$ foram obtidas por meio das Equações (1) e (2), respectivamente:

$$
\% \operatorname{Re} m=\left(\frac{C_{0}-C}{C_{0}}\right) * 100
$$

em que: \% Rem é a percentagem de chumbo removido; $C_{i}$ é a concentração inicial (mg.L-1 $)$; C é a concentração final (mg.L-1). 


$$
q_{e q}\left(m g \cdot g^{-1}\right)=\frac{V}{m}\left(C_{0}-C\right)
$$

em que: qeq é a capacidade de remoção no equilíbrio (mg de metal/g de argila); $V$ é o volume do adsorbato $(\mathrm{mL}) ; \mathrm{m}$ é a massa de argila (g).

\section{RESULTADOS E DISCUSSÃO}

Na Figura 2 (a,b) estão ilustrados os difratogramas de raios X das argilas Bofe e Brasgel natural

Figura 2. Difratogramas de raios $\mathrm{X}$ das argilas Brasgel natural (a) e Bofe natural (b).

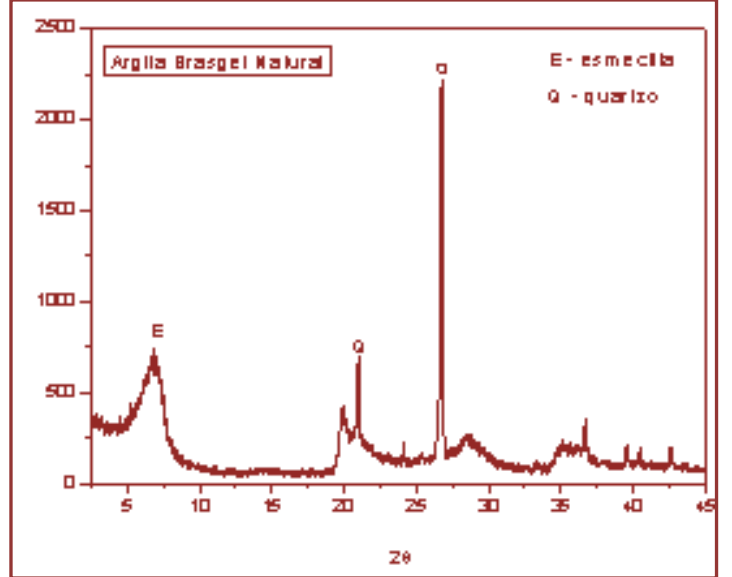

(A)

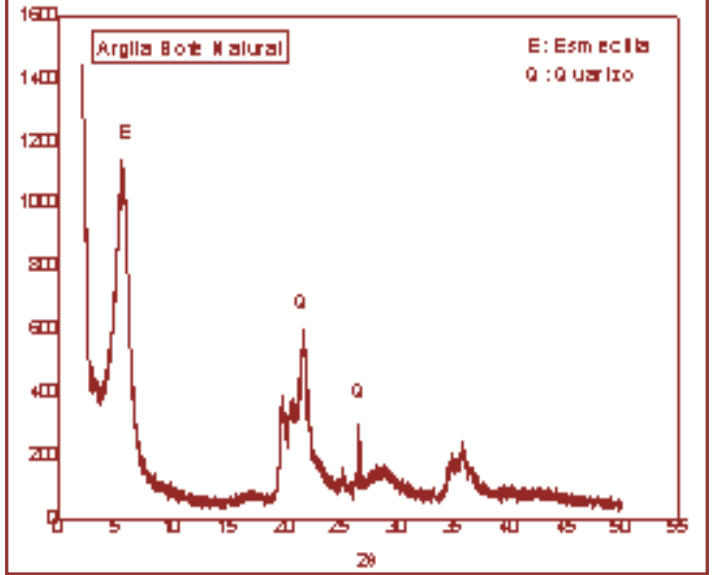

(B)

Nos difratogramas de raios $\mathrm{X}$ das argilas Brasgel (Figura 2a) e Bofe (Figura 2b) observam-se o pico característico em do01 correspondente ao argilomineral possivelmente da esmectita (d=13,00 Å) e (d=17,9 $\AA ̊$ ), respectivamente. Valores que estão de acordo com Wang et al., (2004) e Pinto (2005). A espessura da camada basal varia com o cátion presente de 12 a $40 \AA ̊$ e os valores típicos podem ser encontrados em Souza Santos (1992). Observam-se também a presença de picos característicos a uma distância interplanar na região de $d=3,34 \AA$ e $d=4,24 \AA$, que corresponde à presença de quartzo como impureza, característica comum as duas argilas como relatam Souza Santos (1992), Pinto (2005) e Sdiri et al., (2014). A identificação por difração de raios X mostrou que as argilas possuem como argilomineral predominante a esmectíta.

Por meio do método do acetato de amônio realizado em equipamento de Kjeldahl, obteve-se o resultado apresentado na Tabela 3.

Tabela 3. Capacidade de troca catiônica das argilas Bofe e Brasgel.

\begin{tabular}{|c|c|}
\hline Amostra & CTC (meq/100 g de argila) \\
\hline Argila Bofe Natural & 71 \\
\hline Argila Brasgel Natural & 92 \\
\hline
\end{tabular}

A Capacidade de Troca Catiônica é uma importante propriedade de minerais argilosos que determina sua capacidade de sorção. O CTC é o total de cargas negativas presentes na argila que podem atrair e reter cátions de metais pesados (Al-ani e Sarapàà, 2008). Os valores das capacidades de troca catiônica estão de acordo com a faixa esperada para argilas esmectíticas encontrados na literatura, 3 a $150 \mathrm{meq} / 100 \mathrm{~g}$ de argila por Grim (1968) e Gomes (1988).

A argila Bofe natural apresentou uma troca cationnica no valor de 0,71 meq/g de argila natural, e a argila Brasgel apresentou $0,92 \mathrm{meq} / \mathrm{g}$, valores esses que, encontram-se dentro da faixa esperada para argilas do tipo esmectita. Valores altos indicam que o argilomineral apresenta uma baixa quantidade de impurezas ou um alto nível de substituições isomórficas, conforme Pereira (2008). 
Na Tabela 4 estão ilustrados os resultados da composição química das argilas Bofe e Brasgel. E na tabela 5, observam-se os resultados obtidos da percentagem de remoção para cada argila.

Tabela 4. Composição química das argilas Brasgel e Bofe.

\begin{tabular}{|c|c|c|}
\hline \multicolumn{1}{|c|}{ Composição Química } & Argila Brasgel Natural (\%) & Argila Bofe Natural (\%) \\
\hline $\mathrm{SiO}_{2}$ & 66,59 & 72,82 \\
\hline $\mathrm{Al}_{2} \mathrm{O}_{3}$ & 16,53 & 14,77 \\
\hline $\mathrm{Fe}_{2} \mathrm{O}_{3}$ & 10,12 & 7,20 \\
\hline $\mathrm{K}_{2} \mathrm{O}$ & 0,40 & 0,2 \\
\hline $\mathrm{MgO}$ & 2,13 & 2,14 \\
\hline $\mathrm{CaO}$ & 1,56 & 0,97 \\
\hline Outros & 2,67 & 1,9 \\
\hline Total & $\mathbf{1 0 0}$ & $\mathbf{1 0 0}$ \\
\hline
\end{tabular}

Analisando os resultados da Tabela 4, observa-se que as amostras apresentaram uma maior quantidade de óxido de silício $\left(\mathrm{SiO}_{2}\right)$ 66,59\% da composição total da argila Brasgel e 72,82\% para a argila Bofe, para teores de óxido de alumínio $\left(\mathrm{Al}_{2} \mathrm{O}_{3}\right)$ a argila Brasgel contem 16,53\% e a argila Bofe 14,77\% se comparado com os outros componentes. As amostras também apresentaram um teor apreciável de óxido de ferro na forma de óxido de ferro III ( $\left.\mathrm{Fe}_{2} \mathrm{O}_{3}\right)$ 10,12\% para a argila Brasgel e 7,20\% na argila Bofe. Os óxidos com teores menores de 1\%, no geral, não influenciam significativamente as propriedades das argilas.

O magnésio, o cálcio e o potássio, estão presentes na amostra como óxidos de cátions trocáveis de acordo com Rodrigues et al., (2004) e Menezes et al., (2009). A presença de sílica, óxidos de alumina, ferro, cálcio e magnésio nas argilas pode sugerir maior quantidades de remoção de cátions metálicos presentes em efluentes contaminados por metais (Sdiri et al., 2016; Uddin, 2017).

Tabela 5. Resultados obtidos a partir do Planejamento Fatorial $2^{2}$ com três pontos centrais para remoção de chumbo das argilas Bofe e Brasgel.

\begin{tabular}{|c|c|c|c|c|c|c|}
\hline \multirow{2}{*}{ Ensaio } & \multirow{2}{*}{$\begin{array}{c}\mathrm{C}_{\mathrm{i}} \\
\left(\mathrm{mg} \cdot \mathrm{L}^{-1}\right)\end{array}$} & \multirow{2}{*}{$\mathrm{pH}$} & \multicolumn{2}{|c|}{ Bofe } & \multicolumn{2}{|c|}{ Brasgel } \\
\hline & & & \%Rem & $\mathrm{q}_{\mathrm{eq}}\left(\mathrm{mg} \mathrm{g}^{-1}\right)$ & $\%$ Rem & $\mathrm{q}_{\mathrm{eq}}\left(\mathrm{mg} \cdot \mathrm{g}^{-1}\right)$ \\
\hline 1 & 10 & 3 & 99,80 & 0,50 & 86,41 & 0,45 \\
\hline 2 & 50 & 3 & 99,97 & 3,38 & 82,95 & 3,12 \\
\hline 3 & 50 & 5 & 97,38 & 0,48 & 99,80 & 3,80 \\
\hline 4 & 10 & 5 & 99,95 & 3,36 & 98,06 & 0,51 \\
\hline 5 & 30 & 4 & 99,94 & 2,10 & 99,55 & 2,19 \\
\hline 6 & 30 & 4 & 99,95 & 2,10 & 99,50 & 2,19 \\
\hline 7 & 30 & 4 & 99,95 & 2,10 & 98,82 & 2,17 \\
\hline
\end{tabular}

Verifica-se que para os ensaios de remoção de chumbo utilizando a argila Bofe, o melhor resultado de percentagem de remoção é atingido em pH $(\mathrm{pH}=3)$ no ensaio 2, removendo $(99,97 \%)$, já para a remoção utilizando a argila Brasgel a melhor eficiência foi obtida em $\mathrm{pH}=5$, onde pode ser observado no ensaio 3 $(99,80 \%)$ de remoção da concentração inicial de chumbo. Em relação aos valores de resposta para capacidade de remoção, o melhor resultado é atingido no nível de concentração $\left(C_{i}=50\right.$ ppm), obtidos no ensaio 2 removendo 3,38 mg de chumbo por cada grama de argila Bofe. Já a argila Brasgel sorveu 3,80 mg de chumbo para cada grama de argila.

Nessa faixa de pH (3-5), os efeitos da precipitação de metais em forma de hidróxidos são reduzidos, ou seja, a remoção se dá potencialmente por sorção conforme Kaya; Ören, (2005). Valores elevados na taxa de remoção de metais também foram observados por Es-Shahbany et al., (2019) quando ajustado o pH no meio reacional. Otunola e Ololade (2020) mencionam que pode ocorrer um aumento abrupto na taxa de remoção de $35 \%$ para $80 \%$ com um aumento de pH de 2 para 4. 
Resultados obtidos que foram corroborados com resultados reportados na literatura como ilustrados na Tabela 5.

Tabela 5. Argilominerais utilizados para remoção de metais pesados.

\begin{tabular}{|c|c|c|c|c|}
\hline $\begin{array}{c}\text { Material/ } \\
\text { Remediação }\end{array}$ & $\begin{array}{l}\text { Metal pesado } \\
\text { removido }\end{array}$ & Parâmetros & Resultados & Referências \\
\hline $\begin{array}{l}\text { Bentonita } \\
\text { Água residuais }\end{array}$ & $\begin{array}{l}\mathrm{Co}^{2+}, \\
\mathrm{Cu}^{2+}, \\
\mathrm{Ni}^{2+}, \\
\mathrm{Pb}^{2+} \\
\mathrm{Zn}^{2+} \\
\end{array}$ & $\begin{array}{c}\mathrm{C}_{0}=50 \mathrm{mg} \cdot \mathrm{L}^{-1} \\
\mathrm{pH}<3\end{array}$ & $\begin{array}{l}\text { Remoção de 99\% de todas as } \\
\text { espécies metálicas. }\end{array}$ & $\begin{array}{l}\text { Vhahangwele e } \\
\text { Mugera, (2015) }\end{array}$ \\
\hline $\begin{array}{l}\text { Bentonita, } \\
\text { Sepiolita, } \\
\text { Vermiculita } \\
\text { Água residuais }\end{array}$ & $\begin{array}{l}\mathrm{Cd}, \\
\mathrm{Zn}, \\
\mathrm{Ni}, \\
\mathrm{Cu}, \\
\mathrm{Pb}\end{array}$ & $\begin{array}{l}\text { sorção binária } \\
\mathrm{Cd}^{2+} / \mathrm{Ni}^{2+} ; \\
\mathrm{Zn}^{2+} / \mathrm{Cd}^{2+} \\
\mathrm{Pb}^{2+} / \mathrm{Cu}^{2+}\end{array}$ & $\begin{array}{l}\text { Vermiculita removeu melhor } \mathrm{Pb} \text { e } \\
\mathrm{Cu} \text {. A presença de outros metais } \\
\text { interferiu a remoção das espécies } \\
\text { específicas. }\end{array}$ & $\begin{array}{l}\text { Padilla-Ortega } \\
\text { et al., (2013) }\end{array}$ \\
\hline $\begin{array}{l}\text { Caulinita Bentonita } \\
\text { Soluções aquosas }\end{array}$ & $\begin{array}{l}\mathrm{Zn}, \\
\mathrm{Pb}, \\
\mathrm{Cu}\end{array}$ & $\begin{array}{c}\mathrm{C}_{0}=0,1 ; 1,0 ; 10 ; 50 \\
100 \mathrm{mM} \\
\mathrm{pH} \leq 10\end{array}$ & $\begin{array}{c}\mathrm{Em} \mathrm{pH}=5,2 \text { a sorção foi de até } \\
68 \% \text { de } \mathrm{Cu}, 78 \% \text { de } \mathrm{Zn} \text { e } 98 \% \text { de } \\
\mathrm{Pb} .\end{array}$ & $\begin{array}{l}\text { Liu et al., } \\
\text { (2016) }\end{array}$ \\
\hline $\begin{array}{l}\text { Mistura de argilas } \\
\text { Água residuais }\end{array}$ & $\mathrm{Ni}^{2+}$ & $\begin{array}{c}\mathrm{C}_{0}=100 \mathrm{mg} \cdot \mathrm{L}^{-1} \\
\mathrm{pH}=5,5\end{array}$ & $\begin{array}{l}\text { Remoção } 75 \% \text { de íons de } \mathrm{Ni}^{2+} \text {, } \\
\text { com o aumento do } \mathrm{pH} \text {. }\end{array}$ & $\begin{array}{l}\text { Es-sahbany, et } \\
\text { al., (2019) }\end{array}$ \\
\hline $\begin{array}{l}\text { Atapulgita } \\
\text { Solo e lodo }\end{array}$ & $\begin{array}{l}\mathrm{Sb} \\
\mathrm{Pb} \\
\mathrm{Cd} \\
\text { As }\end{array}$ & $\begin{array}{l}\mathrm{pH}=8,0 \text { com } \\
\text { variação de } \\
\text { temperatura }\end{array}$ & $\begin{array}{l}\text { Até } 100 \% \text { de remoção para a } \\
\text { maioria das espécies metálicas }\end{array}$ & $\begin{array}{l}\text { Argyraki et al., } \\
\text { (2017) }\end{array}$ \\
\hline $\begin{array}{l}\text { Bentonita orgânica } \\
\text { Solução aquosa }\end{array}$ & $\begin{array}{l}\mathrm{Cu}, \mathrm{Cd} \\
\mathrm{Pb}\end{array}$ & $\begin{array}{c}\mathrm{C}_{0}=0,05 \mathrm{mmol} . \mathrm{L}^{-1} \\
\mathrm{pH}=(1 \mathrm{a} 8)\end{array}$ & $\begin{array}{c}\text { Aumento de } 4 \text { vezes a capacidade } \\
\text { de remoção }\end{array}$ & $\begin{array}{l}\text { Kostenko et al., } \\
2019\end{array}$ \\
\hline $\begin{array}{l}\text { Montmorilonita } \\
\text { Ácida } \\
\text { Efluente oleosos } \\
\end{array}$ & $\begin{array}{l}\mathrm{Ni}, \mathrm{Cu}, \mathrm{Pb} \\
\mathrm{Mn}, \mathrm{Cd}, \mathrm{Zn},\end{array}$ & $\begin{array}{c}\mathrm{C}_{0}=100 \mathrm{mg} \cdot \mathrm{L}^{-1} \\
\mathrm{pH}=(2 \mathrm{a} 8)\end{array}$ & $\begin{array}{l}\text { Argila modificada foi eficaz para a } \\
\text { sorção de todos os } \\
\text { metais pesados. }\end{array}$ & $\begin{array}{l}\text { Akpomie e } \\
\text { Dawodu, } \\
(2016)\end{array}$ \\
\hline $\begin{array}{l}\text { Monólitos alveolares de } \\
\text { argila } \\
\text { Efluente sintético }\end{array}$ & $\mathrm{Pb}$ & $\begin{array}{c}\mathrm{C}_{0}=30 \text { e } 250 \mathrm{mg} \cdot \mathrm{L}^{-1} \\
\mathrm{pH}=4,5\end{array}$ & Remoção de $70 \%$ e $80 \%$ de $\mathrm{Pb}$. & $\begin{array}{l}\text { Ahrouch et al., } \\
\text { (2019) }\end{array}$ \\
\hline
\end{tabular}

\section{CONCLUSÃO}

Neste estudo, a remoção de íon metálico (chumbo) foi investigada usando as argilas Bofe e Brasgel sem tratamentos.

A partir dos resultados obtidos de caracterização pôde-se perceber na análise de difração de raios X, que as argilas são formadas basicamente pelo argilomineral esmectita. Os valores da capacidade de troca de cátions foram valores esperados para argilas esmectíticas.

Para os resultados relacionados à remoção e a capacidade de remoção de chumbo nas argilas em sistema de banho finito com o planejamento fatorial $2^{2}$, as condições que apresentaram melhores resultados foram em pH igual a (3-5) e concentração inicial de 50 mg. $\mathrm{L}^{-1}$ para remoção e capacidade de remoção no equilíbrio. Onde se obteve 99,97 \% de remoção de chumbo e para capacidade de remoção 3,38 miligramas de chumbo foram removidos em 1 grama de argila Bofe. Para remoção usando a argila Brasgel as condições que apresentaram melhores resultados foram em pH igual a 5 e concentração inicial 50 mg.L-1 para remoção e capacidade de remoção no equilíbrio. Onde se obteve 99,80 \% de remoção e para capacidade de remoção 3,80 miligramas de chumbo foram removidos em 1 grama de argila Brasgel.

Assim, pode-se sugerir que as argilas Bofe e Brasgel apresentaram-se excelentes materiais ecológicos na aplicação de remoção de metais pesados, especificamente o chumbo, sendo uma tecnologia alternativa, desempenhando a importância de minerais argilosos como sorventes no tratamento de efluentes tóxicos contaminados por metais. 


\section{AGRADECIMENTOS}

Os autores agradecem à Bentonit e BENTONISA por doar a argila, à Petrobras e a CAPES (Coordenação de Aperfeiçoamento de Pessoal de Nível Superior).

\section{REFERÊNCIAS}

[1] ABOUDI MANA, S. C., Hanafiah, M. M., Chowdhury, A. J. K., Environmental characteristics of clay and claybased minerals. Geology, Ecology, and Landscapes, v.1(3), p.155-161, 2017.

[2] ADDY, M.; Losey, B.; Mohseni, R.; Zlotnikov, E.; Vasiliev, A. Adsorption of heavy metal ions on mesoporous silica-modified montmorillonite containing a grafted chelate ligand. Applied Clay Science, v.59, p.115-120, 2012.

[3] AHMARUZZAMAN, M. Industrial wastes as low-cost potential adsorbents for the treatment of wastewater laden with heavy metals, Advances in Colloid and Interface Science. v.116, p.36-59, 2011.

[4] AKPOMIE, K. G.; Dawodu, F. A. Acid-modified montmorillonite for sorption of heavy metals from automobile effluent. Beni-Suef University Journal of Basic and Applied Sciences, v.5, p.1-12, 2016.

[5] AL-ANI, T.; SARAPÄÄ, O. Clay and clay mineralogy. Physical-chemical Properties and Industrial Uses, 2008.

[6] ALMEIDA NETO, F. A. Desempenho de argilas bentoniticas na remoção de cátions de cádmio e cobre em colunas de leito fixo. Dissertação de mestrado em Engenharia Química, Unidade Acadêmica de Engenharia química, Universidade Federal de Campina Grande, Campina Grande, 92f, 2007.

[7] ARGYRAKI, A.; Boutsi, Z.; Zotiadis, V. Towards sustainable remediation of contaminated soil by using diasporic bauxite: Laboratory experiments on soil from the sulfide mining village of Stratoni, Greece. Journal of geochemical Exploration, v. 183, p. 214-222, 2017.

[8] AHROUCH, M.; Gatica, J. M.; Draoui, K.; Bellido, D.; VIDAL, H. Lead removal from aqueous solution by means of integral natural clays honeycomb monoliths. Journal of Hazardous Materials, v.365, p.519-530, 2019.

[9] BERGAYA, F.; Theng, B. K. G.; LAGALY, G., Handbook of clay science, Ed. Elsevier. v. 1, 2006.

[10] CABRAL, S. B.; Rodrigues, S. C. G.; Pereira, K. R. O.; Valenzuela-DÍAZ, F. R.; Rodrigues, M. G. F. Síntese e caracterização de argila organofílica visando sua utilização como adsorvente na remoção de cromo. Revista Eletrônica de Materiais e Processos, v.4.3, p.21-28, 2009.

[11] ChURChmAN, G. J., Gates, W. P., Theng, B. K. G., YUAN, G., Clays and clay minerals for pollution control. Developments in clay science, v.1, p.625-675, 2006.

[12] CUNHA R.S.S.; J.D. Mota, M.G.F. Rodrigues, Evaluation of chocolate clay removal of lead in $\mathrm{b}\left(\mathrm{Pb}^{2+}\right)$ system in finite bath. Materials Scice Forum, v. 805, p.279-283, 2015.

[13] DURAND, J.F., The impact of gold mining on the Witwatersrand on the rivers and karst system of Gauteng and North West Province, South Africa. Journal of African Earth Sciences, v.68, p.24-43, 2012.

[14] ES-SAHBANY, H.; Berradi, M.; Nkhili, S.; Hsissou, R.; Allaoui, M.; Loutfi, M.; EL Youbi, M. S. Removal of heavy metals, nickel contained in wastewater-models by the adsorption technique on natural clay. Materials Today: Proceedings, v.13, p.866-875, 2019.

[15] GOMES, C. F. Argilas: O Que São e Para que Servem, Fundação Calouste Gulbenkian, Lisboa, 1988.

[16] GRIM, R. E. Clay mineralogy (International Series in the Earth and Planetary Sciences). McGraw-Hill, New York, 1968.

[17] JIA, H.; NULAJI, G.; GAO, H.; WANG, F.; ZHU, Y.; WANG, C. Formation and stabilization of environmentally persistent free radicals induced by the interaction of anthracene with Fe, III)-modified clays. Environmental science, technology, v.50(12), p.6310-6319, 2016.

[18] KAYA, A.; ÖREN, A. H.; Adsorption of zinc aqueous solutions to bentonite. Journal of Hazardous Materials, v. B125, p. $183-189,2005$.

[19] KOSTENKO, L. S., Tomashchuk, I. I., Kovalchuk, T. V., Zaporozhets, O. A. Bentonites with grafted aminogroups: Synthesis, protolytic properties and assessing $\mathrm{Cu}, \mathrm{II}), \mathrm{Cd}, \mathrm{II})$ and $\mathrm{Pb}$, II) adsorption capacity. Applied Clay Science, v.172, p.49-56, 2019. 
[20] LIMA, W. S. Estudo da aplicação de argilas para atenuação de metais pesados destinadas à aplicação em aterro de resíduo industrial. Dissertação de Mestrado (Engenharia Química) Universidade Federal de Campina Grande - UFCG, 103f, 2011a.

[21] LIMA, W. S.; A; Brito, A. L. F. de; Rodrigues, M. G. F; Mota, M. F.; Silva, M. M. Characterization of National Clays After Acid Treatment and Thermal. Eighth International Latin American Conference on Powder Technology - Ptech, Florianópolis, 2011.

[22] LIMA, W. S.; Brito, A. L. F.; Rodrigues, M. G. F. Adsorção de zinco a partir de soluções aquosas usando argila Brasgel. Scientia Plena, v. 8, p. 1- 3, 2012.

[23] LIMA, W. S.; Rodrigues, M. G. F.; Brito, A. L. F.; Silva, V. J.; Silva, J. A. Caracterização da Argila Cinza para Utilização na Remoção de Zinco em Efluentes Sintéticos. 54ํㅡㄹ Congresso Brasileiro de Cerâmica, 2010, Foz do Iguaçu, p. $2296-2307,2010$.

[24] LIU, X.; HICHER, P.; Muresan, B.; Saiyouri, N.; Hicher, P. Y. Heavy metal retention properties of kaolin and bentonite in a wide range of concentration and different pH conditions. Applied Clay Science, v. 119, p. 365-374, 2016.

[25] MEnEzES, R. R.; Souto, P. M.; Santana, L. N. L.; Neves, G. A.; Kiminami, R. H. G. A.; Ferreira, H. C. Argilas Bentoníticas de Cubati, Paraíba, Brasil: Caracterização física-mineralógica. Cerâmica, v. 55, p.163-169, 2009.

[26] MONTGOMERY, D. C.; Design and Analysis of Experiments. 4를. Ed. Jonh Wiley e Sons, Inc. New York, 1996.

[27] MOTA, J. D.; Cunha, R. S. S.; Vasconcelos, P. N. M. Cadmium Sorption Kinetic Study Using Natural Brasgel Clay the adsorbent. Materilas Science Forum, v. 912, p. 202-206, 2017.

[28] MOTA, J. D.; Cunha, R. S. S.; Vasconcelos, P. N. M.; Rodrigues, M. G. F. Modificação Térmica de Argila Brasgel Visando Sua Utilização na Adsorção de Níquel em Sistema de Banho Finito. 11 Encontro Brasileiro Sobre Adsorção. Aracaju/SE, 2016.

[29] MOTA, J. D.; R. S. S. Cunha, M.G.F. Rodrigues, Study and characterization of Chocolate B clay on sorption of heavy metals (lead and zinc) in bath finite system. Materials Science Forum, p.798-799, 2014.

[30] OTUNOLA, B.O.; Ololade, 0.0. A review on the application of clay minerals as heavy metal adsorbents for remediation purposes. Environmental Technology \& Innovation, v.18, 2010.

[31] PADILLA-ORTEGA, E.; LEYVA-RAMOS, R.; FLORES-CANO, J. V. Binary adsorption of heavy metals from aqueous solution onto natural clays. Chemical Engineering Journal, v. 225, p. 535-546, 2013.

[32] PATRÍCIO, A. C. L. Remoção de metais pesados (Zn, Pb, Zn/Pb) utilizando como adsorvente a argila Brasgel organofilizada. Dissertação de Mestrado (Engenharia Química) Universidade Federal de Campina Grande - UFCG, 86f, 2012.

[33] PATRÍCIO, A. C. L.; Silva, M. M.; Lima, W. S.; Laborde, H. M.; Rodrigues, M. G. F. Tratamento e Caracterização de Argilas (Brasgel e Bentonita Verde) Visando o Uso de Testes de Remoção de Zinco de Efluentes Sintéticos. 55o Congresso Brasileiro de Cerâmica, 2011, Porto de Galinhas - PE, 2011.

[34] PEREIRA, K. R. O. Estudo, em escala de laboratório, do uso de argilas do tipo Bofe na obtenção de argilas organofílicas e ativadas. Tese (Doutorado de Engenharia Metalúrgia e de Materias) Escola Politécnica da Universidade de São Paulo, 139f, 2008.

[35] PINTO, C. A. Estudo da Estabilização por Solidificação de Resíduos Contendo Metais Pesados. Tese de Doutorado em Engenharia Química; Universidade de São Paulo; São Paulo - SP, 2005.

[36] RODRIGUES, M. G. F.; Silva, M. L. P.; Silva. M. G. C. Caracterização da Argila Bentonitíca para Utilização na Remoção de Chumbo de Efluentes Sintéticos. Cerâmica, v.50 p. 190 - 196, 2004.

[37] SDIRI, A.; Higashi, T.; Bouaziz, S.; Benzina, M. Synthesis and characterization of silica gel from siliceous sands of southern Tunisia. Arabian Journal of Chemistry. v.7, p. 486-493, 2014.

[38] SDIRI, A.; KHAIRY, Mohamed.; Bouaziz, S.; EL-SAFTY, S. A natural clayey adsorbent for selective removal of lead from aqueous solutions, Applied Clay Science, v. 126, p. 89-97, 2016. 
[39] SHAHID, M., Dumat, C., Khalid, S., Schreck, E., XIONG, T., Niazi, N. K., Foliar heavy metal uptake, toxicity and detoxification in plants: A comparison of foliar and root metal uptake. Journal of Hazardous Materials, v.325, p.36-58, 2017.

[40] SILVA, J. V. N. Remoção de metais pesados (Cd, Pb, Zn) utilizando como adsorventes argilas nacionais: Chocobofe e Chocolate B, Tese de Doutorado em Engenharia Química, Universidade Federal de Campina Grande UFCG. Campina Grande/PB, 111f, 2015.

[41] SILVA, J. V. N.; Oliveira, G. C.; Rodrigues, M.G.F., Feasibility Study of the Properties of Clay Chocobofe Removal of Lead in Synthetic Wastewater, Materials Science Forum, v. 805, p. 284-290, 2015.

[42] SILVA, M. L. P. Remoção de cádmio de efluentes sintéticos pela argila bentonita. Dissertação de Mestrado em Engenharia Química, Unidade Acadêmica de Engenharia química, Universidade Federal de Campina Grande, Campina Grande, 83f, 2005.

[43] SOUSA, L. J.; Vilar, W. C. T.; Rodrigues, M. G. F., Brito, A. L. F. Tratamento de efluente líquido contendo metais pesados. 25 o Congresso Brasileiro de Engenharia Sanitária e Ambiental ABES - Associação Brasileira de Engenharia Sanitária e Ambiental, 2009.

[44] SOUZA SANTOS, P. Ciência e Tecnologia de Argilas. 2ª ed., São Paulo: Ed. Edgard Blücher Ltda., v. 1-3, 1992.

[45] STATHI, P.; Litina, K.; Gournis, D.; Giannopoulos, T. S.; Deligiannakis, Y. Physicochemical study of novel organoclays as heavy metal ion adsorbents for environmental remediation. Journal of Colloid and Interface Science, v.316(2), p.298-309. 2007.

[46] UDDIN, M.K., A review on the adsorption of heavy metals by clay minerals, with special focus on the past decade. Chemical Engineering Journal, v3, p.438-462, 2017.

[47] VACA, R.; LUGO, J.; Martinez, R.; Esteller, M. V.; Zavaleta, H. Effects of sewage sludge and sewage sludge compost amendment on soil properties and Zea mays L. plants, heavy metals, quality and productivity). Revista Internacional de Contaminación Ambiental, v.27, p.303-311, 2011.

[48] VASCONCELOS, P.N.M. Modificação e caracterização de argila esmectita brasgel visando seu uso no processo de remoção de metais pesados ( $\mathrm{Cd}, \mathrm{Ni}$ e $\mathrm{Cd} / \mathrm{Ni}$ ), Tese de Doutorado em Engenharia Química, Universidade Federal de Campina Grande - UFCG. Campina Grande/PB, 108f, 2013.

[49] VASCONCELOS, P.N.M.; Lima, W.S.; Silva M.L.P.; BRITO, A.L.F.; Laborde, H.M.; RODRIGUES, M. G. F. Sorption of Zinc from Aqueous Solutions Using Modified Brazilian Gray Clay. American Journal Analytical Chemistry, v.4, p. 510$519,2012$.

[50] VHAHANGWELE, M., Mugera, G. W. The potential of ball-milled South African bentonite clay for attenuation of heavy metals from acidic wastewaters: Simultaneous sorption of $\mathrm{Co}^{2+}, \mathrm{Cu}^{2+}, \mathrm{Ni}^{2+}, \mathrm{Pb}^{2+}$, and $\mathrm{Zn}^{2+}$ ions. Journal of Environmental Chemical Engineering, v.3, p. 2416-2425, 2015.

[51] VILAR, W. C. T. Remoção de metal pesado (níquel) de efluentes sintéticos utilizando argila chocolate. Dissertação de Mestrado. Universidade Federal de Campina Grande, Campina Grande, 102f, 2007.

[52] VILAR, W. C. T.; Brito, A. L. F.; Laborde, H. M.; Rodrigues, M. G. F.; Ferreira, H. S. Ativação térmica e caracterização da argila chocolate visando sua aplicação como adsorvente na remoção de níquel. Revista Eletrônica de Materiais e Processos, v.4.3, p. 39-47, 2009.

[53] WANG, C. C.; JUANG, L. C.; LEE, C. K.; HSU, T. C.; LEE, J. F.; CHAO, H. P. Effects of Exchanged Surfactant Cations on the Pore Structure and Adsorption Characteristics of Montmorillonite. Journal of Colloid and Interface Science, v.280, p.27-35, 2004

[54] YANG, Y., CHEN, Y., LENG, F., HUANG, L., WANG, Z., TIAN, W., Recent advances on surface modification of halloysite nanotubes for multifunctional applications. Applied Sciences, v.7(12), p.1215, 2017.

[55] YI, X. U.; LIANG, X.; YINGMING, X. U.; XU, Q. I. N.; HUANG, Q.; LIN, W. A. N. G.; YUEBING, S. U. N. Remediation of heavy metal-polluted agricultural soils using clay minerals: a review. Pedosphere, v. 27(2), p.193-204, 2017. 


\section{Capitulo 13}

Estudo de parâmetros aplicado a remoção de metais de resíduos eletroeletrônicos

\section{Maria do Socorro Bezerra da Silva \\ Raffael Andrade Costa de Melo \\ André Luis Lopes Moriyama \\ Carlson Pereira de Souza}

Resumo: A eletrodeposição de metais é um dos métodos experimentais mais utilizados na investigação dos fenômenos associados à formação de padrões. Isto se deve ao fato da técnica apresentar fácil implementação e baixo custo, além de permitir a investigação de uma grande diversidade de padrões através da variação de parâmetros experimentais facilmente acessíveis. Neste estudo, são analisados os efeitos causados por diferentes arranjos de eletrodos sobre a eletrodeposição de metais em células eletrolíticas. Foi utilizada uma célula com geometria retangular - onde três arranjos diferentes de eletrodos foram investigados, sendo dois eletrodos paralelos retos suspensos sobre uma base, dois eletrodos paralelos de ponta circular e quatro eletrodos paralelos retos. A distância entre estes eletrodos na célula eletroquímica se manteve constante a $3 \mathrm{~cm}$. A solução eletrolítica foi um licor lixiviado de placas de circuito impresso. Os experimentos foram realizados em tempo constante, variando o arranjo dos eletrodos, sistema com e sem agitação e a densidade de corrente em $0.11 \mathrm{~A} / \mathrm{cm}^{2}, 0.22 \mathrm{~A} / \mathrm{cm}^{2}$ e $0.33 \mathrm{~A} / \mathrm{cm}^{2}$. Os melhores resultados de remoção de metais foram alcançados aplicando a densidade de corrente de $0.33 \mathrm{~A} / \mathrm{cm}^{2}$ e arranjo de dois eletrodos retos paralelos.

Palavras - chave: eletrodeposição, metais, eletrodos, PCBs 


\section{INTRODUÇÃO}

O campo da eletroquímica tem se mostrado como uma alternativa viável na resolução de problemas ambientais. A principal vantagem desta tecnologia é a sua compatibilidade ambiental, devido ao fato de não envolver o uso de reagentes químicos. Outras vantagens estão ligadas à sua versatilidade, alta eficiência energética, utilização em baixas temperaturas, facilidade de automação e segurança (KIM et al.,2002; MARTINEZ-HUITLE et al., 2009).

As primeiras pesquisas no campo da eletroquímica datam do século XVIII, quando Alexander Volta e, posteriormente, Michael Faraday perceberam que existia uma relação entre reações químicas e fenômenos elétricos (CUNHA, 2010).

O objeto de estudo da eletroquímica são os fenômenos químicos que envolvem a separação de cargas elétricas. Em muitos casos esta separação de cargas leva à transferência de cargas na superfície de um eletrodo. Geralmente as reações de transferência de cargas ocorrem em eletrodos diferentes, separados fisicamente e imersos num condutor iônico ou eletrólito. Tipicamente, os eletrodos podem ser formados por metais sólidos ( $\mathrm{Pt}, \mathrm{Al}, \mathrm{Cu}, \mathrm{Ti}$ ), metais líquidos (Hg, amálgamas), carbono e semicondutores (Si) (BARD, 2000).

Neste processo, em geral, a composição química do metal permanece inalterada, porém, a passagem da corrente elétrica pelo condutor pode ser acompanhada de variação de temperatura e de evolução de efeitos magnéticos. Os condutores metálicos são usualmente utilizados como terminais para a entrada e a saída da corrente elétrica no sistema eletroquímico. Esta função confere aos metais (ou a qualquer outra substância que apresente condutância eletrônica) a denominação de eletrodo. Já nos condutores iônicos, os portadores de cargas têm dimensão atômica ou molecular e possuem tanto cargas negativas quanto positivas (CUNHA, 2010). O objetivo deste estudo e avaliar alguns parâmetros experimentais como: densidade de corrente e arranjo dos eletrodos, em uma célula eletroquímica, com a finalidade de remover metais em solução. Estes metais provêm do lixiviado de Resíduos de Equipamentos Eletroeletrônicos, mais precisamente das Placas de Circuito Impresso - PCIs.

\section{PLACAS DE CIRCUITO IMPRESSO - PCIS}

Placa de circuito impresso (PCI) é o componente integral de qualquer equipamento eletrônico à medida que ele se liga eletricamente e suporta mecanicamente os outros componentes eletrônicos. A estrutura básica dos PCI's é o laminado revestido de cobre consistindo em resina epóxi reforçada com vidro e uma série de materiais metálicos, incluindo metais preciosos. A concentração de metais preciosos, especialmente $\mathrm{Au}, \mathrm{Ag}, \mathrm{Pd}$ e $\mathrm{Pt}$, é muito maior do que os respectivos recursos primários, tornando os resíduos de PCI's um minério urbano economicamente atraente para reciclagem (OGUCHI, et al.,2013).

Devido a diversidade de materiais presentes na sua composição, o componente mais complexo dos computadores, ou qualquer equipamento eletrônico, em termos de reciclagem, é a PCI. Se por um lado essa diversidade de materiais torna o processo de reciclagem muito difícil, por outro, a presença de metais preciosos ou de elevado valor econômico como cobre, prata e ouro, entre outros, torna as PCI's uma matéria-prima interessante para reciclagem (PETRANIKOVA, 2009). Neste contexto, o estudo deste artigo volta-se para a investigação de alguns parâmetros eletroquímicos aplicados a remoção destes metais em solução.

\section{DISTRIBUIÇÃO DA CORRENTE NO REATOR ELETROQUÍMICO}

Para aumentar o rendimento do tempo espacial de reatores eletroquímicos, não basta apenas aumentarmos a área do eletrodo, é necessário, também, que a densidade de corrente se distribua igualmente por todo o eletrodo, para que a reação de interesse ocorra com uma velocidade uniforme. Contudo, a distribuição de corrente só é uniforme para eletrodos de geometria bem simples. Em geral, devemos considerar que a distribuição da densidade não é uniforme (BORIN, 1986).

A distribuição da densidade de corrente pelo eletrodo reveste-se de grande importância, porque a ausência de uniformidade pode proporcionar variações locais na espessura do depósito em processos de eletrodeposição, corrosão desigual dos eletrodos em célula industriais, menor eficiência energética de baterias primárias e secundárias, ou um decréscimo no rendimento de tempo espacial de eletrodos tridimensionais. Além disto, uma distribuição não uniforme de corrente pode diminuir a eficiência de corrente de processos eletrolíticos (BORIN, 1986). 
Os principais fatores que influenciam a distribuição de corrente são:

- Geometria da célula;

- Condutividade do eletrólito e dos eletrodos;

- Sobretensão de ativação nos eletrodos, dependente da cinética do eletrodo;

- Sobretensão de concentração, controlada principalmente pelo transporte de massa.

Dependendo de qual dos fatores é considerado, pode-se classificar os tipos de distribuição de corrente em três modos como mostra a Tabela 1 .

A classificação da distribuição de corrente em primária, secundária e terciária resulta da aplicação das leis fundamentais da eletroquímica a sistemas tecnológicos.

Tabela 1 - Distribuição de corrente em três modos

\begin{tabular}{|c|c|c|}
\hline $\begin{array}{c}\text { Tipos de Distribuição } \\
\text { de Corrente }\end{array}$ & Fatores considerados & Parâmetros envolvidos \\
\hline Primária & Ausência de sobretensões. & Geometria (célula, eletrodo). \\
\hline Secundária & $\begin{array}{c}\text { Sobretensão de ativação sem variações de } \\
\text { concentração próximo ao eletrodo. }\end{array}$ & $\begin{array}{c}\text { Geometria, sobretensão de ativação, } \\
\text { condutividade do eletrólito e eletrodos. }\end{array}$ \\
\hline Terciária & Sobretensão de ativação e concentração. & $\begin{array}{c}\text { Geometria, condutividade, sobretensão } \\
\text { de ativação e concentração. }\end{array}$ \\
\hline
\end{tabular}

A distribuição de corrente será uniforme somente se toda a disposição dos eletrodos for geometricamente semelhante. A Figura 1 ilustra quatro geometrias de eletrodo. Na célula com eletrodos planos e paralelos (a), e com eletrodos cilíndricos (b), a distribuição de corrente será uniforme devido á simetria do arranjo. Por outro lado, nas células (c) e (d) com arranjos diferentes, a distribuição de corrente não será uniforme.

Figura 2.2 - Geometria de eletrodos aplicados a processos eletroquímicos (BORIN, 1986).

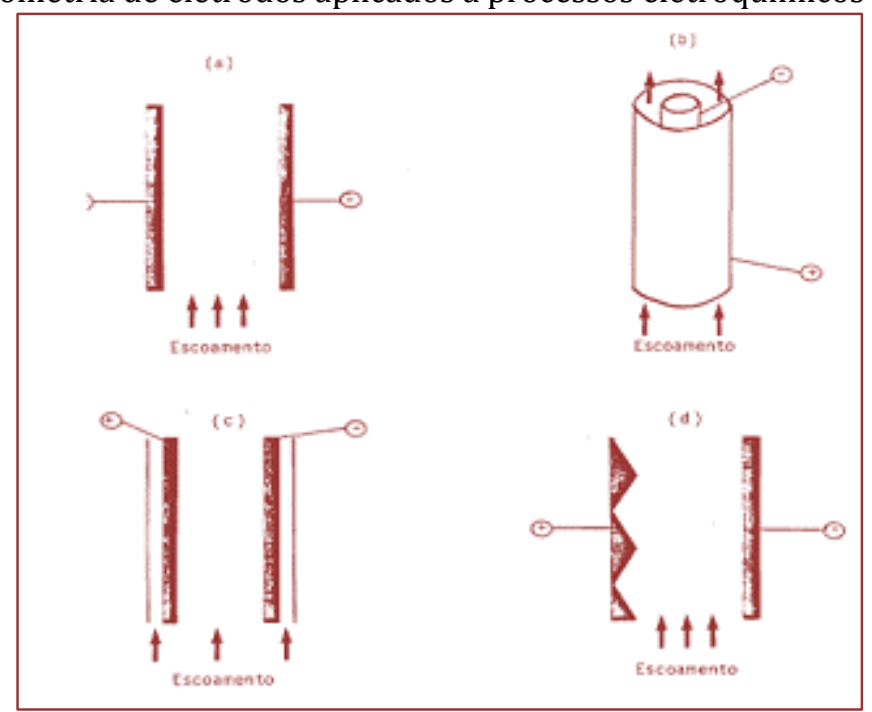

Na célula (c) as faces dos eletrodos voltadas para as paredes da célula não são isoladas, permitindo um pequeno fluxo de corrente através destas faces (o que de fato diminui a eficiência de corrente para o processo); na célula (d), para os pontos do cátodo mais distantes do anodo, o fluxo de corrente será menor do que nos pontos mais próximos do anodo (diminuindo, também, a eficiência da corrente).

Uma maneira utilizada para aumentar a área eletródica ativa consiste em colocar vários eletrodos lados a lado, de forma que ambas as faces sejam utilizadas. Outra solução é utilizar reatores compostos por eletrodos cilíndricos concêntricos. A vantagem deste arranjo de eletrodos, bem como os eletrodos planos paralelos, é que a distribuição de corrente é uniforme, devido a simetria presente. Por isso toda área do eletrodo é ativa. 


\section{MATERIAIS E MÉTODOS}

As soluções eletrolíticas utilizadas neste estudo são lixiviados de Placas de Circuito Impresso (PCI's) de computadores de mesa. Após estes resíduos passarem por processos hidrometalúrgicos, como mostrado na figura 3, e caracterizados, estes foram diluídos com água destilada numa proporção de 1:7 (1 volume do lixiviado e 6 volumes de água destilada, para formar $500 \mathrm{ml}$ de solução) e submetidos a reações eletroquímicas para a otimização da recuperação de metais variando o arranjo dos eletrodos mostrados na figura 4.

Figura 3 - Etapas da lixiviação. Adaptado de Silvas, 2014.

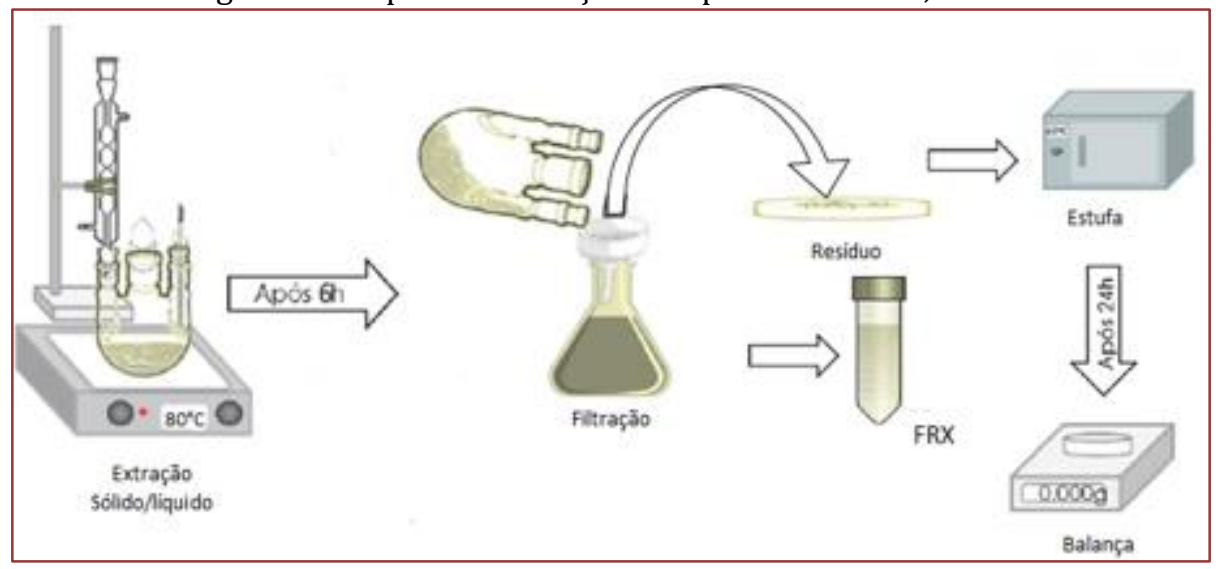

\section{AUMENTO NA ÁREA ATIVA DOS ELETRODOS EM DIFERENTES ARRANJOS}

Alguns experimentos foram realizados aumentado a área ativa do eletrodo e consequentemente um aumento na densidade de corrente no reator. As condições utilizadas estão apresentadas na tabela 2, o tempo se manteve constante.

Tabela 2 - Parâmetros experimentais da célula eletroquímica

\begin{tabular}{|c|c|c|}
\hline Corrente (A) & Agitação (RPM) & Tempo (min.) \\
\hline 0,5 & Com Sem & 60 \\
\hline 1,0 & Com Sem & 60 \\
\hline 1,5 & Com Sem & 60 \\
\hline
\end{tabular}

Os arranjos dos eletrodos foram modificados para verificar a influência na remoção de metais de uma solução lixiviada de metais de Placas de Circuito Impresso (PCI). No primeiro arranjo, foram utilizados dois eletrodos com área ativa circular, sendo um anodo e um catodo, e, no segundo um arranjo de eletrodos paralelos, com área ativa reta, sendo dois anodos e dois catodos, ambos conectados a fonte de corrente contínua. Borin (1986), relata vários arranjos de eletrodos para a remoção de metais em efluentes. Dentre eles estão os arranjos em paralelo.

Nesta pesquisa, também foram realizados processos eletroquímicos utilizando o arranjo paralelo de eletrodos, que funciona como uma maneira de aumentar a área catódica ativa. Neste arranjo, foram colocados 4 eletrodos na célula eletroquímica lado a lado, de forma que ambos os pares fossem utilizados. Manteve-se uma distância entre eles de aproximadamente $3 \mathrm{~cm}$. Este arranjo bipolar foi conectado eletricamente a fonte de alimentação, de forma que a mesma corrente estivesse fluindo por todos os eletrodos. Este tipo de arranjo teve um papel importante nesse estudo devido ao fato de ser ideal para os processos nos quais tanto as reações catódicas quanto anódicas ocorrem no mesmo tipo de material. A figura 4 apresenta os arranjos de eletrodos estudados. 
Figura 4 - Célula eletroquímica. 1) reator eletroquímico, 2) suporte, 3) agitador mecânico, 4) eletrodos de cobre, 5) fonte de alimentação. (a) arranjo com 2 eletrodos (b) arranho com 2 eletros de pontas circulares (c) arranjo com 4 eletrodos.

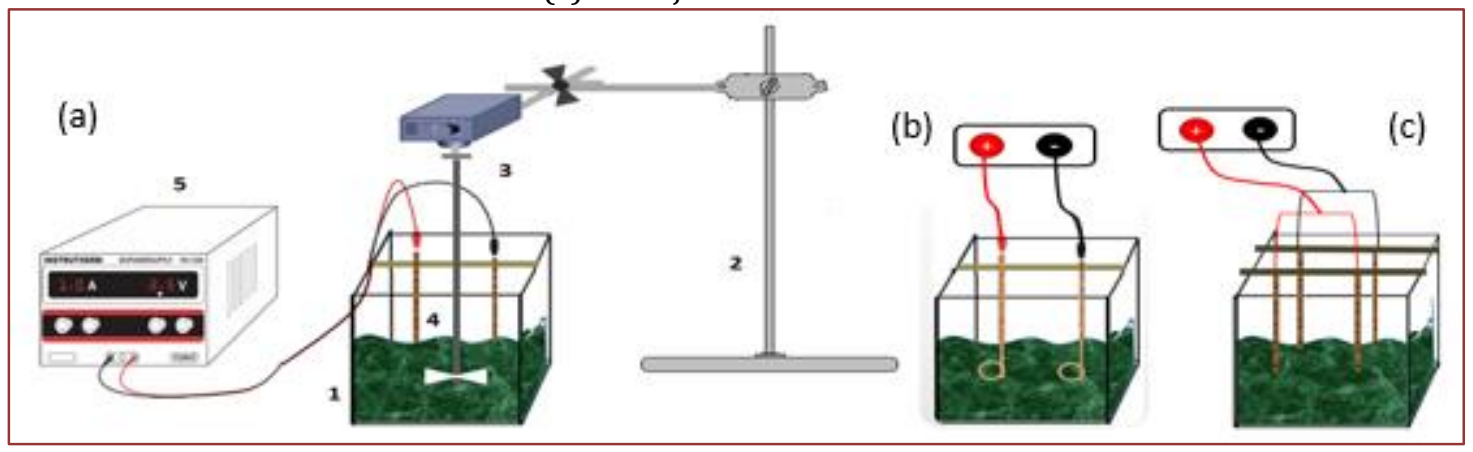

\section{PRODUÇÃO E CARACTERIZAÇÃO DOS ELETRODOS}

Os eletrodos utilizados neste processo são de cobre e fabricados com fios deste metal, adquiridos na indústria comercial. Os eletrodos consistem de um bastão de cobre de forma cilíndrica, alguns medindo $20 \mathrm{~cm}$ e outros $25 \mathrm{~cm}$ de comprimento e diâmetro de 3,5 mm. Inicialmente os eletrodos, já com tamanhos definidos, foram lixados para retirar a resina que envolve os fios evitando a oxidação, e em seguida alguns foram moldados manualmente para ficarem de forma reta, e outros foram moldados de forma que uma das pontas formassem um círculo, como apresentados na Figura 5.

Figura 5 - Eletrodos utilizados no processo de eletrodeposição.

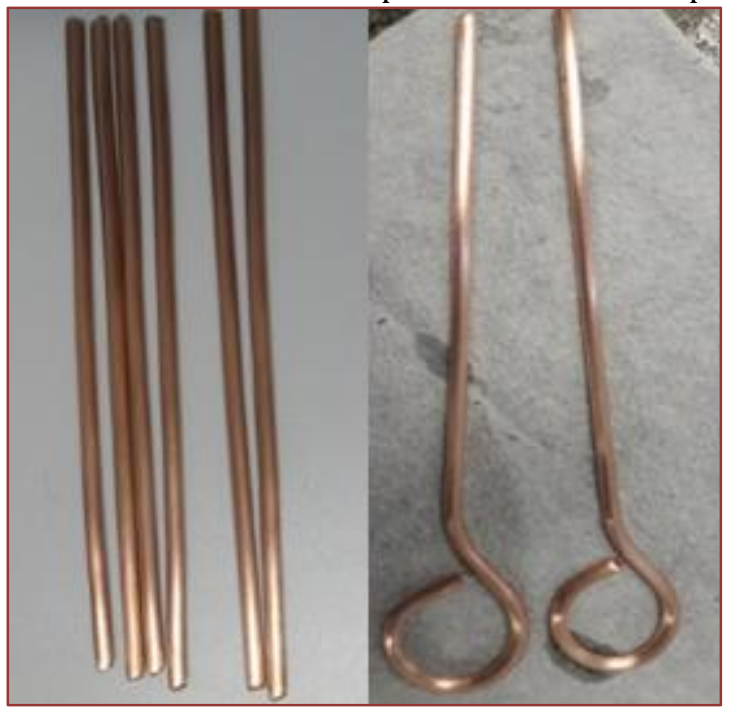

Após esta etapa, foram lavados com esponja e detergente várias vezes, enxaguados com água destilada, secos com papel toalha e armazenados em filme plástico para evitar a oxidação. Os eletrodos foram caracterizados por Espectroscopia de Fluorescência de Raios-X. Posteriormente foram utilizados no processo de deposição de metais.

\section{PESO DOS ELETRODOS}

Para quantificar o ganho e a perda de massa dos eletrodos, estes foram pesados três vezes antes e depois de cada teste. 0 cálculo foi realizado pela diferença do peso inicial e final e os resultados apresentam uma média destes pesos.

Em todas as reações, ao finalizar os processos, com e sem agitação, os eletrodos são retirados, e levados para secar na estufa á $60^{\circ} \mathrm{C}$ por meia hora. Após, os eletrodos são retirados da estufa e pesados para 
verificar o ganho de massa. 0 depósito é removido facilmente, balançando a parte com o depósito dentro de um ependorf, e em seguida encaminhados para a análise química por Fluorescência de Raio-X (FRX), Difração de Raio-X (DRX) e Microscopia Eletrônica de Varredura (MEV-FEG - EDS). Ao iniciar outro processo, novos eletrodos são utilizados.

\section{RESULTADOS E DISCUSSÕES}

A solução utilizada no processo eletroquímica continha uma variedade de metais das mais diferentes concentrações identificadas por FRX. A tabela 3 mostra a concentração dos metais presentes na solução resíduo.

Table 3 - Main elements present in the leachate.

\begin{tabular}{|c|c|c|c|}
\hline Elements & $\begin{array}{l}\text { Concentration on } \\
\text { the leachate }(\%)\end{array}$ & Elements & $\begin{array}{l}\text { Concentration on } \\
\text { the leachate }(\%)\end{array}$ \\
\hline $\mathrm{Cu}$ & 40.71 & $\mathrm{Fe}$ & 1.2 \\
\hline $\mathrm{Cl}$ & 24.9 & $\mathrm{Ag}$ & 1.54 \\
\hline Sn & 17.26 & $\mathrm{Al}$ & 0.6 \\
\hline $\mathrm{Ca}$ & 7.33 & $\mathrm{Ni}$ & 0.21 \\
\hline $\mathrm{Na}$ & 3.34 & $\mathrm{Cr}$ & 0.18 \\
\hline $\mathrm{Pb}$ & 1.97 & $\mathrm{Ti}$ & 0.15 \\
\hline
\end{tabular}

\section{VARIAÇÃO DO POTENCIAL NO CATODO}

Durante todas as reações de eletrodeposição realizadas, foi observado uma variação no potencial catódico. 0 potencial do cátodo, em todas as densidades, tende a diminuir de modo a manter a corrente constante. Em alguns momentos do processo, a concentração de íons fica baixa, e os processos de difusão, migração ou agitação, não são mais suficientes para manter a corrente constante, sendo necessário ajustes de modo a garantir o valor de corrente, assim, o potencial do catodo variará. Neste caso, o potencial ao se deslocar para valores mais negativos atinge o potencial de redução de vários elementos, como mostrado nas tabelas anteriores de deposição catódica, ocasionando um enriquecimento de elementos nos depósitos. Por este motivo, os resultados obtidos, apresentam uma variação de metais depositados, de acordo a densidade de corrente e variação de potencial catódico. A Tabela 4 mostra a tensão catódica inicial e final em cada processo, com e sem agitação.

Tabela 4 - Tensão catódica inicial e final em cada processo com soluções diluídas.

\begin{tabular}{|c|c|c|}
\hline j $\left(\mathrm{A} / \mathrm{cm}^{2}\right)$ & c.a. & s.a. \\
\hline & I F & I F \\
\hline 0,11 & $2,2-1,5 \mathrm{~V}$ & $2,4-1,8 \mathrm{~V}$ \\
\hline 0,22 & $2,7-2,5 \mathrm{~V}$ & $2,3-1,9 \mathrm{~V}$ \\
\hline 0,33 & $3,7-3,2 \mathrm{~V}$ & $3,2-2,9 \mathrm{~V}$ \\
\hline
\end{tabular}

c.a. = com agitação, s.a. $=$ sem agitação, $\mathrm{I}=$ Potencial inicial, $\mathrm{F}=$ Potencial final

Analisando os dados da Tabela 4, observa-se uma diminuição na voltagem da célula em todos os processos. Pode-se considerar que há uma resistência entre o anodo e o catodo nesta célula, então o que ocorre é que a corrente que fui através desta resistência causa uma queda no potencial, governada pela lei de Ohm. Considera-se que existe dois efeitos na mudança total da resistência: a remoção de íons diminui a condutividade no meio aquoso e a transferência de massa para os eletrodos promove um aumento em seu diâmetro e, consequentemente sua área transversal e isso possibilita a diminuição da resistividade na célula.

\section{PERDA E GANHO DE MASSA DOS ELETRODOS}

A perda e o ganho de massa nos eletrodos foram analisados em relação a corrente aplicada e estão apresentados na Figura 5 para a solução diluída numa proporção de 1:3. Para todos os processos com as soluções diluídas, quando a corrente utilizada é baixa, a quantidade de gás formada durante o processo no anodo, principalmente, é menor, o que aumenta a vida útil do eletrodo, como pode ser comprovado no 
desgaste dos eletrodos durante o processo apresentado na figura 5 (a), relacionando a perda de massa versus corrente aplicada.

Já o desgaste mais rápido dos eletrodos está associado a reação anódica de desprendimento de oxigênio, cujas bolhas exercem uma força mecânica sobre os eletrodos, dessa forma liberando mais íons para a solução. Esse comportamento é observado no processo com agitação mecânica em ambas figuras.

Figura 5 - Perda e ganho de massa dos eletrodos em relação a corrente aplicada, perda de massa no anodo (a), ganho de massa no catodo (b).
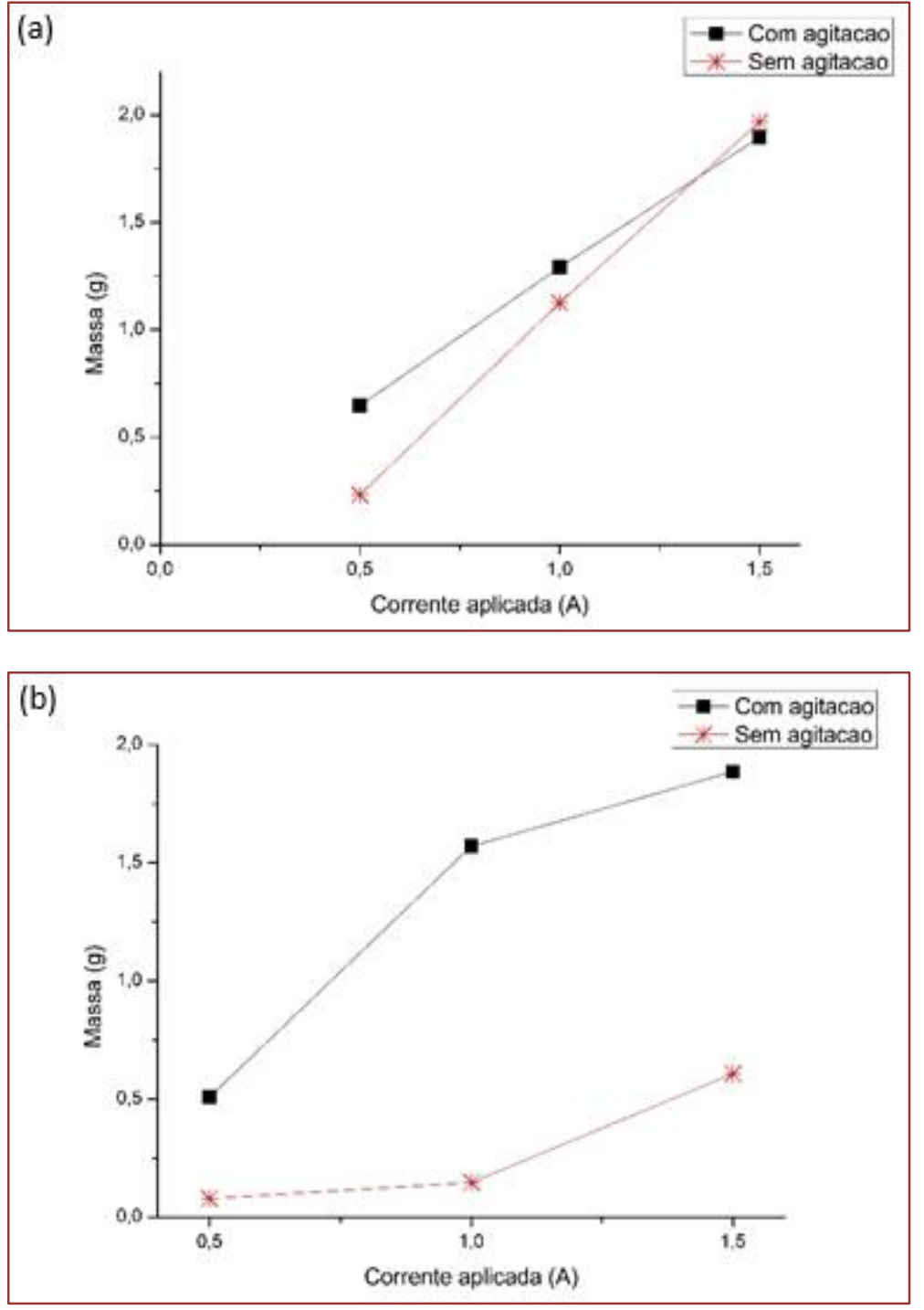

O comportamento de perda de massa ocorre de forma linear e crescente com a corrente aplicada. 0 ganho de massa nos catodos, apresentados na Figura 5 (b), segue a linearidade de acordo com a corrente.

A perda de massa é mais rápida e maior para o processo com agitação, justamente devido a forças mecânicas, mencionadas anteriormente. A tabela 5 mostra as massas iniciais e finais dos eletrodos em cada densidade de corrente. 
Tabela 5 - Peso dos eletrodos antes e depois de cada processo

\begin{tabular}{|c|c|c|c|c|c|c|}
\hline Eletrodos & $\mathrm{j}=0,11$ & $\mathrm{j}=0,22$ & $\mathrm{j}=0,33$ & $\mathrm{j}=0,11$ & $\mathrm{j}=0,22$ & $\mathrm{j}=0,33$ \\
\hline Anodo & 24,1640 & 23,4767 & 23,6150 & 23,1752 & 21,2926 & 20,9793 \\
\hline Catodo & 23,6258 & 23,2670 & 22,1494 & 23,9583 & 23,6321 & 22,6896 \\
\hline
\end{tabular}

Nestes experimentos, a célula eletroquímica foi operada com um par de eletrodos (anodo e catodo) e apresentou resultados satisfatórios em relação a remoção dos metais presentes na solução. A figura 6 (a) apresenta a evolução do processo na célula eletroquímica em aproximadamente 30 minutos de reação, sem agitação mecânica e 1,5 A de corrente aplicada.

Figura 6 - Célula eletroquímica - (a) reação em processo (b) formação de gases.
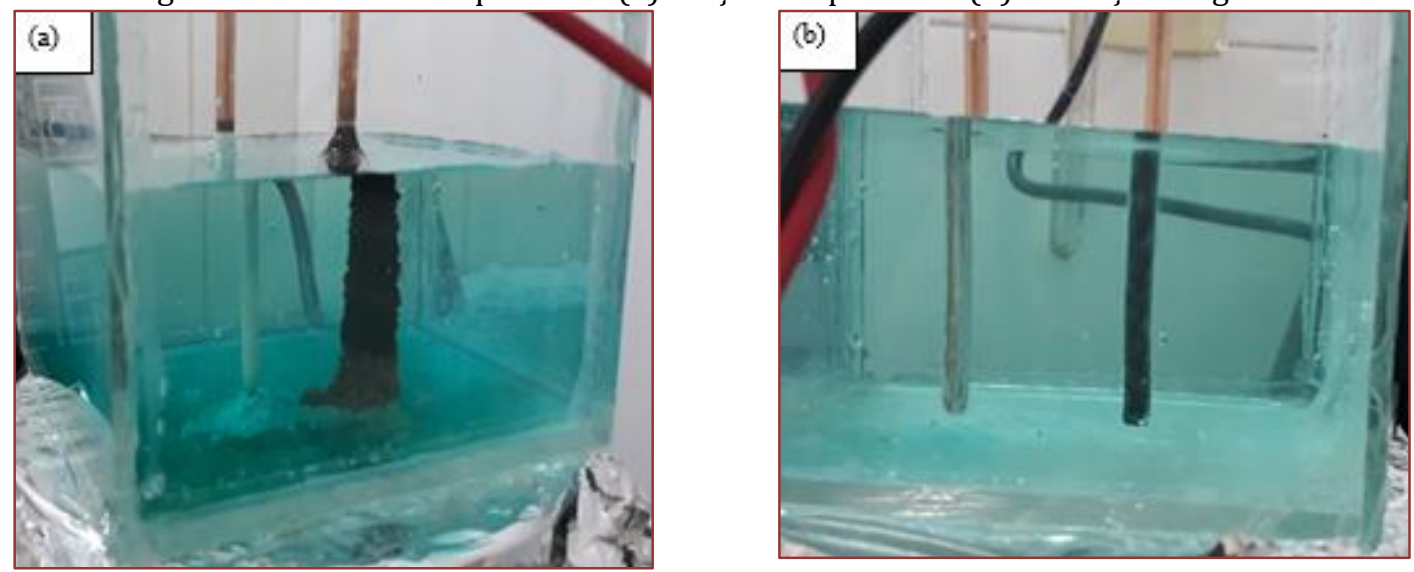

A evolução dos gases, principalmente do gás hidrogênio, é notada logo que o processo é iniciado, isso é observado nos dois eletrodos, principalmente no catodo, e fica visível ao olho no processo sem agitação, apresentado na Figura 6 (b).

A formação do cloreto de sódio no anodo e o depósito no catodo é apresentado na Figura 7 (a), logo após retirados da solução. A Figura 7 (b) ilustra a deposição metálica no catodo com agitação mecânica.

Figura 7 - Eletrodos. (a) após a finalização do processo (b) em processo (c) deposição final
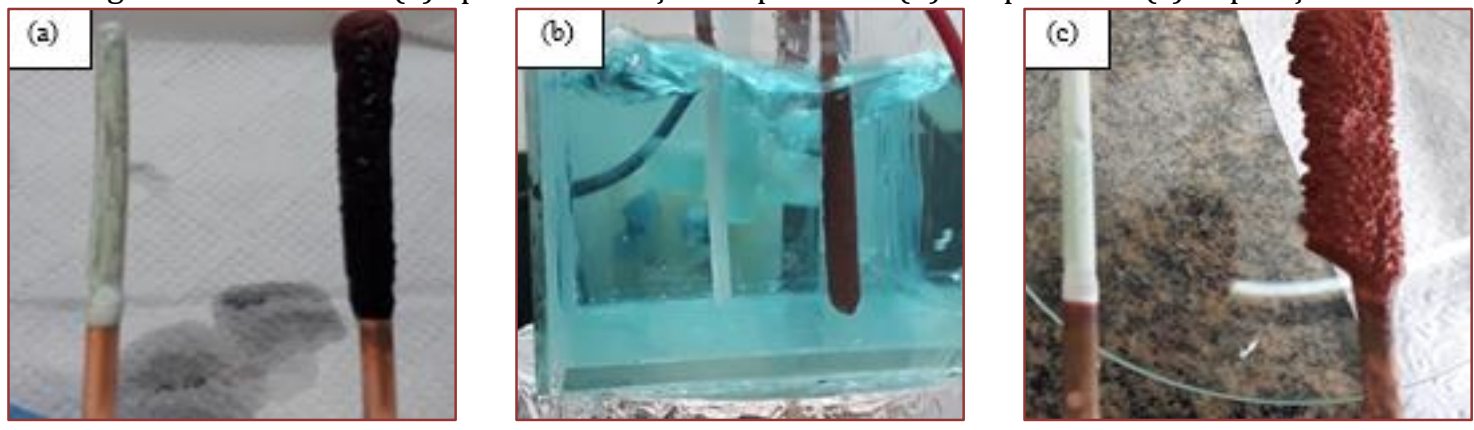

Nos processos sem agitação mecânica, figura 7 (a), observou-se que o depósito formado no catodo, apresentava uma coloração mais escura ao longo da área depositada, e avermelhada na ponta. Sabe-se que a coloração avermelhada, é de cobre metálico, o restante do depósito apresenta esta coloração, devido provavelmente a variedade de metais depositado junto com o cobre e o estanho, pricinpalmente a formação do óxido de prata, que tem coloração preta ou marron. A figura 7 (b) e (c) apresenta a coloração avermelhada em toda área depositada, característica do cobre metálico. Verifica-se na figura 7 (c) que um lado do eletrodo apresenta uma espessura no depósito maior, que o outro lado do eletrodo, próximo a parede da célula. Isso acontece por efeito da densidade da corrente, que se mostra mais uniforme entre os 
dois eletrodos, ocorrendo um maior depósito de metais. A tabela 6 apresenta a remoção dos metais para os processos com e sem agitação mecânica.

Tabela 6 - Composição do depósito do catodo para o processo com e sem agitação

\begin{tabular}{|c|c|c|c|c|c|c|}
\hline \multicolumn{2}{|c|}{} & \multicolumn{3}{c|}{ Sem agitação } & \multicolumn{3}{c|}{ Com agitação } & \\
\hline Elementos & $0,11 \mathrm{~A} / \mathrm{cm}^{2}$ & $0,22 \mathrm{~A} / \mathrm{cm}^{2}$ & $0,33 \mathrm{~A} / \mathrm{cm}^{2}$ & $0,11 \mathrm{~A} / \mathrm{cm}^{2}$ & $0,22 \mathrm{~A} / \mathrm{cm}^{2}$ & $0,33 \mathrm{~A} / \mathrm{cm}^{2}$ \\
\hline $\mathrm{Cu}$ & $\%$ & $\%$ & $\%$ & $\%$ & $\%$ & $\%$ \\
\hline $\mathrm{Cl}$ & 11,586 & 70,609 & 78,576 & 96,167 & 97,288 & 95,974 \\
\hline $\mathrm{Sn}$ & 10,385 & 13,983 & 2,223 & 1,596 & 0,000 & 1,582 \\
\hline $\mathrm{Na}$ & 3,778 & 5,162 & 0,65 & 0,000 & 0,519 & 0,986 \\
\hline $\mathrm{Ca}$ & 0,197 & 0,365 & 0,867 & 0,182 & 0,133 & 0,147 \\
\hline $\mathrm{Pb}$ & 0,712 & 0,644 & 0,732 & 0,044 & 0,147 & 0,215 \\
\hline $\mathrm{Ag}$ & 0,429 & 0,355 & 0,372 & 1,287 & 0,818 & 0,458 \\
\hline $\mathrm{Al}$ & 0,018 & $\ldots$ & $\ldots$ & 0,227 & 0,000 & 0,000 \\
\hline $\mathrm{Fe}$ & 0,836 & 0,198 & 0,163 & 0,000 & 0,130 & 0,133 \\
\hline $\mathrm{Si}$ & 0,035 & 0,031 & 0,103 & 0,075 & 0,038 & 0,022 \\
\hline $\mathrm{Ni}$ & 0,012 & 0,026 & 0.042 & 0,082 & 0,033 & 0,045 \\
\hline $\mathrm{Cr}$ & 0,009 & 0,007 & 0,015 & 0,009 & 0,015 & 0,029 \\
\hline $\mathrm{Ti}$ & $\ldots$ & 0,002 & 0,006 & 0,007 & 0,000 & 0,000 \\
\hline
\end{tabular}

Na tabela 6, observa-se uma variação de deposição de metais, sendo a maior concentração de cobre em ambos os processos. As maiores taxas de deposição de estanho ocorreram no processo sem agitação, mais especificamente para a densidade de corrente de $0,33 \mathrm{~A} / \mathrm{cm}^{2}$.

\section{1. ÁREA ATIVA CIRCULAR PARA DIFERENTES CORRENTES}

A geometria da área ativa dos eletrodos foi modificada para verificar o comportamento da corrente na extração dos metais. Realizadas as reações, verificou-se que para aumentar o rendimento da reação neste reator eletroquímico e nestas condições, não basta aumentarmos a área do eletrodo, se faz necessário também, que a densidade de corrente se distribua igualmente por todo o eletrodo, para que a reação ocorra de forma uniforme. Contudo, a distribuição de corrente só é uniforme para eletrodos de geometria bem simples, como ocorreram nos primeiros arranjos. No entanto, podemos considerar que na geometria circular utilizada, a densidade de corrente não é uniforme. Com isso, a distribuição de corrente só será uniforme se a disposição dos eletrodos for geometricamente semelhante. A figura 8 apresenta a reação com os eletrodos de ponta circular.

Figura 8 - Processo eletroquímico com eletrodos de forma circular.

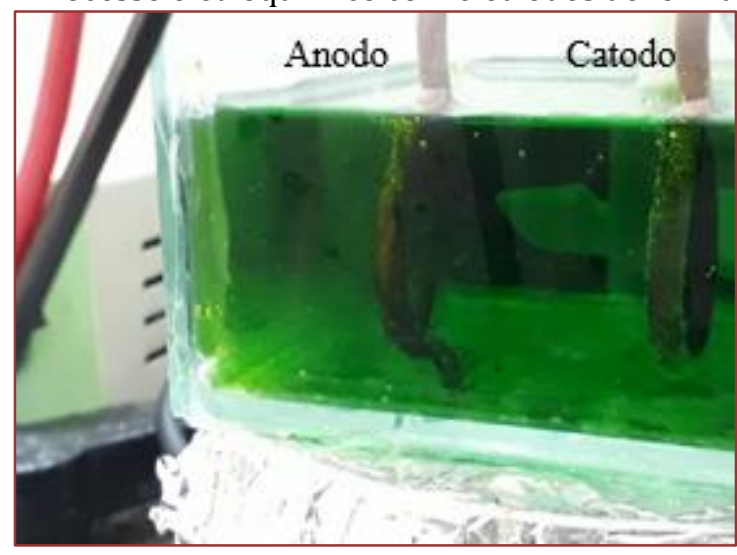

Observa-se na figura 8, que visivelmente ocorre uma perda de massa no anodo, na qual, os íons transportados para a catodo não são reduzidos. No catodo, ocorre uma evolução constante de gases, que pelo processo utilizado, possivelmente seja o gás hidrogênio. Em todos os testes realizados com esta geometria de eletrodo, não foram observadas deposições de metais. 
A Figura 9 apresenta a massa dos catodos em cada reação, com e sem agitação. 0 tempo se mantém constante para todas as correntes.

Figura 9 - Massa dos catodos em 60 minutos de reação com variação de corrente.

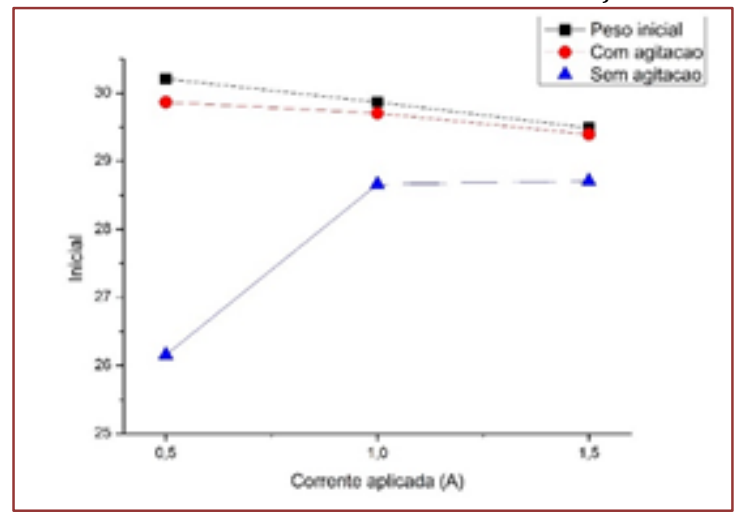

As densidades analisadas variaram entre 10, 20 e $30 \mathrm{~A} / \mathrm{cm}^{2}$. Uma vez que aumenta a área ativa dos eletrodos, também aumenta a densidade de corrente pois a densidade de corrente corresponde à razão entre a corrente contínua aplicada pela área total da superfície ativa do eletrodo. É importante dizer, que não houve deposição dos metais nos eletrodos, o que ocorreu e ficou evidente em todos os processos, foi uma perda de massa, que fica mais evidente em densidades de $10 \mathrm{~A} / \mathrm{cm}^{2}$, sendo mais intensa no processo sem agitação. Sabe-se que neste processo, a oxidação dos anodos ocorre, provocando uma perda de massa, e mesmo com o aumento na perda de massa nos anodos, ou seja, a oxidação da espécie $\mathrm{Cu}^{+} / \mathrm{Cu}^{+2}$ ocorrendo, não há influencia na transferência de íons (depósitos) para os catodos.

\section{ARRANJOS PARALELOS PARA AS DIFERENTES DENSIDADES DE CORRENTES}

Outras reações foram realizadas com a solução original, onde quatro eletrodos foram inseridos na célula eletroquímica lado a lado, de forma que ambos os pares fossem utilizados. Manteve-se a uma distância entre eles de aproximadamente de $3 \mathrm{~cm}$. Este arranjo bipolar foi conectado eletricamente a fonte de alimentação, de forma que que a mesma corrente estivesse fluindo por todos os eletrodos. A Figura 10 apresenta a célula eletroquímica com o arranjo em paralelo para o processo com e sem agitação.

Figura 10 - Célula eletroquímica com o arranjo em paralelo para o processo com e sem agitação.

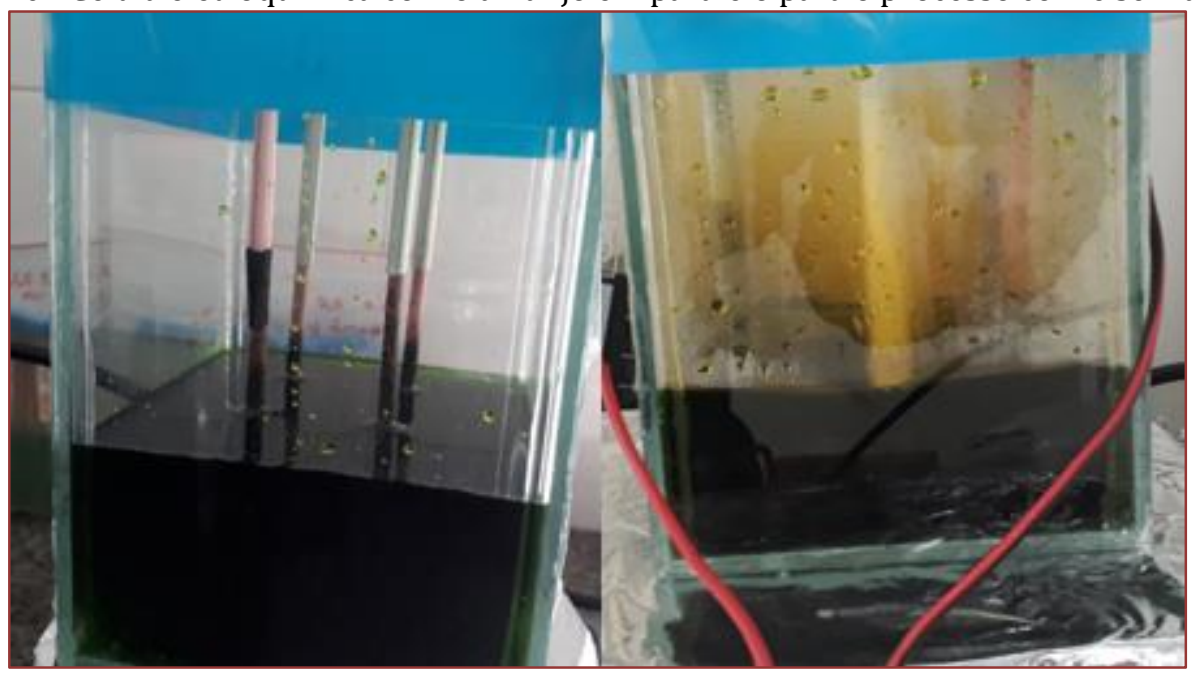


Neste arranjo de eletrodos, não houve deposição de metais em nenhum dos parâmetros estudados, com e sem agitação, e nenhuma corrente se mostrou eficiente. 0 que houve de fato foi o rápido desgaste dos eletrodos, principalmente no processo com agitação, e visualmente observado uma formação de gás gerada desde o início do processo. 0 rápido desgaste de ambos os eletrodos deixa a solução muito escura, logo aos 10 minutos do processo, o que dificulta o acompanhamento da deposição, ou não dos metais. Neste mesmo processo, foi verificado um aumento na temperatura da solução. Isso pode está ocorrendo devido ao choque da grande quantidade de elétrons livres contra átomos do material condutor, transformando a energia elétrica em térmica.

De fato, deve-se observar, que à medida que há variação na área ativa dos eletrodos, há também uma variação na densidade de corrente, ou seja, a densidade da corrente está sendo aumentada nos dois casos descritos acima, então, é importante investigar quais dos dois parâmetros está dificultando o depósito dos metais no catodo, ou provocando a perda de massa de ambos os eletrodos. Na presente tese, este parâmetro não foi investigado.

\section{CONCLUSÕES}

Verificou-se neste estudo, a possibilidade do uso de processos eletroquímicos simples na remoção de metais de um resíduo sólido em solução.

Os arranjos dos eletrodos tiverem influência significativa na remoção de metais, apresentando altas remoções de cobre, estanho dentre outros, quando foi usado um arranjo de eletrodos retos paralelos na célula eletroquímica.

O sistema com e sem agitação também apresentou influência significativa, apresentando melhores resultados na remoção, principalmente do estanho, quando a célula operou sem agitação.

A densidade de corrente, sendo um dos parâmetros mais importantes no processo eletroquímico, mostrou-se favorável a remoção de metais em ambos os processos, com e sem agitação, para o arranjo eletroquímico com dois eletrodos retos. No entanto, nos demais arranjo, verifica-se que o aumento da densidade, devido a variação de área ativa dos eletrodos, dificultou a remoção de metais, havendo um desgaste muito rápido dos eletros, à medida que a densidade de corrente aumentava.

\section{REFERÊNCIAS}

[1] Bard, J. A. and Faulkner, L. R. Electrochemical Methods Fundamentals and Applications. Nova York, John Wiley and Sons, 2001.833p.

[2] BORIN, C.A. (1986). Reator eletroquímico de bancada para remoção de íons de metais a partir de efluentes industriais. Dissertação de mestrado - USP-São Paulo.

[3] Cunha, T. H. R. Investigação dos mecanismos de transporte em eletrólitos quase-bidimensionais, 2010. Dissertação de mestrado - Universidade Federal de Viçosa, MG, 2010.

[4] Kim, T.H.; Park, C.; Lee, J.; Shin, E. B.; \& Kim, S. Pilot scale treatment of textile wastewater by combined process (fluidized biofilm process - chemical coagulation - electrochemical oxidation). Water Research, V 36, p. 39793988, 2002.

[5] Martinez-Huitle, C.A; Brillas, E. Decontamination of wastewaters containing synthetic organic dyes by electrochemical methods: A general review. Applied Catalysis b: Environmental, V 87, p. 105-145, abril 2009.

[6] OGUCHI, M.; SAKANAKURA, H.; TERAZONO, A. Toxic metals in WEEE: Characterization and substance flow analysis in waste treatment processes. Science of the Total Environment, v. 463 - 464, p. 1124 - 1132, 2013.

[7] PETRANIKOVA, M., Orac, C., Miskufova, A., Havlik, T. Hydrometallurgical Treatment of Printed wiring boards from used Computers after Pyrolytic Treatment. In: European Metallurgical Conference. Innsbruck, Austria. July 2009. 


\section{Capítulo 14}

\section{Formulação de tintas com dióxido de titânio}

\section{Gabriela Silva Spirlandelli}

José Roberto Delalibera Finzer

David Maikel Fernandes

Resumo: 0 processo de dispersão das partículas consiste em atuar sobre a junção das matérias-primas por forças eletrostáticas. Na homogeneização utilizam-se dispersantes. Este trabalho tem por objetivo verificar a influência de três formulações com diferentes quantidades de dispersante a base de poliacrilato de sódio (AQ 9921)® em emulsão aquosa com cargas e pigmento dióxido de titânio. Relaciona-se a qualidade das formulações com a viscosidade, tempo de homogeneização e poder de recobrimento. Foram realizadas três formulações com 1\%, 0,1\% e sem dispersante, usando dispersor de bancada do tipo Cowles. Após o tempo de cura, realizou-se análises de $\mathrm{pH}$, consistência, massa específica, poder de cobertura, brilho, aderência, conteúdo de sólidos em porcentagem mássica e viscosidade. 0 teste que apresentou melhores resultados foi com $0,1 \%$ de dispersante, sendo o tempo de dispersão de 40 minutos, viscosidade em copo Ford n⿳⺈ 4 de 83 segundos e quantidade de sólidos em suspensão de $46,8 \%$.

Palavras-chave: Parâmetros químicos; Emulsão aquosa; Dispersantes; Pigmentos. 


\section{INTRODUÇÃO}

As tintas são combinações de elementos sólidos, voláteis e aditivos, responsáveis por oferecer ao substrato resistência a intempéries, proteção e estética. As tintas imobiliárias podem ser subdivididas em produtos aquosos, também conhecidos como látex e produtos base-solvente orgânicos (Cunha, 2011).

As matérias-primas básicas que constituem os materiais de recobrimento são as resinas, pigmentos, solventes e aditivos, e estes, em proporções adequadas oferecem características únicas ao produto. 0 processo de fabricação consiste em pré-mistura, dispersão, completagem, filtração e envase, e cada uma destas etapas é de suma importância para a qualidade final da tinta (Polito, 2006).

0 processo de dispersão de cargas e pigmentos consiste na homogeneização das partículas por etapas físicas (mistura, agitação e forças eletrostáticas), a fim de tornar as partículas aderentes e distribuí-las por igual no meio, em junção com as matérias-primas líquidas (Cunha, 2011).

A utilização de dispersantes colabora para diminuir o tempo de agitação, economizando energia, com melhor aproveitamento da matéria-prima e avanço na produção, obtendo melhor rentabilidade e qualidade final do produto (Donadio e Abrafati, 2011).

A etapa de dispersão é uma das fases mais importantes da produção de tintas, interferindo na aglomeração de cargas e pigmentos. 0 estudo da quantidade de dispersante que se deve colocar em uma formulação para conseguir uma adequada eficiência da dispersão de partículas na solução é de suma importância para que o produto alcance as características padronizadas para liberação de lotes e para que não haja perda de matéria-prima e gastos desnecessários na produção de materiais de recobrimento.

Objetiva-se neste trabalho verificar a influência de parâmetros químicos em três formulações com diferentes quantidades de dispersante acrílico associado em emulsão aquosa, relacionando a viscosidade, dispersão de cargas e do pigmento dióxido de titânio.

\section{TINTAS IMOBILIÁRIAS}

No Brasil, as tintas surgiram na década de 80 e eram utilizadas por vários segmentos industriais. Ao longo dos anos, foram definidas formas de reduzir impactos ambientais e riscos à saúde humana e, hoje, as tintas representam papel indispensável no mundo (Cunha, 2011).

A formulação de tintas consiste em desenvolver uma junção de constituintes em proporções adequadas a fim de se obter um material de recobrimento com característica desejada. Alguns fatores precisam ser verificados ao se formular uma tinta, como o brilho que se deseja adquirir, permeabilidade, dureza, abrasão e cor (Mattoso, 1996).

0 dióxido de titânio - $\mathrm{TiO}_{2}$, componente importante na formulação de tintas, é um pigmento inorgânico e é conhecido como pigmento branco. É um dos pigmentos revolucionários, pelo fato de revelar inércia química e um elevado poder de cobertura no substrato, além de possuir uma ampla faixa de aplicação. Contudo, é uma das matérias-primas mais onerosas, sendo importante limitar sua proporção em formulações (Basf, 1987).

O processo produtivo das tintas para revestimentos é realizado através das operações unitárias - mistura e agitação - com a finalidade de obter produtos uniformes e dispersar os pigmentos e as cargas presentes no meio (Mattoso, 1996).

\section{MATERIAIS E MÉTODOS}

O desenvolvimento deste trabalho ocorreu no período de Setembro e Outubro de 2015 no laboratório de qualidade da indústria Atma tintas e revestimentos em Uberaba - MG. Para o estudo utilizou-se como base uma tinta acrílica fosca da linha standard, formulada em três diferentes modos:

1) Com $1 \%$ de dispersante $49,0 \%$ de água (A1);

2) Com $0,1 \%$ de dispersante $49,9 \%$ de água (A2);

3) Sem dispersante e $50 \%$ de água (A3).

Todas as formulações seguiram a estrutura representada na Tabela 1. 
Tabela 1 - Composição da tinta acrílica fosca standard base A

\begin{tabular}{|c|c|}
\hline $\begin{array}{c}\text { Quantidade } \\
\text { Estabelecido (A1, A2, A3) }\end{array}$ & $\begin{array}{c}\text { Item } \\
\text { Água }\end{array}$ \\
\hline $8 \%$ & Dióxido de titânio \\
\hline $2 \%$ & Extensor \\
\hline $18 \%$ & Carbonato de Cálcio \\
\hline $4 \%$ & Diamatolito \\
\hline Estabelecido (A1, A2, A3) & Dispersante \\
\hline $0,2 \%$ & Carboximetilcelulose de sódio \\
\hline $0,9 \%$ & Solvente \\
\hline $0,9 \%$ & Polimetafosfato de sódio \\
\hline $0,1 \%$ & Fixador de cor \\
\hline $0,1 \%$ & Resinas \\
\hline $13 \%$ & Aditivos \\
\hline $0,8 \%$ & Regulador de pH \\
\hline $0,3 \%$ & Antiespumantes \\
\hline $0,2 \%$ & Biocidas \\
\hline $0,5 \%$ & Espessantes \\
\hline $1 \%$ & Total: $100 \%$ \\
\hline \multicolumn{2}{|c|}{} \\
\hline
\end{tabular}

Dispersante: poliacrilato de sódio (AQ 9921)®

As amostras foram preparadas em embalagens de 3,6 litros e as matérias-primas passaram por etapa de pré-mistura, dispersão, completagem, filtração e envase e foram processadas em misturadores Cowles com tempo de agitação determinado a partir da completa dispersão das partículas de matérias-primas no processo industrial. Os produtos foram submetidos a 24 horas de desaeração e em seguida realizou-se os testes com corpos-de-prova.

Os testes realizados estão citados a seguir:

pH, usando pHmetro digital de bancada, de marca Gehaka, modelo PG1800, calibrado com solução tampão de $\mathrm{pH} 4$ e $\mathrm{pH} 7$;

Consistência, através de viscosímetro do tipo Krebs-Stormer (Escala medida em KU);

\section{CONSISTÊNCIA}

Consistência, através de viscosímetro do tipo Krebs-Stormer (Escala medida em KU). Os testes de consistência foram realizados em escala laboratorial. Utilizou-se béquer de $100 \mathrm{~mL}$ para retirar corpos de prova e medir a temperatura, sendo necessária que a mesma fosse levada à temperatura ambiente. Foi utilizado o viscosímetro tipo Krebs-Stormer. Depois de homogeneizada, um béquer contendo a amostra foi colocado na plataforma do viscosímetro e a haste rotativa ficou totalmente submersa no produto. As polias utilizadas podem ser de 25, 50 ou 100 gramas. Com a ajuda de um cronômetro, mediu-se o tempo necessário para 100 revoluções da haste no produto, sendo a consistência resultante em Unidade Krebs (KU) (JOAQUIM JÚNIOR et al., 2007). Vista do viscosímetro é disponibilizada na Figura 1.

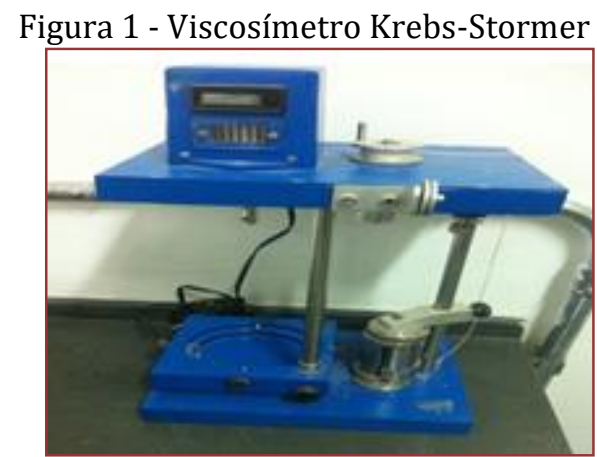




\section{DENSIDADE}

Densidade, $\rho$, usando picnômetro de alumínio de $100 \mathrm{~mL}$, modelo TKB E, e balança analítica de precisão, marca MARTE, modelo AD2000;

\subsection{PODER DE COBERTURA E BRILHO}

Poder de cobertura e brilho, realizados com a ajuda de um espectrofotômetro portátil, de marca BYKGardner, vidro e extensor metálico com diversas aberturas arredondadas;

Os ensaios foram realizados com a ajuda de um espectrofotômetro portátil, de marca BYK-Gardner, vidro e extensor metálico com diversas aberturas arredondadas. Foram realizados filmes de 150 micrometros e colocou-se o sensor do espectrofotômetro voltado para o filme de tinta. A luz refletida possui comprimento de onda entre 400 e $700 \mathrm{~nm}$. 0 teste é repetido cinco vezes e o resultado é em percentual, sendo $0 \%$ quando a tinta não realiza recobrimento do material até $100 \%$, indicando que o substrato foi revestido totalmente. Obtêm-se por média aritmética. A razão para tintas latéx precisam ser superiores a $55 \%$.

0 brilho é representado em UB, em escala de 0 a 1000, sendo 0 a ausência de brilho e 1000 o valor máximo refletido. É determinado por um medidor de brilho. 0 método consiste em determinar o brilho em diferentes ângulos de incidência de feixe de luz: 20, 60 e 85 (ver Figura 2), usando a mesma abertura fonte do equipamento, mas diferentes aberturas de receptor (DALTIN, 2010).

Figura 2 - Geometrias possíveis para teste de brilho

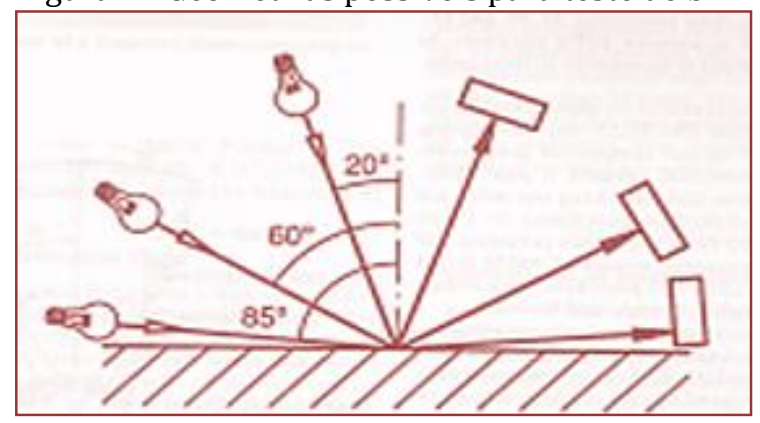

\subsection{ADERÊNCIA, DETERMINADO POR FORÇA MECÂNICA SOB UMA PELÍCULA DE TINTA EM PAPEL ZEBRADO}

Para exemplificar, as tintas imobiliárias látex econômicas, um ensaio consiste na Determinação da Resistência à Abrasão Úmida sem Pasta Abrasiva. Neste ensaio, o objetivo é verificar se a tinta possui resistência mínima capaz de suportar, sem dano aparente, as agressões que naturalmente ocorrem durante uma limpeza ou decorrentes de fatores externos, como água, umidade e poluição atmosférica. Produtos que não atendem aos requisitos mínimos da norma comprometem a durabilidade da pintura e falham potencialmente na proteção, favorecendo o destacamento de camadas de tinta e o aparecimento de fungos nocivos às edificações. Para simular esses efeitos, aplica-se uma demão de tinta em uma superfície, aguardando-se a secagem durante sete dias. Com o auxílio de um aparelho denominado máquina de lavabilidade - cuja função é esfregar com uma escova a superfície pintada - verifica-se quando ocorre o desgaste de $80 \%$ da área percorrida pela escova. Cada passagem de ida e volta da escova é chamada de ciclo, e o resultado é expresso em número de ciclos necessários para remover a película de tinta da superfície (BORGES et al., 2008).

0 teste de aderência é diretamente ligado à capacidade de resistência à corrosão de tintas e revestimentos. O objetivo é verificar se a tinta possui capacidade de suportar danos que possam ocorrer com o contato com água, umidade e poluição atmosférica. Neste ensaio, aplica-se uma força mecânica com uma espuma sob uma película de tinta com o tempo de cura de sete dias. Contam-se os ciclos utilizados e, quanto maior a quantidade de ciclos, melhor a aderência no substrato. Realiza-se a média de três realizações de testes. É estabelecido que a tinta supere acima de 40 ciclos até sua total remoção (FORINI, 2008). 
0 papel zebrado (ver Figura 3), tem a função de determinar a qualidade da tinta, sendo a parte escura o contraste e a parte clara a luminosidade. Quando a tinta possui pouco dióxido de titânio, possui uma cobertura menor, transparecendo a parte escura, sendo classificada em tipo C. Usando o papel zebrado que determina a quantidade de dióxido de titânio que se adiciona na tinta, de acordo com o que se pretende alcançar.

Figura 3 -Extensor de tintas - papel zebrado ATMA tintas e revestimentos

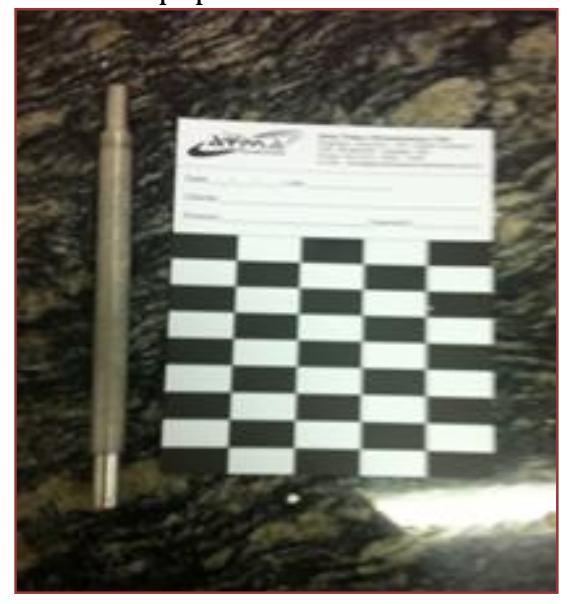

\subsection{QUANTIDADE DE SÓLIDOS}

Quantidade de sólidos em porcentagem mássica não volátil da tinta através da Equação (1), depois da secagem de $100 \mathrm{~g}$ da tinta em estufa a $100^{\circ} \mathrm{C}$ por 1 hora;

$$
\text { Porcentagem mássica }=\frac{\text { Massa da partículas secas }(g)}{\text { Massa da tinta líquida }(g)} * 100
$$

\subsection{VISCOSIDADE}

Viscosidade, em viscosímetro Copo Ford $\mathrm{N}^{\circ} 4$. A Figura 4, ilustra o equipamento com os orifícios ajustáveis na medida da viscosidade. A conversão de segundos para $\mathrm{mm}^{2} / \mathrm{s}$ ou Centistokes é dada pela expressão: $v=A \cdot t+B$, sendo que A e B são constantes do orifício.

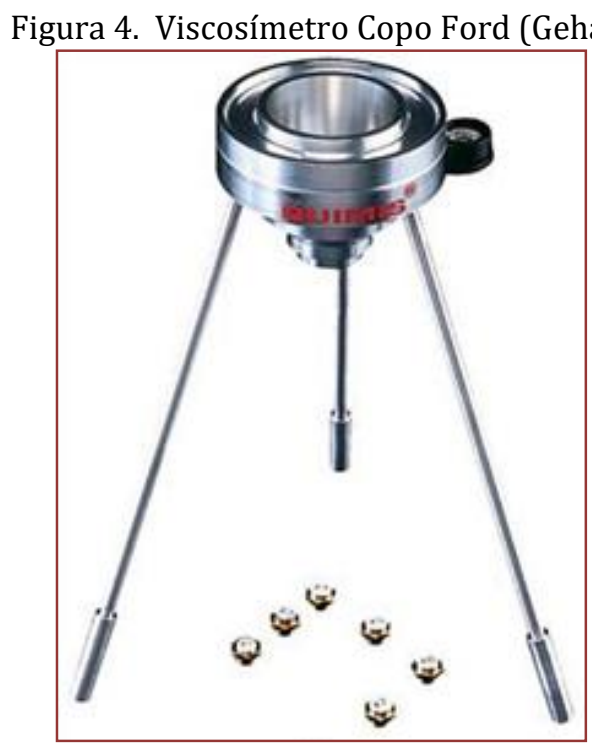




\section{RESULTADOS E DISCUSSÃO}

Conforme já descrito anteriormente, foram realizadas três amostras com diferentes quantidades de dispersantes acrílicos. Estes foram analisados e apresentaram os resultados descritos na Tabela 3.

Para tintas acrílicas, a consistência deve ser entre 82 a 90 KU. A variação da viscosidade se deve pela junção de espessantes de baixa e média capacidade, permitindo que as resinas, cargas e aditivos consigam interferir na viscosidade final do produto.

No estudo atual, verifica-se que a única amostra que está dentro dos padrões necessários é a A2, com 86 KU. A amostra A1, teve uma viscosidade menor, o que pode ser explicado pela alta dispersão das partículas, permitindo que houvesse grande poder de absorção de água e afastamento das moléculas. Já a amostra A3, apresentou $99 \mathrm{KU}$, um índice alto para tintas acrílicas foscas standard.

Tabela 3 - Resultados das análises realizadas nos testes A1, A2 e A3

\begin{tabular}{|c|c|c|c|}
\hline & $\mathrm{A} 1$ & $\mathrm{~A} 2$ & $\mathrm{~A} 3$ \\
\hline $\mathrm{pH}$ & 8,2 & 8,1 & 8,1 \\
\hline Consistência (KU) & 43 & 86 & 99 \\
\hline Massa específica (g/cm ${ }^{3}$ ) & 1,34 & 1,36 & 1,36 \\
\hline Poder de cobertura (\%) & 52,25 & 89,18 & 90,87 \\
\hline $\begin{array}{c}\text { Brilho (Unidades de brilho } \\
\text { UB) }\end{array}$ & 19,7 & 12,3 & 10,6 \\
\hline Aderência (ciclos) & 26 & 102 & 110 \\
\hline Tempo de agitação (minutos) & 38 & 40 & 90 \\
\hline $\begin{array}{c}\text { Sólidos em porcentagem } \\
\text { mássica (\%) }\end{array}$ & 42,1 & 46,8 & 68,2 \\
\hline Viscosidade (segundos) & 34 & 83 & 160 \\
\hline
\end{tabular}

Os fatores que afetam o poder de cobertura das tintas e revestimentos é um conjunto de variáveis que determinam a eficiência e qualidade dos produtos. Quanto maior a quantidade de dispersantes em uma formulação, menor é a influência das partículas de cargas e pigmentos que a mesma apresenta, influenciando a capacidade de dispersão de luz.

Quanto menor a partícula, menor sua capacidade de dispersão de luz. 0 teste que usou menor quantidade de dispersante obteve uma alta porcentagem de poder de cobertura, contudo houve aglomerados e as cargas não dispersaram no meio. A amostra com maior quantidade de dispersante teve um índice de refração e reflexão menor, apresentando baixa opacidade e poder de cobertura.

0 alto poder de cobertura do filme de tinta A3 relaciona-se com a espontaneidade dos flóculos que possuem um efeito óptico de aumentar o tamanho médio da partícula, diminuindo a eficiência de dispersão, mas auxiliando no aumento do poder de cobertura do substrato. 0 poder de cobertura de tintas acrílicas standard situa-se entre 85-89\%.

Já brilho é inversamente proporcional à cobertura do material. Tintas foscas possuem brilho abaixo de 20 UB. Todas as amostras apresentaram característica fosca.

A capacidade de aderência ao substrato de um filme de tinta pode ter algumas influências, como: quantidade de resíduo sólido, variação do $\mathrm{pH}$, aspecto do filme e tamanho das partículas.

A dispersão das tintas e revestimentos é de suma importância para definir se houve aglomerados de pequenos grumos ou ar excessivo no processo.

Se o teor de sólidos for abaixo do esperado, pode indicar uma polimerização deficiente. 0 pH é importante para a estabilidade do produto e o tamanho das partículas indica se houve dispersão das partículas de modo eficiente.

A aderência deve ser superior a 40 ciclos, estando apenas as amostras A2 e A3 dentro dos parâmetros estabelecidos. 0 teste A1, teve baixa quantidade de ciclos, o que se deve a falta de aderência, alta tensão superficial e baixa estabilidade das partículas. Avaliando com a indicação do INMETRO (2008), as amostras A2 e A3 são consideradas conforme.

O teor de sólidos em dispersões aquosas varia de 40-60\%. A amostra A3, se diferencia deste valor, apresentando $68,2 \%$ de sólidos em sua formulação. Isto pode ser entendido pela junção de aglomerados e 
falta de dispersão de cargas e pigmentos, ocorrendo sedimentação e/ou floculação, ocasionando um índice de teor de sólidos mais elevados provavelmente por encapsulamento de líquido.

Em relação a viscosidade, é possível observar na Figura 5, que a viscosidade pode ser lata, porém uma viscosidade muito alta ( $0 \%$ de dispersante) pode provocar problemas na aplicação do material, não sendo possível a homogeneização completa das matérias-primas, gerando alto tempo de secagem, deformação da película e pontos de aglomerados na superfície. Já em viscosidade baixa (1\% de dispersante), o produto escoa rapidamente, não formando camada homogênea e apresentando problemas de aplicação, respingamento, falta de cobertura e durabilidade.

A viscosidade influencia também na etapa de transporte e armazenamento do produto, podendo haver decantação e floculação de cargas, pigmentos e moléculas mais pesadas presentes no material de recobrimento.

A dispersão das partículas nas formulações A1, A2 e A3 contendo diferentes quantidades de dispersante acrílico apresentaram aderências diferentes, cujos resultados podem ser vistos na Figura 6.

A quantidade de dispersante correta na formulação é necessária para obter parâmetros reológicos essenciais para a liberação dos lotes de tintas. 0 papel fundamental dos dispersantes contempla a reologia das tintas, melhorando a dispersão e aperfeiçoando a produção, obtendo maior produtividade e diminuindo o tempo de agitação do material.

Figura 5 - Comparação da viscosidade dos testes A1, A2 e A3.

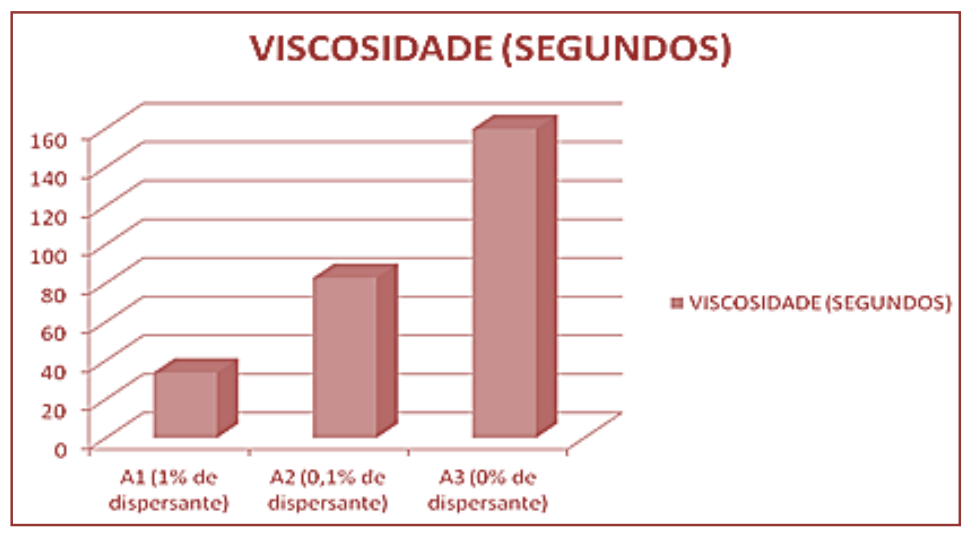

Os dispersantes acrílicos conferem viscosidades baixas e ótima estabilidade, possuindo excelente relação entre cargas e pigmentos. 0 tempo de agitação é diretamente proporcional ao aumento da viscosidade.

Figura 6 - Representação da tinta látex das formulações (a)A1, (b)A2 e (c)A3 em papel zebrado da empresa Atma tintas e revestimentos.

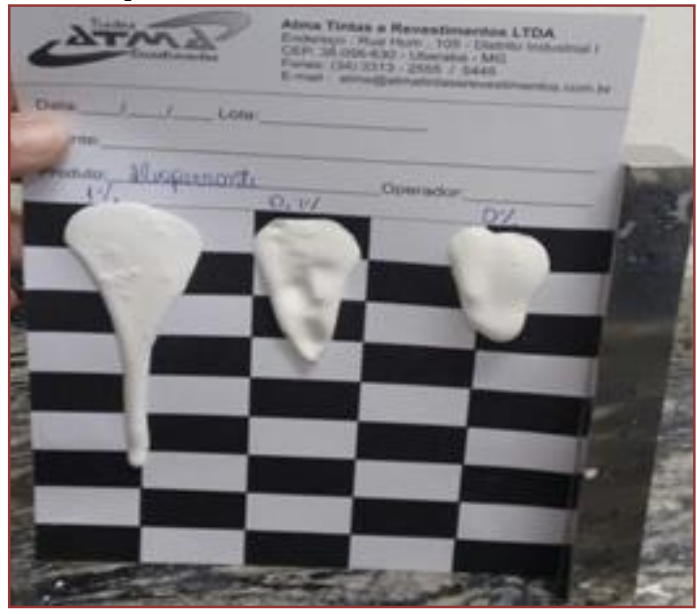




\section{CONCLUSÃO}

Verificou-se que as formulações devem seguir um padrão de $0,1 \%$ de dispersante, para que haja um maior controle do processo, evitando perda de tempo e desperdício de matéria-prima. A determinação da viscosidade dos materiais de recobrimento é uma ferramenta de controle de produção de suma importância em indústrias de tintas, revestimentos e vernizes, visando reduzir problemas durante o processo e na aplicação do material de recobrimento, oferecendo um produto de qualidade e dentro dos padrões definidos para cada tipo de produto. Neste estudo a melhor viscosidade das tintas foi do experimento A2, com viscosidade quantificada em 83 segundos (viscosímetro Copo Ford).

No controle de qualidade, a floculação e sedimentação de matérias-primas é um dos principais problemas da falta de dispersão de cargas e pigmentos, pois as diversas forças que atuam entre as partículas influenciam em todos os aspectos do filme de tinta, resultando em uma tinta de má qualidade e não resistente a fatores naturais. Neste estudo a menor floculação-sedimentação ocorreu com a amostra A2, sendo que na amostra A3, houve grande quantidade de floculados, pela difícil dispersão das partículas e grande formação de aglomerados.

A dispersão em A1, por ter baixa força de aderência e as moléculas estarem muito dispersas no meio, apresenta um maior escoamento e uma baixa viscosidade. A amostra A1 é insuficiente no processo, pois há maior gasto de energia, maior tempo de agitação, mais custo com matéria-prima e menor aderência ao substrato. Já no caso do teste A2, há força de aderência adequada e os constituintes dispersos no meio. É o melhor caso, pois não há viscosidade elevada e nem insuficiente no processo, havendo boa opacidade, apresentando aspecto fosco e eficiência na aderência para/com o substrato.

0 resultado do teste $\mathrm{A} 3$, mostrou que não houve quantidade ótima de dispersão das partículas, formando aglomerados e floculações no produto, interferindo no tempo de agitação, velocidade de rotação, viscosidade do produto e apresentou grande quantidade de sólidos em porcentagem mássica, provavelmente devido a encapsulamento de líquido, não sendo favorável para fabricação.

\section{AGRADECIMENTOS}

Os autores agradecem à ATMA Tintas e Revestimentos - Uberaba-MG; à Uniube- Universidade de Uberaba e à Fundação de Amparo a Pesquisa do Estado de Minas Gerais - FAPEMIG pelo apoio disponibilizado para realização desta publicação.

\section{REFERÊNCIAS}

[1] BASF, Literatura: Pigmentos BASF- Edição 1987.

[2] BORGES, M., MONTEIRO, L. C., LOBO, A. C. O. Programa de análise de produtos: relatório sobre análise em tintas imobiliárias látex econômicas. INMETRO. Rio de janeiro. 2008.

[3] CUNHA, A. O. 0 estudo da tinta/textura como revestimento externo em substrato de argamassa. 2011. $129 \mathrm{f}$. Monografia (Monografia do Curso de Especialização em Construção Civil), Escola de Engenharia, Universidade Federal de Minas Gerais, Belo Horizonte.

[4] DALTIN, D. Introdução à reologia. 2010. Apostila do curso de Química - Parte integrante do curso de processos químicos, Faculdade de São Bernardo, São Paulo.

[5] DONADIO, P. A., ABRAFATI. Manual básico sobre tintas. 2011.

[6] FORINI, S. H. Estudo da dispersão e incorporação de argilas esmecttitícas em plastisol. 2008. 127 p. Tese (Doutorado em Engenharia) - Departamento de Engenharia Metalúrgica e de Materiais, Escola Politécnica da Universidade de São Paulo, São Paulo.

[7] JOAQUIM JÚNIOR, Celso Fernandes. et al. Agitação e Mistura na Indústria. 1 a ed. Rio de Janeiro: LTC, 2007, $236 \mathrm{p}$.

[8] MATTOSO, L. H. C. - Química Nova. p. 388 (1996).

[9] POLITO, G. Principais sistemas de pinturas e suas patologias. 2006. 66f. Departamento de Engenharia de Materiais e Construção. Escola de Engenharia, Universidade Federal de Minas Gerais. Belo Horizonte.

[10] SPIRLANDELLI, G. S. Influência da viscosidade na dispersão de partículas de cargas e do pigmento dióxido de titânio em formulações de tintas. Trabalho de Final de Curso. Universidade de Uberaba, Engenharia Química, 2015. 53 p. 


\section{Capítulo 15}

Análise de desempenho do pré-tratamento do bagaço do abacaxi com peróxido de hidrogênio na obtenção de açúcares redutores totais para produção de bioetanol de segunda geração

Araceli Aparecida Seolatto

Lorena Costa Vasconcelos Macedo

Fernanda Ferreira Freitas

Mariana Bisinotto Pereira

Rodrigo Silva Fontoura

Danielle Pires Nogueira

Resumo: A fim de aproveitar os resíduos gerados pelas indústrias de polpa e suco de frutas, este trabalho teve por objetivo estudar a utilização da biomassa de abacaxi para a produção de bioetanol de segunda geração. Foram avaliadas as melhores condições de pré-tratamento da biomassa seca e triturada, utilizando o peróxido de hidrogênio. 0 estudo foi realizado por meio de um planejamento fatorial completo, analisando os fatores: concentração de peróxido, tempo e temperatura. Em seguida, foi realizada a hidrólise com ácido sulfúrico 2,9\% v/v, em todas as amostras e, por fim, a análise de determinação dos açúcares redutores totais (ART). Analisando os resultados, observouse que os fatores tempo e temperatura não apresentaram respostas significativamente diferentes no intervalo estudado. Por outro lado, a variação na concentração de peróxido de hidrogênio apresentou resultados diferentes significativamente, em que ao se utilizar concentrações menores obtiveram-se maiores valores de ART.

Palavras-chaves: pré-tratamento, bioetanol, açúcares redutores, bagaço 


\section{INTRODUÇÃO}

Dados da Empresa de Pesquisa Energética (EPE), 2014 revelaram que a participação de fontes renováveis na matriz energética brasileira manteve-se entre as mais elevadas do mundo, em 2013 e 2012 foram $41,0 \%$ e $42,3 \%$ respectivamente. Nesse contexto a biomassa da cana-de-açúcar contribui com 16,1\%, dos $41,0 \%$ em 2013.

Embora a biomassa da cana-de-açúcar ou mesmo o seu bagaço seja empregado veementemente na fabricação do bioetanol, seja ele de primeira ou segunda geração, há um alerta para que novas biomassas tão atrativas quanto à cana sejam descobertas, principalmente quando voltado para um aproveitamento de resíduos. Segundo a Agência Internacional de Energia (IEA), 2015 os incentivos econômicos são necessários em função do custo competitivo da produção de energia a partir de biomassa, justificado principalmente pela segurança energética e ambiental associados a uma bioenergia sustentável.

O bioetanol de segunda geração apresenta grande potencial de crescimento, não por apenas não depender da produção de alimentos para sua industrialização e nem tão pouco da expansão da área plantada, mas sim, do reaproveitamento dos resíduos da produção, logo a principal vantagem do bagaço está na logística, pois como se trata de um coproduto já se encontra disponível (ARAÚJO et al., 2013). Estes bagaços podem ser transformados não apenas em matérias-primas para processos secundários, como também se bem aproveitados, podem tornar produtos comerciais.

Os resíduos lignocelulósicos possuem em sua composição celulose e hemicelulose, estas estruturas após sofrem sacarificação podem ser convertidas a açúcares fermentescíveis, como glicose e ainda em xilose, provenientes da fração de celulose e hemicelulose respectivamente (BOUSSARSAR et al., 2009). No entanto, os materiais lignocelulósicos necessitam de pré-tratamentos para possibilitarem a eficácia da hidrólise.

Os principais objetivos do pré-tratamento são: reduzir o grau de cristalinidade da celulose, dissociar o complexo lignina-celulose, aumentar a área superficial da biomassa, preservar as pentoses maximizando os rendimentos em açúcares e evitar ou minimizar a formação de compostos inibidores do processo tanto na etapa de hidrólise quando na etapa de fermentação (SHEN et al., 2011).

0 peróxido de hidrogênio alcalino possui participação na redução cristalinilidade da celulose e com a ação oxidativa dos radicais derivados do peróxido, ocorre elevada despolimerização e solubilização da lignina (KARAGÖZ et al., 2012).

$\mathrm{Na}$ hidrólise ácida podem ser utilizados ácidos concentrados ou diluídos. 0 ácido mais utilizado é o sulfúrico, contudo outros ácidos como o clorídrico, fosfórico e nítrico vêm sendo estudados (MENON e RAO, 2012).

Sendo assim, este trabalho teve por objetivo a análise do desempenho do pré-tratamento com peróxido de hidrogênio no bagaço de abacaxi. Foram avaliados as variáveis: tempo (h), temperatura $\left({ }^{\circ} \mathrm{C}\right)$ e concentração de peróxido de hidrogênio alcalino (\%) do pré-tratamento submetidas a hidrólise ácida diluída, visando a maior obtenção de ART.

\section{MATERIAIS E MÉTODOS}

\subsection{PREPARO DA BIOMASSA}

O bagaço de abacaxi foi fornecido pela indústria Doce Vida, localizada em Anápolis, Goiás. Antes de serem estocados, foi seco em estufa a $60{ }^{\circ} \mathrm{C}$ por três dias, triturado e peneirado, selecionou-se as partículas em maior quantidade de diâmetro médio de 1,242 mm, denominado de bagaço de 20 mesh, armazenado em recipientes hermeticamente fechados.

\subsection{PRÉ-TRATAMENTO COM PERÓXIDO DE HIDROGÊNIO ALCALINO}

Amostras de $4 \mathrm{~g}$ da biomassa seca em base seca foram tratadas com $100 \mathrm{~mL}$ de solução de peróxido de hidrogênio $\left(\mathrm{H}_{2} \mathrm{O}_{2}\right)$, tendo seu $\mathrm{pH}$ ajustado para 11,5 pela adição de hidróxido de sódio $(20 \mathrm{~mol} / \mathrm{L}), \mathrm{de}$ acordo com a metodologia descrita por Krishna (2000). A temperatura, o tempo de reação e a concentração do peróxido de hidrogênio foram estabelecidos pelo planejamento experimental (Delineamento Composto Central Rotacional - DCCR). Em seguida foram levados a um agitador orbital tipo shaker sob agitação de $150 \mathrm{rpm}$. Após o tempo reacional, filtrou e lavou a solução várias vezes com água destilada, a fim de obter um $\mathrm{pH}$ neutro no resíduo. 


\subsection{HIDRÓLISE ÁCIDA}

Após o pré-tratamento o filtrado foi recolhido e seco a $40^{\circ} \mathrm{C}$ até peso constante, posteriormente a hidrólise ácida foi realizada para cada experimento, transferiu-se os sólidos para erlenmeyer de $125 \mathrm{~mL}$ e tratandoos com $25 \mathrm{~mL}$ de ácido sulfúrico $\left(\mathrm{H}_{2} \mathrm{SO}_{4}\right)$ 2,9\% m/v. Posteriormente os frascos de erlenmeyers foram fechados com folha alumínio e autoclavados por $30 \mathrm{~min}$ a $121^{\circ} \mathrm{C}$ (MOUTTA et al., 2011). Após a descompressão da autoclave, os frascos foram retirados e resfriados à temperatura ambiente, sendo a fração sólida separada da fração líquida por filtração a vácuo. 0 hidrolisado de todas as amostras foram neutralizados com hidróxido de sódio e quantificados os açúcares redutores totais.

\subsection{QUANTIFICAÇÃO DOS AÇÚCARES REDUTORES TOTAIS (ART)}

Para a quantificação dos ART utilizou-se o método do ácido dinitro-3,5-salicílico (DNS) descrito por Miller (1959). Para isso, foi necessário construir uma curva-padrão de glicose com concentrações variando de 0 a $10 \mathrm{mg} / \mathrm{mL}$. Sempre que necessário, foram efetuadas diluições das amostras de modo que a absorbância resultante estivesse contida no intervalo da curva-padrão.

\subsection{PLANEJAMENTO EXPERIMENTAL}

Empregou-se um planejamento fatorial $2^{3}$ com três pontos centrais e seis axiais, totalizando 17 experimentos e 34 respostas. A Tabela 1 apresenta os fatores e os níveis escolhidos para o pré-tratamento com o peróxido de hidrogênio alcalino.

Tabela 1. Fatores e níveis reais para o pré-tratamento com peróxido de hidrogênio alcalino.

\begin{tabular}{|c|c|c|c|}
\hline Experimento & Tempo (h) & $\begin{array}{c}\text { Temperatura } \\
\left({ }^{\circ} \mathrm{C}\right)\end{array}$ & $\begin{array}{c}\text { Concentração de } \\
\mathrm{H}_{2} \mathrm{O}_{2}(\% \mathrm{v} / \mathrm{v})\end{array}$ \\
\hline 1 & 8 & 20 & 2 \\
\hline 2 & 8 & 20 & 6 \\
\hline 3 & 8 & 50 & 2 \\
\hline 4 & 8 & 50 & 6 \\
\hline 5 & 24 & 20 & 2 \\
\hline 6 & 24 & 20 & 6 \\
\hline 7 & 24 & 50 & 2 \\
\hline 8 & 24 & 50 & 6 \\
\hline 9 & 2,545 & 35 & 4 \\
\hline 10 & 29,454 & 35 & 4 \\
\hline 11 & 16 & 9,773 & 4 \\
\hline 12 & 16 & 60.227 & 4 \\
\hline 13 & 16 & 35 & 0,636 \\
\hline 14 & 16 & 35 & 7,363 \\
\hline 15 & 16 & 35 & 4 \\
\hline 16 & 16 & 35 & 4 \\
\hline 17 & 16 & 35 & 4 \\
\hline
\end{tabular}


A partir desse planejamento fatorial, estudaram-se as variáveis que afetam a eficiência do pré-tratamento com peróxido de hidrogênio alcalino. A unidade de medida da resposta foi escolhida em g de ART/g de bagaço cru (sem nenhum tratamento) para que se possa comparar o rendimento em massa do processo com a massa do bagaço antes de qualquer tratamento.

\section{RESULTADOS E DISCUSSÃO}

A Tabela 2 apresenta a matriz do planejamento, com os valores reais, e as respostas de quantidade de ART, produzida após a hidrólise ácida, de cada experimento.

Tabela 2. Matriz do planejamento fatorial e respostas de quantidade de açúcares redutores totais para o pré-tratamento com peróxido de hidrogênio alcalino no bagaço do abacaxi.

\begin{tabular}{|c|c|c|c|c|}
\hline Experimento & $t(h)$ & $\mathrm{T}\left({ }^{\circ} \mathrm{C}\right)$ & $\mathrm{C}(\% \mathrm{v} / \mathrm{v})$ & $\begin{array}{c}\text { ART média (g/g } \\
\text { bagaço) }\end{array}$ \\
\hline 1 & 8 & 20 & 2 & 0.0929 \\
\hline 2 & 8 & 20 & 6 & 0.0510 \\
\hline 3 & 8 & 50 & 2 & 0.0779 \\
\hline 4 & 8 & 50 & 6 & 0.0452 \\
\hline 5 & 24 & 20 & 2 & 0.105 \\
\hline 6 & 24 & 20 & 6 & 0.0480 \\
\hline 7 & 24 & 50 & 2 & 0.0709 \\
\hline 8 & 24 & 50 & 6 & 0.0393 \\
\hline 9 & 2.545 & 35 & 4 & 0.0510 \\
\hline 10 & 29.454 & 35 & 4 & 0.0545 \\
\hline 11 & 16 & 9.773 & 4 & 0.0733 \\
\hline 12 & 16 & 60.227 & 4 & 0.0702 \\
\hline 13 & 16 & 35 & 0.636 & 0.0833 \\
\hline 14 & 16 & 35 & 7.363 & 0.0449 \\
\hline 15 & 16 & 35 & 4 & 0.0717 \\
\hline 16 & 16 & 35 & 4 & 0.0674 \\
\hline 17 & 16 & 35 & 4 & 0.0680 \\
\hline
\end{tabular}

Analisando a Tabela 2, nos ensaios 1, 3, 5, 7 e 13 observa-se que a maior produção de açúcares redutores ocorreu em baixas concentrações de peróxido, configurando um bom resultado em função da economia de reagente.

Verifica-se que a variável tempo não possui efeito significativo na resposta, observados pelos ensaios 9 e 10 ou seja, as melhores respostas ocorrem em toda a faixa de tempo estudada. Sendo assim, o tempo ideal adotado para este pré-tratamento poderá ser de menores valores. Isso pode ser justificado, pois a reação com peróxido de hidrogênio ocorre em um tempo curto e cessa, não havendo alteração após esse período. Karagöz et al. (2012) e Rabelo (2007), também verificaram que a variável tempo não foi significativa para o pré-tratamento com o peróxido de hidrogênio alcalino, para a palha de arroz e o bagaço da cana, respectivamente. 
Observando a variável temperatura nota-se que a maior produção de ART ocorre nas menores temperaturas estudadas, sendo assim, verifica-se que se pode conduzir o pré-tratamento em temperaturas ambientes sem que haja interferência no rendimento da hidrólise ácida, o que poderá, por conseguinte gerar economia no processo.

A variável concentração de peróxido possui melhores respostas nas menores faixas estudadas. Uma possível explicação poderia ser que o excesso de peróxido degrade a celulose presente na biomassa. Notase que os melhores resultados foram nos experimentos 1 e 5, onde obteve-se massas de ART de 0,0929 $\mathrm{g} / \mathrm{g}$ de bagaço cru e 0,105 g/g de bagaço cru, respectivamente. Como as respostas foram semelhantes, optou-se por definir o experimento 1 como melhor, por utilizar menor tempo, consequentemente menor gasto energético. As piores respostas foram obtidas nos experimentos 8 e 14 onde se utilizam maiores concentração de peróxido de hidrogênio e maiores temperaturas.

Com isto, verifica-se que os melhores resultados estão nas menores faixas estudadas das variáveis temperatura e concentração (experimento 1), sendo este tratamento adequado por apresentar grande economia de energia e reagente.

\section{CONCLUSÃO}

Como resultado verificou-se que a máxima liberação de açúcares redutores totais pode ser obtida a $20^{\circ} \mathrm{C}$, com concentração de $\mathrm{H}_{2} \mathrm{O}_{2}$ de $2 \%$ por $6 \mathrm{~h}$ em pH 11,5. Portanto, o tempo do pré-tratamento de peróxido de hidrogênio alcalino não se mostrou significativo na faixa estudada. Entretanto, novos estudos deverão ser realizados a fim de se incluir um ponto de maior obtenção de ART neste planejamento.

\section{REFERÊNCIAS}

[1] ARAÚJO, DE G.J.F., NAVARRO, L. F.S, SANTOS, B. A. S., O Etanol de Segunda Geração e sua Importância Estratégica ante o Cenário Energético Internacional Contemporâneo. ANAP. IX Fórum Ambiental da Alta Paulista, 2013.

[2] BOUSSARSAR, H.; ROGÉ B.; MATHLOUTHI, M. Optimization of sugarcane bagasse conversion by hydrothermal. Bioresource Technology, v. 24, p. 6537-6542, 2009.

[3] EPE, Empresa de Pesquisa Energética. Balanço Energético Nacional, MME. BEN 2014/ Relatório Síntese/ Ano base 2013/Rio de Janeiro, maio 2014.

[4] IEA, Internacional Energy Agency. Renewables (Agência Internacional de Energia). 2015. Disponível em: http://www.iea.org/topics/renewables/. Acesso em 24/02/2015.

[5] KARAGÖZ, P.; ROCHA, I. V.; ÖZKAN, M.; ANGELIDAKI, I. Alkaline peroxide pretreatment of rapeseed straw for enhancing bioethanol production by Same Vessel Saccharification and Co-Fermentation. Bioresource Technology., v.104, p. 348-357, 2012.

[6] KRISHNA S. H.; RAO, K. C. S.; BABU, J. S.; REDDY, D. S. Studies on the production and application of cellulose from Trichoderma reesei QM-9414. Bioprocess Engineering, v. 22, p. 467-470, 2000.

[7] MENON, V. e RAO, M. Trends in bioconversion of lignocelluloses: Biofuels, platform chemicals \& biorefinery concept. Progr. Energy Combust. Sci. v. 38, p. 522-550, 2012.

[8] MILLER, G. L. Use of Dinitrosalicylic Acid Reagent for Determination of Reducing Sugar. Analytical Chemistry, 31(3):426-428, 1959.

[9] MOUTTA, R.O.; CHANDEL, A.K.; RODRIGUES,R.C.L.B.; SILVA, M.B.; ROCHA, G.J.M.; SILVA, S.S. Statistical optimization of sugarcane leaves hydrolysis into simple sugars by dilute sulfuric acid catalyzed process. Sugar tech., v. 14, p. 53-60, 2011.

[10] RABELO, S. Avaliação de desempenho do pré-tratamento com peróxido de hidrogênio alcalino para a hidrolise enzimática de bagaço de cana-de-açúcar. 180f. (Dissertação de Mestrado) São Paulo: Escola Engenharia Química. Universidade Estadual de Campinas (UNICAMP), SP. 2007.

[11] SHEN, F.; SADDLER, J. N.; LIU, R.; LIN, L.; DENG, S.; ZHANG, Y.; YANG, G.; XIAO,H.; LI, Y. Evaluation of steam pretreatment on sweet sorghum bagasse for enzymatic hydrolysis and bioethanol production. Carbohydrate Polymers, v. 86, n. 4, p. 1542-1548, 2011. 


\section{Capítulo 16}

Estudo do potencial teórico de geração de biogás para o Aterro Sanitário em Campina Grande - PB

\section{Maria Josicleide Felipe Guedes}

Francisco Gleson dos Santos Moreira

Kellianny Oliveira Aires

Rosires Catão Curi

Veruschka Escarião Dessoles Monteiro

Resumo: 0 objetivo deste trabalho foi simular o potencial de geração de biogás para o Aterro Sanitário em Campina Grande-PB, constituindo-se em um indicativo inicial para projetos futuros de aproveitamento energético do gás metano ( $\mathrm{CH} 4)$. A simulação foi realizada por meio do software Biogás, desenvolvido pela CETESB. Foram delimitados três cenários, denominados de otimista, moderado e pessimista, de acordo com a eficiência da coleta e queima do biogás. Verificou-se, pelos cenários simulados, que há um potencial teórico favorável à geração de CH4 no aterro, o que se constitui em um indicativo inicial para a elaboração de projeto de uma usina de aproveitamento energético, mesmo para o cenário pessimista, no qual a geração de energia elétrica ao final da vida útil do aterro seria suficiente para atender o consumo de 7.200 habitações, com média mensal de $200 \mathrm{KWh}$.

Palavras-Chave: energia renovável; aterro sanitário; metano. 


\section{INTRODUÇÃO}

A biodegradação anaeróbia da fração orgânica dos Resíduos Sólidos Urbanos (RSU) em aterros sanitários resulta na formação de subprodutos, dentre estes o biogás, formado principalmente por $\mathrm{CH}_{4}$ (metano) e $\mathrm{CO}_{2}$ (dióxido de carbono). Mesmo quando estes resíduos são tratados de maneira ambientalmente adequada, em aterros, muitas vezes o biogás gerado é simplesmente canalizado e queimado. Essa queima é possível devido às ligações químicas existentes entre os átomos de hidrogênio e carbono do $\mathrm{CH}_{4}$, que ao reagir com o oxigênio, libera uma grande quantidade de calor, na forma de energia térmica; podendo ser aproveitada como uma fonte adicional de energia (ICLEI-BRASIL, 2009).

Nesse contexto, a problemática que permeia este estudo relaciona-se ao desperdício do potencial energético proveniente da degradação anaeróbia da fração orgânica dos resíduos, que compreende um percentual de 46,5\% dos RSU para o município de Campina Grande, na Paraíba (ARAÚJO NETO, 2016), favorável à geração de biogás. Sendo assim, o objetivo deste trabalho foi simular o potencial de geração de biogás para o Aterro Sanitário em Campina Grande-PB, constituindo-se em um indicativo inicial para projetos futuros de aproveitamento energético do $\mathrm{CH}_{4}$.

\section{METODOLOGIA}

A área de estudo compreendeu o Aterro Sanitário em Campina Grande (ASCG), na Paraíba. Esse aterro ocupa uma área total de 64 ha, sendo 40 ha destinados à disposição de RSU, e recebia, no ano de 2017, resíduos provenientes dos municípios de Campina Grande, Puxinanã, Montadas, Boa Vista e Lagoa Seca, além de Resíduos da Construção Civil (RCC) coletados por empresas especializadas. Sendo assim, o ASCG atendia uma população de 461.387 habitantes, resultando no aterramento de 500 t.d $^{-1}$ de RSU, aproximadamente (ECOSOLO, 2016; IBGE, 2017).

Desde o início da operação do ASCG, em julho de 2015, foram encerradas 3 células de resíduos, de 22 previstas no projeto, com área de base de $100 \times 100 \mathrm{~m}$ e altura em torno de $20 \mathrm{~m}$, escalonadas em platôs de $5 \mathrm{~m}$ de altura, com bermas de $6 \mathrm{~m}$ de comprimento; perfazendo uma massa de resíduos aterrados de 259.753,98 t, em 17 meses de operação do aterro (ECOSOLO, 2016). Cada célula é composta por 9 drenos de gases.

A simulação do potencial de geração de biogás no ASCG foi realizada por meio do software Biogás, versão 1.0, desenvolvido pela CETESB (2006), o qual se baseia em um modelo de primeira ordem, isto é, considera a hipótese de que a formação de biogás a partir de um determinado montante de resíduos decai exponencialmente com o tempo. Para a estimativa da vazão de metano pelo software Biogás, em $\mathrm{m}^{3} \mathrm{CH}_{4}$.ano-1 , tem-se como principais parâmetros de entrada: i) a constante de decaimento (k), em ano-1; ii) o potencial de geração de biogás $\left(\mathrm{L}_{0}\right), \mathrm{em} \mathrm{m}^{3} \cdot \mathrm{kg}^{-1}$; iii) o fluxo de resíduos $(\mathrm{Rx})$, em t. ano-1; iv) ano de início e provável fechamento do aterro. Como não se dispunha do fluxo de resíduos no aterro ao longo do tempo, visto que o ASCG possui pouco mais de um ano de operação, esse foi estimado a partir de dados populacionais, envolvendo: a taxa de crescimento populacional, em \%; população atual, em hab.; taxa de geração de resíduos, em t.hab.ano-1; taxa de coleta de resíduos, em \%.

Foram delimitados três cenários, denominados de otimista, moderado e pessimista, de acordo com a eficiência da coleta e queima do biogás. No cenário otimista, foi considerada a eficiência da coleta e queima de biogás de 75 e 95\%, respectivamente; sendo estes valores sugeridos pela CETESB (2006). Para os cenários moderado e pessimista, esses percentuais foram reduzidos para 60 e $80 \%$ e 45 e $65 \%$, respectivamente. Para cada cenário, foram realizadas duas simulações, designadas de (A), para os parâmetros Lo e k sugeridos pela USEPA (2001) e (B) para os parâmetros sugeridos pela CETESB (2006); totalizando seis simulações (1-A e 1-B, 2-A e 2-B, 3-A e 3-B).

Os valores dos parâmetros Lo e $\mathrm{k}$ sugeridos pela USEPA (2001) são de $0,100 \mathrm{~m}^{3} \cdot \mathrm{kg}^{-1}$ e $0,04 \mathrm{ano}^{-1}$, respectivamente, e de $0,120 \mathrm{~m}^{3} \cdot \mathrm{kg}^{-1}$ e 0,08 ano-1 $^{-1}$ pela CETESB (2006). Para todas as simulações, foram adicionados os seguintes parâmetros (Tabela 1): i) ano de início e fechamento das atividades no aterro, 2015 e 2040, respectivamente, para uma vida útil de 25 anos; ii) taxa de crescimento populacional de 0,81\% (ECOSAM, 2014); iii) população de 461.387 hab., envolvendo os municípios que dispõem seus resíduos no ASCG; iv) taxa de geração de resíduos de 0,388 t.hab.ano-1 ${ }^{-1}$ determinado por meio do fluxo de resíduos conhecido para o ano de 2016 no ASCG (ECOSOLO, 2016); v) taxa de coleta de resíduos, de 95\% (SNIS, 2013). 
Tabela 1. Resumo dos dados de entrada utilizados no software Biogás da CETESB (2006).

\begin{tabular}{|l|c|}
\hline \multicolumn{1}{|c|}{ Aspectos relevantes } & $\begin{array}{c}\text { Dados de } \\
\text { entrada }\end{array}$ \\
\hline Área total das células de disposição (ha) & 40 \\
\hline Ano de início de atividade do aterro & 2015 \\
\hline Ano de fechamento do aterro & 2040 \\
\hline Quantidade total de drenos & 198 \\
\hline Taxa de crescimento da população ${ }^{1}(\%)$ & 0,81 \\
\hline População em 2016² (hab.) & 461.387 \\
\hline $\begin{array}{l}\text { Taxa de geração de resíduos } \\
\text { (t/hab.ano) }\end{array}$ & 0,388 \\
\hline Taxa de coleta de resíduos ${ }^{4}(\%)$ & 95 \\
\hline
\end{tabular}

1Plano Municipal de Gestão Integrada de Resíduos Sólidos do Município de Campina Grande-PB (ECOSAM, 2014), obtido por meio de dados censitários de 2000 e 2010 para o município de Campina Grande. Foi considerada essa taxa de crescimento em virtude do município de Campina Grande representar aproximadamente 90\% dos resíduos dispostos no ASCG; ${ }^{2}$ considerando os municípios de Campina Grande (407.754 habitantes), Puxinanã (13.638 habitantes), Boa Vista (6.986 habitantes), Montadas (5.611 habitantes) e Lagoa Seca (27.398 habitantes); ${ }^{3}$ determinado por meio do fluxo de resíduos no aterro para o ano de 2016, que foi de aproximadamente 179 mil toneladas de resíduos (ECOSOLO, 2016); ${ }^{4}$ SNIS (2013).

\section{RESULTADOS E DISCUSSÃO}

Para todos os cenários simulados, a vazão máxima de $\mathrm{CH}_{4}$ ocorrerá em 2040, ao final da vida útil do ASCG; período no qual se encerrará o incremento de resíduos, com previsão de 4.821.631,538 t de RSU depositados.

No cenário otimista a vazão máxima de $\mathrm{CH}_{4}$ seria de $9.337 \times 10^{3}$ e $15.715 \times 10^{3} \mathrm{~m}^{3}$.ano-1, respectivamente, para a simulação 1-A (USEPA, 2001) e 1-B (CETESB, 2006) (Figura 1a); e volume acumulado de $284.716 \times 10^{3}$ e $425.981 \times 10^{3} \mathrm{~m}^{3}$. Considerando o total de resíduos acumulados até o final do ano de 2017 no ASCG, com previsão de 500.000 t; este montante seria compatível com um projeto de uma usina de biogás com potência instalada de 1,6 e 3,8 MW. A potência máxima instalada, em 2040, atingirá um patamar de 10,5 e 17,7 MW (1-A e 1-B, nesta ordem), de acordo com o observado na Figura $1 \mathrm{~b}$.

Figura 1. Simulação para o cenário otimista: (a) vazão coletada de metano; (b) potência instalada.
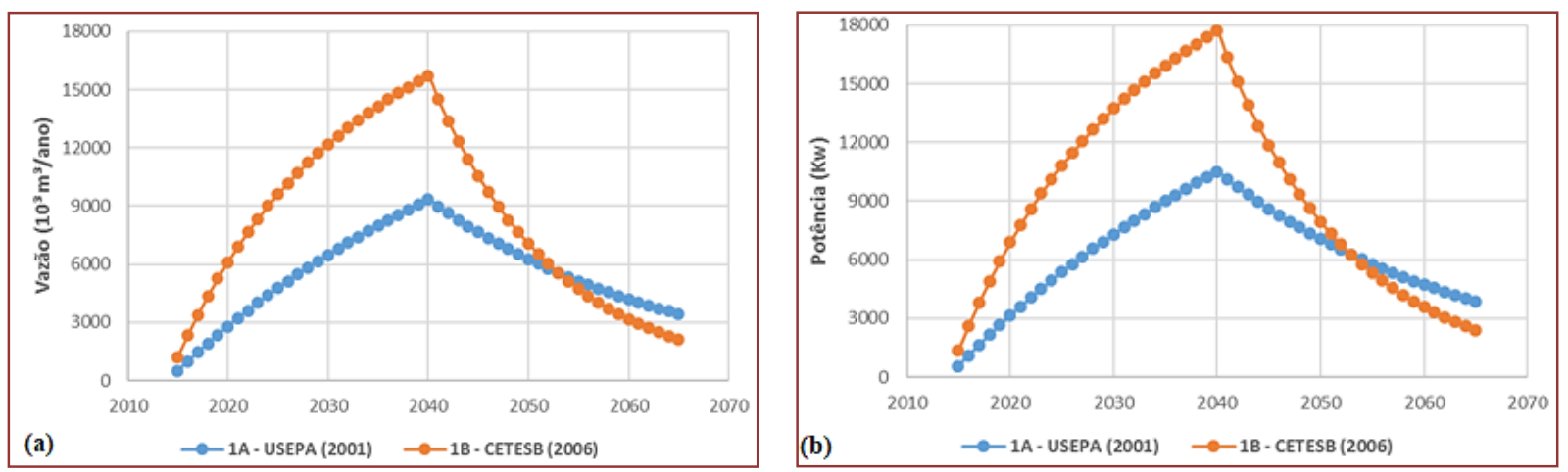

No cenário moderado, a vazão máxima de $\mathrm{CH}_{4}$, em 2040 , seria de $7.470 \times 10^{3}$ e $12.572 \times 10^{3} \mathrm{~m}^{3}$.ano-1 (Figura 2a); com volume acumulado de $227.776 \times 10^{3}$ e $340.784 \times 10^{3} \mathrm{~m}^{3}$. Já a potência instalada, prevista no final do ano de 2017, seria de 1,3 e 3,0 MW; e a potência máxima instalada, em 2040, atingirá valores em torno de 8,4 e 14,2 MW (simulações 2-A e 2-B, respectivamente), como ilustrado na Figura $2 \mathrm{~b}$. 
Figura 2. Simulação para o cenário moderado: (a) vazão coletada de metano; (b) potência instalada.
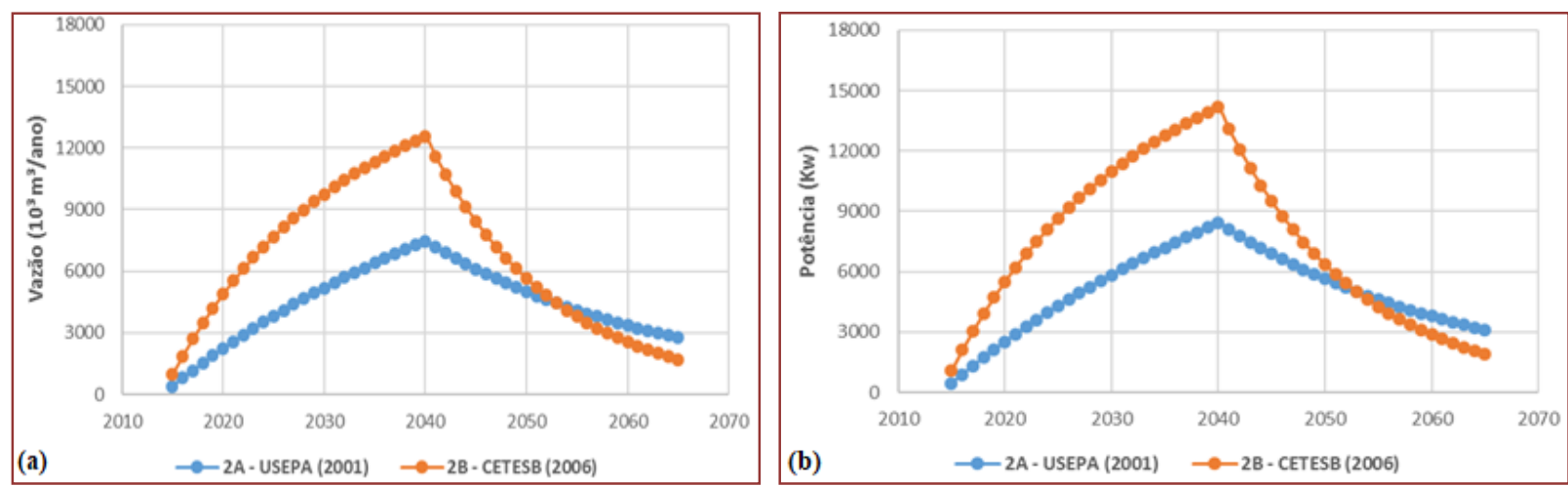

Já no cenário pessimista, são previstos valores para a vazão máxima de $\mathrm{CH}_{4}$, em 2040 , de $5.602 \times 10^{3}$ e $9.429 \times 10^{3} \mathrm{~m}^{3}$.ano ${ }^{-1}$ (Figura 3a); com volume acumulado de $170.833 \times 10^{3}$ e $255.591 \times 10^{3} \mathrm{~m}^{3}$. Para este cenário, a potência disponível ao término de 2017 seria de 1,0 e 2,3 MW e a potência máxima instalada, em 2040, será de 6,3 e 10,6 MW (simulações 3-A e 3-B, respectivamente), conforme apresentado na Figura 3b.

Figura 3. Simulação para o Cenário Pessimista: (a) vazão coletada de metano; (b) potência instalada.
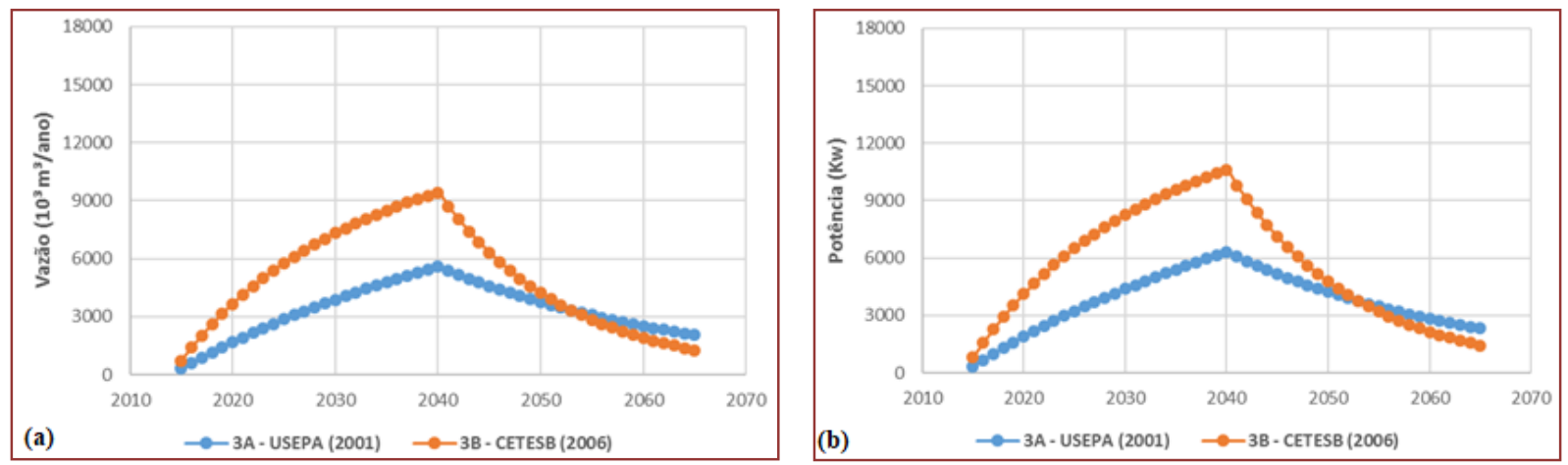

Os resultados obtidos para os três cenários simulados indicam uma geração de resíduos, ao final da vida útil do ASCG, suficiente para a implantação de uma matriz de aproveitamento energético do biogás no aterro, mesmo em uma condição mais desfavorável, simulada no cenário pessimista.

No entanto, os resultados obtidos para a vazão máxima de metano (Tabela 2), nas simulações com os valores de Lo e $\mathrm{k}$ sugeridos pela CETESB (2006), foram aproximadamente $40 \%$ superiores aqueles especificados pela USEPA (2001), para os três cenários estudados. Essas discrepâncias denotam a importância de determinar esses parâmetros levando em consideração às características locais dos resíduos em estudo; tendo-se, desta forma, uma estimativa mais realista para o ASCG.

Tabela 2. Resumo dos valores de vazão e potência máxima calculados para cada cenário.

\begin{tabular}{|c|c|c|c|c|c|c|c|}
\hline \multirow[b]{2}{*}{ Cenários } & \multicolumn{3}{|c|}{ Parâmetros } & \multirow{2}{*}{$\begin{array}{c}\text { Eficiên- } \\
\text { cia da } \\
\text { coleta de } \\
\text { biogás } \\
(\%)\end{array}$} & \multirow{2}{*}{$\begin{array}{c}\text { Eficiên-cia } \\
\text { da queima } \\
\text { de biogás } \\
(\%)\end{array}$} & \multirow{2}{*}{$\begin{array}{c}\text { Vazão } \\
\text { máxima } \\
\left(10^{3} \mathrm{~m}^{3} \mathrm{CH} \mathrm{H}^{4} \cdot \mathrm{a}\right. \\
\left.\mathrm{no}^{-1}\right)\end{array}$} & \multirow{2}{*}{$\begin{array}{l}\text { Potência } \\
\text { máxima } \\
\text { (KW) }\end{array}$} \\
\hline & Referência/Valor & $\mathrm{L}_{0}\left(\mathrm{~m}^{3} \cdot \mathrm{t}^{-1}\right)$ & $\begin{array}{c}\mathrm{K}\left(\text { ano }^{-}\right. \\
\text {1) }\end{array}$ & & & & \\
\hline \multirow{2}{*}{ Otimista $^{1}$} & USEPA $(2001)^{4}$ & 100 & 0,04 & 75 & 95 & 9.337 & 10.520 \\
\hline & CETESB $(2006)^{5}$ & 120 & 0,08 & 75 & 95 & 15.715 & 17.706 \\
\hline \multirow{2}{*}{ Moderado ${ }^{2}$} & 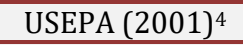 & 100 & 0,04 & 60 & 80 & 7.470 & 8.416 \\
\hline & CETESB $(2006)^{5}$ & 120 & 0,08 & 60 & 80 & 12.572 & 14.165 \\
\hline \multirow{2}{*}{ Pessimista $^{3}$} & 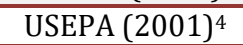 & 100 & 0,04 & 45 & 65 & 5.602 & 6.312 \\
\hline & CETESB $(2006)^{5}$ & 120 & 0,08 & 45 & 65 & 9.429 & 10.623 \\
\hline
\end{tabular}

${ }^{1}$ Eficiência de coleta e queima de biogás sugeridos no software da CETESB (2006); 2,3redução da eficiência de coleta e queima de biogás sugeridos no software da CETESB (2006); ${ }^{4}$ valores inventário/convencional; ${ }^{5}$ valores sugeridos no software da CETESB (2006). 
Pinãs et al. (2016) utilizaram o software da CETESB (2006) para estimar a geração de biogás em um aterro sanitário (com vida útil prevista para 20 anos), no município de Três Corações-MG, cuja população urbana em 2015 de 69.618 hab. (aproximadamente sete vezes menor que a do presente estudo). Os dados apresentados por esses autores mostram que a geração de $\mathrm{CH}_{4}$ atinge valores em torno de $24.000 .000 \mathrm{~m}^{3}$, até o encerramento do aterro, previsto para 2035.

\section{CONSIDERAÇÕES FINAIS}

Mediante os resultados obtidos para os cenários simulados, há um potencial teórico favorável à geração de metano no ASCG, o que se constitui em um indicativo inicial para a elaboração de projeto de uma usina de aproveitamento energético. Esta assertiva é evidenciada uma vez que mesmo no cenário pessimista, a geração de energia, ao final da vida útil do aterro, resultaria numa potência disponível de 6,3 MW. Nesse caso, utilizando-se um motor de combustão interna a pistão, por exemplo, o qual tem eficiência de conversão elétrica de 33\%, haveria uma potência de aproximadamente 2,0 MW; suficiente para atender o consumo de energia de 7.200 habitações, com média mensal de $200 \mathrm{KWh}$.

\section{REFERÊNCIAS}

[1] ECOSOLO - Gestão Ambiental de Resíduos LTDA, por meio do convênio No 001/2015 celebrado com a UFCG/PaqTcPB, para o Monitoramento Geoambiental do ASCG-PB.

[2] ARAÚJO NETO, C. L. Análise do comportamento dos resíduos sólidos urbanos e desenvolvimento de modelos estatísticos para previsão das deformações de aterros sanitários. 2016. Dissertação (Mestrado em Engenharia Civil e Ambiental), Universidade Federal de Campina Grande, Campina Grande, 2016.

[3] CETESB - Companhia Ambiental do Estado de São Paulo. Biogás: geração e uso energético: Aterro, versão 1.0. São Paulo, 2006. Disponível em: <http://biogas.cetesb.sp.gov.br/softwares/>. Acesso em: fevereiro 2017.

[4] ECOSAM - Consultoria em Saneamento Ambiental Ltda. Plano Municipal de Gestão Integrada de Resíduos Sólidos do Município de Campina Grande-PB. ECOSAM: João Pessoa, 2014.

[5] ECOSOLO - Gestão Ambiental de Resíduos Ltda. Dados do monitoramento do Aterro Sanitário de Campina Grande. 2016. (Documento impresso).

[6] IBGE - Instituto Brasileiro de Geografia e Estatística. Cidades. 2017. Disponível em: < http://cidades.ibge.gov.br/xtras/uf.php?lang=\&coduf=25\&search=paraiba>. Acesso: fev 2017.

[7] ICLE-BRASIL - Governos Locais pela Sustentabilidade. Manual para aproveitamento do biogás. V. 1 - Aterros sanitários. Secretariado para América Latina e Caribe. São Paulo. 2009.

[8] PIÑAS, J. A. V.; VENTURINI, O. J.; LORA, E. E. S.; OLIVEIRA, M. A.; ROALCABA, O. D. C. Aterros sanitários para geração de energia elétrica a partir da produção de biogás no Brasil: comparação dos modelos LandGEM (EPA) e Biogás (Cetesb). Revista Brasileira de Estudos de População, Rio de Janeiro, v. 33, n. 1, p. 175-188, jan./abr. 2016.

[9] SNIS - Sistema Nacional de Informações sobre Saneamento. Séries Históricas: Municípios. 2013. Disponível em:< http://www.cidades.gov.br/serieHistorica/\#>. Acesso em: dez de 2016.

[10] USEPA - United States Environmental Protection Agency. Landfills. V. III. Eastern Research Group: 2001. 


\section{Capítulo 17}

Modelagem termoquímica da reforma do $\mathrm{CO}_{2}$ para a produção de hidrogênio em um reformador termoquímico solar: Um estudo computacional

Vitória da Fonseca Dias

Jornandes Dias da Silva

Resumo: 0 desempenho da transferência de calor, transferência de massa e armazenamento termoquímico da reforma do $\mathrm{CO}_{2}$ movido à energia solar são investigados numericamente ao longo do comprimento do reator em alta temperatura. Um modelo matemático pseudo-homogêneo é desenvolvido para simular os processos de transferência de calor e massa acoplados à cinética de reação termoquímica em um reator termoquímico solar com perda de calor por radiação. Assim, o perfil de temperatura na superfície da fase sólida e o perfil de temperatura na fase gasosa são obtidos. Além disso, as conversões de reagentes de $\mathrm{CH}_{4}$ e $\mathrm{CO}_{2}$ são estudadas em diferentes temperaturas de operação. Por outro lado, o FTA de $\mathrm{H}_{2}$ e Q Chem também são avaliados na temperatura de operação. 


\section{INTRODUÇÃO}

A energia renovável em todo o mundo é amplamente dominada pela queima de combustíveis fósseis, o que leva às emissões de $\mathrm{CO}_{2}$ na atmosfera e é conhecido por contribuir para o aquecimento global indesejado. As questões de esgotamento de combustíveis fósseis e mudanças climáticas resultaram no desenvolvimento de soluções de processos industriais solares. Os processos de reforma que utilizam o calor solar para conduzir reações químicas endotérmicas de alta temperatura são conhecidos como processos termoquímicos solares. A reforma termoquímica solar é baseada no uso de energia solar concentrada como fonte de aquecimento de alta temperatura para conduzir uma transformação química endotérmica (Matienzo, 2018).

A tecnologia de reforma solar pode ser usada para produzir energias renováveis (como a produção de hidrogênio solar) a partir de sistemas de reação termoquímica solar (RTS). Na verdade, o hidrogênio $\left(\mathrm{H}_{2}\right)$ tem uma longa tradição como transportador de energia e como importante matéria-prima nas indústrias, petroquímicas, químicas e refinarias (Cruz e Silva, 2017, Silva e Abreu, 2016). Teoricamente, todo o $\mathrm{H}_{2}$ produzido hoje é proveniente de combustíveis fósseis, usando a reforma a vapor do metano $\left(\mathrm{CH}_{4}\right)$ como processo principal.

A reforma do dióxido de carbono $\left(\mathrm{CO}_{2}\right)$ movida à energia solar (RDCMES) pode ser considerada como um processo promissor para a produção de $\mathrm{H}_{2}$ solar. 0 processo da RDCMES é baseado na utilização da irradiação solar concentrada (ISC) como fonte de energia para manter a alta temperatura de operação. Neste contexto, foi definido o conceito de reator termoquímico solar (RTS) para estudar o processo da RDCMES (Jin et al. 2018). O RTS é um dispositivo importante e valioso para intensificação de processos, onde muitas aplicações podem ser realizadas em alta temperatura operacional.

Neste trabalho, um modelo matemático foi desenvolvido para investigar os fenômenos de transferência de calor e massa acoplados à cinética de reação termoquímica no RTS. O desempenho da RTS usando o processo da RDCMES é investigado numericamente em termos de perfis de temperatura nas fases gasosa e sólida. Além disso, a produção de $\mathrm{H}_{2}$ no RTS foi analisada.

\section{MODELAGEM TERMOQUÍMICA SOLAR}

\subsection{DESCRIÇÃO DO PROBLEMA}

Nas últimas duas décadas, as pesquisas comprovaram o uso eficiente da energia solar térmica para transformar as reações de reforma altamente endotérmicas. Para esse fim, uma configuração esquemática (Figura 1) foi construída para estudar o processo da RDCMES no RTS.

Figura 1: Configuração esquemática do RTS.

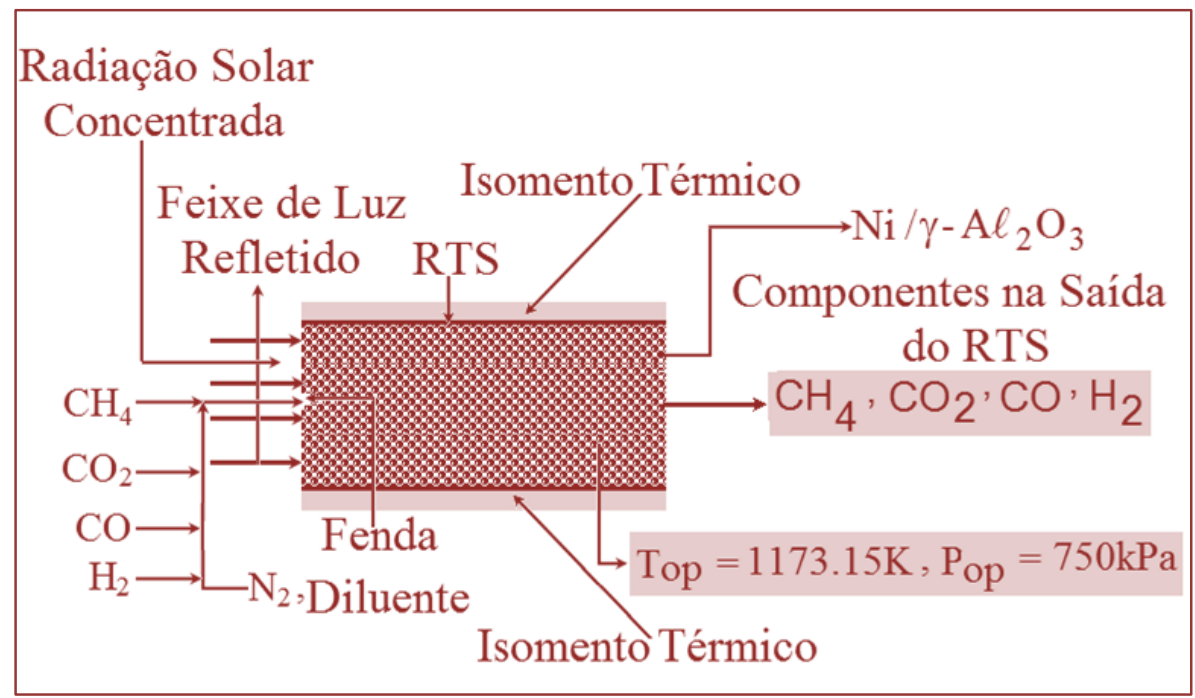




\subsection{MECANISMO CINÉTICO}

Neste estudo, a reação do processo da RDCMES foi considerada como segue.

$$
\mathrm{CH}_{4}+\mathrm{CO}_{2} \rightarrow \mathrm{CO}+3 \mathrm{H}_{2} ; \Delta \mathrm{H}_{298 \mathrm{~K}}^{0}=206.11 \mathrm{~kJ} / \mathrm{mol}(1)
$$

Os componentes dessas reações são definidos como $\mathrm{CH}_{4}$, dióxido de carbono $\left(\mathrm{CO}_{2}\right)$, carbono e monóxido (CO) e $\mathrm{H}_{2}$.

\subsection{MODELO CINÉTICO}

A taxa global da Equação 1 é definida da seguinte forma.

$$
R_{I}=\frac{k_{1} \mathrm{~K}_{\mathrm{CH}_{4}} \mathrm{~K}_{\mathrm{CO}_{2}} P_{\mathrm{CH}_{4}} P_{\mathrm{CO}_{2}}}{\left(1+\mathrm{K}_{\mathrm{CH}_{4}} P_{\mathrm{CH}_{4}}+K_{\mathrm{CO}_{2}} P_{\mathrm{CO}_{2}}\right)^{2}}
$$

Na Equação 2, R1 (kmol/kgcat.h) é a taxa cinética da reação 1; k1 (kmol /kgcat.h) é a constante de velocidade cinética da reação do processo da RDCMES, $\mathrm{K}_{\mathrm{CO} 2}\left(\mathrm{kPa}^{-1}\right)$ é a constante de equilíbrio de adsorção do $\mathrm{CO}_{2}$ na superfície da fase solida, $\mathrm{K}_{\mathrm{CH} 4}\left(\mathrm{kPa}^{-1}\right)$ é a constante de equilíbrio de adsorção do $\mathrm{CH}_{4}$ na superfície da fase solida, $\mathrm{P}_{\mathrm{CH} 4}(\mathrm{kPa})$ é a pressão parcial do $\mathrm{CH}_{4}, \mathrm{P}_{\mathrm{CO} 2}(\mathrm{kPa})$ é a pressão parcial do $\mathrm{CO}_{2}$,respectivamente.

As taxas líquidas de cada componente químico $\left(\mathrm{r}_{\mathrm{i}}, \mathrm{i}=\mathrm{CH}_{4}, \mathrm{CO}_{2}, \mathrm{CO}\right.$ e $\left.\mathrm{H}_{2}\right)$ são apresentadas na Tabela 1 abaixo.

Tabela 2: Taxas líquidas dos componentes i da Equação 1.

\begin{tabular}{|c|c|}
\hline Componentes & Eqs. das Taxas Líquidas \\
\hline $\mathrm{CH}_{4}$ & $r_{\mathrm{CH}_{4}}=-\eta_{1} R_{S D R M}$ \\
\hline $\mathrm{CO}_{2}$ & $r_{\mathrm{CO}_{2}}=-\eta_{1} R_{S D R M}$ \\
\hline $\mathrm{CO}$ & $r_{\mathrm{CO}}=+\eta_{1} R_{S D R M}$ \\
\hline $\mathrm{H}_{2}$ & $r_{\mathrm{H}_{2}}=+\eta_{1} R_{S D R M}$ \\
\hline
\end{tabular}

\subsection{EQUAÇÕES DO MODELO NO RTS}

Uma equação dinâmica é desenvolvida para descrever a temperatura da fase gasosa no RTS. 0 balanço energético da temperatura na fase gasosa dentro RTS é construído da seguinte maneira.

- Balanço de energia na fase gasosa;

$$
\begin{aligned}
& \sum_{i=1}^{4} \rho_{g, i} C_{p, g, i}\left(\frac{\partial T_{g}}{\partial t}+\frac{4 q_{g}}{\pi d_{\mu}^{2}} \frac{\partial T_{g}}{\partial z}\right)=\lambda_{g, e f f} \frac{\partial^{2} T_{g}}{\partial z^{2}} \\
& -h_{g s} \frac{\left(1-\varepsilon_{b}\right)}{\varepsilon_{b}} \frac{6}{d_{p}}\left(T_{g}-T_{s}\right) ; 0 \leq z \leq L_{z}, t>0
\end{aligned}
$$


Na Equação 3, $\rho_{\mathrm{g}, \mathrm{i}}\left(\mathrm{kg} / \mathrm{m}^{3}\right)$ é densidade da mistura gasosa, Cp,g,i $(\mathrm{kJ} / \mathrm{kg} \mathrm{K})$ é a capacidade de calor molar a pressão constante da mistura gasosa, $\operatorname{Tg}(\mathrm{K})$ é a temperatura do gás, $\mathrm{q}_{\mathrm{g}}\left(\mathrm{m}^{3} / \mathrm{s}\right)$ é a vazão da mistura gasosa, $\mathrm{d}_{\mu}(\mathrm{m})$ é o diâmetro do RTS, z (m) é a direção axial, respectivamente; $\lambda \mathrm{g}$,eff $(\mathrm{W} / \mathrm{m} \mathrm{K})$ é a condutividade térmica efetiva da fase gasosa, $\mathrm{h}_{\mathrm{gs}}\left(\mathrm{W} / \mathrm{m}^{2} \mathrm{~K}\right)$ é o coeficiente de transferência de calor gás-sólido, $\varepsilon \mathrm{b}\left(\mathrm{m}^{3} \mathrm{de}\right.$ gas $/ \mathrm{m}^{3}$ de micro-empacotado), dp $(\mathrm{m})$ é o diâmetro das partículas sólidas, Ts $(\mathrm{K})$ é a temperatura sólida, respectivamente.

As condições iniciais e de contorno adequadas da Equação 3 são dados como segue.

$$
\begin{aligned}
& \left.T_{g}\right|_{t=0,0 \leq z \leq L_{z}}=0 \\
& \left.\frac{\partial T_{g}}{\partial z}\right|_{z=0^{+}, t \geq 0}=\frac{\sum_{i=1}^{4} \rho_{g, i} C_{p, g, i}}{\lambda_{g, e f f}} \frac{4 q_{g}}{\pi d_{\mu}^{2}}\left(\left.T_{g}\right|_{z=0^{+}, t \geq 0}-T_{g, 0}\right) \\
& \left.\frac{\partial T_{g}}{\partial z}\right|_{z=L_{z}, t \geq 0}=0
\end{aligned}
$$

0 leito micro-empacotado reativo consiste em uma estrutura de rede de partículas com porosidade tipicamente de cerca de 40-60\%. 0 armazenamento térmico ocorre nas partículas sólidas para garantir energia suficiente para processar as reações endotérmicas do processo da RDCMES. Na presença da radiação, a equação do balanço de energia para a temperatura na superfície da fase sólida é apresentada a seguir.

\section{- Balanço de energia na superfície da fase sólida;}

$$
\begin{aligned}
& \rho_{s} C_{p, s} \frac{\partial T_{s}}{\partial t}=\left(\lambda_{s}\left(T_{g}\right)+\frac{16 n^{2} \sigma T_{\infty}^{3}}{3 k_{R}}\right) \frac{\partial^{2} T_{s}}{\partial z^{2}}+\rho_{s} \\
& \frac{\left(1-\varepsilon_{p}\right)}{\varepsilon_{p}} \Delta H_{1} \eta_{1} R_{1}+h_{g s} \frac{6}{d_{p}} \frac{\left(1-\varepsilon_{b}\right)}{\varepsilon_{b}}\left(T_{g}-T_{s}\right) \\
& -\varepsilon_{w} A_{c s} \sigma\left(T_{s}^{4}-T_{\infty}^{4}\right) ; 0 \leq z \leq L_{z}, t>0
\end{aligned}
$$

Na Eq. (7), $\rho s\left(\mathrm{~kg} / \mathrm{m}^{3}\right)$ é a densidade da fase sólida, $\mathrm{C}_{\mathrm{p}, \mathrm{s}}(\mathrm{kJ} / \mathrm{kg} \mathrm{K})$ é a capacidade térmica à pressão constante da fase sólida, $\lambda_{\mathrm{s}}(\mathrm{W} / \mathrm{m} \mathrm{K})$ é a condutividade térmica da fase sólida, qirrad. $\left(\mathrm{W} / \mathrm{m}^{2}\right)$ é o fluxo de calor irradiante, $\varepsilon_{\mathrm{p}}\left(\mathrm{m}^{3}\right.$ gas $/ \mathrm{m}^{3}$ reactor) é a fração de vazio na fase sólida, $\Delta \mathrm{H}_{\mathrm{j}}(\mathrm{kJ} / \mathrm{kmol})$ é o calor da reação, $\eta_{j}(-)$ é o fator de efetividade da reação, $\mathrm{Rj}\left(\mathrm{kmol} / \mathrm{kg}_{\text {cat. }} \mathrm{min}\right)$ é a taxa global da reação , $\varepsilon_{\mathrm{w}}(-)$ é a emissividade da parede, $A_{c s}\left(\mathrm{~m}^{2}\right)$ é a área da seção transversal, $\sigma\left(\mathrm{W} / \mathrm{m}^{2} \mathrm{~T}^{4}\right)$ é a Stefan- Constante de Boltzmann e $\mathrm{T}_{\infty}(\mathrm{K})$ é a temperatura ambiente, respectivamente. 
As condições iniciais e de contorno adequadas da Equação 7 são dados como se segue.

$$
\begin{aligned}
& \left.T_{s}\right|_{t=0,0 \leq z \leq L_{z}}=0 \\
& \left.\frac{\partial T_{s}}{\partial z}\right|_{z=0^{+}, t \geq 0}=\frac{D N I}{\lambda_{s}\left(T_{g, 0}\right)} \\
& \left.\frac{\partial T_{s}}{\partial z}\right|_{z=L_{z}, t \geq 0}=0
\end{aligned}
$$

As equações de balanço de massa são apresentadas para cada componente i $\left(\mathrm{i}=\mathrm{CH}_{4}, \mathrm{CO}_{2}\right.$, $\mathrm{CO}$ e $\mathrm{H}_{2}$ ) no RTS. Um modelo pseudo-homogêneo é desenvolvido para relatar detalhadamente cada componente químico i. Neste modelo, assume-se que as propriedades do gás e o fluxo na seção transversal da entrada do reator são uniformes. Assim, a equação de balanço de massa de cada componente químico i no RTS é dada como segue.

$$
\begin{gathered}
\varepsilon_{b} \frac{\partial C_{i}}{\partial t}+\frac{4 q_{g}}{\pi d_{\mu}^{2}} \frac{\partial C_{i}}{\partial z}=\varepsilon_{b} D_{a x, i} \frac{\partial^{2} C_{i}}{\partial z^{2}}+\rho_{s} \eta_{1} \sum_{i=1}^{4} r_{i} ; \\
0 \leq z \leq L_{z}, t>0
\end{gathered}
$$

Na Equação 11, $\mathrm{C}_{\mathrm{i}}\left(\mathrm{mol} / \mathrm{m}^{3}\right)$ é a concentração dos componentes i na superfície das partículas de catalisador, $D_{\mathrm{ax},}$ i $\left(\mathrm{m}^{2} / \mathrm{min}\right)$ é o coeficiente de dispersão de massa axial dos componentes $\mathrm{i}, \mathrm{r}_{\mathrm{i}}$

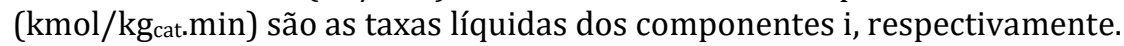

As condições iniciais e de contorno adequadas da Equação 11 são dados como segue.

$$
\begin{aligned}
& \left.C_{i}\right|_{t=0,0 \leq z \leq L_{z}}=0 \\
& \left.D_{a x, i} \frac{\partial C_{i}}{\partial z}\right|_{z=0^{+}, t \geq 0}=\frac{4 q_{g}}{\pi d_{\mu}^{2}}\left(\left.C_{i}\right|_{z=0^{+}, t \geq 0}-C_{i, i n}\right) \\
& \left.\frac{\partial C_{i}}{\partial z}\right|_{z=L_{z}, t \geq 0}=0
\end{aligned}
$$

\subsection{SOLUÇÃO NUMÉRICA DO MODELO MATEMÁTICO}

A transformada de Laplace é usada para transformar as equações diferenciais parciais governantes em conjunto com suas condições de contorno para um sistema de equações ordinárias não lineares. No presente trabalho, o sistema das equações transformadas (Equações 2-14) em conjunto com as condições de contorno são discretizadas pelo método do volume finito (VF). Após a discretização das equações transformadas usando o método de VF, a transformação inversa de Laplace é aplicada. Verifica-se que a variação da etapa de integração tem influência desprezível nos resultados obtidos deste trabalho. Portanto, uma etapa de integração de $10^{-6}$ foi usada para atingir todos os resultados simulados neste artigo. 


\section{RESULTADO E DISCUSSÃO}

O sistema de armazenamento de energia termoquímico solar utiliza energia solar concentrada para gerar alta temperatura e depois converte energia solar em energia química. Um modelo matemático tem sido usado para investigar o desempenho do RTS usando a energia solar para produzir gás de síntese $\left(\mathrm{H}_{2}\right.$ e $\left.\mathrm{CO}\right)$ a partir da reação de reforma Equação 1. Esta conversão termoquímica faz com que seja possível obter a conversão do $\mathrm{CH}_{4}$ e $\mathrm{CO}_{2}$.

\subsection{PARÂMETROS DO MODELO PARA AS SIMULAÇÕES}

Nesta seção, um modelo completo é desenvolvido para simular os processos de transferência de calor e massa juntamente com a cinética de reação termoquímica no RTS. Um algoritmo computacional utilizando o FORTRAN 95 foi elaborado pelos autores para resolver as equações do modelo mencionadas neste trabalho. Os valores dos parâmetros usados para alimentar o algoritmo computacional são mostrados na Tabela 2.

Tabela 2: Parâmetros Iniciais usados para alimentar o código computacional.

\begin{tabular}{|c|c|c|}
\hline Parâmetros & Valores & Referências \\
\hline $\mathrm{K}_{1}$ (kmol/ kg cat. seg.) & $5,775 \times 10^{5}$ & Chein et al., (2017) \\
\hline $\mathrm{K}_{\mathrm{CH} 4}\left(\mathrm{kPa}^{-1}\right)$ & $2,4317 \times 10^{-6}$ & Chein et al., (2017) \\
\hline $\mathrm{K}_{\mathrm{CO2}}\left(\mathrm{kPa}^{-1}\right)$ & $3,9008 \times 10^{-5}$ & Chein et al., (2017) \\
\hline $\mathrm{P}_{\mathrm{CH} 4}(\mathrm{kPa})$ & 5,5664 & Cruz e Silva, (2017) \\
\hline $\mathrm{P}_{\mathrm{CO} 2}(\mathrm{kPa})$ & 4,8471 & Cruz e Silva, (2017) \\
\hline $\mathrm{T}_{\mathrm{g}, 0}(\mathrm{~K})$ & 300 & Estimado \\
\hline $\mathrm{T}_{\mathrm{s}, 0}(\mathrm{~K})$ & 2000 & Estimado \\
\hline $\mathrm{d} \mu(\mathrm{mm})$ & 2,00 & Estimado \\
\hline $\mathrm{d}_{\mathrm{p}}(\mathrm{mm})$ & 0,10 & Estimado \\
\hline $\mathrm{L}_{\mathrm{z}}(\mathrm{mm})$ & 20.00 & Estimado \\
\hline $\mathrm{qg}_{\mathrm{g}}\left(\mathrm{m}^{3} \mathrm{sec}^{-1}\right)$ & $(2,53-5,49) \times 10^{-6}$ & Estimado \\
\hline $\mathrm{P}_{\text {op. }}(\mathrm{kPa})$ & 650 & Estimado \\
\hline$\varepsilon_{b}\left(m^{3}\right.$ gas $/ m^{3}$ reator $)$ & 0,41 & Silva et al., (2019) \\
\hline$\lambda_{\text {g,eff. }}(\mathrm{W} / \mathrm{m} \mathrm{K})$ & 107,383 & Chen et al., (2018) \\
\hline$h_{g s}\left(W^{-2} K^{-1}\right)$ & 1,9561 & Chen et al., (2018) \\
\hline $\mathrm{C}_{\mathrm{p}, \mathrm{g}}\left(\mathrm{J} \mathrm{kg}^{-1} \mathrm{~K}^{-1}\right)$ & 35.00 & Chen et al., (2018) \\
\hline$\rho_{\mathrm{g}}\left(\mathrm{kg} \mathrm{m}^{-3}\right)$ & 0,3857 & Cruz e Silva, (2017) \\
\hline$\rho_{\mathrm{s}}\left(\mathrm{kg} \mathrm{m}^{-3}\right)$ & 3200 & Cruz e Silva, (2017) \\
\hline $\mathrm{C}_{\mathrm{p}, \mathrm{s}}\left(\mathrm{J} \mathrm{kg}^{-1} \mathrm{~K}^{-1}\right)$ & 336 & Silva e Abreu, (2016) \\
\hline$\lambda_{\mathrm{s},}\left(\mathrm{T}_{\mathrm{g}, 0}\right)(\mathrm{W} / \mathrm{m} \mathrm{K})$ & 126,115 & Chen et al., (2018) \\
\hline n (-) & 1,00 & Chen et al., (2018) \\
\hline$\sigma\left(\mathrm{W} \mathrm{m}^{-2} \mathrm{~T}^{-4}\right)$ & $2,67 \times 10^{-8}$ & Chen et al., (2018) \\
\hline $\mathrm{k}_{\mathrm{R}}\left(\mathrm{m}^{-1}\right)$ & $1,738 \times 10^{4}$ & Chen et al., (2018) \\
\hline$\varepsilon_{\mathrm{p}}\left(\mathrm{m}^{3}\right.$ gas $/ \mathrm{m}^{3}$ reator $)$ & 0.47 & Silva et al., (2019) \\
\hline$\left(\Delta \mathrm{H}_{1}\right)^{1}\left(\mathrm{~kJ} / \mathrm{kmol}^{-1}\right)$ & 293.872 & Cruz e Silva, (2017) \\
\hline$\eta_{1}(-)$ & 0.0219 & Cruz e Silva, (2017) \\
\hline
\end{tabular}


Tabela 2: Parâmetros Iniciais usados para alimentar o código computacional (Continuação)

\begin{tabular}{|c|c|c|}
\hline$\varepsilon_{W}(-)$ & 0.92 & Abdesslem et al., (2013) \\
\hline$A_{c s}\left(m^{2}\right)$ & 279 & Abdesslem et al., (2013) \\
\hline $\mathrm{T}_{\infty}(\mathrm{K})$ & 300 & Estimado \\
\hline $\mathrm{D}_{\mathrm{ax}, \mathrm{CH} 4}\left(\mathrm{~m}^{2} / \mathrm{seg}.\right)$ & $9.32 \times 10^{-6}$ & Cruz e Silva, (2017) \\
\hline $\mathrm{D}_{\mathrm{ax}, \mathrm{co2}}\left(\mathrm{m}^{2} / \mathrm{seg}.\right)$ & $4.95 \times 10^{-6}$ & Cruz e Silva, (2017) \\
\hline $\mathrm{D}_{\mathrm{ax}, \mathrm{co}}\left(\mathrm{m}^{2} / \mathrm{seg}.\right)$ & $1.13 \times 10^{-5}$ & Cruz e Silva, (2017) \\
\hline $\mathrm{D}_{\mathrm{ax}, \mathrm{H} 2}\left(\mathrm{~m}^{2} / \mathrm{seg}.\right)$ & $8.21 \times 10^{-6}$ & Cruz e Silva, (2017) \\
\hline $\mathrm{kg}$, CH4, eff. (m/ seg.) & 0.289 & Silva et al., (2019) \\
\hline 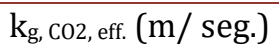 & 0.697 & Silva et al., (2019) \\
\hline $\mathrm{kg}, \mathrm{co}$, eff. (m/sec.) & 0.379 & Silva et al., (2019) \\
\hline $\mathrm{kg}_{\mathrm{g}, \mathrm{H} 2 \text {, eff. (m/ seg.) }}$ & 0.134 & Silva et al., (2019) \\
\hline $\mathrm{C}_{\infty}\left(\mathrm{kg} / \mathrm{m}^{3}\right)$ & 0.00 & Estimado \\
\hline
\end{tabular}

\subsection{PERFIS DE TEMPERATURA}

A Figura 2 relata o perfil de temperatura na superfície da fase sólida e o perfil de temperatura na fase gasosa ao longo do comprimento do RTS.

Figura 2: Perfil de temperatura na superfície da fase sólida e o perfil de temperatura na fase gasosa.

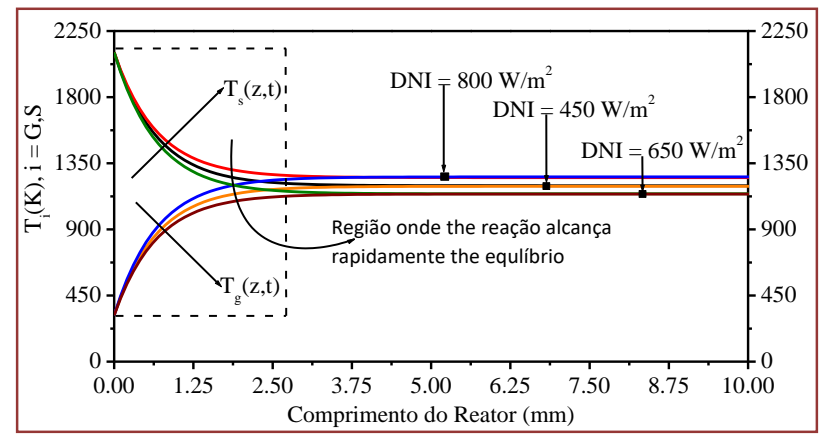

Como mostrado na Figura 2, o perfil de temperatura na superfície da fase sólida diminui de $2100 \mathrm{~K}$ para mais ou menos $1185 \mathrm{~K}$, enquanto o perfil de temperatura da fase gasosa aumenta de $300 \mathrm{~K}$ para mais ou menos $1185 \mathrm{~K}$. Os perfis de temperatura das fases sólida e gasosa atingem a mesma temperatura a mais ou menos 3,125 mm do comprimento do RTS. A partir de 3,125 mm, as temperaturas das duas fases de 1185 $\mathrm{K}$ foram mantidas constantes até o comprimento final da RTS.

\subsection{CONVERSÕES $\mathrm{CH}_{4} \mathrm{E} \mathrm{CO}_{2}$}

A Figura 3 apresenta o efeito da temperatura de operação sob a conversão total dos reagentes $\left(\mathrm{CH}_{4}\right.$ e $\left.\mathrm{CO}_{2}\right)$ na condição de operação de $650 \mathrm{kPa}$ com perda de calor por radiação. Além disso, os resultados da conversão global dos reagentes $\left(\mathrm{CH}_{4}\right.$ e $\left.\mathrm{CO}_{2}\right)$ foram calculados em cinco diferentes temperaturas de operação. Da Figura 3, a conversão global de $\mathrm{CH}_{4}$ é alcançada na superfície de saída do RTS com os valores de 0,6694 $(\mathrm{T}=925 \mathrm{~K}), 0,7701(\mathrm{~T}=1000 \mathrm{~K}), 0,8419(\mathrm{~T}=1075 \mathrm{~K}), 0,9216(\mathrm{~T}=1150 \mathrm{~K})$. $)$ e $0,9895(\mathrm{~T}=$ $1225 \mathrm{~K}$ ), respectivamente. Por outro lado, a conversão do $\mathrm{CO}_{2}$ é um pouco menor que a conversão de $\mathrm{CH}_{4}$ na superfície de saída do RTS, como mostrado na Figura 3, a conversão global de $\mathrm{CO}_{2}$ é atingido na superfície de saída com os valores de 0,4578 ( $\mathrm{T}=925 \mathrm{~K}), 0,5401(\mathrm{~T}=1000 \mathrm{~K}), 0,5813(\mathrm{~T}=1075 \mathrm{~K})$, $0,6897(\mathrm{~T}=1150 \mathrm{~K})$ e $0,7789(\mathrm{~T}=1225 \mathrm{~K})$, respectivamente. 
Figura 3: Conversões de $\mathrm{CH}_{4}$ e $\mathrm{CO}_{2}$ em diferentes temperaturas de operação no centro da superfície de saída da RTS.

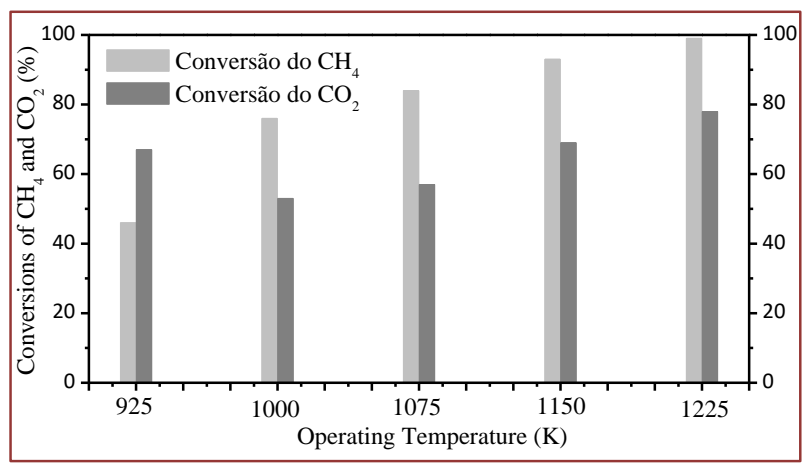

\subsection{TEMPERATURA DE OPERAÇÃO NO DFR E Q QHEM}

Um método adequado é usado para calcular a taxa de fluxo adimensional (TFA) do $\mathrm{H}_{2}$ em relação à concentração inicial de $\mathrm{CH}_{4}$ do processo de reforma. $\mathrm{O}$ efeito da temperatura de operação sob a TFA do $\mathrm{H}_{2}$, bem como a energia armazenada como energia química (Q $\mathrm{Q}_{\mathrm{chm}}$ ) é apresentada na Figura 4. À medida que a temperatura de operação é aumentada, os resultados simulados do TFA de $\mathrm{H}_{2}$ e Qchem são notavelmente aumentando. Como resultados, o TFA do $\mathrm{H}_{2}$ e Q operação de 1225K. Assim, o TFA do H2 e Qchem alcançou os valores máximos de 162,92 e 138,21 kJ/seg. na temperatura operação de $1225 \mathrm{~K}$, respectivamente.

Figura 4: Efeito da temperatura de operação sob a TFA e o Qchem.

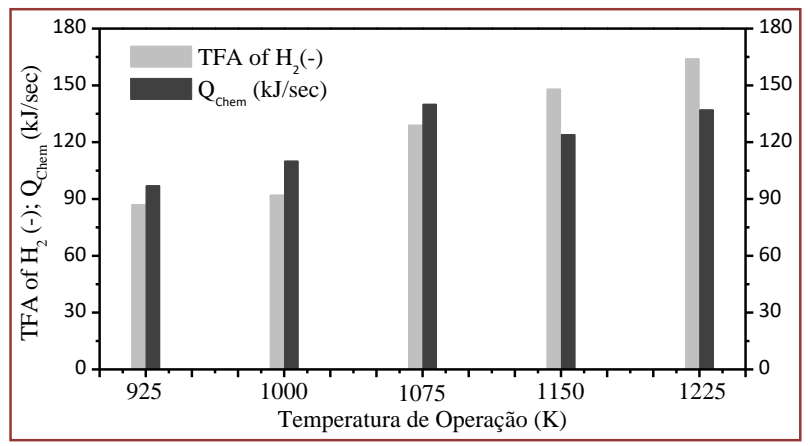

\section{CONCLUSÕES}

A transferência de calor e o desempenho termoquímico do processo dentro do RTS são investigados numericamente com perda de calor por radiação. Um código de computador para simular e analisar o desempenho das variáveis do processo termoquímico permitiu as seguintes conclusões:

1. Os perfis de temperatura na superfície da fase sólida e os perfis de temperatura da fase gasosa são fortemente afetados pelo DNI. Como resultados, a temperatura de reação na região da superfície de saída do RTS variou de $1021,26<\mathrm{T}_{\text {react. }}<1245,27 \mathrm{~K}$.

2. As conversões globais dos reagentes de $\mathrm{CH}_{4}$ e $\mathrm{CO}_{2}$ alcançaram os valores de 98,95\% e 77,89\%, respectivamente, na temperatura de operação de $1225 \mathrm{~K}$.

3. Os valores da TFA de H2 e Qchem atingiram seus valores máximos de 162,92 e 138,21 kJ/seg., respectivamente, na temperatura de operação de $1225 \mathrm{~K}$.

\section{AGRADECIMENTO}

Os autores deste trabalho gostariam de agradecer ao CNPq (Conselho Nacional de Desenvolvimento Científico e Tecnológico) pelo apoio financeiro concedido (Processo 48354/2012). 


\section{REFERÊNCIAS}

[1] ABDESSLEM J., KHALIFA S., ABDELAZIZ N. AND ABDALLAH M., (2013), "Radiative properties effects on unsteady natural convection inside a saturated porous medium. Application for porous heat exchangers", Energy Vol. 61, p. 224-233.

[2] CHEN X., WANG F., YAN X., HAN Y., CHEN Z. AND JIE Z., (2018), "Thermochemical performance of solar driven $\mathrm{CO}_{2}$ reforming of methane in volumetric reactor with gradual foam structure", Energy Vol. 151 , p. 545-555.

[3] CRUZ B. M, SILVA J. D. (2017), "A two-dimensional mathematical model for the catalytic steam reforming of methane in both conventional fixed-bed and fixed-bed membrane reactors for the Production of hydrogen", Int J of Hydrogen Energy Vol 42, p. 23670-23690

[4] Jin J, Wei X, Liu M, Yu Y, Li W, Kong H, Hao Y. (2018), "A solar methane reforming reactor design with enhanced efficiency" Applied Energy Vol 226,p. 797-807

[5] MATIENZO J. M. R. (2018), "Influence of addition of hydrogen produced on board in the performance of a stationary diesel engine" Int J of Hydrogen Energy Vol 43, p.17889-17897.

[6] Silva J. D, Abreu C. A. M. (2016), "Modelling and simulation in conventional fixed-bed and fixedbed membrane reactors for the steam reforming of methane" Int J of Hydrogen Energy Vol 41, p.1166011674. 


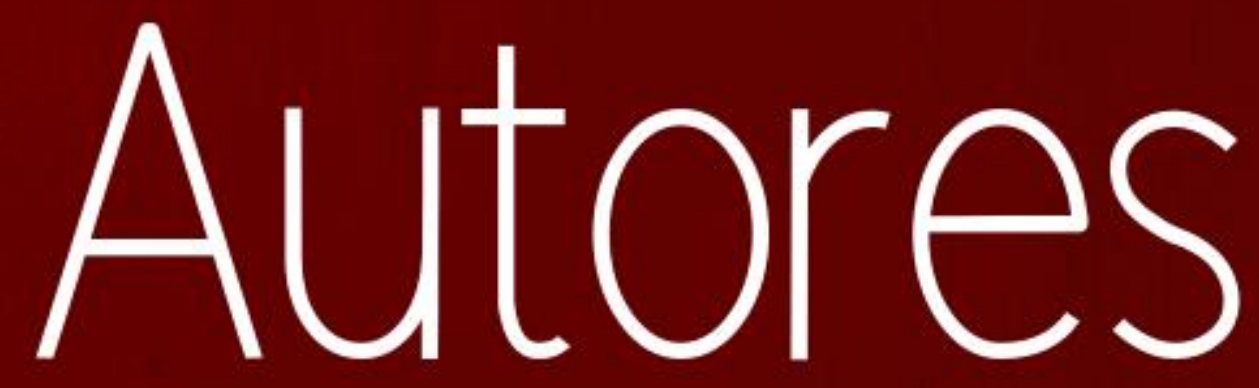




\section{ANDRÉ LUIS LOPES MORIYAMA}

Possui graduação em Engenharia Química pela Universidade Federal do Rio Grande do Norte (2009), mestrado em Engenharia Química pela Universidade Federal do Rio Grande do Norte (2011), doutorado em Engenharia Química pela Universidade Federal do Rio Grande do Norte (2014), e doutorado em Química pela Université de Toulon (2014). Atualmente é professor adjunto do Departamento de Engenharia Química da Universidade Federal do Rio Grande do Norte. Tem experiência na área de Engenharia Química, Engenharia de Petróleo e Ciências de Materiais. Atualmente, desenvolve atividades focadas em tecnologias ambientais e termodinâmica, envolvendo principalmente a síntese de nanomateriais à base de óxidos mistos para aplicação em diferentes processos químicos e na detecção de gases poluentes.

\section{RAFFAEL ANDRADE COSTA DE MELO}

Mestre e bacharel em engenharia química pela Universidade Federal do Rio Grande do Norte (UFRN) (2017 e 2014), tecnólogo em gestão ambiental pelo Instituto Federal de Educação, Ciência e Tecnologia do Rio Grande do Norte (IFRN) (2011). Atualmente é doutorando em engenharia química, atua no Laboratório de Materiais Nanoestruturados e Reatores Catalíticos (LAMNRC), e graduando em química licenciatura ambos pela UFRN. Possui experiência na área de engenharia química, com ênfase na caracterização e processamento de placas de circuito impresso de resíduos de equipamento eletroeletrônicos, termodinâmica química e equilíbrio de fases. Também possui experiência nas áreas de gestão ambiental, química e de ciência e engenharia de materiais.

\section{AMANDA LOPES GUEIROS}

Graduanda em Nutrição do Centro Universitário Maurício de Nassau (UNINASSAU/ Recife-PE)

\section{ANA LÚCIA FIGUEIREDO PORTO}

Possui graduação em Licenciatura Em Química pela Universidade Federal Rural de Pernambuco (1980), mestrado em Bioquímica e Fisiologia pela Universidade Federal de Pernambuco (1994), doutorado em Engenharia Química pela Universidade Estadual de Campinas (1998) com Doutorado Sanduiche Bolsista do Cnpq pela Universidade Técnica de Lisboa (1996). Atualmente é pesquisador colaborador da Universidade Católica de Pernambuco, Universidade Estadual de Campinas, Universidade Federal do Amazonas, e Universidade Federal de Pernambuco. Orienta nos Programas de Pós-graduação Doutorado em Biotecnologia-RENORBIO e Biociência Animal -UFRPE, Biologia Aplicada á Saùde e Ciência Biológicas-UFPE. Professora Titular da Universidade Federal Rural de Pernambuco. Tem experiência na área de Bioquímica e Microbiologia, com ênfase em Bioquímica dos Microrganismos e plantas, atuando principalmente nos seguintes temas: enzimas hidrolíticas( protease), sistemas de duas fases aquosas, processos biotecnológicos para produção de enzimas, peptídeos bioativos, probióticos , prebióticose e lectinas. Membro da Academia Pernambucana de Ciências desde 2019, e Coordenadora do Programa de Pós-Graduação em Biologia Aplicada à Saúde da UFPE.

\section{ANA LÚCIA FIGUEIREDO PORTO}

Graduada em Licenciatura em Química pela Universidade Federal Rural de Pernambuco (UFRPE), possui mestrado em Bioquímica e Fisiologia pela Universidade Federal de Pernambuco (UFPE), doutorado em Engenharia Química pela Universidade Estadual de Campinas (UNICAMP) com Doutorado Sanduiche Bolsista do Cnpq pela Universidade Técnica de Lisboa, realizou pós doutorado no International Iberian Nanotechnology Laboratory (INL) e University do Minho (UMINHO), ambos em Portugal; na Universidade de São Paulo (USP) e na Universidade de Genova (UNIGE) - Itália. É Professora Titular da Universidade Federal Rural de Pernambuco. Tem experiência na área de Bioquímica e Microbiologia, com ênfase em Bioquímica dos Microrganismos e plantas, atuando principalmente nos seguintes temas: enzimas hidrolíticas (protease), sistemas de duas fases aquosas, processos biotecnológicos para produção de enzimas, peptídeos bioativos, probióticos, prebióticos e lectinas. 


\section{ANA SILVIA DE LIMA VIELMO}

Doutoranda em Engenharia Ambiental, Mestre em Engenharia de Produção, Pós- graduada em Gestão Empresarial, graduada em Engenharia Industrial Têxtil pelo Centro de Tecnologia da Indústria Química e Têxtil (SENAI/CETIQT) (2005). Atuou como professora nos cursos de Engenharia Industrial Têxtil, Bacharelado em Design - Habilitação Moda, Bacharelado em Design Habilitação Superfície, Tecnologia em Produção de Vestuário, Bacharelado em Administração. Trabalhou como professora especialista em têxtil no Senai Jaraguá do Sul e atualmente é professora do ensino básico, técnico e tecnológico no Instituto Federal Catarinense.

\section{ANDREY MOACIR DO ROSARIO MARINHO}

Andrey Moacir do Rosario Marinho - tem mestrado e doutorado em Química Orgânica pela UFSCar, atualmente é professor associado 2 da Faculdade de Química/UFPA e tem orientado alunos em nível de mestrado e doutorado no Programa de Pós-graduação em Química/UFPA nos temas: Química de Produtos Naturais, Biotransformação, RMN e EM.

\section{ANTONIELLY DOS SANTOS BARBOSA}

Possui graduação em Química Industrial pela Universidade Estadual da Paraíba (2007), mestrado em Engenharia Química pela Universidade Federal de Campina Grande (2009), doutorado em Engenharia Química pela Universidade Federal de Campina Grande (2013) e Pós-doutorado em Engenharia Química da Universidade Federal de Campina Grande. Tem experiência na área de Engenharia Química, atuando principalmente nos seguintes temas: zeólitas, membranas zeolíticas, membranas cerâmicas, tratamento de efluentes, cereus jamacaru, cereus gounellei, caracterização e alimentos. Atualmente trabalha como pesquisador do Instituto Nacional do Semiárido - INSA, na área de Recursos Hídricos.

\section{ANTONIO DOS SANTOS SILVA}

Físico, Químico e Estatístico formado pela UFPA. Mestre em Física (UFPA, 1999) e mestre em Química Analítica (UFPA, 2010). Doutor em Química Analítica (UFPA, 2020). Prof. da Faculdade de Farmácia (UFPA). Coordenador do Laboratório de Física Aplicada a Farmácia (LAFFA).

\section{ANTONIO PEDRO DA SILVA SOUZA FILHO}

Eng.: Agrônomo, Mestrado pela Universidade Federal de Lavras. Doutor pela Universidade Estadual Paulista. Atualmente é Pesquisador na Embrapa Amazônia Oriental.

\section{ARACELI APARECIDA SEOLATTO}

Possui graduação em Engenharia Química pela Universidade Estadual do Oeste do Paraná (2003), mestrado (2005) e doutorado (2008) em Engenharia Química pela Universidade Estadual de Maringá. Tem experiência na área de Tecnologia Ambiental, com ênfase em desenvolvimento de processos, atuando principalmente nos seguintes temas: produção de bioetanol por meio de biomassas, tratamentos de efluentes líquidos, remoção de poluentes utilizando adsorventes alternativos. É professora nível Associado 2 do Instituto de Química da Universidade Federal de Goiás.

\section{BEATRIZ LIMA SANTOS KLIENCHEN DALARI}

Engenheira Ambiental (UDESC), Técnica em Saneamento (IFSC), Mestre em Engenharia Ambiental (UFSC), ênfase em Tratamento de efluentes industriais por Processos Oxidativos Avançados. Doutoranda em Engenharia Ambiental (UFSC), na linha de pesquisa de tratamento de efluentes industriais, com ênfase em Processos de Extração líquido-líquido com Líquidos Iônicos, no Laboratório de Reúso de Águas (LARA- UFSC) e LABTRAT (UDESC). 


\section{BRUNA MACHADO SANINI}

Mestranda do programa de pós graduação em Engenharia Ambiental da Universidade Federal de Santa Maria

\section{CAMILA SOUZA PORTO}

Possui graduação em Bacharelado em Ciências Biológicas pela Universidade Federal Rural de Pernambuco-UFRPE (2006), Doutorado no Programa de Pós-graduação em BiotecnologiaRENORBIO com ênfase em Biotecnologia Industrial. Concluiu o Pós-doutorados na UFRPE no Programa de Pós-graduação em Biociência Animal. Docente da Universidade Federal de Alagoas, onde desenvolve pesquisas no Laboratório de Desenvolvimento de Bioprodutos e BioprocessosLADBIOPROS UFAL-PENEDO e no Laboratório de Tecnologia de Bioativos-LABTECBIO.

\section{CARLSON PEREIRA DE SOUZA}

Graduado em Engenharia Química pela Universidade Federal do Rio Grande do Norte (1980), mestrado em Engenharia Mecânica com enfase em Extração Líquido-Líquido pela UFRN (1987) e doutorado em Engenharia Química - Université Claude Bernard - Lyon 1- INSA (1992), França. Pós -Doutorado na Université de Toulon et du Var, Toulon, França (2000). Atualmente é professor Titular da UFRN, lotado no Departamento de Engenharia Química, participando como professor permanente nos programas de Pós-Graduação em Engenharia Química e Ciência e Engenharia de Materiais da UFRN. Além disso tem desenvolvido atividades como professor visitante na Université de Toulon et du Var, França. Tem experiência na área de Engenharia Química, com ênfase em Processos de Separação e Mistura, Termodinâmica dos Materiais, com ênfase em Nanociência/Nanotecnologia e Reatores Químicos, atuando principalmente nos seguintes temas: Processos de separação envolvendo equilíbrio de fases L-L e S-L usando óleos vegetais como extratantes, síntese de nanomateriais com aplicações voltadas para catalise heterogênea, fotocatálise e metal duro, síntese de membranas cerâmicas (membranas inorgânicas), secagem de nanomateriais por spray drying, reação gás-sólido, e produção de carbetos, nitretos, carbonitretos de metais refratários (nióbio, tântalo, tungstênio e molibdênio) e materiais a base de elementos de Terras Raras com aplicações em catalise.

\section{DAIANA CARDOSO DE OLIVEIRA}

Doutoranda em Engenharia Ambiental, Mestre em Engenharia de Produção, Pós- graduada em Gestão Empresarial, graduada em Engenharia Industrial Têxtil pelo Centro de Tecnologia da Indústria Química e Têxtil (SENAI/CETIQT) (2005). Atuou como professora nos cursos de Engenharia Industrial Têxtil, Bacharelado em Design - Habilitação Moda, Bacharelado em Design Habilitação Superfície, Tecnologia em Produção de Vestuário, Bacharelado em Administração. Trabalhou como professora especialista em têxtil no Senai Jaraguá do Sul e atualmente é professora do ensino básico, técnico e tecnológico no Instituto Federal Catarinense.

\section{DANIELLE PIRES NOGUEIRA}

Graduada em Engenharia de Alimentos e Mestra em Engenharia Química pela Universidade Federal de Goiás. Experiência na indústria nas áreas de qualidade e processos industriais. Experiência como docente em educação a distância e presencial.

\section{DAVID MAIKEL FERNANDES}

Graduado em Licenciatura/Bacharelado em Química, com atribuições tecnológicas pela Universidade Federal de Uberlândia, (Julho de 2009). Mestre em Química pela Universidade Federal de Uberlândia (Agosto/2011). Doutor em Química, pela Universidade Federal de Uberlândia (Julho/2015). Atualmente é professor EBTT no Instituto Federal de Minas Gerais - Campus Bambuí, nas disciplinas de Química Geral (Técnico Integrado) e Zootecnia e Química Orgânica (Ensino Superior) para os curso de Biologia e Agronomia. 


\section{DAYANE GONZAGA DOMINGOS}

Possui graduação em Licenciatura em Química pela Universidade do Sul de Santa Catarina (2016), graduação em Química Industrial pela Universidade do Sul de Santa Catarina (2015) e mestrado em Engenharia Ambiental pela Universidade Federal de Santa Catarina (2019). Doutorado em andamento em Engenharia Ambiental pela Universidade Federal de Santa Catarina. Com realização de estágio em laboratório de análises físico-químicas, possui experiência em análises para efluentes. Participou de projetos de iniciação científica durante a graduação do curso de Química Industrial e do programa PIBID - Programa de Iniciação à Docência durante a graduação de Licenciatura em Química. Participou de cursos EAD em Licenciamento Ambiental e realizou o curso de extensão Planejamento e Desenvolvimento de Cursos na Modalidade a Distância pelo Instituto Federal de Educação, Ciência e Tecnologia de Santa Catarina- IFSC. Durante a realização do mestrado atuou principalmente em sistema de tratamento de esgoto sanitário.

\section{DÉBORA MENDES DE ANDRADE}

Graduanda em Farmácia pela UFPA.

\section{EDSON LUIZ FOLETTO}

Professor Permanente do Departamento de Engenharia Química da Universidade Federal de Santa Maria. Atua no desenvolvimento de novos materiais para aplicação na área de adsorção e processos oxidativos avançados.

\section{ELVIS CARISSIMI}

Professor dos cursos de Engenharia Ambiental e Civil da Universidade Federal de Santa Maria

\section{EVANDRO STOFFELS MALLMANN}

Professor Permanente do Departamento de Engenharia Química da Universidade Federal de Santa Maria. Desenvolve pesquisa na área de síntese e caracterização de poliuretanos, bem como, na área de adsorção visando a remoção de poluentes em soluções líquidas.

\section{FABIANA MEDEIROS DO NASCIMENTO SILVA}

Possui graduação em Licenciatura em Química pela Universidade Estadual da Paraíba (2008), especialização em Metodologia do Ensino de Química e Biologia (UNINTER) (2010), graduação em Química Industrial pela Universidade Estadual da Paraíba (2014), Mestre em Engenharia Química pela Universidade Federal de Campina Grande (2013). Doutora em Engenharia Química pela Universidade Federal de Campina Grande (2017), atuou na operação e manutenção dos equipamentos de Difratometria de raios X (Schimadzu) e Adsorção Física de N2 (ASAP 2020 Micromeritics) no LABNOV/CCT/UFCG, atuando principalmente nas seguintes áreas: Catálise e meio ambiente, preparação e caracterização de membranas zeolíticas, síntese e caracterização de catalisadores. Experiência profissional como professora no Colégio Santa Rita Areia/PB 2010 - 2011, na EEEFM.José Bronzeado Sobrinho Remígio/PB 2006 - 2011 e no Ensino Básico, Técnico e Tecnológico (Substituta) no Instituto Federal da Paraíba - Campus Picuí/Campus Guarabira 2018 2020.

\section{FERNANDA FERREIRA FREITAS}

Possui graduação em Engenharia Química pela Universidade Federal de Uberlândia (1999), mestrado em Engenharia Química pela Universidade Federal de Uberlândia (2001) e doutorado em Engenharia Química pela Universidade Federal de Uberlândia (2007). Atualmente é professor adjunto 1 da Universidade Federal de Goiás. Tem experiência na área de Engenharia Química, com ênfase em Processos Bioquímicos, atuando principalmente nos seguintes temas: pré-tratamento, bioetanol, imobilização, enzima beta galactosidase e digestibilidade de bagaço. 


\section{FLAVIA SCIGLIANO DABBUR}

Farmacêutica Industrial (1994 - UNAERP), Mestre em Fármacos e Medicamentos (2001 - USP), Doutoranda em Desenvolvimento e Inovação Tecnológica (2018 - UFRN), Especialista em Farmácia Homeopática (1995 - Instituto Lamasson), Especialista em Ecologia e Meio Ambiente (2015 Cesmac), Formação em Aromaterapia e Florais de Bach (2020). Consultora. Professora Titular II do Curso de Graduação em Farmácia do Centro Universitário Cesmac ministrando as Disciplinas Tecnologia de Cosméticos, Tecnologia de Medicamentos, Garantia da Qualidade, Estágios de Manipulação e Industrial. Membro do Núcleo Docente Estruturante (NDE), Conselheira Regional pelo Estado de Alagoas CRF-AL, Membro da Comissão de Ensino CRF-AL. Orienta pesquisa e projetos de extensão na área de Cosméticos, Controle de Qualidade Físico-Químico e Microbiológico.

\section{FRANCISCO GLESON DOS SANTOS MOREIRA}

Fiscal de Urbanismo e Meio Ambiente na Prefeitura Municipal de Sobral - CE. Engenheiro Ambiental graduado pelo Instituto Federal de Educação, Ciência e Tecnologia do Ceará. Possui Mestrado em Engenharia Civil e Ambiental pela Universidade Federal de Campina Grande. Doutorando em Engenharia Civil (Saneamento) pela Universidade Federal do Ceará.

\section{GABRIELA SILVA SPIRLANDELLI}

Possui graduação em Engenharia Química pela Universidade de Uberaba (2015), pós-graduação em Docência nos ensinos médio, técnico e superior (2016) e pós-graduação em Engenheira de Segurança do Trabalho pela Unifran (2017). Mestre Engenharia Química pela Universidade de Uberaba com a Dissertação: amido de milho modificado para produção de painéis derivados de madeira.

\section{GABRIELY DOS SANTOS}

Graduada em Farmácia pela UFPA.

\section{GEZIANE CELINA SÁTIRO}

Graduanda em Nutrição do Centro Universitário Maurício de Nassau (UNINASSAU/ Recife-PE)

\section{GLEIDCE NAYRA ANDRE DA SILVA}

Graduada em Licenciatura Plena Ciências Biológicas pela Faculdade de Formação de Professores da Mata Sul (FAMASUL/ Palmares-PE). Graduanda em Nutrição do Centro Universitário Maurício de Nassau (UNINASSAU/ Recife-PE).

\section{GUILHERME LUIZ DOTTO}

Professor Permanente do Departamento de Engenharia Química da Universidade Federal de Santa Maria. Atua no desenvolvimento de novos adsorventes para remoção de contaminantes emergentes em águas residuais.

\section{HERIBERTO RODRIGUES BITENCOURT}

Graduado em Farmácia e Licenciatura em Biologia pela Universidade Federal do Pará (UFPA), Mestre em Química de Produtos Naturais e Doutor em Química pela UFPA. Professor Associado IV da UFPA, professor colaborador do Programa de Pós-Graduação em Ciências Farmacêuticas da UFPA, Professor da Faculdade de Química-ICEN. Trabalhando com obtenção de produtos naturais e síntese de Chalconas. 


\section{ISADORA ARGENTA PREIGSCHADT}

Graduanda em Engenharia Química pela Universidade Federal de Santa Maria. Desenvolve pesquisa abordando a preparação de novos adsorventes para remoção de contaminantes emergentes em águas residuais industriais.

\section{IWALISSON NICOLAU DE ARAÚJO}

Possui graduação em Química Industrial pela Universidade Estadual da Paraíba (2009) e mestrado em Engenharia Química pela a Universidade Federal de Campina Grande (2013). Atualmente é doutorando do Programa de Pós-graduação de Engenharia Química. Tem experiência na área de Ciência e Tecnologia de Alimentos, Processos Industriais de fabricação de Alimentos e Calçados, Processo de separação óleo/água utilizando como adsorventes argilas organofílicas, atuando principalmente nos seguintes temas: Química, Gestão da Qualidade, Análise de Alimentos, Processos Industriais e Meio Ambiente.

\section{JANDIRA LEICHTWEIS}

Doutoranda do programa de pós graduação em Engenharia Ambiental da Universidade Federal de Santa Maria

\section{JORNANDES DIAS DA SILVA}

Coordenador do mestrado em tecnologia da energia (PPTE) da Universidade de Pernambuco (UPE), professor associado 2D do quadro efetivo da Escola Politécnica de Pernambuco, Universidade de Pernambuco (UPE), professor da graduação da UPE, membro permanente do Programa de PósGraduação em Engenharia de sistemas (PPGS) da UPE. É livre-docente (tese apresentada em 2014) na UPE. Foi coordenador de Graduação na Escola Politécnica de Pernambuco de 2011 a 2014, UPE. Foi presidente da comissão relatora do regime de dedicação exclusiva na Escola Politécnica de Pernambuco de 2011 a 2015. Foi membro da comissão do concurso para o cargo de professor associado da UPE nos anos de 2015, 2016 e 2017. É líder do Grupo de Pesquisa em Energia Renovável (GPER) na UPE, cadastrado no CNPq. - É Coordenador do Laboratório de Tecnologia Energética e Ambiental (2008-atual). Tem experiência na área de pesquisa e desenvolvimento de processo, com ênfase em Aproveitamento de Energia da biomassa para geração de energia elétrica e Combustão Catalítica atuando principalmente nos seguintes temas: modelagem de processo, simulação computacional de processo, petróleo e gás, projeto de gaseificadores de leito fluidizado e leito fixo, projeto de reatores catalíticos para combustão catalítica, Projeto de equipamento para limpeza de gases resultantes dos processos gaseificação e combustão. Além disso, foi coordenador dos seguintes projetos: P\&D Proset, P\&D Universal 2004 e P\&D Universal 2007.

\section{JOSÉ ANTÓNIO COUTO TEIXEIRA}

Possui graduação em Engenharia Química pela Universidade do Porto (1980) e doutorado em Engenharia Química pela Faculdade de Engenharia da Universidade do Porto (1988). Atualmente é Professor Catedrático no Departamento de Engenharia Biológica da Universidade do Minho, Braga/Portugal. Tem experiência na área de Engenharia Química, com ênfase em Engenharia Química e Biotecnologia.

\section{JOSÉ CIRÍACO PINHEIRO}

Graduação em Química Industrial pela Universidade Federal do Pará (1977), Mestrado em Química pela Universidade Federal de São Carlos (1987) e Doutorado em Ciências (Físico-Química) pela Universidade de São Paulo (1994) - Menção Honrosa: Distinção e Louvor. Aperfeiçoamento, PósDoutorado, no Grupo de Quimiometria Teórica e Aplicada, Universidade Estadual de Campinas (2000/2001). Atualmente é Professor Titular da Faculdade de Química (FAQUI), Instituto de Ciências Exatas e Naturais (ICEN), Universidade Federal do Pará (UFPA). Tem experiência na área de Química, com ênfase em Química Teórica, atuando principalmente nos seguintes temas: Desenvolvimento de metodologias para investigar propriedades de materiais usando computador; 
Desenvolvimento de metodologias para investigar compostos bioativos e, com isso, propor novos derivados promissores para sínteses e avaliações biológicas usando computador; Ensino de Química Computacional. Publicou 44 (quarenta e quatro) artigos em periódicos internacionais, 03 (três) capítulos de livro e 106 (cento e seis) trabalhos em eventos científicos (trabalhos completos, resumos e resumos expandidos). Orientou 14 (catorze) teses de doutorado, 21 (vinte e um) dissertações de mestrado, 34 (trinta e quatro) planos de iniciação científica e 26 (vinte e seis) trabalhos de conclusão de cursos.

\section{JOSÉ ROBERTO DELALIBERA FINZER}

Possui graduação em Curso de Engenharia Química pela Universidade Federal de Uberlândia (1973), mestrado em Engenharia de Alimentos pela Universidade Estadual de Campinas (1984) e doutorado em Engenharia de Alimentos pela Universidade Estadual de Campinas (1989). Atualmente é professor do Curso de Graduação em Engenharia Química: Universidade de UberabaUNIUBE e Coordenador do Curso de Mestrado Profissional em Engenharia Química.

\section{JOSÉ ROBERTO DELALIBERA FINZER}

Possui graduação em Curso de Engenharia Química pela Universidade Federal de Uberlândia (1973), mestrado em Engenharia de Alimentos pela Universidade Estadual de Campinas (1984) e doutorado em Engenharia de Alimentos pela Universidade Estadual de Campinas (1989). Atualmente é professor do Curso de Graduação em Engenharia Química: Universidade de UberabaUNIUBE e Coordenador do Curso de Mestrado Profissional em Engenharia Química.

\section{JOSEANE DAMASCENO MOTA}

Possui graduação - Licenciatura Plena em Química (2015) e Bacharelado em Química Industrial (2011) pela Universidade Estadual da Paraíba (UEPB). Tem Mestrado (2013) e Doutorado (2017) em Engenharia Química pela Universidade Federal de Campina Grande (UFCG). Atuou principalmente no processo de caracterização de argilas nacionais e seu tratamento de águas contaminadas por metais pesados e desenvolvimento de membranas poliméricas e compósitas no tratamento de efluentes oleosos. Atualmente exerce a função docente no ensino superior na Faculdade Irecê (FAI) ministrando as disciplinas de Química Analítica Qualitativa, Química Analítica Quantitativa e Química Orgânica II no curso de Farmácia e Bioquímica no curso de Engenharia Agronômica. Atua também na rede estadual de ensino da Bahia.

\section{JOSEANE DAMASCENO MOTA}

Possui graduação - Licenciatura Plena em Química (2015) e Bacharelado em Química Industrial (2011) pela Universidade Estadual da Paraíba (UEPB). Tem Mestrado (2013) e Doutorado (2017) em Engenharia Química pela Universidade Federal de Campina Grande (UFCG). Atuou principalmente no processo de caracterização de argilas nacionais e seu tratamento de águas contaminadas por metais pesados e desenvolvimento de membranas poliméricas e compósitas no tratamento de efluentes oleosos. Atualmente exerce a função docente no ensino superior na Faculdade Irecê (FAI) ministrando as disciplinas de Química Analítica Qualitativa, Química Analítica Quantitativa e Química Orgânica II no curso de Farmácia e Bioquímica no curso de Engenharia Agronômica. Atua também na rede estadual de ensino da Bahia.

\section{JOSEFA RENALVA DE MACÊDO COSTA}

Farmacêutica, Pesquisadora e Extensionista. Mestre em Educação pela UNIVERSIDAD DE LA EMPRESA (UDE/Montevidéu). Graduada em Farmácia pelo Centro Universitário Cesmac. Especialista em Docência no Ensino Superior, Tecnologia Industrial Farmacêutica e Farmacologia Clínica, especializações feitas pelo Cesmac. Atualmente é professora Titular I do Curso de Farmácia do Cesmac. Leciona as disciplinas de graduação: Tecnologia de Medicamentos e Cosméticos, Estágios Manipulação de Medicamento, Cosméticos e fitoterapia. Metodologia da Pesquisa e Prescrição de Fitoterápicos em Curso de Pós-Graduação (Lato Sensu). Tem experiência na área de Farmácia, com ênfase em Ciências da Saúde, atuando principalmente nos seguintes temas: Manipulação de 
medicamentos, cosméticos, fitoterapia e controle de qualidade de medicamentos, cosméticos e fitoterápicos. Coordenadora e RT da Farmácia Universitária do Cesmac. Membro do Colegiado do Curso de Farmácia do Cesmac.

\section{JUANIZE MATIAS DA SILVA BATISTA}

Doutora e Mestre em Biociência animal pela Universidade Federal Rural de Pernambuco, Especialista em Microbiologia pela Funeso, Licenciada em Ciências Biológicas pela Universidade de Pernambuco e Pedagoga pelo Centro Universitário Internacional UNINTER. Possui experiência na área de Biotecnologia, Bioquímica e Microbiologia, atuando principalmente nos seguintes temas: produção biomoléculas de interesse biotecnológico por microrganismos, purificação de enzimas microbianas por sistema de duas fases aquosas (SDFA) e métodos cromatográficos.

\section{JULIANA BARDEN SCHALLEMBERGER}

Mestranda no Programa de Pós-Graduação em Engenharia Ambiental da Universidade Federal de Santa Catarina. Graduada em Engenharia Ambiental e Sanitária pela Universidade Federal de Santa Maria (2018).

\section{KAMILA LEAL CORREA}

Graduada em Farmácia pela UFPA. Mestranda do Programa de Pós Graduação em Ciências Farmacêuticas.

\section{KAROLINE MIRELLA SOARES DE SOUZA}

Possui graduação em Licenciatura Plena Ciências Biológicas pela Universidade Federal Rural de Pernambuco (UFRPE). Mestra em Biociência Animal pela Universidade Federal Rural de Pernambuco (PPGBA-UFRPE). Atualmente é doutoranda pelo programa de pós-graduação em Ciências Biológica na Universidade Federal de Pernambuco (PPGCB-UFPE). Atuando na área de Bioquímica, Biotecnologia e Microbiologia Básica, principalmente na área Biotecnológica utilizando microrganismos fermentativos, extração de moléculas bioativas e avaliação in vitro de suas atividades biológicas.

\section{KELIANE GONÇALVES COSTA}

Graduada em Farmácia pelo Centro Universitário Cesmac (2020); Técnica em enfermagem, atuando em emergência hospitalar 2013-2018; Participou de projetos de extensão e apresentação de trabalhos em congressos; Estagiou extracurricular na Santa Casa de Misericórdia de Maceió, nos setores Farmácia Clínica e Centro Cirúrgico 2018-2020; Experiência em Drogaria 2008-2012; Formação complementar em Auriculoterapia.

\section{KELLIANNY OLIVEIRA AIRES}

Analista Técnica em Gestão e Promoção da Saúde atuando como Bióloga pela Secretaria de Estado da Saúde, no município de Blumenau-SC. Doutora em Engenharia Ambiental pela Universidade Estadual da Paraíba (UEPB). Mestre em Engenharia Civil e Ambiental pela Universidade Federal de Campina Grande (UFCG). Especialista em Saúde Coletiva pela Faculdades Integradas de Patos (FIP). Graduada em Ciências Biológicas pela Universidade Estadual da Paraíba (UEPB).

\section{KELSON DO CARMO FREITAS FAIAL}

Doutor em Química pela UFPA 


\section{KLÍVIA FARIA FINZER}

Possui graduação em Medicina pela Universidade Federal de Uberlândia (2000). Realizou Iniciação científica na UFU por ocasião da graduação. Tem experiência na área de Medicina, com ênfase em Clínica Médica (Especialização) e Dermatologia (Especialização). Atualmente é professora da Universidade de Rio Verde-GO.

\section{LORENA COSTA VASCONCELOS MACEDO}

Possui graduação em Licenciatura Plena em Química pela Universidade Estadual de Goiás (2007), graduação em Licenciatura Plena em Pedagogia pela Fundação Padre Cleto Caliman (2016), mestrado em Engenharia Química pela Universidade Federal de Goiás (2016), atualmente cursando Especialização em Libras e Educação Inclusiva - UAB/IFMT.

\section{LUANA ARAUJO DE OLIVEIRA}

Doutoranda em Engenharia de Materiais pela Universidade Federal da Paraíba (2017). Possui Mestrado em Engenharia Química pela Universidade Federal de Campina Grande (2016). Graduação em Engenharia Química pela Universidade Federal da Paraíba (2014). Participação em Projetos de Pesquisa (2010-2013). Atuou em áreas, como: adsorção para tratamento de efluente oleoso, desenvolvimento de membranas híbridas para remoção de efluentes industriais, remoção de corantes ativos através de argilas, desenvolvimento de compósitos aplicados ao revestimento de reservatórios e obtenção de fluido de perfuração de petróleo a base de glicerina.

\section{MARCIA NIEVES CARNEIRO DA CUNHA}

Possui graduação em Licenciatura em Ciências Biológicas pela Universidade Federal de Pernambuco. Mestrado em Biociência Animal pela Universidade Federal Rural de Pernambuco com ênfase na área de Microbiologia Aplicada, concluiu Doutorado em Biotecnologia pelo programa de Pós-Graduação em Biotecnologia/RENORBIO com ênfase em Biotecnologia Industrial. Desenvolve projetos no Laboratório de Tecnologia em Bioativos/LABTECBIO da Universidade Federal Rural de Pernambuco. Tem experiência nas áreas de Biotecnologia e Microbiologia Aplicada, atuando principalmente nos seguintes temas: processos fermentativos, produção, purificação e imobilização de moléculas bioativas e produção de antimicrobianos.

\section{MARIA DAS GRAÇAS CARDOSO TAVARES}

Graduada em Farmácia/UFPA. Especialista em Medicamentos - Ênfase em Melhoramentos de Fitoterápicos Tradicionais/UFPA. Farmacêutica Titular na Secretaria Municipal de Saúde de Acará/Pará.

\section{MARIA DO SOCORRO BEZERRA DA SILVA}

Licenciada em Química pela Universidade Federal de Campina Grande - UFCG, com pesquisa voltada para remoção de tiofeno por adsorção utilizando argilas. Mestre em Ciência e Engenharia de Petróleo pela Universidade Federal do Rio Grande do Norte - UFRN, área de concentração Engenharia de Reservatórios, com pesquisa voltada para a remoção de óleos pesados em reservatórios de petróleo. Doutora em Engenharia Química pela Universidade Federal do Rio Grande do Norte - área de concentração Termodinâmica e separações com pesquisa voltada para a remoção de metais do lixo eletrônico por processos hidrometalúrgicos e eletroquímicos. Atuou de 2011 à 2015 como professora voluntária de Química no Pré vestibular Solidário da UFCG. Ainda em 2014 atuou como Orientadora no PRONATEC do IFPB campus Picuí. Em 2017 atuou como professora substituta de Química no IFRN campus Nova Cruz. Em 2018 atuou como professora do curso EAD de pedagogia na Faculdade Anne Sullivan em São José de Campestre - RN. Em 2019 atuou como Coordenadora Pedagógica no Ensino Fundamental I na Empresa Prefeitura Municipal de Jaçanã - RN. Atualmente é colaboradora no projeto "reciclagem de placas de circuito impresso de computadores desktops obsoletos da UFRN por eletrohidrometalurgia: uma abordagem educacional, ambiental e tecnológica" na Universidade Federal do Rio Grande do Norte - UFRN, do 
Laboratório de Materiais Nanoestruturados e Reatores Catalíticos, onde atua há aproximadamente 6 anos, Cursa Especialização em práticas assertivas da Educação Profissional pelo Instituto Federal do Rio Grande do Norte - IFRN e segunda Licenciatura em Pedagogia pela UNIASSELVI, polo Cuité PB, ambas em fase de conclusão. Ingressante do Pós Doutorado em Engenharia Química pela UFRN, com pesquisa voltada para a engenharia de reservatório de petróleo.

\section{MARIA JOSICLEIDE FELIPE GUEDES}

Possui graduação em Engenharia Civil (2006), mestrado em Engenharia Civil e Ambiental (2009) e doutorado em Recursos Naturais (2018), pela Universidade Federal de Campina Grande - UFCG. Atuou como Analista Ambiental/Engenheira Civil na Agência Estadual de Meio Ambiente (CPRH/PE) - 2009/2011. É professora adjunta da Universidade Federal Rural do Semi-Árido UFERSA (2011-atual). Atua na área de Recursos Hídricos e Saneamento.

\section{MARIANA BISINOTTO PEREIRA}

Graduada em Engenharia Química na Universidade Federal de Goiás (2016). Participou de projetos de pesquisa como Jovens Talentos para a Ciência (2013), Programa de iniciação em Desenvolvimento Tecnológico e Inovação (2014) e Programa de Iniciação Científica (2015/2016), atuando principalmente em temas como: Pré-tratamento Alcalino, Hidrólise Ácida e Enzimática, objetivando a otimização no processo de produção de etanol de segunda geração. Mestranda em Engenharia Química na Universidade Federal de Goiás (2019) em parceira com a Embrapa Agroenerigia, atuando na área de bioprocessos.

\section{MATHEUS GUISONI PEREIRA}

Graduação em Medicina pela Faculdade de Medicina da Universidade Federal de Uberlândia. Desenvolveu projetos como bolsista PIBIC na área de reologia/angiologia. Tem experiência em monitoria nas disciplinas de anatomia, embriologia, citologia, histologia e bioquímica. Colaborou como colunista na revista eletrônica meucerebro.com. Membro fundador da Liga acadêmica de Neurologia e Neurocirurgia. Tem como principal área de interesse as neurociências com destaque para neurocirurgia e neurologia.

\section{MATIAS SCHADECK NETTO}

Graduado e Mestre em Engenharia Química pela Universidade Federal de Santa Maria. Atualmente é doutorando do Programa de Pós-Graduação em Engenharia Química da Universidade Federal de Santa Maria, atuando com foco na síntese de novos materiais adsorventes para remoção de compostos orgânicos e metais em soluções aquosas.

\section{MEIRE DOS SANTOS FALCÃO DE LIMA}

Graduada em Licenciatura Plena Ciências Biológicas pela Universidade Federal Rural de Pernambuco (UFRPE). Graduanda em Nutrição na Universidade Federal de Pernambuco (UFPE). Mestre na área de Biotecnologia pelo Programa de Pós-Graduação em Biociência Animal da Universidade Federal Rural de Pernambuco (PPGBA-UFRPE). Doutora em Biologia Aplicada à Saúde pela Universidade Federal de Pernambuco (PPGBAS-UFPE). Docente do Núcleo de Saúde do Centro Universitário Maurício de Nassau (UNINASSAU/ Recife-PE). Atua na área de Bioquímica, Biotecnologia e Microbiologia Básica e Microbiologia Aplicada voltada ao uso de bactérias ácido láticas, probióticos, peptídeos bioativos, extração de moléculas bioativas e avaliação in vitro de suas atividades biológicas.

\section{MEIRY GLAUCIA FREIRE RODRIGUES}

Possui graduação em Engenharia Química pela Universidade Federal da Paraíba (1989), mestrado em Engenharia Química pela Universidade Federal de São Carlos (1992) e doutorado (Doctorat de Chimie Appliquée) pela Université de Poitiers, França (1996). Pós-doutorado na UNICAMP sobre 
Potencialidade das argilas brasileiras aplicadas à catálise e ao meio-ambiente (2003). Pósdoutorado na UFRN sobre Síntese Hidrotérmica de aluminossilicatos microporosos e mesoporosos e modelagem cinética e gravimétrica (2010). Pós-doutorado na Universidade de Zaragoza, Grupo de pesquisa Catalysis, Molecular Separations and Reaction Engineering Group (CREG), Espanha sobre Sínteses das membranas do tipo fibra oca (ZIF-93/P-84) (2017). Atualmente é Professor Titular da Universidade Federal de Campina Grande, Unidade Acadêmica de Engenharia Química. Tem experiência na área de Engenharia Química e Engenharia Ambiental, com ênfase em Catálise, Química Verde, Petróleo e Petroquímica, atuando principalmente nos seguintes temas: 1) Desenvolvimento de catalisadores (zeólitas, peneiras moleculares, MOFs, ZIFs); 2) Desenvolvimentos de argilas organofílicas utilizando líquidos iônicos) 3) Tratamentos de efluentes oleosos, têxteis e metais pesados utilizando adsorventes e membranas; 4) Produção de membranas cerâmicas de baixo custo, zeolíticas, compósitas (argila/polímero ou nanocompósito/polímero) e membranas tipo MOF ZIF-8; 5) Processos catalíticos: Isomerização de alcanos, Síntese de FischerTropsch e transesterificação de óleos vegetais com etanol para produção de biodiesel.

\section{MEIRY GLAUCIA FREIRE RODRIGUES}

Possui graduação em Engenharia Química pela Universidade Federal da Paraíba (1989), mestrado em Engenharia Química pela Universidade Federal de São Carlos (1992) e doutorado (Doctorat de Chimie Appliquée) pela Université de Poitiers, França (1996). Pós-doutorado na UNICAMP sobre : Potencialidade das argilas brasileiras aplicadas à catálise e ao meio-ambiente (2003). Pósdoutorado na UFRN sobre ?Síntese Hidrotérmica de aluminossilicatos microporosos e mesoporosos e modelagem cinética e gravimétrica (2010). Pós-doutorado na Universidade de Zaragoza, Grupo de pesquisa Catalysis, Molecular Separations and Reaction Engineering Group (CREG), Espanha sobre Sínteses das membranas do tipo fibra oca (ZIF-93/P-84) (2017). Atualmente é Professor Titular da Universidade Federal de Campina Grande, Unidade Acadêmica de Engenharia Química. Tem experiência na área de Engenharia Química e Engenharia Ambiental, com ênfase em Catálise, Química Verde, Petróleo e Petroquímica, atuando principalmente nos seguintes temas: 1) Desenvolvimento de catalisadores (zeólitas, peneiras moleculares, MOFs, ZIFs); 2) Desenvolvimentos de argilas organofílicas utilizando líquidos iônicos) 3) Tratamentos de efluentes oleosos, têxteis e metais pesados utilizando adsorventes e membranas; 4) Produção de membranas cerâmicas de baixo custo, zeolíticas, compósitas (argila/polímero ou nanocompósito/polímero) e membranas tipo MOF ZIF-8; 5) Processos catalíticos: Isomerização de alcanos, Síntese de FischerTropsch e transesterificação de óleos vegetais com etanol para produção de biodiesel.

\section{MEIRY GLÁUCIA FREIRE RODRIGUES}

Possui graduação em Engenharia Química pela Universidade Federal da Paraíba (1989), mestrado em Engenharia Química pela Universidade Federal de São Carlos (1992) e doutorado (Doctorat de Chimie Appliquée) pela Université de Poitiers, França (1996). Pós-doutorado na UNICAMP sobre ?Potencialidade das argilas brasileiras aplicadas à catálise e ao meio-ambiente? (2003). Pósdoutorado na UFRN sobre ?Síntese Hidrotérmica de aluminossilicatos microporosos e mesoporosos e modelagem cinética e gravimétrica? (2010). Pós-doutorado na Universidade de Zaragoza, Grupo de pesquisa Catalysis, Molecular Separations and Reaction Engineering Group (CREG), Espanha sobre Sínteses das membranas do tipo fibra oca (ZIF-93/P-84) (2017). Atualmente é Professor Titular da Universidade Federal de Campina Grande, Unidade Acadêmica de Engenharia Química. Tem experiência na área de Engenharia Química e Engenharia Ambiental, com ênfase em Catálise, Química Verde, Petróleo e Petroquímica, atuando principalmente nos seguintes temas: 1) Desenvolvimento de catalisadores (zeólitas, peneiras moleculares, MOFs, ZIFs); 2) Desenvolvimentos de argilas organofílicas utilizando líquidos iônicos) 3) Tratamentos de efluentes oleosos, têxteis e metais pesados utilizando adsorventes e membranas; 4) Produção de membranas cerâmicas de baixo custo, zeolíticas, compósitas (argila/polímero ou nanocompósito/polímero) e membranas tipo MOF ZIF-8; 5) Processos catalíticos: Isomerização de alcanos, Síntese de FischerTropsch e transesterificação de óleos vegetais com etanol para produção de biodiesel.

\section{NEUTON TRINDADE VASCONCELOS JUNIOR}

Químico formado pela UFPA 


\section{NICOLY WELTER}

Mestranda do programa de pós graduação em Engenharia Ambiental da Universidade Federal de Santa Maria

\section{OSSALIN DE ALMEIDA}

Doutor e Engenharia de Recursos Naturais da Amazônia (UFPA, 2014). Mestre em Engenharia Química (UFPA, 2004). Especialista em Oleoquímica (UFPA, 2001). Graduado em Engenharia Química (UFPA, 1999) e em Licenciatura Plena em química (UFPA, 1996). Tem experiência nos seguintes temas: Tecnologia de Fluidos Supercríticos (extração de produtos naturais de matrizes sólidas e reações de biocatálises), Transformação de Biomassa de Resíduos Agrícola em Bioetanol, Produção e Tratamento Térmico de Catalizadores e Adsorventes de Insumos da indústria de Alumínio (Alumina) e de Cervejaria (Lodo).

\section{RAÍSSA DA CUNHA BEVILACQUA}

Graduanda em Engenharia Química pela Universidade Federal de Santa Maria. Tem interesse em pesquisa envolvendo o desenvolvimento e aplicação de adsorventes para a remediação de poluentes orgânicos em efluentes líquidos.

\section{RICARDO AMÂNCIO MALAGONI}

Possui Graduação em Engenharia Química pela Universidade Federal de Uberlândia (2003). Fez Mestrado (2006/UFU) em Engenharia Química na área de Termodinâmica. Tornou-se Doutor em Engenharia Química em 2010 pela UFU. Atualmente é Diretor da Faculdade de Engenharia Química. Tem experiência na área de Engenharia Química, atuando principalmente nos seguintes temas: solubilidade, entalpia de vaporização, técnicas de extração e purificação, cristalização, utilização de leito vibrado e leito de jorro.

\section{ROCHELIA SILVA SOUZA CUNHA}

Possui Graduação em Química Industrial pela Universidade Estadual da Paraíba - Campina Grande, Mestrado em Engenharia Química pela Universidade Federal da Paraíba - Campina Grande. Doutorado em Engenharia Química pela Universidade Federal de Campina Grande, atuando principalmente nos seguintes temas: adsorção para purificação de corpos aquáticos contaminados e desenvolvimento de novos materiais destinados a remoção de efluentes industriais. Atuou como docente substituta no Departamento de Química na Universidade Estadual da Paraíba.

\section{ROCHELIA SILVA SOUZA CUNHA}

Possui Graduação em Química Industrial pela Universidade Estadual da Paraíba - Campina Grande, Mestrado em Engenharia Química pela Universidade Federal da Paraíba - Campina Grande. Doutorado em Engenharia Química pela Universidade Federal de Campina Grande, atuando principalmente nos seguintes temas: adsorção para purificação de corpos aquáticos contaminados e desenvolvimento de novos materiais destinados a remoção de efluentes industriais. Atuou como docente substituta no Departamento de Química na Universidade Estadual da Paraíba.

\section{ROCHELIA SILVA SOUZA CUNHA}

Possui Graduação em Química Industrial pela Universidade Estadual da Paraíba - Campina Grande, Mestrado em Engenharia Química pela Universidade Federal da Paraíba - Campina Grande. Doutorado em Engenharia Química pela Universidade Federal de Campina Grande, atuando principalmente nos seguintes temas: adsorção para purificação de corpos aquáticos contaminados e desenvolvimento de novos materiais destinados a remoção de efluentes industriais. Atuou como docente substituta no Departamento de Química na Universidade Estadual da Paraíba. 


\section{RODRIGO SILVA FONTOURA}

Graduado em Engenharia Química pela Universidade Federal de Uberlândia (2012). Especialização realizada na École Nationale Supérieure de Chimie de Montpellier, França, com enfase em Engenharia dos Princípios de Ativos Naturais (2011) e Especialista em Engenharia de Segurança do Trabalho pela Faculdade Araguaia (2016). Atualmente servidor responsável pelos laboratórios de engenharia química da Universidade Federal de Goiás e professor celetista do Centro Universitário UniAlfa. Mestre em Eng. Química pela UFG.

\section{RONDINELE NUNES DE ARAÚJO}

Possui graduação em Química Industrial pela Universidade Estadual da Paraíba (2016). Graduando em Engenharia de Materiais e mestrando no Programa de Pós Graduação em Ciências e Engenharia de Materiais pela Universidade Federal de Campina Grande. Fez estágio na Companhia de Água e Esgotos da Paraíba (CAGEPA), trabalhou no Laboratório de Avaliação e Desenvolvimento de Biomateriais do Nordeste.

\section{ROSIRES CATÃO CURI}

Engenheira Civil, Mestre em Engenharia Civil na área de Recursos Hídricos, Especialização em Irrigação e Drenagem, Ph.D. em Systems Design Engineering, University of Waterloo, Canadá. Professora Titular da Universidade Federal de Campina Grande. Lotada na Unidade Acadêmica de Engenharia Civil. Participa do Programa de Pós-Graduação em Recursos Naturais da UFCG. Ministra as disciplinas Metodologia de Pesquisa e Comunicação Científica e Manejo Integrado de Bacias Hidrográficas.

\section{SIARA SILVESTRI}

Possui pós doutorado pelo programa de pós graduação em Engenharia Ambiental da Universidade Federal de Santa Maria

\section{THIAGO PAJEÚ NASCIMENTO}

Doutor em Biologia Aplicada a Saúde pelo LIKA (Laboratório de Imunopatologia Keizo Asami) na Universidade Federal de Pernambuco (UFPE), Mestre em Ciências Biológicas (Biotecnologia) pela mesma instituição (UFPE), é Bacharel em Ciências Biológicas pela Universidade Federal Rural de Pernambuco (UFRPE). Atua na área de Biotecnologia, no Laboratório de Tecnologia e Bioativos (LABTECBIO - UFRPE). Tendo experiência na área de Bioquímica, Biofísica e Microbiologia, com ênfase em produção de antibióticos e proteases por Actinomicetos, produção de proteases fibrinolíticas por fungos filamentosos, purificação de biomoléculas por sistema de duas fases aquosas (SDFA) e métodos cromatográficos, e influência de campos magnéticos na produção de enzimas fibrinolíticas. É membro do corpo editorial da Advances Enzyme Research.

\section{VERUSCHKA ESCARIÃO DESSOLES MONTEIRO}

Possui Graduação em Engenharia Civil pela Universidade Federal de Pernambuco (1993), Especialização em "Mecánica del Suelo e Ingénieria de Cimentaciones" pelo Centro de Estudios y Experimentación de Obras Públicas - CEDEX. Madrid- España, (1994). Mestrado em Engenharia Civil pela Universidade Federal de Pernambuco (1998) e Doutorado em Engenharia Civil pela Universidade Federal de Pernambuco (2003). Professora associada III do Departamento de Engenharia Civil e do Programa de Pós-Graduação em Engenharia Civil e Ambiental da Universidade Federal de Campina Grande-UFCG. Pesquisadora Produtividade em Pesquisa do CNPq. Tem experiência na área de Engenharia Civil, com ênfase em Geotecnia Ambiental e Resíduos Sólidos Urbanos. Coordenadora do Grupo de Pesquisa em Geotecnia Ambiental (GGA/ UFCG) e dos Planos de Monitoramento dos Aterro Sanitários dos Município de Campina Grande-PB e Guarabira-PB. 


\section{VITÓRIA DA FONSECA DIAS}

Vitória da Fonseca Dias graduanda em Ciências Biológicas Bacharelado na Universidade Católica de Pernambuco (UNICAP), possui os certificados KET (2013), PET (2014) e FCE (2016) da Universidade de Cambridge pela Cultura Inglesa. Cursou o ensino médio na Escola Parque do Recife(2013-2015). Atuou como estagiária ministrando aulas de inglês no Projeto Bilíngue do Colégio Divino Mestre durante o ano de 2017. Estagiou voluntariamente na Unicap no Laboratório de Biologia Marinha no ano de 2017.1., no Museu de Arqueologia da Unicap em 2018.2. e no Herbário da Universidade Católica de Pernambuco (HUCPE) em 2019.2. No presente momento é bolsista do CNPq no laboratório de Biologia Floral da UFPE (POLINIZAR) sob a orientação da Profa. Dra. Isabel Cristina Machado.

\section{WELLINGTON SIQUEIRA LIMA}

Graduado em Engenharia Química pela Universidade Federal de Campina Grande (2009). Mestrado na área de Meio Ambiente/Tratamento de Efluentes e Resíduos Sólidos contendo Metais Pesados (2011). Doutorado pela Universidade Federal de Campina Grande na área de Catálise Heterogênea (2015).

\section{YASMIN VIEIRA}

Doutoranda do programa de pós graduação em Química da Universidade Federal de Santa Maria

\section{MÔNIA MARIA CARVALHO DA SILVA}

Possui graduação em Química Industrial pela Universidade Federal do Pará (2008). Mestrado em GEOQUÍMICA E PETROLOGIA (2013). Cursando doutorado em Saúde Coletiva pela Universidade Federal do Rio de Janeiro.

\section{ALLYSON ALLENNON PINHEIRO DO ROSÁRIO}

Bacharel em Farmácia, formado pela UFPA.

\section{CHARLES ALBERTO BRITO NEGRÃO}

Graduado em Engenharia Química em 2014 pela UFPA; Mestre em Físico-Química (2017), com ênfase em Química Teórica Relativística, pela UFPA; atualmente doutorando em Química, subárea Analítica, pela UFPA. Possuo experiência em técnicas de caracterização de materiais (Difração de Raio-x, Microscopia Eletrônica de Transmissão, Florescência de Raio-X, Análise Termogravimétrica, Espectróscopia da região do Infravermelho e Adsorção); Análise de alimentos e plantas medicinais (ICP-OS, Espectrofotometria da região do Ultravioleta) e desenvolvimento de métodos analíticos.

\section{EWERTON CARVALHO DE SOUZA}

Possui graduação em Licenciatura em Química pela Universidade Federal do Pará (2002), graduação em Engenharia Ambiental pela Universidade do Estado do Pará (2003), graduação em Química Industrial pela Universidade Federal do Pará (2009) e mestrado em Química pela Universidade Federal do Pará (2007). Atualmente é professor da Universidade Federal Rural da Amazônia. Tem experiência na área de Química, com ênfase em Química Analítica

\section{RÔMULO AUGUSTO FEIO FARIAS}

Graduado em Farmácia pela Universidade Federal do Pará (UFPA) e Mestre em Farmacologia pelo Programa de Pós-Graduação em Farmacologia pela Universidade Federal do Ceará. Professor da Universidade Federal do Pará, trabalhando com produtos naturais. 


\section{MARIA TACIANA HOLANDA CAVALCANTI}

Médica Veterinária formada pela Universidade Federal Rural de Pernambuco (UFRPE), Mestre em Bioquímica pela Universidade Federal de Pernambuco (UFPE), Doutora em Tecnologia Bioquímica Farmacêutica pela Universidade de São Paulo (USP), Pós-doutora em Engenharia Biológica pela UMINHO. É professora Adjunta da Universidade Federal Rural de Pernambuco (UFRPE). Realiza pesquisas nas áreas de microbiologia aplicada aos produtos lácteos, probióticos, prebióticos e peptídeos de produtos lácteos. 


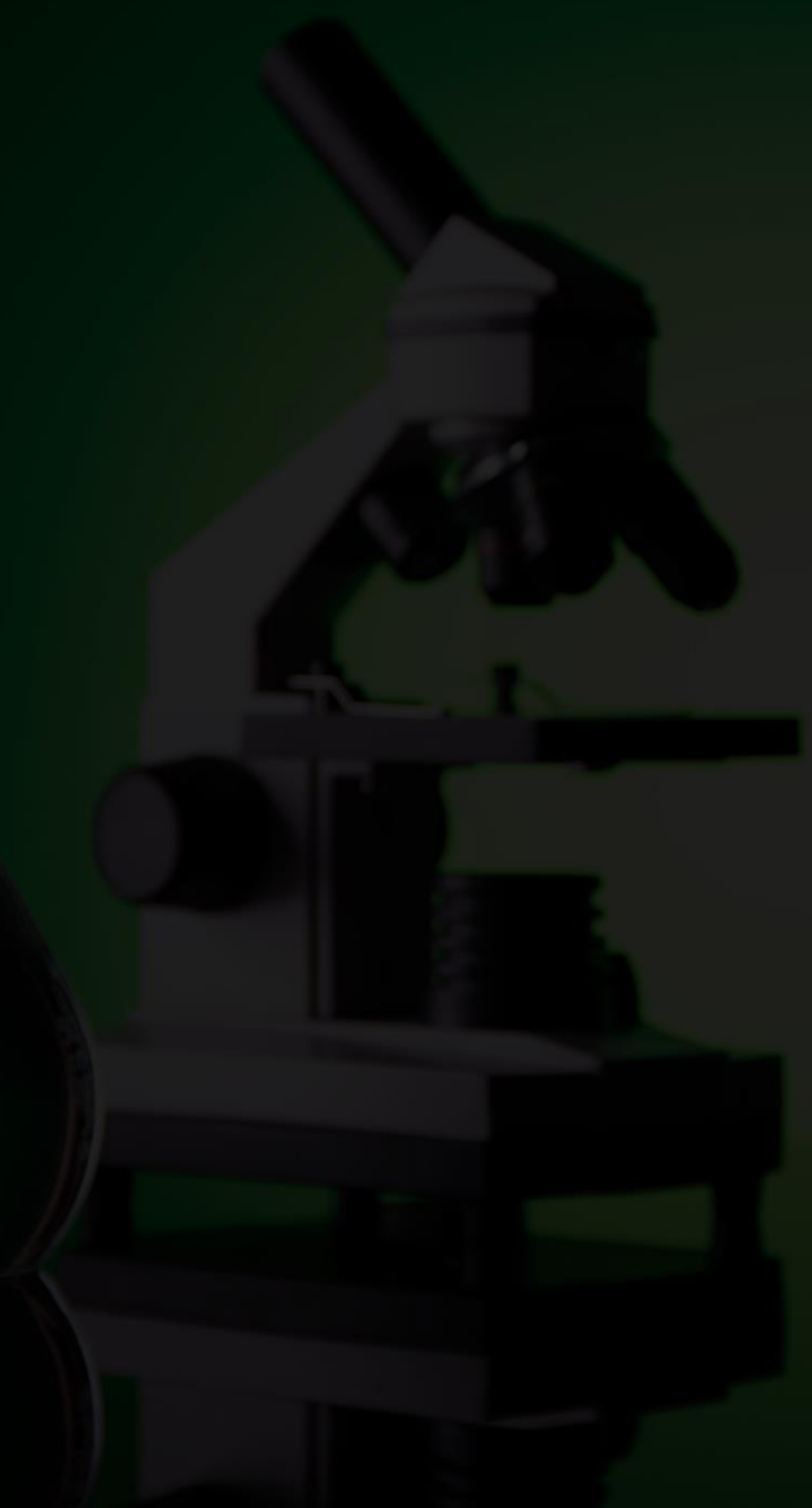

